\title{
ÉCOLE NORMALE SUPÉRIEURE DE LYON
}

\section{Laboratoire de Physique}

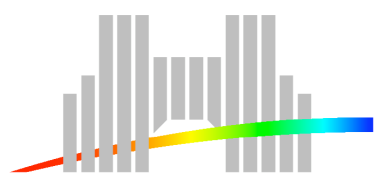

\section{THÈSE}

Pour obtenir le titre de :

Docteur de l'École Normale Supérieure de Lyon

Spécialité : Physique

École doctorale de : Physique et d'Astrophysique de Lyon

présentée et soutenue publiquement le 13 Juillet 2006 par :

\section{Michaël SUISSA}

\section{Dynamique interne du noyau d'une cellule vivante : Étude par diffusion dynamique de la lumière}

Directeur de thèse : Eric FREYSSINGEAS, MCF ENSL

Codirecteur de thèse : Christophe PLACE, CR1 CNRS

Après avis de : $\quad$ M. Xavier RONOT, DR EPHE

M. Laurent BOURDIEU, CR1 CNRS

Devant la commission d'examen formée de :
M. Michel PEYRARD, Professeur ENSL
Président
M. Xavier RONOT, DR EPHE
Rapporteur
M. Laurent BOURDIEU, CR1 CNRS
Rapporteur
M. Pierre JURDIC, DR2 INSERM
M. Christophe PLACE, CR1 CNRS
M. Eric FREYSSINGEAS, MCF ENSL 



\title{
REMERCIEMENTS
}

\author{
Je tiens tout d'abord à exprimer ma profonde gratitude envers mes deux directeurs de \\ thèse :
}

Eric Freyssingeas, dit «Monsieur Chef », pour toute l'attention et le temps qu'il m'a accordé. J'ai beaucoup appris avec lui et j'ai pu apprécier ses connaissances et sa culture aussi bien en physique que dans tout un tas d'autres domaines. Nos nombreuses discussions, particulièrement celles au coin café (qu'il m'a toujours payé), me manqueront certainement (à l'opposé de son "petit" coté taquin et surtout de son "gros" coté maniaque...).

Christophe Place, dit "Gentil Chef», qui m'a beaucoup apporté en sciences expérimentales. Il a toujours fait preuve d'une grande patience avec moi et pourtant, D. sait que je l'ai mise un nombre incalculable de fois à l'épreuve. Il a également toujours su me remonter le moral quand Eric me remontait les bretelles...

Encore mille mercis à vous deux.

Toute la partie biologie de ce travail a été rendue possible par la collaboration de Evelyne Goillot et de toute son équipe. Elle a toujours été là pour m'aider les nombreuses fois où je venais la voir avec mes "petits » problèmes. Je m'excuse pour lui en avoir fait quand même voir de toutes les couleurs. Je remercie aussi Sabine Caussanel et Katia Ancelin qui ont toujours répondu à mes questions avec gentillesse.

Beaucoup d'éléments du montage expérimental utilisé pendant cette thèse sont l'œuvre de Frank Vittoz et de Marc Moulin de l'atelier de mécanique du labo et je les en remercie.

Je voudrais également remercier MM. Xavier Ronot et Laurent Bourdieu qui ont très gentiment accepté de juger mon manuscrit. Je tiens à préciser que je n'en serais pas là sans Xavier Ronot qui m'a «introduit » à l'ENS Lyon et je l'en remercie (mes chefs peut-être un peu moins...).

Je remercie M. Michel Peyrard qui m'a fait l'honneur d'accepter de présider mon jury ainsi que M. Pierre Jurdic pour sa participation à ce même jury, pour m'avoir mis en contact avec mes chefs il y a trois ans et pour avoir suivi mes travaux avec intérêt. Merci aussi à Bruno Berge qui est à l'origine de mon sujet de thèse.

En arrivant au laboratoire, mes connaissances en physique étaient un peu limitées et je remercie vivement tous ceux qui m'ont aidé à progresser. Particulièrement, Artyom Petrossian qui m'a apporté une aide précieuse en optique, Jean-François Palierne qui m'a aidé sur tout un tas de problème avec une humeur toujours très joviale, Doru Constantin qui m'a guidé et conseillé sur de nombreux points et Pierre Borgnat que j'ai beaucoup sollicité sur la partie traitement du signal.

Je tiens également à remercier Bruno Gilles qui m'a soutenu et m'a donné de nombreux et avisés conseils tout au long de cette thèse. Il a toujours su trouver les mots pour me remonter le moral quand il lui arrivait d'être au plus bas et l'on peut dire qu'il aura été mon « psychothésapeute » attitré !! Merci aussi pour tout à Hélène et aux petits !

L'ambiance au labo a toujours été excellente et ce notamment grâce aux autres "compagnons de galère » qu'ont été François, Bertrand, Brice, Corinne, Emeline, Sébastien,... Cette ambiance doit aussi beaucoup à nos merveilleuses secrétaires Laurence et Nadine (j'attends toujours les samoussas !!!). Merci aussi à tous ceux qui ont accepté de prendre sur leur temps pour m'aider à répéter mon oral de soutenance : Valérie, Etienne, Benjamin, Cendrine, Karine,...

Je remercie tout particulièrement ma famille, et surtout mes parents, qui m'ont toujours soutenu et encouragé.

Enfin, merci à Sandrine qui a été à mes cotés pendant les moments joyeux comme pendant les autres et qui m'a toujours supporté avec tendresse. 



\section{TABLES DES MATIERES}

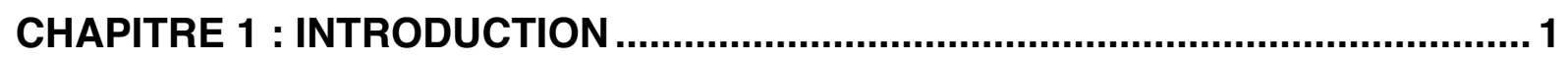

I> Problématique............................................................................................................................................................................. 1

II > Diffusion dynamique de la lumière ............................................................................................................................ 2

III> Plan de la thèse ................................................................................................................................................................ 3

BIBLIOGRAPHIE ............................................................................................................................................................................ 4

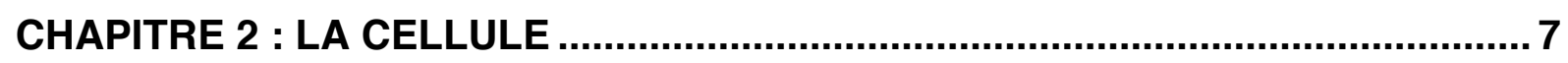

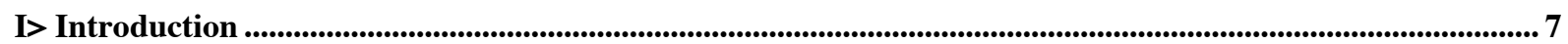

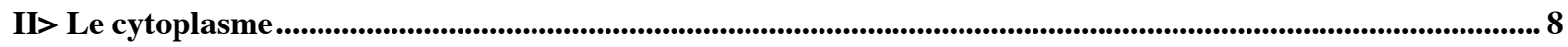

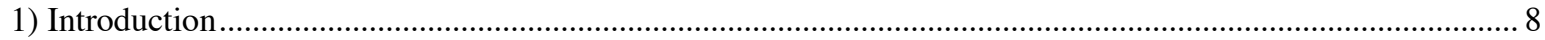

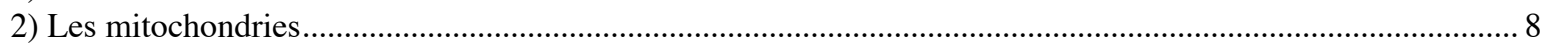

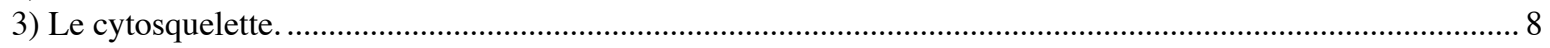

III> Le noyau : composition et structure .........................................................................................................................9

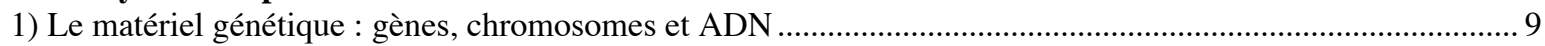

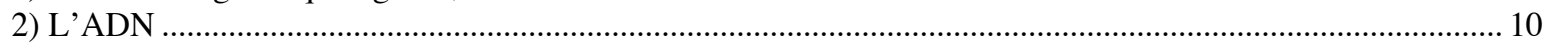

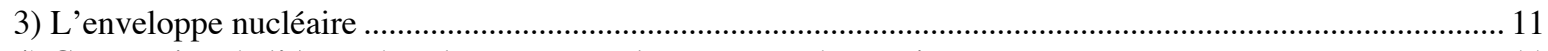

4) Compaction de l'ADN dans le noyau : nucléosomes et chromatine ………..................................................11

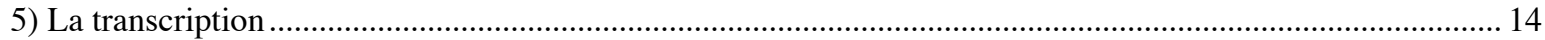

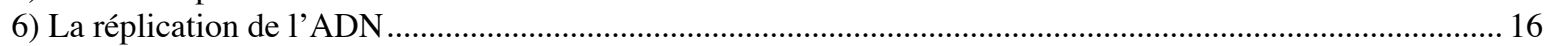

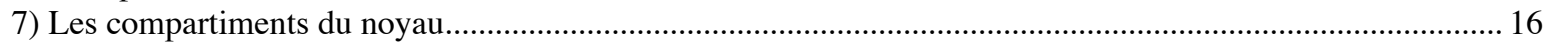

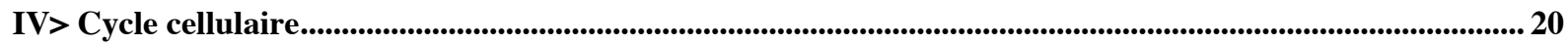

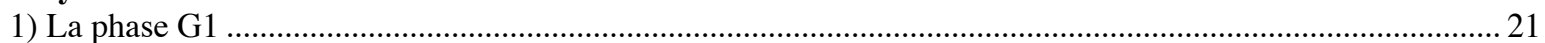

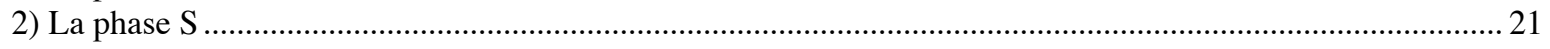

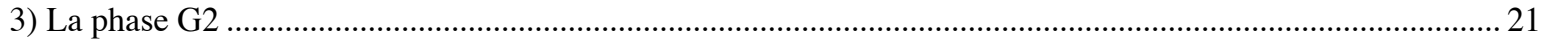

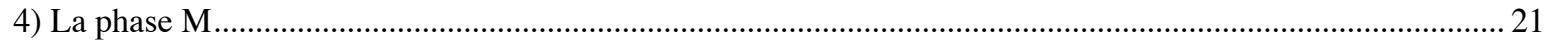

V> Dynamique du noyau......................................................................................................................................... 22

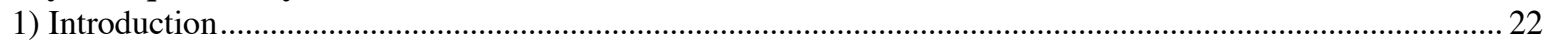

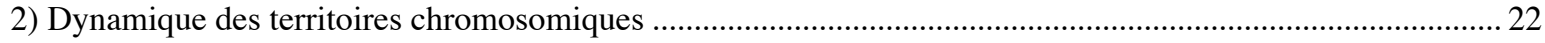

3) Dynamique de la chromatine au sein du territoire chromosomique ...............................................................2 23

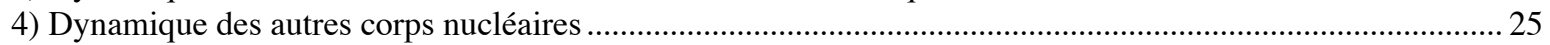

5) Dynamique des macromolécules dans le nucléoplasme.................................................................................2

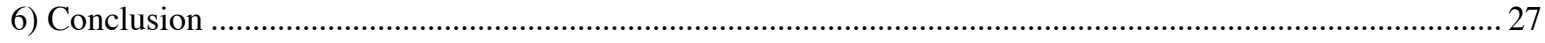

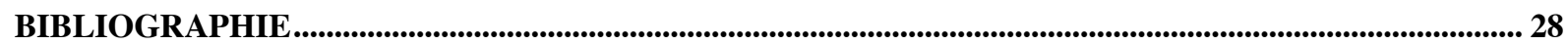


I> Introduction à la diffusion dynamique de la lumière par le noyau d'une cellule vivante ...............................33

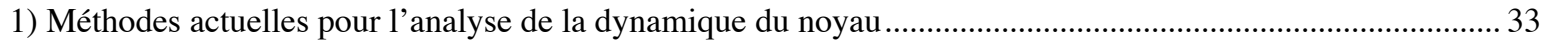

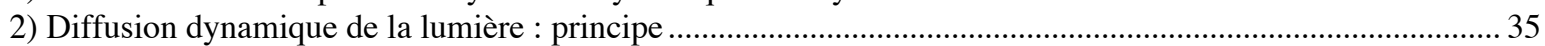

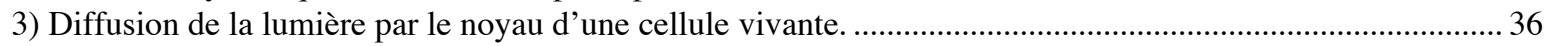

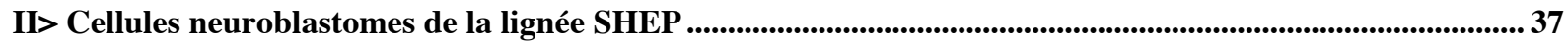

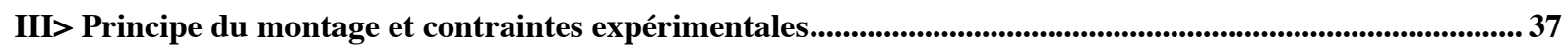

IV> Eclairer le noyau d'une cellule vivante avec un faisceau laser..................................................................39

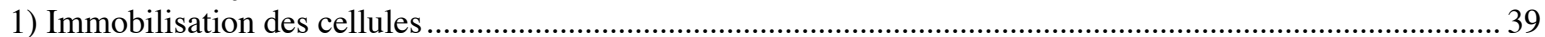

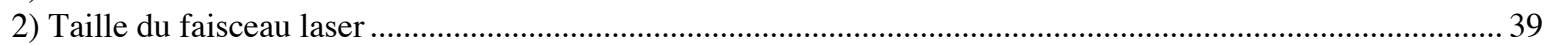

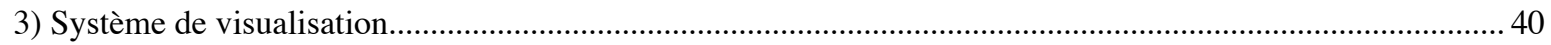

V> Système de mesure de la lumière diffusée .......................................................................................................................................442

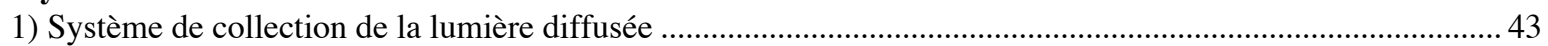

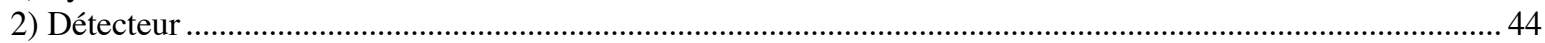

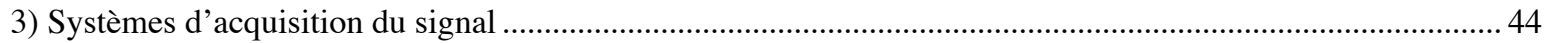

4) Validation et géométrie du montage expérimental.......................................................................................48

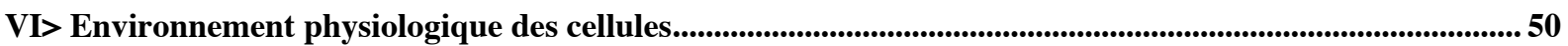

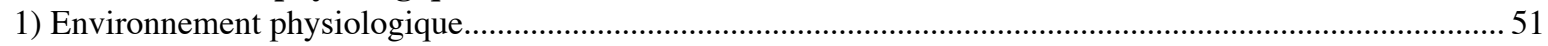

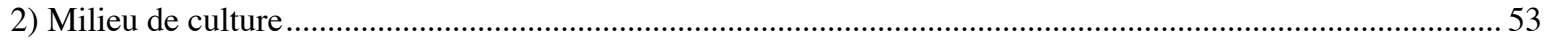

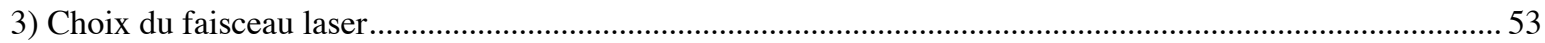

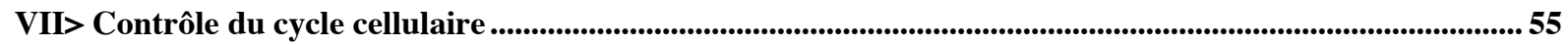

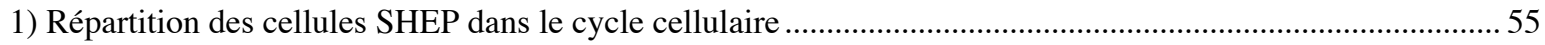

2) Blocage du cycle cellulaire par une drogue cytobloquante : HU..........................................................55

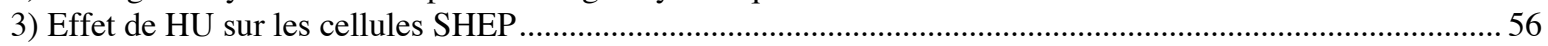

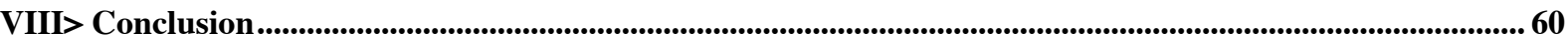

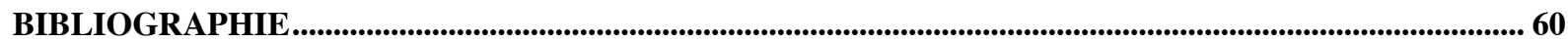

\section{CHAPITRE 4 : RESULTATS ET DISCUSSION ................................................. 63}

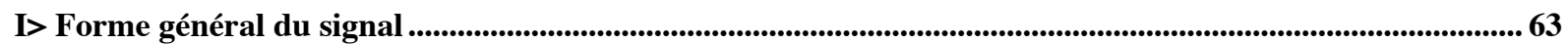

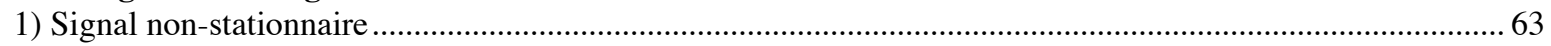

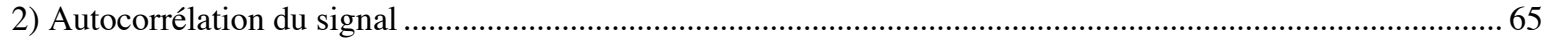

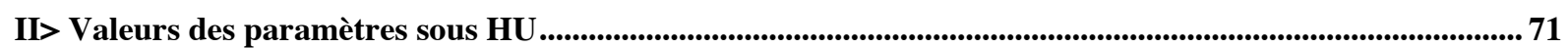

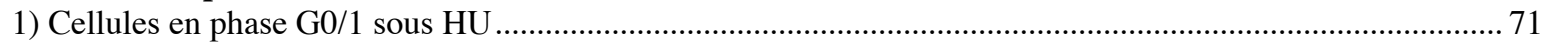

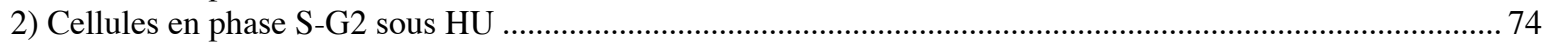

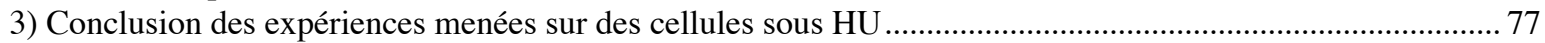

III > Valeurs des paramètres en fonction du cycle cellulaire ........................................................................77

1) Evolution de la contribution du mode rapide à la fonction d'autocorrélation au cours du cycle cellulaire ..... 77

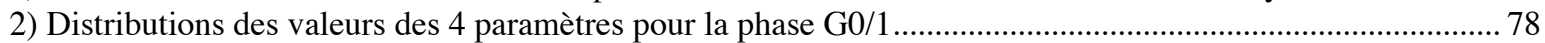

3) Distributions des valeurs des 4 paramètres pour la phase $\mathrm{S}$ majoritaire....................................................... 82

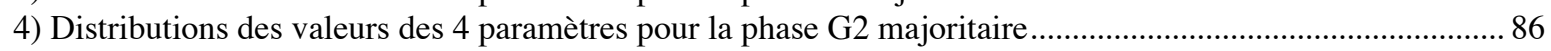

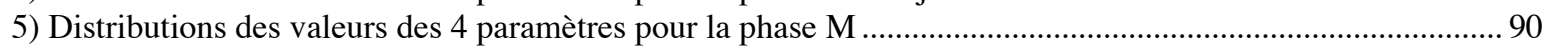

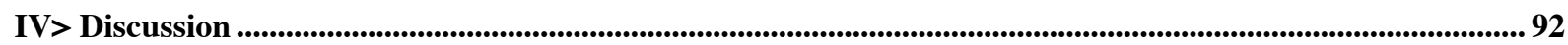

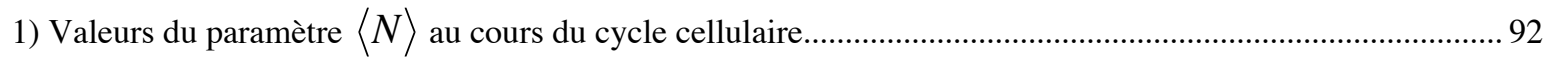

2) Valeurs du coefficient d'étirement $\alpha$ au cours du cycle cellulaire ..........................................................93

3) Valeurs du temps de relaxation $\tau_{1}$ au cours du cycle cellulaire ...............................................................95 


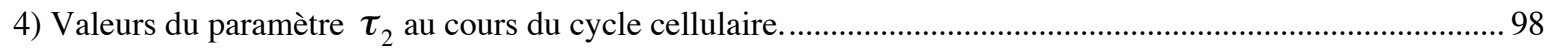

5) Influence de la taille et de la constitution du volume diffusant sur les paramètres..................................... 101

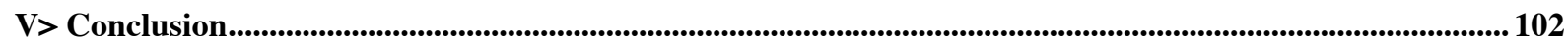

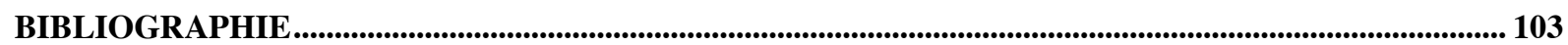

CHAPITRE 5 : TRANSMISSION DE L'APOPTOSE .......................................... 105

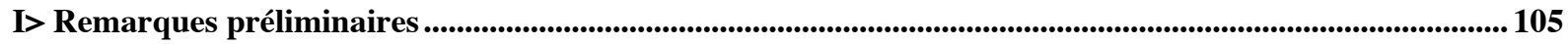

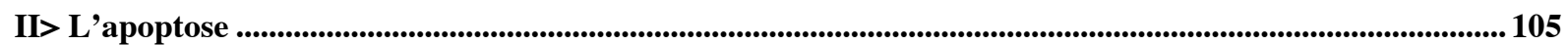

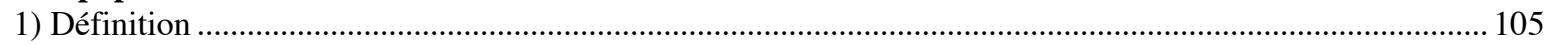

2) Activation de l'apoptose par les récepteurs membranaires .................................................................... 107

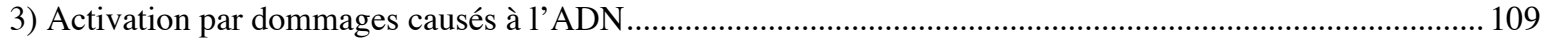

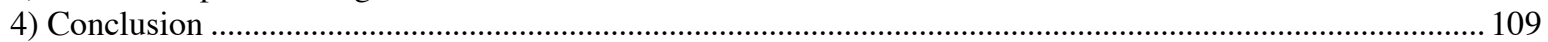

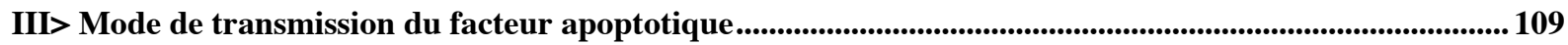

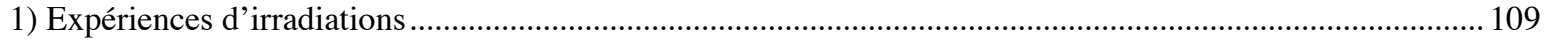

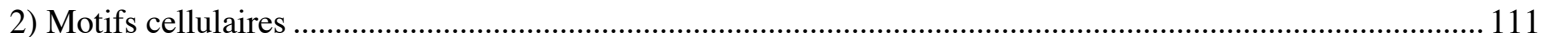

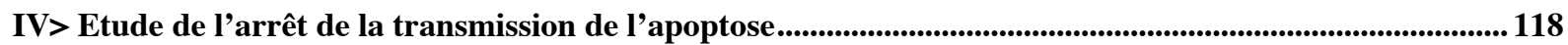

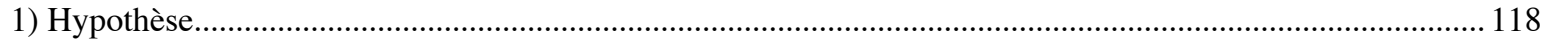

2) Sensibilité des cellules SHEP à l'apoptose en fonction du cycle cellulaire .............................................. 118

3) Transmission du facteur apoptotique dans une population de cellules à majorité en G1 ............................. 119

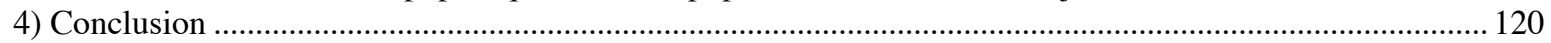

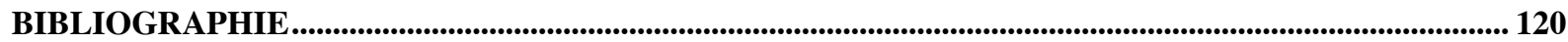

CHAPITRE 6 : CONCLUSIONS ET PERSPECTIVES ....................................... 123

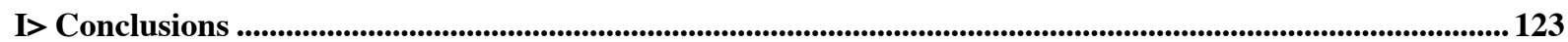

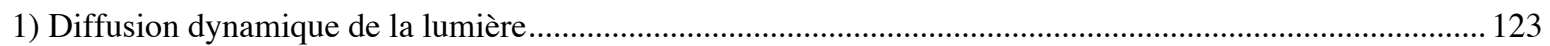

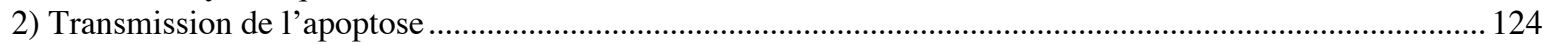

II $>$ Perspectives

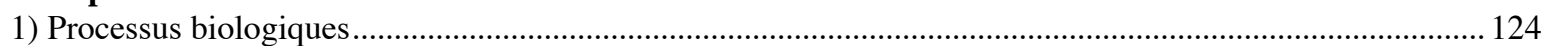

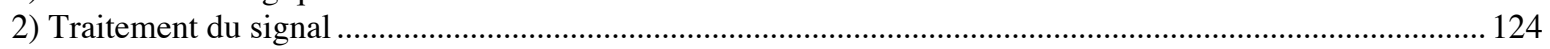

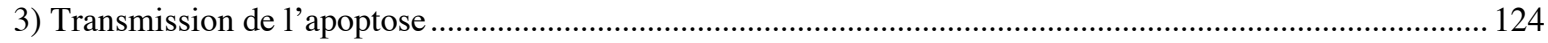

ANNEXE A : DIFFUSION DYNAMIQUE DE LA LUMIÈRE..................................... I

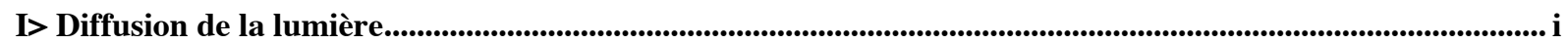

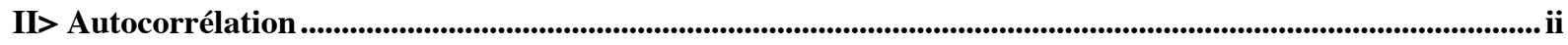

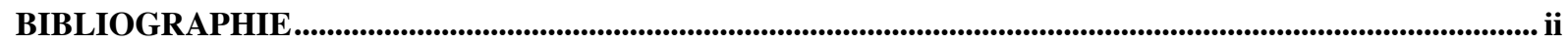

ANNEXE B : PROTOCOLES EXPÉRIMENTAUX................................................. III

I $>$ Protocole de remise en culture des cellules ................................................................................................................iii

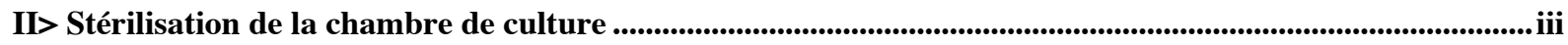

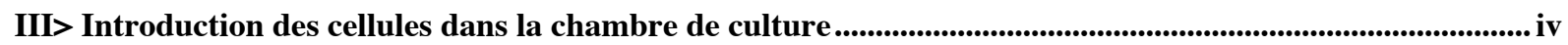




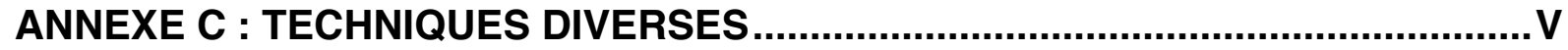

I> Cytométrie en flux : FACS................................................................................................................................................. v

II> Méthodes de redistribution de fluorescence après photoblanchiment (FRAP) ..................................................vi

III> Immuno-précipitation de la chromatine (ChIP) ................................................................................................... vi 


\section{Chapitre 1 : INTRODUCTION}

\section{I> Problématique}

Les progrès récents de la recherche en biologie cellulaire ont montré, de plus en plus clairement, que le noyau possède une architecture propre, caractérisée par une organisation en domaines, qui ne sont pas délimités par des membranes. Ces domaines se répartissent au cours de l'interphase, dans l'espace nucléaire sous la forme suivante :

- les territoires chromosomiques, structure tridimensionnelle de la chromatine, topologiquement bien ordonnée, qui définissent les territoires occupés par chaque chromosome (Manuelidis, 1985 et 1990)

- une zone d'exclusion, l'espace interchromosomique, situé à l'interface des différents territoires qui contient les différents éléments nécessaires à l'expression des gènes et à la réplication de l'ADN (Cremer et Cremer, 2001).

Ainsi, ces domaines distincts possèdent chacun leurs fonctions propres (Dundr et Mistelli, 2001)

Cette organisation spatiale bien définie est dynamique. Chaque compartiment du noyau a une activité propre et interagit fortement avec les autres compartiments. Les territoires chromosomiques ont un diamètre compris entre 400 et $800 \mathrm{~nm}$ et ne sont pas figés; ils changent de forme et de position en fonction de l'état cellulaire (Bridger et al., 2000 ; Zinc et al., 1998). En fait, toutes les modifications de l'organisation spatiale du noyau traduisent des modifications de cet état cellulaire. Il a, notamment, été montré qu'au cours du cycle cellulaire les changements de la structure spatiale du noyau qui étaient observés reflétaient les différents changements d'état de la cellule (Brown, 1999). Historiquement cette dynamique a d'abord été observée sur des cellules fixées. L'observation de protéines (Belmont et Straight, 1998 ; Buchenau et al., 1997 ; Marshall et al., 1997), ou d'ADN (Zink et al., 1998), marqués par des fluorophores à l'intérieur de cellules vivantes a ensuite permis de discriminer trois types de mouvements : mouvement brownien de macromolécules et de complexes protéiques, remodelage des régions subchromosomiques et larges déplacements des territoires chromosomiques (Zink et Cremer, 1998). Les larges mouvements des territoires chromosomiques sont liés aux changements fonctionnels de la cellule (De Boni, 1994). Lors d'un changement d'état cellulaire, on observe, en plus de ces mouvements, une réorganisation des territoires chromosomiques. Pour un état cellulaire donné on observe, à la fois, des réarrangements de la chromatine et de la diffusion brownienne de protéines. Toutefois, les limites intrinsèques de la mesure de la dynamique à l'aide de la microscopie de fluorescence (marquage fluorescent, résolutions spatiale et temporelle) ne permettent pas d'analyser l'ensemble de la dynamique du noyau. Donc, la dynamique de ces réarrangements structuraux, ainsi d'ailleurs que les propriétés dynamiques du noyau, dans un état cellulaire stable, sont encore très mal connues. Il est évident que la compréhension de ces propriétés dynamiques est un objectif important pour la biologie cellulaire.

Parallèlement, des développements récents en physique ont permis la manipulation (pincette optique, platine de micromanipulation,...) et l'observation (technologie laser, caméra haute définition,...) d'objets uniques de petites tailles, ainsi que le développement de nouvelles techniques optiques (microscopie confocale). Ces nouvelles techniques ont entraîné un développement de l'étude expérimentale, par des physiciens et des biophysiciens, des propriétés dynamiques des processus biologiques à l'intérieur des systèmes vivants. On observe, ainsi, de plus en plus de travaux dans ce sens (diffusion de protéines dans le 
cytoplasme (Elowitz et al., 1999), étude de l'évolution temporelle de la concentration d'une protéine dans une bactérie (Barkai et Leibler, 2000),...). Les travaux que nous avons menés se situent dans cette optique : l'utilisation des concepts et des techniques expérimentales développés pour étudier la dynamique des systèmes moléculaires organisés, pour l'étude de la dynamique de la matière vivante. Nous avons, ainsi, étudié la dynamique interne du noyau d'une cellule vivante, lors du cycle cellulaire, par diffusion dynamique de la lumière.

\section{II> Diffusion dynamique de la lumière}

La diffusion dynamique de la lumière (Bern et Pecora, 1976) est une technique bien développée et parfaitement adaptée à l'étude des propriétés dynamiques des systèmes moléculaires organisés. Elle est utilisée avec succès, que ce soit pour l'étude des systèmes colloïdaux, des surfactants, ou des polymères en solutions, des gels et des cristaux liquides. Dans ces systèmes, la diffusion de la lumière est due aux fluctuations spatio-temporelles de l'indice de réfraction de la solution. Celles-ci reflètent les fluctuations de la densité massique moyenne ; c'est-à-dire les fluctuations de la concentration en colloïdes, surfactants, polymères, etc ..., en solution dans le solvant. L'analyse, par autocorrélation, de cette lumière diffusée permet de remonter aux temps de relaxations caractéristiques de ces fluctuations. Cette analyse permet de sonder les propriétés dynamiques des systèmes étudiés sur des échelles de temps très variables, depuis la microseconde jusqu'à la minute.

La diffusion de la lumière a déjà été utilisée pour étudier des systèmes biologiques. Cependant, ces études ont, à ce jour, principalement porté sur des cellules en suspension pour caractériser la taille des cellules ou du noyau, in vitro (Mourant et al., 1998 ; Hahn et al., 1999) ou dans des tissus vivants (Backman et al., 2000). D'autres groupes ont étudié, avec cette technique, les propriétés mécaniques et de diffusion de colloïdes de macromolécules (Janmey et al., 1994) ou encore les propriétés dynamiques des membranes (Tishler et Carlson, 1993). Les propriétés dynamiques de macromolécules, comme l'ADN, en solution ont également été étudiées (He et al., 2000). À notre connaissance, aucune étude n'a jamais porté sur l'analyse de la fonction d'autocorrélation de la lumière diffusée, uniquement, par le noyau d'une cellule vivante.

Le noyau est, comme nous l'avons fait remarquer, un objet complexe. Son organisation spatiale et son activité biochimique évoluent toutes les deux au cours du temps, en fonction de l'état de la cellule. On s'attend à ce que les mouvements de la chromatine engendrés par ces réorganisations, ainsi que la diffusion brownienne des complexes protéiques à travers le noyau et les différentes réactions biochimiques provoquent des modifications de l'indice de réfraction du noyau. On peut donc espérer, grâce à des expériences de diffusion dynamique de la lumière, obtenir, par une mesure physique non invasive et non destructrice pour la cellule, une information relative à la dynamique des fluctuations de la densité de matière à l'intérieur du noyau dans un état cellulaire donné. De plus, ces expériences peuvent, aussi, renseigner sur les temps caractéristiques de réarrangements spatiaux de la matière, se produisant à l'intérieur du noyau, lors d'un changement d'état de la cellule. Finalement, en suivant l'évolution des temps caractéristiques au cours d'événements fondamentaux modifiant l'état nucléaire, comme le cycle cellulaire, cette mesure pourrait permettre de suivre la cinétique d'évolution d'une cellule au cours de ces évènements. La diffusion dynamique de la lumière présente un certain nombre d'avantages en comparaison d'autres méthodes développées à l'heure actuelle. Notons, par exemple, que par rapport à des techniques comme la corrélation de fluorescence, qui se développe fortement en biologie, et qui sonde des échelles de temps identiques à celles de la diffusion de la lumière (de la microseconde à la minute), nous n'avons pas besoin, ici, de marquer les différents constituants du noyau.

Comme dans toute expérience de diffusion de la lumière, il s'agit de faire passer un faisceau laser à travers l'échantillon, c'est-à-dire l'intérieur du noyau d'une cellule, et de 
recueillir sur un détecteur, dans une direction donnée, la lumière diffusée par le volume éclairé. Ensuite, il faut un système d'analyse de l'intensité de la lumière diffusée, comprenant notamment un corrélateur. A l'aide de ce dernier, on construit la fonction d'autocorrélation de l'intensité de la lumière diffusée. Cette fonction d'autocorrélation permet de remonter aux temps caractéristiques des phénomènes qui sont à l'origine de la diffusion de la lumière. Ces phénomènes sont, bien sûr, les variations spatio-temporelles de l'indice de réfraction du noyau dues aux réarrangements de la densité locale de matière (chromatine et protéines) à l'intérieur du noyau.

\section{III> Plan de la thèse}

Les travaux que nous avons menés durant cette thèse ont d'abord consisté à construire un montage expérimental original de diffusion dynamique de la lumière et, aussi, à mettre au point des protocoles adaptés de manipulation de cellules, pour permettre l'étude de la dynamique interne du noyau d'une cellule vivante. Ensuite, nous avons utilisé ce montage pour regarder les propriétés dynamiques du noyau au cours d'un processus biologique particulier et bien connu : le cycle cellulaire. L'idée étant de voir si la dynamique interne du noyau est fonction des différentes phases du cycle cellulaire.

Le plan de cette thèse s'articule de la façon suivante :

- Dans un premier temps, nous présenterons une vue d'ensemble de la cellule, en nous intéressant tout particulièrement à la composition et la structure du noyau, ainsi qu'aux connaissances actuelles sur la dynamique interne du noyau. Cette présentation sera l'objet du chapitre 2.

- Puis, après un rappel et une comparaison des différentes techniques développées en physique pour l'étude de la dynamique des systèmes biologiques, nous expliciterons, au cours du chapitre 3, les différents éléments du montage expérimental de diffusion dynamique de la lumière que nous avons construit. Nous décrirons également les protocoles que nous avons établis : le protocole de culture cellulaire permettant de maintenir les cellules dans un bon état physiologique au cours des expériences, ainsi que celui permettant de synchroniser un maximum de cellules dans la phase du cycle cellulaire dans laquelle nous souhaitons étudier la dynamique du noyau.

- Ensuite, au cours du chapitre 4, nous décrirons les expériences que nous avons réalisées avec ce montage expérimental ainsi que les résultats que nous avons obtenus. Nous terminerons cette partie par une discussion dans laquelle nous décrirons les hypothèses pouvant expliquer nos résultats, puis nous aborderons les nombreuses questions qu'ils soulèvent.

- Dans le chapitre 5, nous parlerons d'un autre type d'expérience. Ces expériences découlent d'une observation que nous avons faite lors de tests que nous avons effectués sur la survie des cellules dans notre montage expérimental de diffusion de la lumière. Ces observations ont montré un phénomène de transmission de la mort par apoptose d'une cellule vers les cellules voisines. Nous avons essayé de comprendre comment cette transmission se faisait et pour cela nous avons développé une technique permettant de faire adhérer les cellules sur une lame de verre, dans des motifs préalablement «imprimés ». Dans ce dernier chapitre, nous décrirons cette technique, ainsi que les résultats obtenus sur la transmission de la mort par apoptose aux plus proches voisins. 


\section{BIBLIOGRAPHIE :}

- Backman V, Wallace MB, Perelman LT, Arendt JT, Gurjar R, Müller MG, Zhang Q, Zonios G, Kline E, McGillican T, Shapshay S, Valdez T, Badizadegan K, Crawford JM, Fitzmaurice M, Kabani S, Levin HS, Seiler M, Dasari RR, Itzkan I, Van Dam J, Feld MS. (2000) Detection of preinvasive cancer cells. Nature. 406 : 35-36.

- Barkai $\mathrm{N}$ et Leibler S. (2000) Circadian clocks limited by noise. Nature. 403 : 267268.

- Belmont AS et Straight AF. (1998) In vivo visualization of chromosomes using lac operator-repressor binding. Trends in cell biology. 8 : 121-124.

- Bern BJ et Pecora R. Dynamic Light Scattering. Wiley \& Sons, New York. 1976.

- Bridger JM, Boyle S, Kill IR and Bickmore WA. (2000) Re-modelling of nuclear architecture in quiescent and senescent human fibroblasts. Current biology. 10 : 149152.

- Brown K. (1999) Nuclear structure, gene expression and development. Critical Review in Eukaryotic Gene Expression. 9 : 203-212.

- Buchenau P, Saumweber H et Arndt-Jovin DJ. (1997) The dynamic nuclear redistribution of an hnRNP K-homologous protein during Drosophila embryo developments and heat shock. Flexibility of transcription sites in vivo. Journal of Cell Biology. 137 : 291-303.

- Cremer T et Cremer C. (2001) Chromosome territories, nuclear architecture and gene regulation in mammalian cells. Nature Review Genetics. 2 : 292-301.

- de Boni U. (1994) The interphase nucleus as a dynamic structure. International review of cytology. 150 : 149-171.

- Dundr M et Misteli T. (2001) Functional architecture in the cell nucleus. Biochemical Journal. 356 : 297-310.

- Elowitz MB, Surette MG, Wolf PE, Stock JB and Leibler S. (1999) Protein mobility in the cytoplasm of Escherichia coli. Journal of Bacteriology. 181 : 197-203.

- Hahn WC, Counter CM, Lundberg AS, Beijersbergen R., Brooks MW et Weinberg RA. (1999) Creation of human tumor cells with defined genetic elements. Nature. 400 : 464-468.

- He S, Arscott PG et Bloomfield VA (2000) Condensation of DNA by multivalent cations experimental studies of condensation kinetics. Biopolymers. 53, 329-341.

- Janmey PA, Hvidt S, Kas J, Lerche D, Maggs A, Sackmann E, Schliwa M et Stossel TD. (1994) The mechanical properties of actin gels. Elastic modulus and filament motions. Journal of Biological Chemistry. 269 : 32503-32513.

- Manuelidis L. (1985) Individual interphase chromosome domains revealed by in situ hybridization. Human Genetics.71 : 288-293.

- Manuelidis L. (1990) A view of interphase chromosomes. Science. 250 : 1533-1540.

- Marshall WF, Straight A, Marko JF, Swedlow J, Dernburg A, Belmont AS, Murray AW, Agard DA et Sedat JW. (1997) Interphase chromosome undergo constrained diffusional motion in living cells. Current Biology. 7 : 930-939.

- Mourant JR, Hielscher AH, Eick AA, Johnson TM et Freyer JP. (1998) Evidence of intrinsic differences in the light scattering properties of tumorigenic and nontumorigenic cells. Cancer. 84 : 366-374.

- Tishler RB et Carlson FD. (1993) A study of the dynamic properties of the human red blood cell membrane using quasi-elastic light scattering spectroscopy. Biophysical Journal. 65 : 2586-2600. 
- Zink D et Cremer T. (1998) Cell nucleus : chromosome dynamics in nuclei of living cells. Current biology. 8 : R321-R324.

- Zink D, Cremer T, Saffrich R, Fischer R, Trendelenburg MF, Ansorge W et Stelzer EH. (1998) Structure and dynamics of human interphase chromosome territories in vivo. Human genetics. 102 : 241-251. 


\section{Chapitre 2 : LA CELLULE}

\section{$\underline{\text { I }>\text { Introduction }}$}

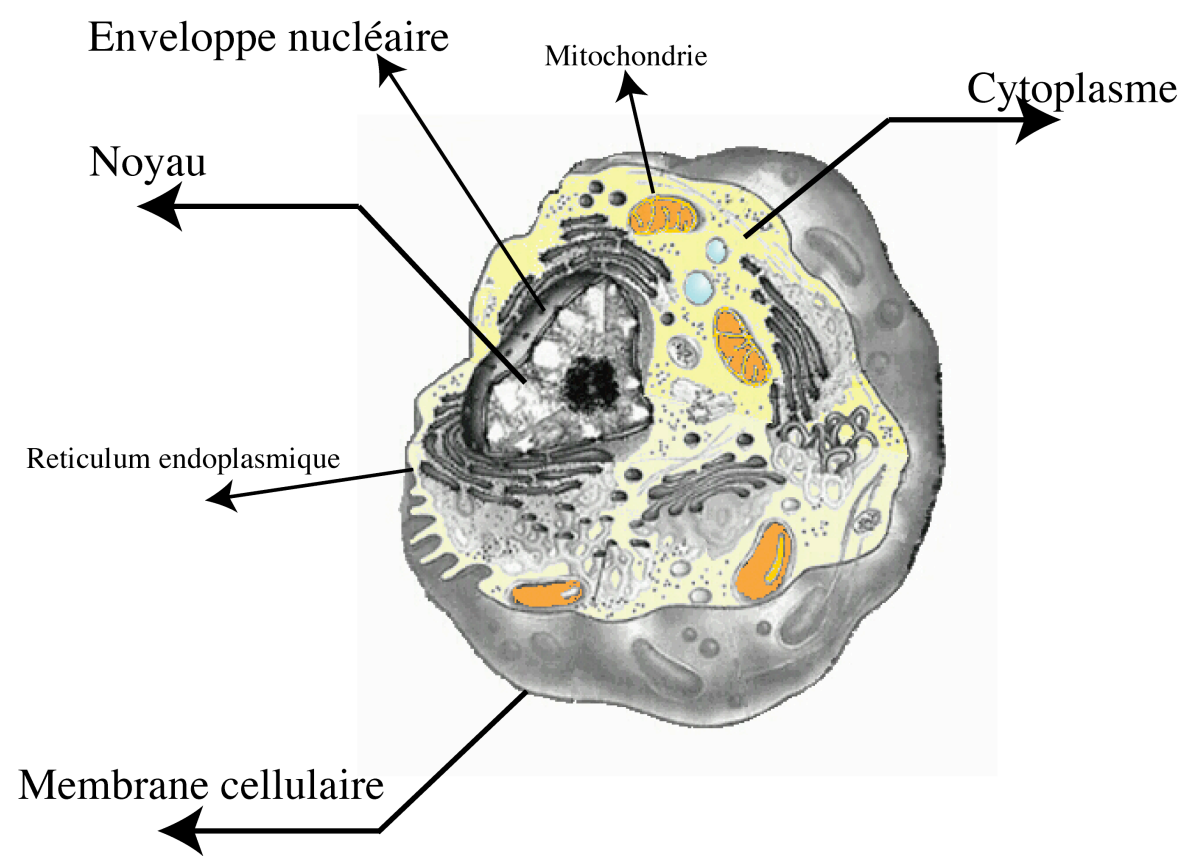

Figure 2-1 : Représentation d'une cellule eucaryote. On distinguera particulièrement le noyau, siège de l'information génétique, l'enveloppe nucléaire, le cytoplasme et la membrane cellulaire.

La cellule est l'unité de structure fonctionnelle fondamentale de tous les organismes vivants. Les organismes les plus simples, les protozoaires, peuvent n'en contenir qu'une seule. Les plus compliqués, les métazoaires, comme l'être humain, peuvent en contenir plus de 1000 milliards. Les cellules interagissent entre elles de façon très coordonnée. Dès les années 1970, les cellules ont été divisées en deux grandes familles :

- les cellules procaryotes (comme les bactéries) pour lesquelles le matériel génétique est constitué d'un unique chromosome circulaire (appelé nucléoïde) qui baigne dans le cytoplasme. Il est replié en longues boucles dont la base est reliée à un ensemble protéique, le coeur (core). Ce dernier est fixé à la membrane plasmique. Cette région contenant l'information génétique n'est pas séparée physiquement du cytoplasme de la cellule.

- les cellules eucaryotes (Figure 2-1) pour lesquelles la quasi-totalité du matériel génétique est contenue dans un noyau séparé du reste de la cellule par une membrane nucléaire.

Nous avons travaillé exclusivement avec des cellules eucaryotes (les cellules procaryotes n'ayant servi qu'à polluer certaines de nos expériences...). Pour ce type de cellules, nous retiendrons quatre zones d'intérêt : le noyau, objet de nos études, l'enveloppe nucléaire, le cytoplasme et la membrane cellulaire. 


\section{II> Le cytoplasme}

\section{1) Introduction}

Le cytoplasme (Figure 2-1) rassemble tout le matériel de la cellule qui ne fait pas partie du noyau. Il est délimité par la membrane plasmique et se compose d'une matrice aqueuse colloïdale, le cytosol, dans laquelle baignent de petites structures délimitées par des membranes, les organites. Le cytoplasme contient également des systèmes complexes de membranes, comme le réticulum endoplasmique (voir paragraphe III $>3$ ), ainsi que des protéines nécessaires à la dynamique de la structure de la cellule qui forment ce que l'on appelle le cytosquelette. Dans un premier temps, nous aborderons le rôle essentiel de certaines organites du cytoplasme, puis nous parlerons des différentes protéines qui composent le cytosquelette.

\section{2) Les mitochondries}

Les mitochondries (Figure 2-2) sont des petites organites (environ $1 \mu \mathrm{m}$ de diamètre), qui ont la particularité de contenir de l'ADN, présentes en grand nombre dans la cellule. Ce sont les « centrales d'énergie » de la cellule (Alberts et al., 1994). La base de cette production d'énergie est l'oxydation des éléments nutritifs de l'environnement de la cellule. Cela permet, au final, à une enzyme présente sur la membrane interne de la mitochondrie (Figure 2-2), l'ATP synthase (Boyer, 2001), de synthétiser de l'Adénosine TriPhosphate (ATP) à partir d'Adénosine DiPhosphate (ADP) et de Phosphate $\left(\mathrm{P}_{\mathrm{i}}\right)$. L'ATP passe ensuite dans le cytoplasme où la dernière liaison phosphate peut facilement se casser par hydrolyse. L'énergie ainsi libérée permet la réalisation de la plupart des réactions de biosynthèse dans le cytoplasme, réactions biochimiques qui sont, en général, énergétiquement défavorables. L'ATP est utilisé très rapidement et les molécules d'ADP, ainsi produites, entrent à nouveau dans les mitochondries grâce aux pompes à ADP présentes sur la membrane externe des mitochondries pour se « recharger » (Alberts et al., 1994). Ces dernières produisent, ainsi, de l'ATP en permanence et sont donc essentielles à la survie de la cellule.

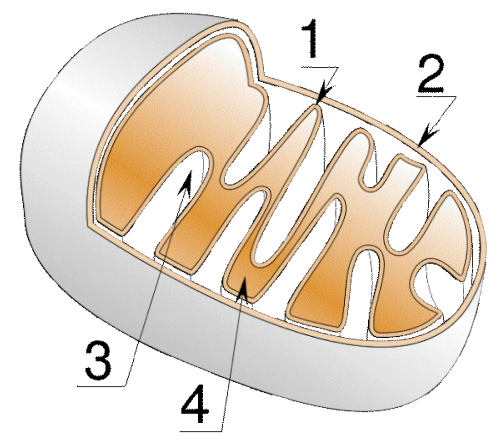

Figure 2-2 : Schéma représentatif d'une mitochondrie. 1. Membrane interne. 2. Membrane externe. 3. Espace inter-membranaire. 4. Matrice.

\section{3) Le cytosquelette.}

Le cytosquelette est un réseau de fibres intra-cellulaires qui jouent un rôle essentiel dans la dynamique de la cellule (motilité, adhésion,...). Il est constitué de trois grandes familles de protéines (Alberts et al., 1994) parmi lesquelles nous retiendrons les microtubules et l'actine. Bien que leur rôle et leur composition soient relativement différents, elles ont certaines propriétés en commun. On les trouve notamment sous deux formes dans la cellule : 
- une forme monomérique, forme soluble dans laquelle elles sont dispersées dans le cytoplasme

- une forme polymérisée où elles sont organisées en filaments.

Ces filaments sont dynamiques. La polymérisation des filaments se fait lorsque la concentration en monomères dépasse un certain seuil. Au-dessous de ce seuil de concentration, les filaments dépolymérisent. La polymérisation est toujours dirigée vers l'extrémité appelée extrémité (+) du filament tandis que la dépolymérisation se fait vers l'extrémité (-).

\section{3-1) Les microtubules}

Les microtubules sont les plus gros filaments du cytosquelette ( $25 \mathrm{~nm}$ de diamètre). Ils sont formés de 13 protofilaments. Chacun de ces protofilaments est assemblé à partir de petites protéines, sous-unités de la tubuline : les tubulines $\alpha$ et les tubulines $\beta$. Les microtubules servent principalement au transport de composants (organelles, vésicules synaptiques,...) grâce à des moteurs moléculaires qui se déplacent le long des filaments : les dynéines et les kinésines (Yildiz et Selvin, 2005). Les microtubules jouent également un rôle important lors de la mitose (Cassimeris, 2004) : les chromatides migrent vers les kinétochores, le long de filaments de microtubules grâce à des kinésines. Les filaments dépolymérisent au fur et à mesure juste derrière les chromatides.

\section{3-2) Les microfilaments d'actine}

L'actine est la protéine la plus représentée chez les cellules eucaryotes. Les microfilaments d'actine, ou actine-F (pour filamenteuse) ont un diamètre de $8-9 \mathrm{~nm}$ et sont composés à partir de la polymérisation des monomères d'actine, ou actine- $G$ (pour globulaire). La dynamique de polymérisation/dépolymérisation des filaments d'actine est le fondement du contrôle des oscillations du cytoplasme (Ehrengruber et al., 1996) et de la motilité cellulaire. L'actine-F est également un composant essentiel des structures d'adhésions qui permettent à la cellule d'adhérer à son substrat, comme les points focaux d'adhésion ou les podosomes (Linder et Aepfelbacher, 2003).

\section{III> Le noyau : composition et structure}

\section{1) Le matériel génétique : gènes, chromosomes et $\mathrm{ADN}$}

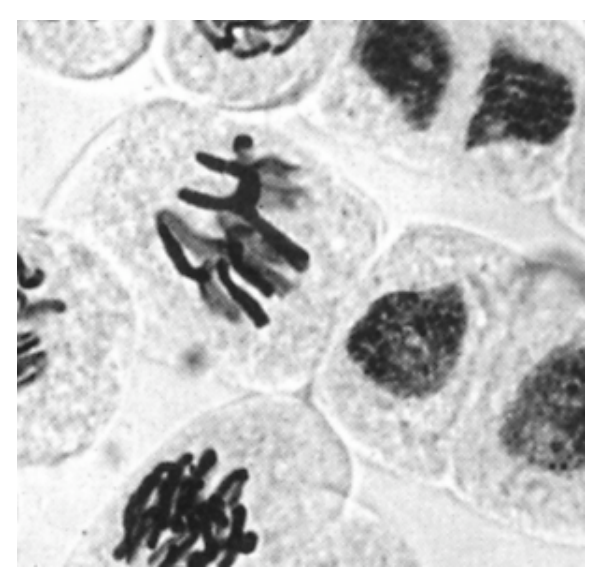

Figure 2-3 : Cellules de racine de plantes à différentes étapes de leur évolution. On distingue nettement les chromosomes des cellules sur le point de se diviser (cellule au centre de la photo, par exemple) (tirée de Alberts et al., 1994). 
Dès la fin du XIXème siècle, il a été établi que chaque cellule contenait toute l'information nécessaire à son développement et à son évolution. Cette information est contenue dans ce que l'on a appelé les gènes. Il a été ensuite établi que ces gènes se trouvaient sur des petits bâtonnets, les chromosomes, uniquement visibles peu avant que la cellule se divise (Figure 2-3). Les chromosomes sont composés de deux bras, un court et un long, reliés par une zone apparaissant relativement dense : le centromère. Lors de la division cellulaire, une copie de chacun des chromosomes est transmise à chaque cellule fille, ce qui permet la transmission du matériel génétique. Ce n'est que vers le milieu du XXème siècle que le support physique des gènes a été identifié : l'ADN.

\section{2) L'ADN}

L'ADN (Acide DésoxyriboNucléique) est une macromolécule dont la structure est une double hélice (Watson et Crick, 1974) composée de deux brins. Le squelette de chaque brin est composé de phosphodiester et de sucre (désoxyribose) en alternance. Chaque molécule de désoxyribose porte une base azotée. Il existe quatre bases azotées différentes : la thymine $(\mathrm{T})$, l'adénine (A), la guanine (G) et la cytosine (C) (Figure 2-4). Le complexe moléculaire formé par un phosphodiester, un désoxyribose et une base azotée forme un nucléotide. Un brin d'ADN est formé par une séquence ordonnée de nucléotide. L'autre brin est formé par la séquence complémentaire du premier : une base A (respectivement $\mathrm{G}$ ) sur le premier est forcément liée à une base $\mathrm{T}$ (respectivement $\mathrm{C}$ ) sur le second et vice-versa. La structure en double hélice est maintenue par des liaisons hydrogène qui relient entre elles les bases complémentaires (deux liaisons pour les paires A-T et trois pour les paires $\mathrm{C}-\mathrm{G}$ ). Chaque chromosome est constitué d'une unique molécule d'ADN (Hayes, 2000) et un gène correspond, en fait, à une portion spécifique de l'ADN.

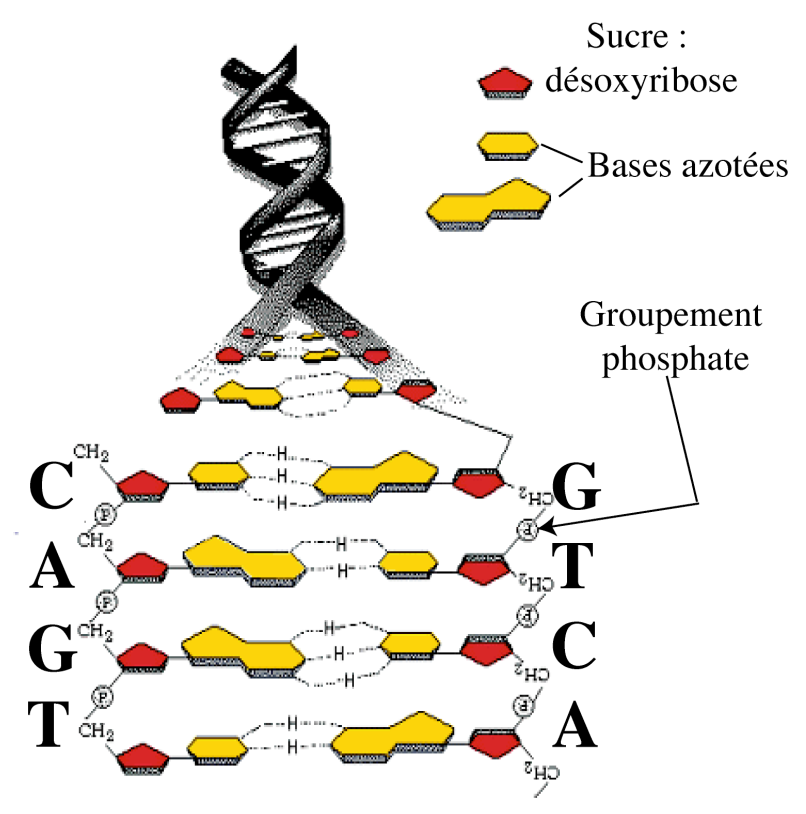

Figure 2-4 : Schéma représentatif d'une molécule d'ADN. Elle est composée de deux brins complémentaire. Chaque base A (respectivement $G$ ) est liée à une base $T$ (respectivement $C$ ) sur l'autre brin par des liaisons hydrogène. 


\section{3) L'enveloppe nucléaire}

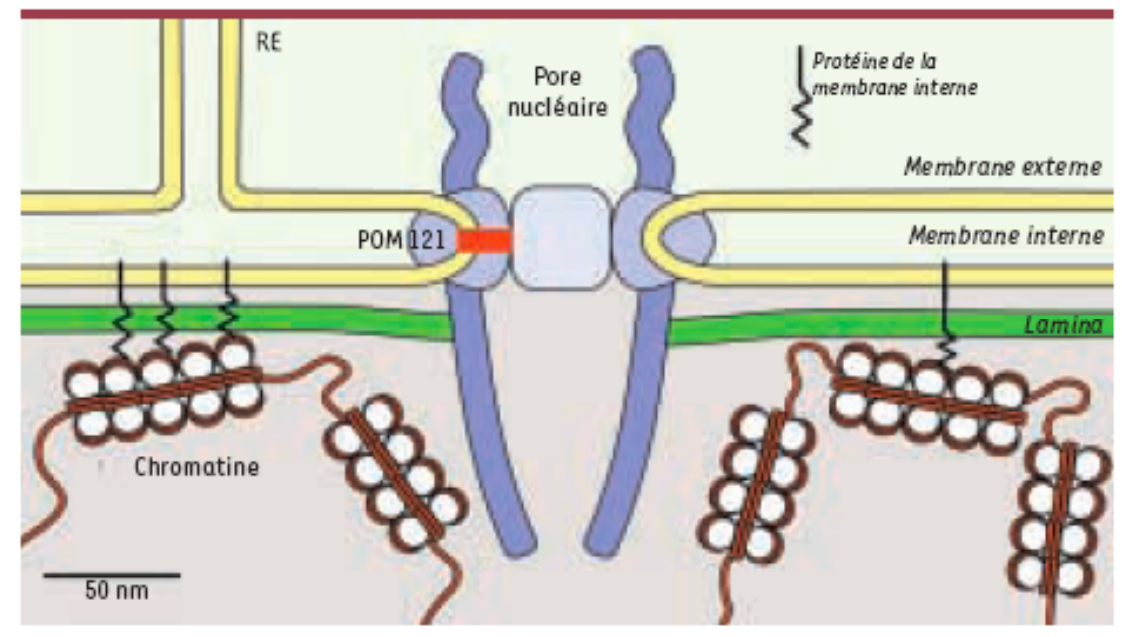

Figure 2-5 : Représentation schématique de la structure de l'enveloppe nucléaire. La membrane interne est connectée à la lamina et sert de point d'ancrage à certains éléments du noyau. La membrane externe est au contact du cytoplasme et est reliée à la membrane interne au niveau des pores nucléaires. Ces derniers permettent un échange sélectif de molécules entre le noyau et le cytoplasme.

L'enveloppe nucléaire entoure le matériel génétique de la cellule eucaryote et définie les contours du noyau (Figure 2-1). Elle sert de barrière active entre le cytoplasme et le noyau, en jouant un rôle fondamental dans de nombreux phénomènes physiologiques, comme la régulation du trafic de protéines et autres macromolécules (Dingwall et Laskey, 1992). Elle est composée de deux membranes, la membrane interne et la membrane externe (Figure 2-5). La membrane interne, au contact du nucléoplasme, est liée de façon stable à un réseau de filaments, la lamina. Il s'agit d'un réseau protéique fibreux composé de filaments intermédiaires qui double la membrane interne de l'enveloppe nucléaire. La lamina nucléaire sert de point d'ancrage à certains éléments du noyau comme l'ADN, sous une forme compactée appelée chromatine, présent à la périphérie du noyau (Hetzer et al., 2005). La lamina nucléaire représente un support structural pour l'enveloppe nucléaire. La membrane externe est au contact du cytoplasme. Des parties de la membrane nucléaire externe sont en contact avec le reticulum endoplasmique (RE). Ce RE est constitué d'un réseau étendu de membrane dont une partie est en continuité avec l'espace intermembranaire du noyau. Une partie du RE est couverte de ribosomes qui assemblent les acides aminés en chaînes protéiques suivant l'information venue du noyau. Les deux membranes se rejoignent au niveau des pores nucléaires, complexes protéiques ancrés dans la lamina (Daigle et al., 2001) permettant une circulation sélective, principalement en fonction de leur tailles, des molécules entre le noyau et le cytoplasme.

\section{4) Compaction de l'ADN dans le noyau : nucléosomes et chromatine}

\section{4-1) Introduction}

Chez les cellules eucaryotes, tous les chromosomes sont inclus dans le noyau. Les cellules humaines, par exemple, disposent chacune de 46 chromosomes, représentant un total d'environ 3 milliards de paires de bases (Hayes, 2000). Ainsi, la totalité de l'ADN déroulé contenu dans le noyau d'une cellule humaine mesure environ 1 mètre. Pourtant le noyau ne mesure pas plus de 6-7 $\mu \mathrm{m}$ de diamètre. En fait, les molécules d'ADN ne sont pas nues dans 
le noyau, mais associées à de nombreuses protéines qui permettent leur compaction. Cette association forme la chromatine.

\section{4-2) Le nucléosome : structure}

A

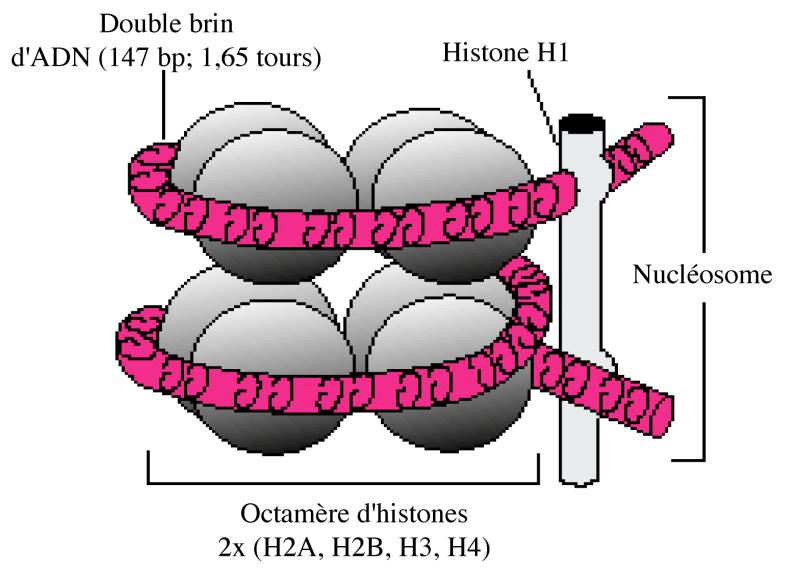

B

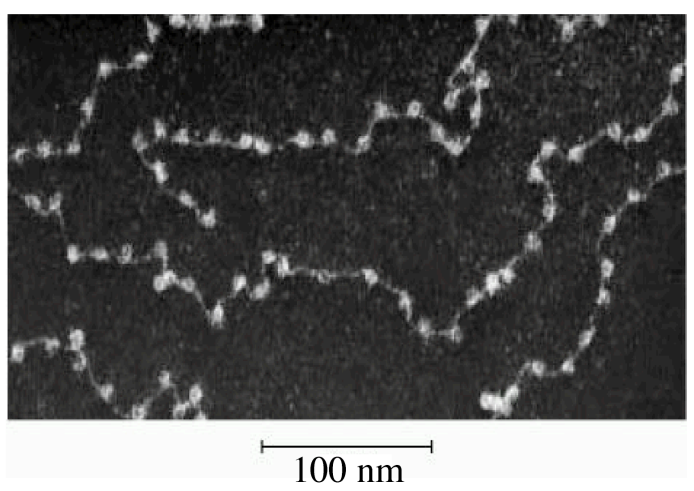

Figure 2-6 : A. Schéma représentatif du nucléosome. (tiré de Hayes (2000)) B. Fibre chromatinienne observée par microscopie électronique après décondensation de sa forme native. La combinaison des nucléosome et de l'ADN internucléosomale donne à cette forme décondensée l'aspect d'un chapelet de perles.

Le nucléosome est l'unité de base de la chromatine et forme le premier niveau de compaction de l'ADN (Figure 2-6). Le nucléosome est sans doute l'élément le mieux connu de la chromatine. Sa structure cristallographique (Figure 2-7) a été résolue avec une résolution de 1,9 Angström (Davey et al., 2002). Il est constitué de 147 paires de bases d'ADN double-brin enroulé en 1,65 tours autour d'un octamère de protéines appelées histones (Davey et al., 2002 ; Luger et Hansen, 2005). Le cœur du nucléosome est composé de 4 types d'histones : $\mathrm{H} 2 \mathrm{~A}, \mathrm{H} 2 \mathrm{~B}, \mathrm{H} 3$ et $\mathrm{H} 4$ (réparties en un tétramère de $\mathrm{H} 3-\mathrm{H} 4$ et deux dimères de $\mathrm{H} 2 \mathrm{~A}-\mathrm{H} 2 \mathrm{~B}$ ) (Kornberg et Lorch, 1999). La chromatine est principalement composée de centaine de milliers de nucléosomes reliés entre eux par 20 à 80 paires de bases formant 1'ADN internucléosomal (Luger, 2003). Cet enchaînement donne à la fibre chromatinienne déroulée un aspect en chapelet de perles d'environ $11 \mathrm{~nm}$ de diamètre (Figure 2-6 B).

A

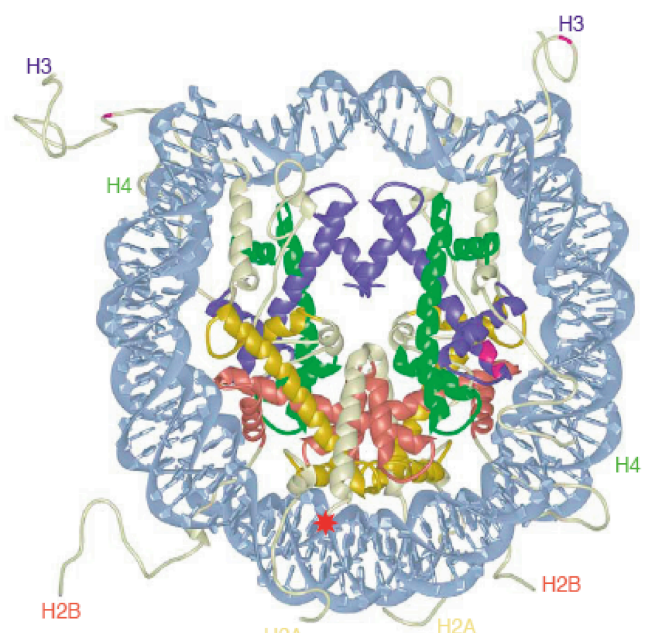

B

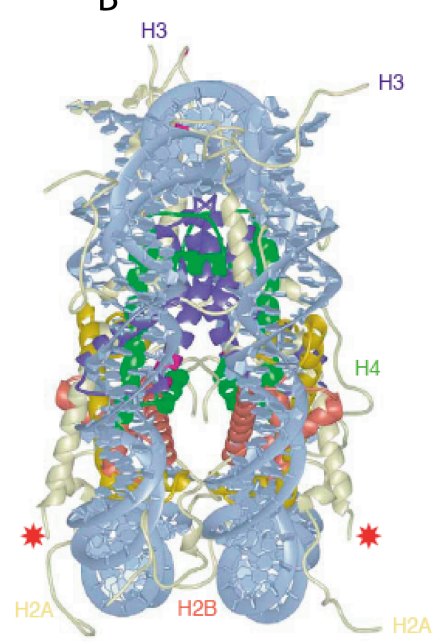

Figure 2-7 : A. Structure cristallographique du cour du nucléosome avec une résolution de 1,9 Angström. L'ADN est enroulé autour d'un octamère d'histones. B. Vue de coté de la structure (rotation de $90^{\circ}$ par rapport à l'axe vertical) (tiré de Luger, 2003). 


\section{4-3) L'histone H1}

A

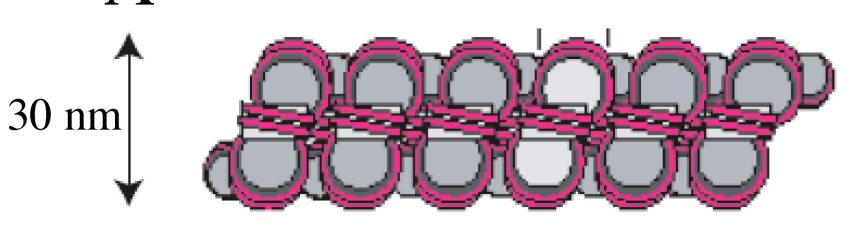

B

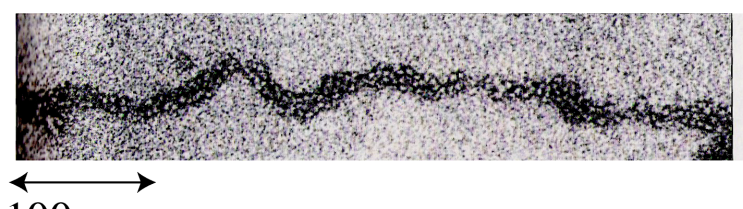

$100 \mathrm{~nm}$

Figure 2-8 : Surempilement du chapelet de perles, grâce aux histones H1, en une structure de $30 \mathrm{~nm}$ de diamètre. $\boldsymbol{A}$. Schéma représentatif. $\boldsymbol{B}$. Observation de cette structure par microscopie électronique.

L'histone H1 ne fait pas partie des histones nucléosomiques. Elle est située à l'extérieur du cœur du nucléosome (Figure 2-6). Elle dispose d'une partie globulaire qui est liée à une portion spécifique du nucléosome ainsi qu'à l'ADN internucléosomique (Sivolob et Prunell, 2004 ; Kimura, 2005). De cette manière, elle permet, dans un premier temps, le maintien de la structure du nucléosome. Elle dispose également d'un bras qui se lie aux histones du cœur des nucléosomes adjacents (Alberts et al., 1994). Ce bras lui permet de rapprocher les nucléosomes les uns par rapport aux autres. Cela permet un surempilement de la structure en chapelet de perles et représente le deuxième niveau de compaction de la chromatine en une fibre de $30 \mathrm{~nm}$ de diamètre (Figure 2-8).

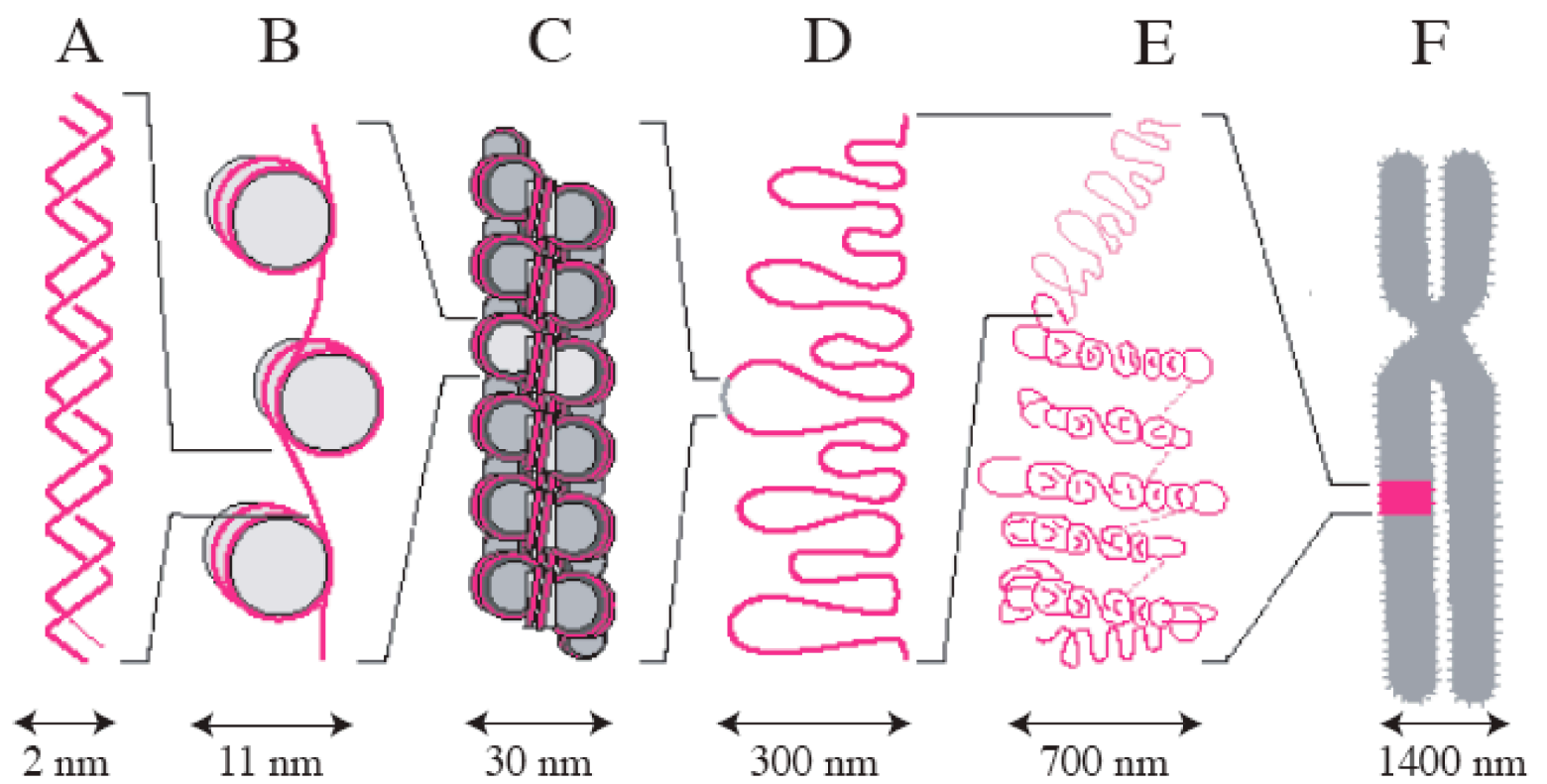

Figure 2-9 : Les différentes étapes de la compaction de l'ADN. A : Double brins d'ADN. B : Enroulement de l'ADN autour des octamères d'histones. Forme en collier de perles de la chromatine. $\boldsymbol{C}$ : Surenroulement du chapelet de perles en hélice. $\boldsymbol{D}:$ Repliement de l'hélice en boucle. $\boldsymbol{E}$ : Forme interphasique de la chromatine. $\boldsymbol{F}$ : Condensation de la chromatine en chromosome lors de la mitose. Sous cette forme, la plus compactée, la molécule d'ADN est 50000 fois plus courte. (tiré de Hayes(2000)) 
Les niveaux de compactions supérieurs de la chromatine sont encore relativement peu connus (Luger, 2003). Toutefois, il semble que le surenroulement du chapelet de perles s'organise en boucles d'environ 300 à $400 \mathrm{~nm}$ de longueur (Hayes, 2000). Ces boucles se regroupent en une spirale d'environ $700 \mathrm{~nm}$, plus ou moins dense en fonction de l'état de la cellule. En effet, en dehors de la division cellulaire, durant l'interphase, la chromatine est sous une forme décondensée, très étirée et emmêlée, un peu comme une pelote de laine qui s'étend sur tout l'espace du noyau. Par contre, lors de la division cellulaire, la chromatine se condense plusieurs milliers de fois rendant les chromosomes visibles (Figure 2-3 et Figure 2-9 F).

La compaction de la chromatine lors de l'interphase n'est, toutefois pas uniforme. Certaines zones sont nettement plus denses que d'autre

\section{4-5) Compaction de la chromatine pendant l'interphase : euchromatine et hétérochromatine}

L'observation d'une cellule au microscope, permet de voir dans le noyau des zones plus ou moins denses. Dès les années 1930, il a été mis en évidence l'existence de deux formes de chromatine : l'euchromatine et l'hétérochromatine (Alberts et al., 1994). L'euchromatine est la partie décondensée de la chromatine durant l'interphase. Sa forme décompactée rend l'ADN, et donc les gènes qu'il contient, accessible. A l'opposé, l'hétérochromatine est la partie de la chromatine qui reste condensée quelque soit la phase du cycle où se trouve la cellule. Cet état de condensation a d'abord laissé penser que l'hétérochromatine ne contenait pas de gènes. Ce n'est que dans les années 60 (Hess et Meyer, 1963) qu'il a été montré qu'elle contenait des gènes susceptibles de s'exprimer. On distingue deux formes d'hétérochromatine :

- la forme constitutive est principalement composée de séquences répétées d'ADN (ADN satellite). Elle contient très peu de gènes et est surtout située vers le centromère et les télomères du chromosome. Sa constitution la rend très stable et de ce fait elle ne change jamais d'état au cours du cycle cellulaire.

- la forme facultative est principalement composée de régions codantes. Elle est principalement située à la périphérie du noyau. A la différence de la forme constitutive, l'hétérochromatine facultative peut se décondenser. Elle contient ainsi certains gènes susceptibles de s'exprimer (Eberl et al., 1993 ; Yasuhara et al., 2005). Par exemple, des changements létaux dans la position des gènes hétérochromatiniens ont été observés chez la drosophile (Eberl et al., 1993). Eberl et al. (1993) montrent toutefois que contrairement aux gènes euchromatiniens qui sont réprimés par condensation, les gènes hétérochromatiniens ont besoin de la proximité d'hétérochromatine pour s'exprimer correctement (voir aussi Yasuhara et al., 2005). Le rôle de l'hétérochromatine constitutive serait de fournir l'environnement adéquat à l'expression de ces gènes.

Tout ce que nous venons de décrire concernant l'organisation et le degré de compaction de la chromatine influence son activité. En effet, l'ADN doit être rapidement accessible afin de permettre son interaction avec les machineries protéiques régulant les fonctions de la chromatine telles que la réplication et la transcription. Ainsi l'organisation dynamique de la structure chromatinienne influence, potentiellement, toutes les fonctions du génome.

\section{5) La transcription}

La transcription des gènes permet l'adaptation de la cellule à son environnement, ainsi que sa survie. En effet, tous ces processus nécessitent en permanence la production de protéines (enzymes,...). Le code permettant la fabrication d'une protéine est donné par l'enchaînement de nucléotides qui compose le gène correspondant. Toutefois, si ce code se trouve dans le noyau, les ribosomes, qui permettent de synthétiser la protéine, se trouvent dans le cytoplasme. Jacob et Monod (1961) ont montré l'existence d'un intermédiaire : l'ARN 
messager (Acide RiboNucléique). L'ARN messager est une molécule simple brin dont certains constituants diffèrent de l'ADN (le désoxyribose de l'ADN est remplacé par un ribose pour l'ARN messager). Toutefois, il s'agit également d'une macromolécule constituée de la succession de 4 bases azotées $\mathrm{A}, \mathrm{C}, \mathrm{G}$ et U (Uracile ; à la place de la Thymine). L'ARN messager porte ainsi la même information que l'ADN. La transcription consiste en la synthèse d'une molécule d'ARN messager, copie du gène d'intérêt. (Figure 2-10).

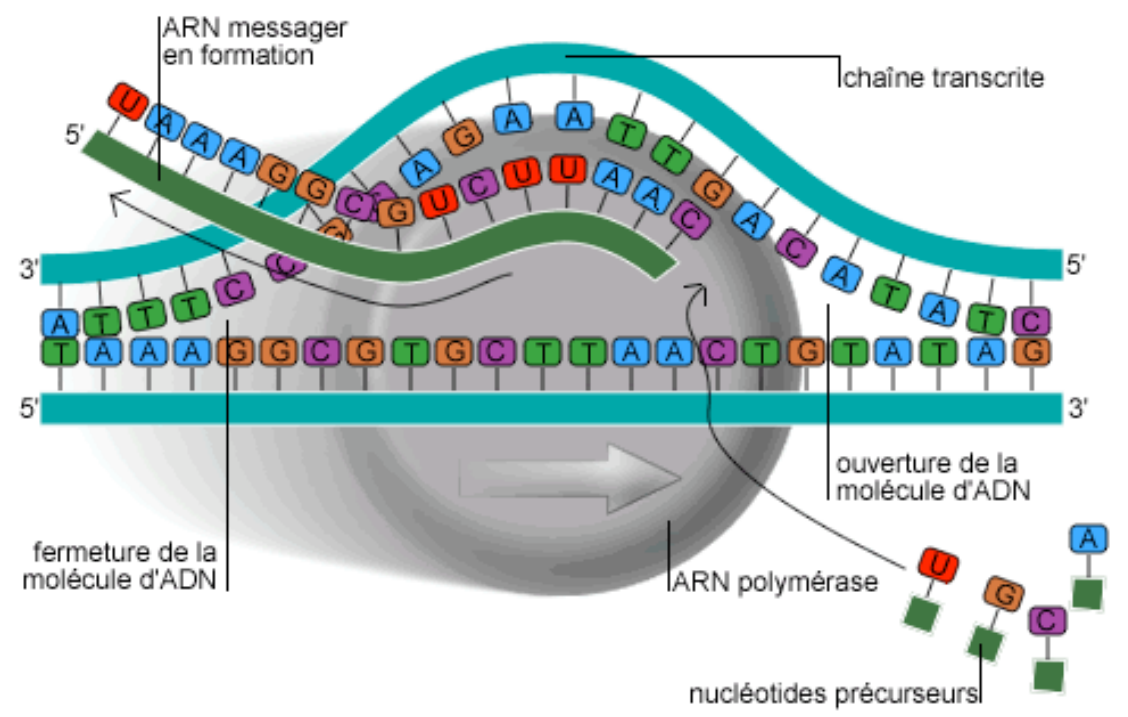

Figure 2-10 : Transcription des gènes par l'ARN polymérase. Le gène est recopié sous forme d'ARN messager. L'ARN messager migre ensuite vers le cytoplasme où il sera traduit en protéines par les ribosomes. (tiré de Wikipédia, encyclopédie en ligne)

Une enzyme, l'ARN polymérase se fixe sur un promoteur en amont du gène d'intérêt, ce qui permet la séparation des deux brins d'ADN juste à ce niveau'. Ensuite, l'ARN polymérase parcours le brin d'ADN tout le long du gène. Des données récentes montre que l'ARN polymérase, engagée dans un vaste complexe protéique, le transcriptosome, est fixe dans le noyau une fois la transcription commencée (Halle et Meisterernst, 1996 ; Gall et al., 1999). L'ADN est tracté au travers de ce complexe. L'ARN polymérase copie le gène et assemble les nucléotides de l'ARN messager (Figure 2-10). Une fois la transcription terminée, l'ARN messager est libérée et migre vers l'enveloppe nucléaire. Du fait de sa taille, son passage du noyau vers le cytoplasme nécessite un processus actif des pores nucléaires. Une fois dans le cytoplasme, l'ARN messager sera «traduit » en protéines par les ribosomes présents à la périphérie du noyau (Alberts et al., 1994).

Lors de la transcription, seule une portion de l'ADN est désappariée et recopiée puis réappariée. Un autre processus physiologique concerne la totalité de l'ADN présent dans le noyau : la réplication.

\footnotetext{
${ }^{1}$ On comprend bien, ici, que si la chromatine est trop compactée, l'enzyme ne sera pas capable de se fixer sur le promoteur
} 


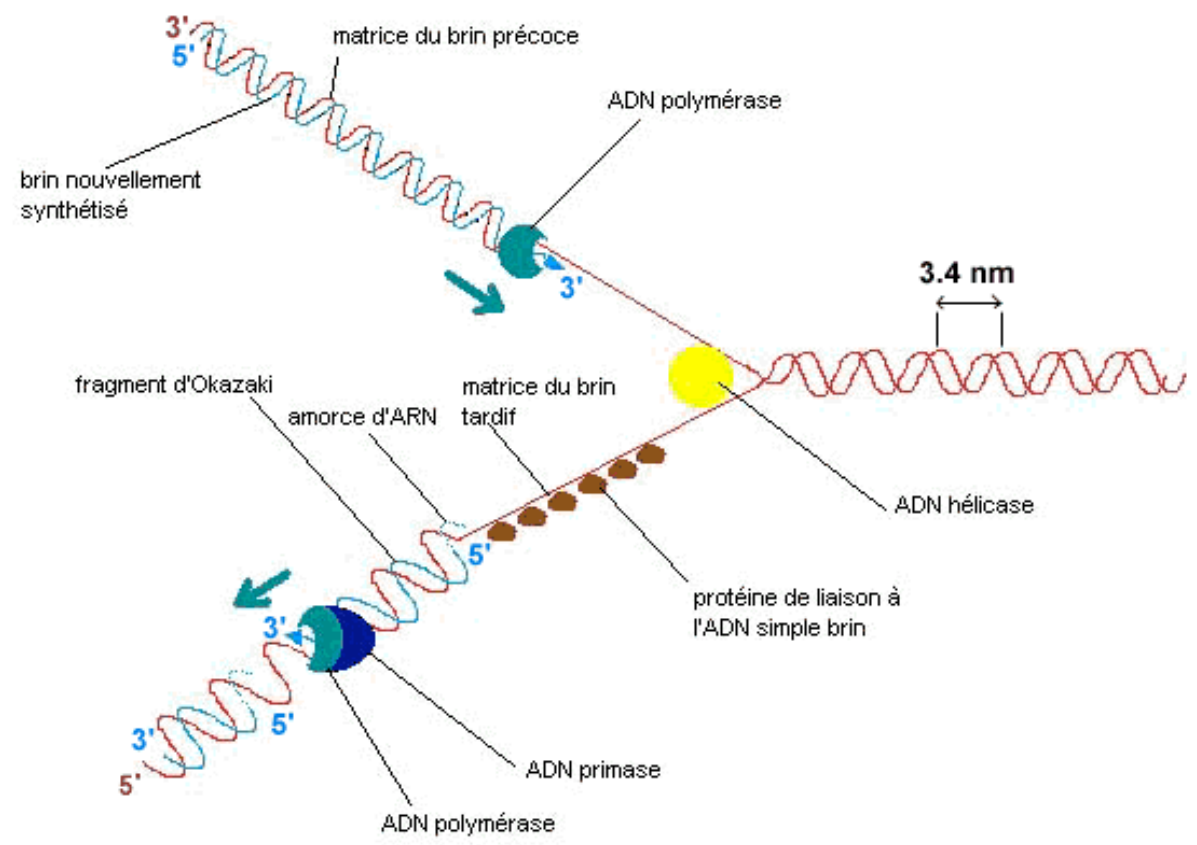

REPLICATION DE L'ADN

Figure 2-11 : Réplication de la molécule d'ADN. Les deux brins complémentaires sont séparés puis sur chacun d'eux un nouveau brin complémentaire est synthétisé par une ADN polymérase.

\section{6) La réplication de l'ADN}

La réplication de l'ADN est un processus fondamental à l'origine de la transmission des gènes aux cellules filles lors de la division cellulaire. Pour chaque chromosome, les paires de bases de sa molécule d'ADN sont désappariées, par rupture des liaisons hydrogène (Figure 2-11). Cette rupture est effectuée par une enzyme, l'ADN polymérase. Deux ADN polymérases parcourent ensuite chaque brin en sens opposé et synthétisent au fur et à mesure un nouveau brin complémentaire. Il y aura donc, au final, deux molécules d'ADN identiques contenant chacune un brin de l'ancienne molécule. C'est pourquoi le processus de réplication est dit semi-conservatif puisque chaque cellule fille aura un brin d'ADN de la cellule mère.

\section{7) Les compartiments du noyau}

\section{7-1) Introduction}

L'expression d'un gène répond souvent à un besoin immédiat nécessaire à la survie de la cellule. Ces dernières années, on a noté un intérêt croissant pour l'élucidation d'une question fondamentale : comment les complexes protéiques nécessaires à la transcription peuvent-ils se former et agir au bon endroit et au bon moment ? Un élément de réponse a été apporté par la mise en évidence de l'existence de structures morphologiques distinctes à l'intérieur du noyau (Mistelli, 2001 ; Dundr et Mistelli, 2001). Une des principales caractéristiques de ces structures est l'absence de membrane pour les délimiter. De nombreux efforts ont été menés pour comprendre comment ces différentes structures sont formées et maintenues, et comment elles interagissent les unes par rapport aux autres. Elles ont été ainsi séparées en deux grands groupes distincts : les territoires chromosomiques dans lesquels les chromosomes se positionnent distinctement et le domaine interchromosomique lieu de la transcription et de la maturation des ARN messager (Cremer et Cremer, 2001). Le domaine interchromosomique 
est donc principalement composé de compartiments distincts jouant chacun un rôle dans ces deux processus : les nucléoles, les corps de Cajal, les splicéosomes et les corps de Kremer.

\section{7-2) Territoire chromosomique}

On a longtemps considéré que, durant l'interphase, la répartition de la chromatine dans le noyau était aléatoire. Le développement de techniques de fluorescence in situ (FISH) a permis de démontrer que, bien au contraire, même sous cette forme décondensée, chaque chromosome occupe un territoire tridimensionnel distinct (Manuelidis, 1985 ; Cremer et al., 2000) que l'on a appelé «territoire chromosomique » (la position de ces territoires chromosomiques a récemment pu être cartographiée en 3D lors des phases $\mathrm{G} 0, \mathrm{~S}$ et peu avant la division cellulaire, par Bolzer et al. $\left.(2005)^{2}\right)$. Cette découverte a permis une meilleure compréhension de la manière dont la transcription de certains gènes est réprimée ou au contraire facilitée. En effet, il ne suffit pas pour un gène d'être présent sur l'euchromatine pour être exprimé (Dundr et Mistelli, 2001). Deux autres facteurs ont été mis en évidence : la position du gène dans le territoire chromosomique et à une plus grande échelle la position du territoire chromosomique dans le noyau.

Concernant le premier facteur, plusieurs expériences menées sur différents types cellulaires ont tout d'abord laissé penser que seuls les gènes présents à la périphérie du territoire chromosomique pouvaient être exprimés (Cremer et Cremer, 2001 ; Williams, 2003). Cela a abouti à un modèle dit «domaine interchromosomique»(IDC). Ce modèle considère les territoires chromosomiques comme des espaces clos à l'intérieur du noyau. Seule la périphérie serait donc au contact du domaine interchromosomique qui contient, entre autres, toutes les protéines nécessaires à la transcription. Ce modèle est à présent largement controversé. Les expériences menées par Mahy et al. (2002), par exemple, montrent que des gènes présents à l'intérieur des territoires chromosomiques peuvent aussi être exprimés. Cela a conduit à une modification du modèle IDC. Ainsi, le domaine interchromosomique semble plutôt s'étendre à l'intérieur des territoires chromosomiques (Williams, 2003). Les gènes actifs seraient donc situés soit à la surface du territoire chromosomique, soit à la surface de domaines à l'intérieur de ces territoires. Les gènes silencieux se situeraient à l'intérieur de ces domaines.

Concernant le deuxième facteur, il semble admis que les territoires chromosomiques sont répartis dans le noyau en fonction de leur taille et de leur densité en gène (Cremer et Cremer, 2001 ; Bolzer et al., 2005). Ainsi, les chromosomes de grandes tailles se trouvent plutôt à la périphérie du noyau, tandis que les chromosomes de petites tailles sont plutôt situés vers le centre. Pour deux chromosomes de tailles à peu près identiques, on a pu observer que le plus pauvre en gènes était plus proche de la périphérie du noyau que l'autre (Cremer et Cremer, 2001). Ces résultats sont en accord avec ceux présentés par Tumbar et Belmont (2001) concernant la réorganisation de la position des gènes au cours de la transcription. Ces résultats montrent que suite à l'activation de la transcription d'un gène, le territoire chromosomique auquel il appartient à tendance à se déplacer vers l'intérieur du noyau. La périphérie du noyau semble, donc, être une zone trancriptionellement peu active .

Nous allons à présent tâcher de définir les différents compartiments du territoire interchromosomique et leurs rôles dans l'expression des gènes.

\footnotetext{
${ }^{2}$ Il a également été démontré (Gerlich et al., 1993) que la position de ces territoires chromosomiques était conservée dans les cellules filles après la division cellulaire.
} 


\section{7-3) Les nucléoles}

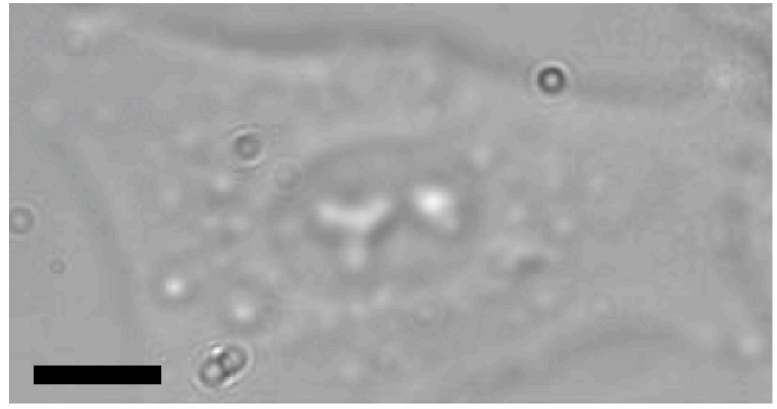

A

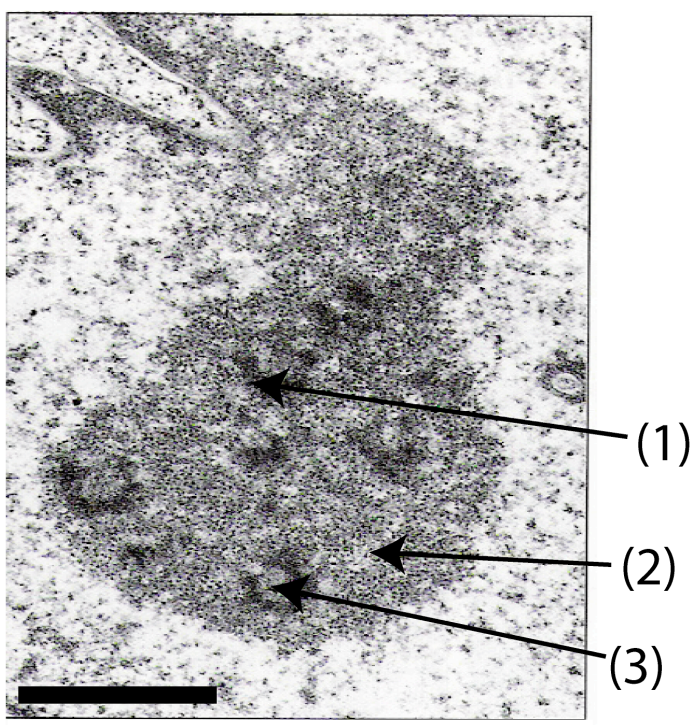

B

Figure 2-12 : A. Cellule eukaryote (SHEP-Neuroblastome) en interphase visualisée par microscopie optique à fond clair. On distingue clairement dans le noyau les nucléoles (points blancs) "usine de fabrication" des ribosomes. (La barre représente $5 \mu \mathrm{m}$; la mauvaise résolution de l'image est due à l'agrandissement de l'image originale) $\boldsymbol{B}$. Visualisation d'un nucléole de fibroblaste par microscopie électronique. On distingue plusieurs sous-structures : (1) composant fibrillaire dense, (2) le composant granulaire et (3) centre fibrillaire englobé dans (1). (La barre représente 1 нm) (tiré de Alberts et al., 1994)

Les nucléoles sont des structures, d'environ $1 \mu \mathrm{m}$ de diamètre, visibles dans le noyau des cellules par simple observation avec un microscope optique à fond clair (Figure 2-12). Elles sont sans doute les structures les mieux étudiées de l'espace interchromosomique, aussi bien structurellement que fonctionnellement (Dundr et Mistelli, 2001). La fonction principale des nucléoles est la fabrication des ribosomes (Olson et al., 2000). Un nucléole est, ainsi, principalement composé par l'agrégation de différents gènes sur différents chromosomes codant pour les gènes ribosomaux. Il regroupe donc la transcription des $\mathrm{ARN}$ ribosomiques (ARNr), leur maturation (clivages nucléiques, modifications chimiques des bases), et l'assemblage des sous-unités ribosomiques à partir des $\mathrm{ARNr}$ et des petites ribonucléoprotéines (snRNP). Les protéines impliquées dans ces différentes fonctions sont regroupées en trois sous-structures morphologiquement distinctes, pour les cellules humaines, (Scheer et Hock, 1999 ; Olson et al., 2000 ; Dundr et Mistelli, 2001) comme présenté en Figure 2-12 B :

- les centres fibrillaires qui semblent être le lieu de stockage des ARN polymérases I nécessaires à la transcription de l'ADN ribosomique.

- le composant fibrillaire dense qui englobe les centres fibrillaires et qui contient l'ARN ribosomique en cours de synthèse.

- le composant granulaire où se déroule la maturation des $\mathrm{ARNr}$

La transcription de l'ADN ribosomal se produit entre les centres fibrillaires et le composant fibrillaire dense (Olson et Dundr, 2005). Une fois la transcription terminée, l'ARN ribosomique est maturé et associé aux protéines constitutives des ribosomes. Elles seront assemblées dans le composant granulaire des nucléoles en deux sous-structures (Alberts et al., 
1994). Ces deux sous-structures sortent à nouveaux du noyau et s'assemblent dans le cytoplasme pour former un ribosome.

\section{7-4) Les splicéosomes}

Les splicéosomes, également connus sous le nom de speckles, du fait qu'ils ont l'aspect d'une tache de diffraction lors de la visualisation par microscopie électronique, sont des structures de l'espace interchromosomique qui occupent environ $20 \%$ de l'espace du noyau (Misteli, 2001). Ils sont composés d'agrégats de granules interchromatiques entourés de fibres périchromatiques (Dundr et Misteli, 2001). Ils sont également caractérisés par une forte concentration en facteurs d'épissage de l'ARN, facteurs permettant la suppression de certaines parties non codantes des ARN messagers ${ }^{3}$, par la présence de facteur de transcription et par la présence d'ARN polymérase II. Même si leur rôle n'est pas totalement élucidé, plusieurs observations permettent de penser que la transcription et l'épissage de la plupart des gènes se produit à la périphérie des splicéosomes (Misteli, 2001). Ainsi, l'activation d'un gène, dans ce cas, dépendrait :

- de la distance initiale du gène par rapport à l'usine d'assemblage. Plus un gène serait près du site de polymérisation, plus il pourrait s'attacher facilement. Un gène masqué à l'intérieur d'un territoire chromosomique s'attachera au contraire beaucoup plus rarement.

- de la mobilité du promoteur, ce qui est lié à son degré de compaction au sein de la chromatine. Les gènes compactés près de la lamina ou du nucléole deviennent pratiquement immobiles et ont donc une probabilité plus faible de rencontrer un site de polymérisation.

\section{7-5) Les corps de Cajal}

Les corps de Cajal sont des petites structures, souvent localisées à la périphérie de la face interne de la membrane nucléaire (Platani et al, 2000), dont la taille peut varier de 0,1 à $1 \mu \mathrm{m}$ en fonction du type cellulaire. A l'heure actuelle, leur rôle exact est encore mal connu. Plusieurs hypothèses ont toutefois pu être avancées. Il a tout d'abord été démontré qu'ils contenaient une très forte concentration en ribonucléoprotéines et en facteurs de transcription (Dundr et Misteli, 2001). De plus, on a pu observer de nombreux mouvements des corps de Cajal vers et depuis les nucléoles (Platani et al., 2000). Tout cela semble indiquer qu'ils jouent un rôle important dans la fabrication des ribosomes. Une autre hypothèse, qui n'exclut cependant pas la première, avance l'idée qu'ils pourraient être le lieu d'assemblage des ARN polymérases (Gall et al., 1999). Enfin, du fait qu'ils sont souvent associés à des histones actives, on suppose qu'ils ont un rôle dans la régulation de l'expression des gènes codant pour les histones (Shopland et al., 2001).

\section{7-6) Les corps de Kremer}

Les corps de Kremer ou PML ( Promyelocitic Leukaemia) sont des petites structures sphériques présentes dans tout le nucléoplasme. Leur rôle est également mal connu, mais il semble qu'ils soient associés à de nombreux phénomènes comme la différenciation, la régulation de la transcription, la croissance cellulaire ou encore l'apoptose (Dundr et Misteli, 2001). Il a également été démontré qu'ils jouent un rôle important dans la transcription virale (Wienzek et Dobbelstein, 2001). Ainsi, il a été suggéré que certains facteurs de transcription pouvaient être concentrés dans des sites de polymérisation particuliers. Les gènes activés par

\footnotetext{
${ }^{3}$ La même molécule d'ARN messager n'est pas toujours épissée de la même manière. Le résultat est qu'elle pourra coder pour différentes protéines (Alberts et al., 1994). Un même gène peut donc être à l'origine de plusieurs protéines, on parle alors d'épissage alternatif.
} 
ces facteurs ne sont donc transcrits que s'ils sont associés à ce site particulier. Ainsi, les corps de Kremer semblent regrouper de l'ARN polymérase II et certains gènes particuliers nécessaires aux processus cités dans ce paragraphe. Ces domaines sont plus particulièrement associés à certains chromosomes et pourraient donc, comme le nucléole, concentrer des gènes particuliers dans une région propice à leur transcription.

\section{7-7) Conclusion}

Même si le rôle de tous les compartiments du noyau n'est pas encore clairement établi, il paraît évident que l'architecture du noyau est un paramètre clé dans la régulation de la production des protéines. Ainsi, les gènes sont recrutés dans des domaines transcriptionnels. Bien évidemment, le degré de compaction de la chromatine influence ce phénomène car un gène décompacté est plus apte au mouvement et donc au recrutement. De la même façon, les données biochimiques de la dynamique des protéines dans le noyau peuvent aboutir à une nouvelle approche des régulations. De nombreuses études montrent qu'il existe un flux de molécules dans le noyau notamment au sein des régions interchromatiques. Ces études ont permis de montrer que la dynamique des protéines nucléaires, et notamment leur stabilité sur la molécule d'ADN, va jouer un rôle prépondérant dans la régulation de l'expression des gènes.

\section{$\underline{\text { IV }>\text { Cycle cellulaire }}$}

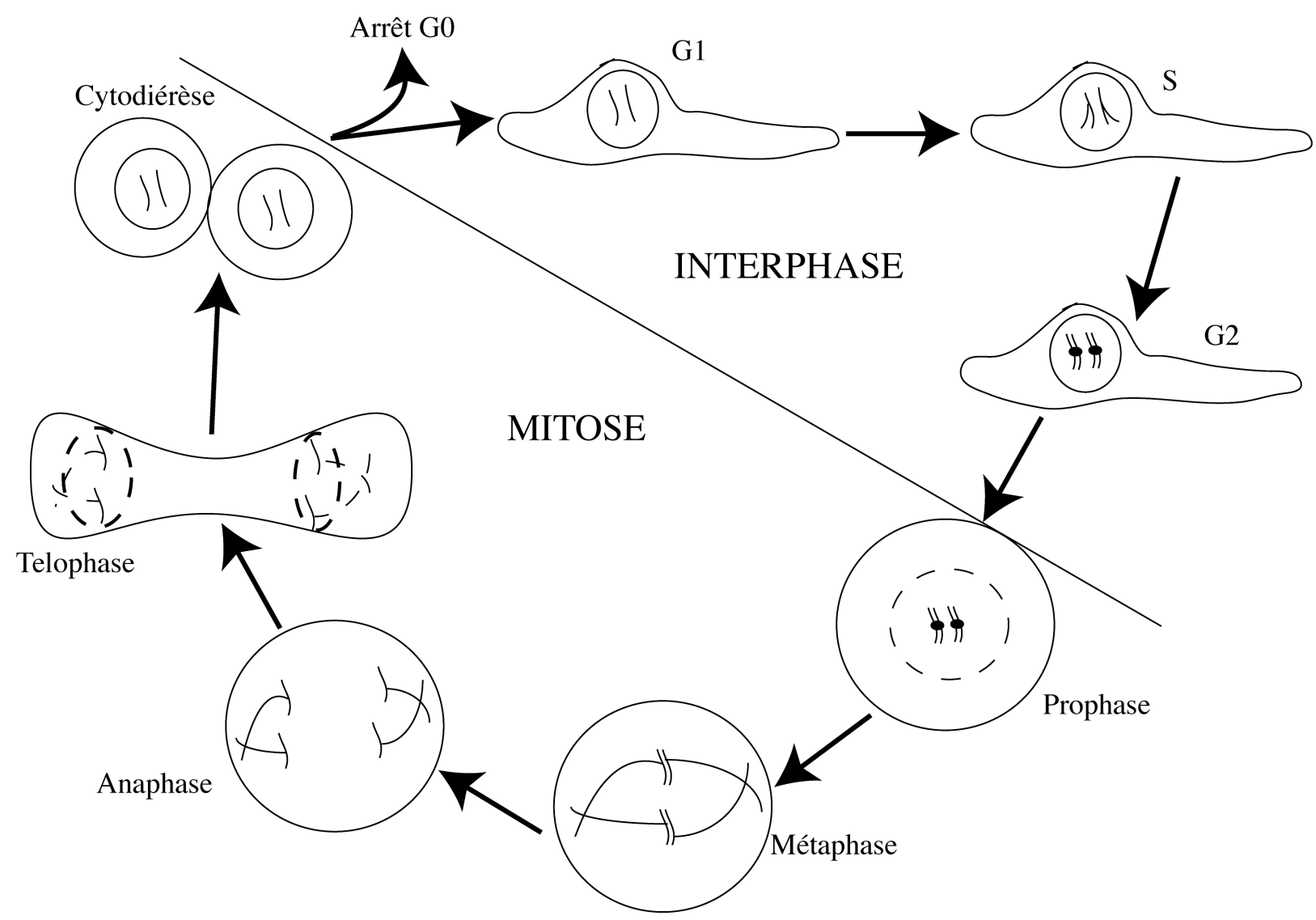

Figure 2-13 : Le cycle cellulaire. Les deux phases principales sont l'interphase et la mitose (ou phase M). L'interphase comprend les phases G1, S et G2. La mitose comprend la prophase, la métaphase, l'anaphase, la télophase et la cytodiérèse. A la fin du cycle, si la cellule n'a pas besoin de se diviser à nouveau elle rentre en G0. Dans des conditions normales, les cellules cancéreuses ne rentrent pas en GO et continuent à se diviser (par soucis de simplicité, les chromosomes sont représentés dès le départ sous forme de bâtonnets) 
Le cycle cellulaire (Figure 2-13 ; Baserga, 1981) aboutit à la division d'une cellule en deux cellules filles. Le noyau de chaque cellule fille contient le même matériel génétique que la cellule d'origine. Le cycle cellulaire contient quatre grandes phases : la phase G1, la phase $S$, la phase G2 et la phase M. Les phases G1, S et G2 forment l'interphase, période pendant laquelle une observation des cellules avec un simple microscope optique ne permet pas de voir de changements significatifs sur les cellules. La phase $\mathrm{M}$ est la phase de mitose où l'on peut voir la cellule se diviser.

\section{1) La phase G1}

La première phase du cycle cellulaire est la phase G1 (Gap 1). Sous l'influence de facteurs de croissance, la cellule commence sa division. Durant cette phase, le matériel à l'intérieur du cytoplasme est répliqué et l'on note une forte activité transcriptionnelle à l'intérieur du noyau. Vue de l'extérieur, la cellule grossie.

\section{2) La phase $S$}

Lorsque la cellule a suffisamment grossi, elle effectue un premier contrôle. Si son ADN est en bon état, elle entre en phase S (Synthèse). Sinon elle déclenchera le mécanisme d'apoptose. C'est durant la phase $S$ que se déroule la réplication de l'ADN (voir paragraphe III $>6$ ). Chaque chromosome est ainsi copié à l'identique.

\section{3) La phase G2}

La phase G2 débute une fois la réplication de l'ADN terminé. La quantité d'ADN dans le noyau a donc doublé par rapport à la phase G1. La phase G2 est une phase de contrôle durant laquelle la cellule vérifie que les chromosomes sont bien dupliqués et qu'il n'y a aucune anomalie. Le cas échéant une réparation post-réplicative peut être effectuée.

\section{4) La phase M}

La phase $\mathrm{M}$ est la phase durant laquelle la cellule se sépare en deux cellules filles. Elles comprend 5 étapes majeures : la prophase, la métaphase, l'anaphase, la télophase et la cytodiérèse.

\section{4-1) La prophase}

Durant cette phase la plupart des points d'adhésion focale de la cellule, qui maintiennent la cellule attachée à son substrat, se relâche. Vue de l'extérieur, la cellule s'arrondit. La chromatine se condense et les chromosomes prennent la forme de petits bâtonnets. La membrane nucléaire commence à disparaître.

\section{4-2) La métaphase}

Ici, la membrane nucléaire disparaît complètement. Les chromosomes s'alignent au centre de la cellule. Des fuseaux de microtubules (Cassimeris, 2004), solidement ancrés à des pôles invisibles présents à chaque extrémité de la cellule, les kinétochores, se forment. Ils s'attachent au centromère de chaque chromosome.

\section{4-3) L'anaphase :}

les fuseaux de microtubules se condensent. Les deux copies de chaque chromosome sont ramenées chacune vers une extrémité de la cellule. Cette phase est la plus rapide de la phase M. Selon Gerlich et al. (2003), les temps de migration des chromosomes ne sont pas identiques. Cela permet la conservation de la position des chromosomes dans les noyaux des cellules filles par rapport à celle de la cellule mère. 


\section{4-4) La télophase}

lors de cette phase, chaque groupe de chromosomes commence à être entouré par une nouvelle enveloppe nucléaire. La chromatine se décondense et les chromosomes ne sont plus visibles. Les fuseaux de microtubules se désagrègent.

\section{4-5) La cytodiérèse}

la cellule se divise en deux cellules filles. Chacune est enveloppée de sa propre membrane cellulaire. L'enveloppe nucléaire est complètement formée. Les deux cellules filles possèdent exactement les mêmes chromosomes que la cellule mère.

A la fin du cycle, les deux cellules filles rentrent en G1. Si une division n'est plus nécessaire, elles rentreront en G0 et se différencieront. Les cellules cancéreuses continueront à cycler et ne rentreront pas en G0 si le milieu contient suffisamment d'éléments nutritifs pour le leur permettre.

\section{V>Dynamique du noyau}

\section{1) Introduction}

Les observations du noyau de cellules vivantes, lors de l'interphase, réalisées par microscopie optique à fond clair, ne montraient que très peu de mouvements (Belmont, 2003) en comparaison des spectaculaires réarrangements observés durant la mitose. C'est pourquoi il a été longtemps considéré que, durant l'interphase, l'organisation structurale du noyau était peu dynamique. Cette hypothèse a été confortée par la mise en évidence de l'organisation du noyau en compartiments que l'on pensait relativement stable (Belmont, 2003). De plus, des expériences de reconstitution in-vitro des complexes de pré-initiation de la transcription ont abouti à des modèles prévoyant une stabilité sur une échelle de temps supérieure à l'heure de leurs interactions avec l'ADN (Belmont, 2003). Cependant, le développement de nouvelles méthodes d'analyse in situ sur les cellules et les tissus, telles que l'hybridation in situ fluorescente (FISH) et l'immunofluorescence (Robinett et al., 1996), ainsi que diverses techniques d'imagerie microscopique (microscopie confocale à balayage laser, microscopie quantitative avec capteurs CCD refroidis,...) ont mis en évidence une dynamique intense intra et inter compartiments nucléaires. Ces techniques permettent, grâce à des nouvelles méthodes de marquages de l'ADN, des ARNs et des protéines (comme le couplage à des protéines fluorescentes telles la GFP (Green Fluorescent Protein)) de détecter la position de chromosomes, de gènes, de transcrits ou encore de complexes protéiques à l'intérieur du noyau. Elles permettent également d'obtenir des informations sur la forme et le volume de territoires chromosomiques. Elles ont, aussi, permis d'observer de larges déplacements des territoires chromosomiques (Gasser, 2002; Belmont, 2003), des mouvements de la chromatine à l'intérieur de ces territoires (Belmont, 2003 ; Ehrenhofer-Murray, 2004), des déplacements des autres compartiments dans l'espace interchromosomique (nucléoles, corps de Cajal,...) et enfin des mouvements de macromolécules comme les ARN messagers. Les principaux phénomènes physiologiques à l'origine de ces mouvements ont été identifiés comme étant la transcription des gènes (Gasser, 2002; Belmont, 2003), la réplication de l'ADN et la maturation des ARN (Misteli et al., 1997 ; Gall, 2000 ; Shav-Tal et al., 2004).

\section{2) Dynamique des territoires chromosomiques}

D'importants mouvements des territoires chromosomiques ont été observés de la périphérie du noyau vers l'intérieur et vice-versa (Gasser, 2002 ; Belmont, 2003) sur une échelle de 
temps allant de 30 minutes à 2 heures (Tumbar et Belmont, 2001). Ces mouvements reflètent en général :

- l'évolution de la cellule dans le cycle. Ainsi, il a été montré que certains chromosomes se repositionnaient transitoirement vers le centre du noyau au début de la phase G1 (Tumbar et Belmont, 2001). Toujours lors de la phase G1, des contacts interchromosomes ou entre les chromosomes et certains corps cellulaires ont été mis en évidence. Des mouvements, manifestement dus à la rupture de tous ces contacts (Gasser, 2002), ainsi qu'un nouveau repositionnement transitoire des chromosomes vers le centre du noyau (Tumbar et Belmont, 2001) sont observés durant la phase S. En début de phase G2, on peut mettre en évidence un déplacement dirigé des centromères de chaque chromosome, sans doute en préparation de la mitose (Gasser, 2002).

- des changements dans l'activité transcriptionnelle. Ainsi, des expériences d'activation de la transcription par l'utilisation du système LacSwitch, qui utilise plusieurs éléments modifiés de l'opéron lactose pour le contrôle des gènes dans les cellules eucaryotes, a permis de montrer, chez la levure, que le chromosome portant la région ciblée se repositionne vers le centre du noyau (Tumbar et Belmont, 2001 ; Belmont, 2003). De même, la relocalisation transitoire d'un chromosome vers le centre suite au passage de la cellule de la phase G0 à la phase G1, est altérée par l'inhibition de l'action des ARN polymérases (Gasser, 2002) suggérant que l'activité transcriptionnelle influence la centralisation des chromosomes.

Les territoires chromosomiques bougent donc lentement sur de grandes distances à l'échelle du noyau. Ces mouvements sont sans doute liés à une dynamique plus locale de la chromatine (Gasser, 2002) qu'il convient de définir.

\section{3) Dynamique de la chromatine au sein du territoire chromosomique}

\section{3-1) Mouvements de la chromatine}

Abney et al. (1997) ont mené les premières études par photoblanchiment (FRAP ; voir Annexe C) et par marquage de l'ADN grâce à un intercalant fluorescent (Bromure d'éthidium), sur la dynamique de la chromatine. Leurs observations suggéraient que la chromatine est relativement immobile pour des échelles de longueur de 0,4 $\mu \mathrm{m}$. La découverte de nouveaux marqueurs fluorescents et la précision accrue des méthodes de détection ont permis de montrer que la chromatine était, en fait, une structure hautement dynamique même sur ces échelles. Ainsi, des observations précises des mouvements de la chromatine ont pu être réalisées par suivi des mouvements de sondes fluorescentes en microscopie de fluorescence en temps réel (Gasser, 2002 ; Belmont, 2003). Des mouvements très rapides de la chromatine ont été mis en évidence, avec des temps caractéristiques qui semblent inférieurs à la dizaine de millisecondes, sur des échelles de longueur de quelques centaines de nanomètres. Ces résultats ne contredisent donc pas les mesures de Abney et al. (1997) mais montrent une dynamique sur des échelles beaucoup plus fines, indétectable avec les méthodes alors utilisées. La découverte de cette dynamique a amené plusieurs questions, toujours débattues à l'heure actuelle (Gasser, 2002) : ces mouvements sont-ils browniens ou dirigés ? Ensuite, sont-ils liés à une activité spécifique du noyau ?

L'hypothèse d'un mouvement dirigé de la chromatine a été rapidement écartée par le suivi durant plusieurs minutes de portions spécifiques de l'ADN. Ce suivi montre que la chromatine explore une partie importante de l'espace auquel elle appartient. Par ailleurs, le mouvement de la chromatine n'est pas dirigé par des microtubules, comme les chromosomes lors la mitose, puisque l'ajout de drogue induisant la dépolymérisation des microtubules ne change pas cette dynamique (Gasser, 2002). Par contre, il a été montré que la dynamique de la 
chromatine était largement sensible à une déplétion de l'ATP. De plus, cette dynamique est énormément restreinte par l'inhibition de l'activité transcriptionnelle (Gasser, 2002). Il est donc plutôt admis, que la dynamique de la chromatine dépend principalement de l'action d'enzyme ATP dépendante nécessaire à la transcription ou au remodelage de la chromatine (Gasser, 2002 ; Belmont, 2003). En menant des expériences de FRAP à deux photons sur des cellules dont l'ADN a été marquée avec le colorant Hoechst 33342, Davis et Bardeen (Davis et Bardeen, 2003 ; Davis et Bardeen, 2004 ; Davis et Bardeen, 2005) ont montré que les mouvements de la chromatine résultaient d'une diffusion brownienne avec des coefficients de diffusion de l'ordre de $5.10^{-4} \mu \mathrm{m}^{2} / \mathrm{s}$ dans un espace limité à environ $1 \mu \mathrm{m}$ de diamètre. Ces coefficients de diffusion sont très petits et dénotent donc une dynamique très lente (à titre de comparaison, les coefficients de diffusion que l'on trouve généralement dans les systèmes colloïdaux sont de l'ordre de 1 à $10 \mu \mathrm{m}^{2} / \mathrm{s}$ ). Plus récemment, Levi et al. (2005) ont affiné ces résultats par l'utilisation d'une méthode de suivi de particules par microscopie confocale à 2 photons sur des cellules vivantes. Ils ont préalablement marqué l'ADN des cellules en utilisant des lac-répresseur fusionnés avec de la GFP (Robinett et al., 1996). Ils ont ainsi mis en évidence deux coefficients de diffusion pour la chromatine. Le plus rapide des deux est de l'ordre de $3.10^{-3} \mu \mathrm{m}^{2} / \mathrm{s}$. Cette diffusion est confinée dans un espace dont le rayon n'excède pas $40 \mathrm{~nm}$ ce qui est comparable à la taille de la fibre chromatinienne surempilée $(30 \mathrm{~nm}$, voir paragraphe III >4). Ce coefficient de diffusion est donc sans doute lié à des oscillations locales de la chromatine. Le coefficient de diffusion le plus lent est de l'ordre de $2,5.10^{-4} \mu \mathrm{m}^{2} / \mathrm{s}$ ce qui est comparable au coefficient de diffusion donné par Davis et Bardeen. Ce dernier coefficient est, toutefois, susceptible de changer en fonction du cycle cellulaire. Il reflète, donc, certainement les interactions entre la chromatine et les structures du noyaux responsables de la transcription ou de la réplication.

Davis et Bardeen montrent également que l'origine de cette diffusion semble intimement liée à la dynamique des histones et au remodelage de la chromatine (Davis et Bardeen, 2004 ; Davis et Bardeen, 2005).

\section{3-2) Dynamique des histones}

La chromatine permet la structuration du noyau mais elle ne doit pas en empêcher l'activité. Cette activité est principalement concentrée dans deux fonctions essentielles de la cellules vivantes : la réplication de l'ADN et la transcription que nous avons définies au chapitre précédent. L'activité de transcription repose sur la capacité d'une ARN polymérase à interagir avec un promoteur. Or la présence d'histones masque ce promoteur. La manière dont l'ARN polymérase accède à l'ADN est donc un facteur clef de l'expression ou de la répression de certains gènes. De même, l'accès des $\mathrm{ADN}$ polymérases à l'ADN est à la base du phénomène de réplication de l'ADN. De nombreuses études ont donc été menées sur les modifications subies par les histones lors de la transcription et lors de la réplication. Elles ont montré que deux activités enzymatiques étaient principalement responsables de la régulation de l'accès des protéines à la chromatine (Berger, 2002 ; Ehrenhofer-Murray, 2004) : le remodelage du nucléosome et les modifications post-traductionelle.

Le remodelage de la chromatine consiste en des modifications structurelles réversibles des nucléosomes la rendant plus accessible. Les complexes enzymatiques qui opèrent ces modifications agissent de plusieurs façons. Ils peuvent, ainsi, rendre accessible l'ADN :

- en changeant la position d'un nucléosome

- en altérant la liaison entre l'ADN et le nucléosome

- en participant à l'éviction complète de certaines histones (Boeger et al., 2003)

Des études récentes ont également montré que, lors de la transcription, ils pouvaient induire un remplacement de certains histones par des formes variantes qui changent les propriétés 
biochimiques du nucléosome (Mizugushi et al., 2004). Ce phénomène a donc un effet important dans la régulation de l'activité génétique.

Les modifications post-traductionnelles affectent principalement le recrutement de certaines protéines nécessaires à la transcription. Les quatre types de modifications les plus étudiées sont :

- l'acétylation des lysines (acide aminé présent sur la partie amino-terminale de chaque histone) : cette modification entraîne un changement des charges des lysines provoquant une diminution d'interaction entre les histones et l'ADN. Cette modification est ajoutée sous l'action d'une enzyme, l'histone acétyltransférase (HAT). La structure du nucléosome est, ainsi, déstabilisée ce qui permet l'accès des protéines de transcription à l'ADN (Turner, 2000 ; Ehrenhofer-Murray, 2004). La réaction inverse, la déacétylation, est assurée par des histones deacétylases (HDAC). Une hypoacétylation est la marque d'une répression de la transcription (EhrenhoferMurray, 2004). Ces phénomènes d'acetylation/déacétylation aboutissent à une grande capacité de remodelage de la chromatine comme le montrent les mesures effectuées suite à l'inhibition des HAT ou des HDAC. La chromatine retrouve, alors, son état initial en quelques minutes.

- la méthylation des lysines et des arginines (un autre acide aminé) : elle est effectuée par des enzymes HMT (Histone Methyltransférase). Son action dépend principalement du résidu ciblé sur les histones. Elle peut être aussi bien impliquée dans l'activation des gènes que dans leur répression (Berger, 2002 ; Ehrenhofer-Murray, 2004). A plus grande échelle, certaines méthylations sont aussi impliquées dans la formation et la stabilité de l'hétérochromatine (Ehrenhofer-Murray, 2004). Ce n'est que récemment que des processus de réversion de la méthylation par des histones déméthylases ont été mis en évidence (Shi et al., 2004).

- la phosphorylation : elle est régulée par des protéines kinases et phosphatases. Dans le cas des histones $\mathrm{H} 1$, la phosphorylation contribue à leur dissociation de la chromatine permettant ainsi une décondensation de cette dernière. La mobilité des histones H1 semble très rapide, de l'ordre de la dizaine de secondes (Belmont, 2003). A contrario, la phosphorylation de l'histone $\mathrm{H} 3$ semble plutôt impliquée dans la condensation de la chromatine mais ce rôle est sujet à controverse (De la Barre et al., 2001).

- la mono-ubiquitination : cette modification assurée par des enzymes, les ubiquitine ligases, a été également associée à la régulation de la transcription des gènes (Sun et Allis, 2002).

La dynamique des histones dépend donc de la coordination de plusieurs phénomènes, dont le recrutement de certaines protéines. Des expériences d'immunoprécipitation de la chromatine (ChIP ; voir Annexe C) sur des séquences régulatrices de gènes dont l'expression est hormono-dépendante ont permis d'identifier des dynamiques de modifications des histones sur une échelle de temps allant de la minute à la dizaine de minutes en réponse à la stimulation des cellules en culture par les hormones (Métivier et al., 2003). Ceci implique l'existence de plusieurs voies de modifications des histones.

\section{4) Dynamique des autres corps nucléaires}

L'ADN n'est pas la seule structure dynamique du noyau. Les corps nucléaires présents dans le domaine interchromosomique ont également une dynamique propre qui est aussi reliée aux trois facteurs présentés en introduction (transcription, réplication, maturation des ARN messager) 


\section{4-1) Les splicéosomes}

La dynamique des splicéosomes (voir paragraphe III >7) a été étudiée, en microscopie de fluorescence time-lapse, par Misteli et al. (1997) en fusionnant des GFP avec un important facteur d'épissage, le SF2/ASF. Les résultats concernant la position des splicéosomes montrent que celle-ci est relativement stable. D'un autre coté, la structure même du splicéosomes semble quant à elle excessivement dynamique. Deux types de dynamique ont principalement été observées :

- des extensions de la périphérie des splicéosomes pouvant aller de $300 \mathrm{~nm}$ à plus d'1 $\mu \mathrm{m}$ avec une persistance d'environ 5 minutes. L'inhibition des facteurs de transcription aboutit à l'arrêt de ces mouvements.

- l'association et la dissociation de facteur d'épissage au splicéosome. Ces mouvements sont particulièrement remarquables 15 à 20 minutes après l'activation de la transcription d'un gène (préalablement marqué par FISH). Il est observé la formation d'une queue de facteurs d'épissage partant du splicéosome et orientée vers le gène en question. L'élongation de cette queue par le recrutement de facteur d'épissage se poursuit pendant environ $30 \mathrm{~min}$.

\section{4-2) les corps de Cajal}

En utilisant des lignées cellulaires pour lesquelles les principales protéines des corps de Cajal étaient fusionnées avec de la GFP, plusieurs équipes (revue dans Bubulya et Spector, 2004) ont montré que la dynamique des corps de Cajal résultait d'une diffusion anormale ${ }^{4}$ La diffusion aléatoire des corps de Cajal est, en fait, modifiée par leur possibilité de fusionner ou de se diviser en de plus petites structures (Platani et al., 2000). Le suivi par microscopie de fluorescence des mouvements des corps de Cajal montre que ceux mesurant moins de $2 \mu \mathrm{m}$ de diamètre peuvent se déplacer à une vitesse maximum d'environ $0,65 \mu \mathrm{m} / \mathrm{min}$ tandis que ceux résultant de plusieurs fusions (plus de $4 \mu \mathrm{m}$ de diamètre) ne se déplaçaient qu'à une vitesse maximum d'environ $0,48 \mu \mathrm{m} / \mathrm{min}$. Une autre modification de la diffusion aléatoire provient de l'immobilisation des corps de Cajal lors de leur fixation sur la chromatine (Platani et al. 2000). Platani et al. (2000) ont également observé les déplacements dans le nucléoplasme de la principale protéine présente dans les corps de Cajal, la coilin, en la fusionnant avec de la GFP. Ils montrent que le taux de coilin dans le noyau semble constant et il est noté de fréquents échanges entre différents corps de Cajal. Des expériences de FRAP menées sur de la GFP-coilin dans les corps de Cajal de vésicules germinales de Xenopus ${ }^{5}$ (Handwerger et al, 2003), ont, en fait, montré l'existence de trois temps de résidence de la coilin dans les corps de Cajal. Le premier est de l'ordre de $15 \mathrm{~s}$, le deuxième de l'ordre de $5 \mathrm{~min}$ et le dernier de l'ordre de $30 \mathrm{~min}$. Des expériences du même type menées sur d'autres protéines des corps de Cajal ont abouti à des résultats équivalents (Bubulya et Spector, 2004). Ces trois temps semblent provenir des différentes étapes nécessaires à l'assemblage de complexes protéiques.

\footnotetext{
${ }^{4}$ La diffusion anormale est une diffusion brownienne contrainte par les obstacles présents dans l'environnement de la particule. Ainsi, si dans le cadre de la diffusion brownienne la moyenne du carré de la distance $r(t)$ parcourue par la particule est proportionnelle à $t\left(\left\langle r^{2}(t)\right\rangle \propto t\right)$, dans le cadre d'un diffusion anormale on aura $\left\langle r^{2}(t)\right\rangle \propto t^{\alpha}$ avec $\alpha \neq 1$ (Banks et Fradin, 2005). Dans notre cas, le phénomène est sous-diffusif ce qui signifie que $\alpha<1$.

${ }^{5}$ Ces cellules sont beaucoup plus adaptées que n'importe quel autre type de cellules pour l'étude des corps de Cajal puisqu'elles contiennent jusqu'à 100 corps de Cajal de taille variant entre 2 et $10 \mu \mathrm{m}$.
} 


\section{4-3) Les nucléoles}

Observés en microscopie optique, les nucléoles ne semblent pas avoir de dynamique particulière lors de l'interphase. Par contre, ils sont désassemblés durant la mitose pour être ensuite réassemblés dans chacune des cellules filles (Olson et al., 2000). En fait, le besoin permanent de la cellule en protéines, lors de l'interphase, nécessite une production intense de ribosomes et donc une intense activité des nucléoles. Ainsi, la taille des nucléoles augmente ou diminue en fonction de l'activité transcriptionnelle de la cellule (Olson et Dundr , 2005). Ritland-Politz et al. (2003) ont observé la diffusion des sous-unités des ribosomes, des nucléoles vers l'enveloppe nucléaire. Cette diffusion se fait dans toutes les directions à partir du nucléole et semble être sous-diffusive. Toutefois, elle semble suffisamment proche d'une diffusion gaussienne pour pouvoir l'assimiler comme telle et estimer un coefficient de diffusion de l'ordre de $0,3 \mu \mathrm{m}^{2} / \mathrm{s}$.

\section{4-4) Les corps de Kremer}

Muratani et al. (2002) ont étudié la dynamique des corps de Kremer en fusionnant la YFP (Yellow Fluorescent Protein) à la terminaison amine de la protéine Sp100, une protéine présente dans les corps de Kremer. Par microscopie time-lapse, ils ont identifié trois types de corps de Kremer en se fondant sur leurs propriétés dynamiques. Le premier type est immobile sans doute à cause d'interaction avec d'autres éléments du noyau ou à cause de sa localisation dans une zone du noyau qui restreindrait ses mouvements. Le deuxième type est caractérisé par des mouvements très localisés. Enfin, le troisième se définit par des mouvements rapides à travers tout le nucléoplasme à une vitesse moyenne de 4 à 7,02 $\mu \mathrm{m} / \mathrm{min}$ (pouvant atteindre 18 $\mu \mathrm{m} / \mathrm{min}$ ). La particularité de ces déplacements est qu'il semble provenir de mécanismes ATPdépendant puisque suite à une déplétion de l'ATP la vitesse moyenne chute à $1,7 \mu \mathrm{m} / \mathrm{min}$.

\section{5) Dynamique des macromolécules dans le nucléoplasme}

Au delà, de la dynamique des compartiments du noyau de nombreuses macromolécules en suspension bougent en permanence dans le noyau. Parmi ces macromolécules, les dynamiques des ARN Polymérases et des ARN messagers sont particulièrement bien étudiées.

\section{5-1) Dynamique des ARN polymérases}

Les études menées par FRAP sur les ARN polymérases (Belmont 2003 ; Janicki et Spector, 2003) ont montré que ces enzymes ne diffusaient pas dans le noyau sous une forme complète, mais plutôt en deux parties ne s'assemblant que sur le gène cible. Ainsi, la fluorescence de la sous-unité responsable de la fixation sur le promoteur du gène cible est retrouvée en une dizaine de seconde. La dynamique de la partie responsable de l'élongation de l'ADN lors de la transcription serait plutôt de l'ordre de la dizaine de minutes (Belmont, 2003).

\section{5-2) Dynamique des complexes protéiques mRNP (messenger RiboNucleoProtein)}

En fusionnant les mRNP (complexes contenant des ARNm et des protéines) avec de la CFP (Cyan Fluorescent Protein), Shav-Tal et al. (2004) ont caractérisé individuellement leurs mouvements par suivi de particule unique. Ainsi, les mRNP diffusent simplement dans le noyau. Le coefficient de diffusion est en moyenne de $4.10^{-2} \mu \mathrm{m}^{2} / \mathrm{s}$. Cette diffusion semble ralentie par une déplétion de l'ATP mais les auteurs attribuent plutôt cette diminution aux obstacles alors formés par une fibre chromatinienne beaucoup plus rigide.

\section{6) Conclusion}

Le noyau présente donc un nombre important de dynamiques très variées. On peut ainsi relever pas moins de quatre ordres de grandeur différents pour les coefficients de diffusion de 
différents éléments du noyau. Ainsi, les sous-unités du ribosomes diffusent anormalement dans le noyau avec un coefficient de $0,3 \mu \mathrm{m}^{2} / \mathrm{s}$. Pour le même type de diffusion les ARN messager ont un coefficient de $4.10^{-2} \mu \mathrm{m}^{2} / \mathrm{s}$. Enfin, la chromatine présente deux coefficients de diffusion : $3,1.10^{-3} \mu \mathrm{m}^{2} / \mathrm{s}$ et $5.10^{-4} \mu \mathrm{m}^{2} / \mathrm{s}$. Il y a donc un facteur 1000 entre la dynamique la plus rapide et la dynamique la plus lente. De même, on note plusieurs vitesses de déplacement : de l'ordre de $0,5 \mu \mathrm{m} / \mathrm{min}$ pour les corps de Cajal (de $0,48 \mu \mathrm{m} / \mathrm{min}$ à 0,65 $\mu \mathrm{m} / \mathrm{min}$ ) et de l'ordre $5 \mu \mathrm{m} / \mathrm{min}$ pour certains corps de Kremer (de $4 \mu \mathrm{m} / \mathrm{min}$ à $7,02 \mu \mathrm{m} / \mathrm{min}$ ). Contrairement à de la diffusion classique, les coefficients de diffusion des compartiments du noyau ne dépendent pas de leurs tailles mais de la coordination de ces compartiments pour permettre la transcription des gènes. La plupart des dynamiques sont caractérisées par une diffusion anormale ${ }^{6}$. Ce résultat n'est pas surprenant puisque les éléments du noyau bougent, dans une structure très compartimentée, pour remplir un rôle bien précis. Il semble toutefois assez difficile d'observer ces dynamiques dans leur ensemble afin de les relier globalement à un phénomène physiologique bien précis.

\section{BIBLIOGRAPHIE :}

- Abney JR, Cutler B, Fillbach ML, Axelrod D et Scalettar BA. (1997) Chromatin dynamics in interphase nuclei and its implications for nuclear structure. Journal of Cell Biology. 137 : 1459-1468.

- Alberts B, Bray D, Lewis J, Raff M, Roberts K et Watson JD. Molecular Biology of the cell. Garland Publishing, New York. 1994.

- Banks DS et Fradin C. (2005) Anomalous diffusion of proteins due to molecular crowding. Biophysical Journal. 89 : 2960-2971.

- Baserga R. (1981) The cell cycle. The New England Journal of Medicine. 304 :453-459.

- Belmont AS. (2003) Dynamics of chromatin, proteins, and bodies within the cell nucleus. Current Opinion in Cell Biology. 15 : 304-310.

- Berger SL. (2002) Histone modifications in transcriptional regulation. Current Opinion in Genetics and Development. 12 : 142-148.

- Boeger H, Griesenbeck J, Strattan JS et Kornberg RD. (2003) Nucleosomes unfold completely at a transcriptionally active promoter. Molecular Cell. $11: 1587-1598$.

- Bolzer A, Kreth G, Solovei I, Koehler D, Saracoglu K, Fauth C, Müller S, Eils R, Cremer C, Speicher MR et Cremer T. (2005) Three-dimensional maps of all chromosomes in human male fibroblast nuclei and prometaphase rosettes. PloS Biology. 3 : 1-17.

- Boyer PD. (2001) Toward an adequate scheme for the ATP-Synthase catalysis. Biochemistry (Moscow). $66: 10581066$.

- Bubulya PA et Spector DL. (2004) 'On the move'”ments of nuclear components in living cells. Experimental Cell Research. 296 : $4-11$.

- Cassimeris L. (2004) Cell division: eg'ing on microtubule flux. Current biology. 14 : R1000-1002.

- Cremer T et Cremer C. (2001) Chromosome territories, nuclear architecture and gene regulation in mammalian cells. Nature Review Genetics. 2 : 292-301.

- Cremer T, Kreth G, Koester H, Fink RHA, Heintzmann R, Cremer M, Solovei I, Zink D et Cremer C. (2000) Chromosome territories, interchromatin domain compartment, and nuclear matrix: an integrated view of the functional nuclear architecture. Critical Review in

\footnotetext{
${ }^{6}$ Ce qui est en adéquation avec le modèle de diffusion de protéines, à l'intérieur d'un polymère, établi par Banks et Fradin (2005)
} 
Eukaryotic Gene Expression. 10 : 179-212.

- Daigle N, Beaudouin J, Hartnell L, Imreh G, Hallberg E, Lippincott-Schwartz J et Ellenberg J. (2001) Nuclear pore complexes form immobile networks and have a very low turnover in live mammalian cells. Journal of Cell Biology. 154 : 71-84.

- Davis SK et Bardeen CJ. (2003) Cross-linking of histone proteins to DNA by UV illumination of chromatin stained with Hoechst 33342. Photochemistry and Photobiology. 77 : 675-679.

- Davis SK et Bardeen CJ. (2004) The connection between chromatin motion on the $100 \mathrm{~nm}$ length scale and core histone dynamics in live XTC-2 cells and isolated nuclei. Biophysical Journal. 86 : 555-564.

- Davis SK et Bardeen CJ. (2005) Time-resolved Microscopy of Chromatin In Vitro and In Vivo. Photochemistry and Photobiology. 81 : 548-555.

- Davey CA, Sargent DF, Luger K, Maeder AW et Richmond TJ. (2002) Solvent mediated interactions in the structure of the nucleosome core particle at 1.9 Angström resolution. Journal of Molecular Biology. 319 : 1097-1113.

- de la Barre AE, Angelov D, Molla A et Dimitrov S. (2001) The N-terminus of histone $\mathrm{H} 2 \mathrm{~B}$, but not that of histone $\mathrm{H} 3$ or its phosphorylation, is essential for chromosome condensation. EMBO Journal. 20 : 6383-6393.

- $\quad$ Dingwall C et Laskey R. (1992) The nuclear membrane. Science. 258 :942-947.

- Dundr M et Misteli T. (2001) Functional architecture in the cell nucleus. Biochemical Journal. 356 : 297-310.

- Eberl DF, Duyf BJ et Hilliker AJ. (1993) The role of heterochromatin in the expression of a heterochromatic gene, the rolled locus of Drosophila melanogaster. Genetics. 134: 277292.

- Ehrengruber MU, Deranleau DA, Coates TD. (1996) Shape oscillations of human neutrophil leukocytes: characterization and relationship to cell motility. Journal of Experimental Biology. 199(Pt 4) :741-747.

- Ehrenhofer-Murray AE. (2004) Chromatin dynamics at DNA replication, transcription and repair. European Journal of Biochemistry. 271 : 2335-2349.

- Gall JG. (2000) Cajal Bodies: the first 100 years. Annual Review of Cell and Developmental Biology. 2000. $16: 273-300$.

- Gall JG, Bellini M, Wu Z et Murphy C. (1999) Assembly of the nuclear transcription and processing machinery: Cajal Bodies (Coiled Bodies) and transcriptosomes. Molecular Biology of the Cell. 10 : 4385-4402.

- Gasser SM. (2002) Visualizing chromatin dynamics in interphase nuclei. Science. 296 : 1412-1416.

- Gerlich D, Beaudouin J, Kalbfuss B, Daigle N, Eils R et Ellenberg J. (2003) Global chromosome positions are transmitted through mitosis in mammalian cells. Cell. 112 : 75164.

- Halle JP et Meisterernst M. (1996) Gene expression: increasing evidence for a transcriptosome. Trends in Genetics. 12 : 161-163.

- Handwerger KE, Murphy C et Gall JG. (2003) Steady-state dynamics of Cajal body components in the Xenopus germinal vesicle. Journal of Cell Biology. 160 : 495-504.

- Hayes H. (2000) ADN et Chromosomes. Production Animales. HS, Génétique moléculaire : principes et application aux populations animales : 13-20.

- Hess O et Meyer GF. (1963) Chromosomal differentiations of the lampbrush type formed by the Y chromosome in Drosophila Hydei and Drosophila Neohydei. Journal of Cell Biology. 16 : $527-539$.

- Hetzer MW, Walther TC et Mattaj IW. (2005) Pushing the envelope: Structure, function, and dynamics of the nuclear periphery. Annual Review of Cell and Developmental Biology. 
$21: 347-380$.

- Jacob F et Monod J. (1961) Genetic regulatory mechanisms in the synthesis of proteins. Journal of Molecular Biology. 3 : 318-356.

- Janicki SM et Spector DL. (2003) Nuclear choreography: interpretations from living cells. Current Opinion in Cell Biology. 15 : 149-157.

- Kimura H. (2005) Histone dynamics in living cells revealed by photobleaching. DNA Repair. 4 : 939-950.

- Kornberg RD et Lorch Y. (1999) Twenty-five years of the nucleosome, fundamental particle of the eukaryote chromosome. Cell. 98 : 285-294.

- Levi V, Ruan Q, Plutz M, Belmont AS et Gratton E. (2005) Chromatin dynamics in interphase cells revealed by tracking in a two-photon excitation microscope. Biophysical Journal. 89 : 4275-4285.

- Linder S et Aepfelbacher M. (2003) Podosomes : adhesion hot-spots of invasive cells. TRENDS in Cell Biology. 13 : 376-385.

- Luger K. (2003) Structure and dynamic behavior of nucleosomes. Current Opinion in Genetics and Development. $13: 127-135$.

- Luger K et Hansen JC. (2005) Nucleosome and chromatin fiber dynamics. Current Opinion in Structural Biology. 15 : 188-196.

- Mahy NL, Perry PE, Gilchrist S, Baldock RA et Bickmore WA. (2002) Spatial organization of active and inactive genes and noncoding DNA within chromosome territories. Journal of Cell Biology. 157 : 579-589.

- Manuelidis L. (1985) Individual interphase chromosome domains revealed by in situ hybridization. Human Genetics.71 : 288-293.

- Metivier R, Penot G, Hubner MR, Reid G, Brand H, Kos M et Gannon F. (2003) Estrogen receptor-alpha directs ordered, cyclical, and combinatorial recruitment of cofactors on a natural target promoter. Cell. $115:$ 751-763.

- Misteli T. (2001) Protein dynamics: implications for nuclear architecture and gene expression. Science. 291 : 843-847.

- Misteli T, Caceres JF et Spector DL. (1997) The dynamics of a pre-mRNA splicing factor in living cells. Nature. 387 : 523-527.

- Mizuguchi G, Shen X, Landry J, Wu WH, Sen S et Wu C. (2004) ATP-driven exchange of histone H2AZ variant catalyzed by SWR1 chromatin remodeling complex. Science. $\mathbf{3 0 3}$ : 343-348.

- Muratani M, Gerlich D, Janicki SM, Gebhard M, Eils R, Spector DL. (2002) Metabolicenergy-dependent movement of PML bodies within the mammalian cell nucleus. Nature Cell Biology. 4 :106-110.

- Olson MOJ, Dundr M et Szebeni A. (2000) The nucleolus: an old factory with unexpected capabilities. Trends in Cell Biology. 10 : 189-196.

- Olson MOJ et Dundr M. (2005) The moving parts of the nucleolus. Histochemistry and Cell Biology. 123 : 203-216.

- Platani M, Goldberg I, Swedlow JR et Lamond AI. (2000) In vivo analysis of cajal body movement, separation, and joining in live human cells. Journal of Cell Biology. 151 : 1561-1574.

- Ritland-Politz JC, Tuft RA et Pederson T. (2003) Diffusion-based transport of nascent ribosomes in the nucleus. Molecular Biology of the Cell. 14 : 4805-4812.

- Robinett CC, Straight A, Li G, Willhelm C, Sudlow G, Murray A et Belmont AS. (1996) In vivo localization of DNA sequences and visualization of large-scale chromatin organization using Lac Operator/Repressor recognition. Journal of Cell Biology. 135 : 1685-1700.

- Shav-Tal Y, Darzacq X, Shenoy SM, Fusco D, Janicki SM, Spector DL et Singer SH. 
(2004) Dynamics of single mRNPs in nuclei of living cells. Science. 304 : 1797-1800.

- Scheer U et Hock R. (1999) Structure and function of the nucleolus. Current Opinion in Cell Biology. 11 : 365-390.

- Shi Y, Lan F, Matson C, Mulligan P, Whetstine JR, Cole PA, Casero RA et Shi Y. (2004) Histone demethylation mediated by the nuclear amine oxidase homolog LSD1. Cell. 119 :941-953.

- Shopland LS, Byron M, Stein JL, Lian JB, Stein GS et Lawrence JB. (2001) Replicationdependent histone gene expression is related to Cajal Body (CB) association but does not require sustained CB contact. Molecular Biology of the Cell. 12 : 565-576.

- Sivolob A et Prunell A. (2004) Nucleosome conformational flexibility and implications for chromatin dynamics. Philosophical Transactions of the Royal Society of London A. 362 : 1519-1547.

- Sun ZW et Allis CD. (2002) Ubiquitination of histone H2B regulates H3 methylation and gene silencing in yeast. Nature. $418: 104-108$.

- Tumbar T et Belmont AS. (2001) Interphase movements of a DNA chromosome region modulated by VP16 transcriptional activator. Nature Cell Biology. 3 : 134-139.

- Turner BM. (2000) Histone acetylation and an epigenetic code. BioEssays. 22 : 836-845.

- Watson JD et Crick FH. (1974) Molecular structure of nucleic acids: a structure for deoxyribose nucleic acid. Nature. $248: 765$.

- Wienzek S et Dobbelstein M. (2001) Viral and cellular factors that target the promyelocytic leukemia oncogenic domains strongly activate a glucocorticoid-responsive promoter. Journal of Virology. 75 : 5391-5397.

- Williams RRE. (2003) Transcription and the territory: the ins and outs of gene positioning. Trends in Genetics. 6 : 298-302.

- Yasuhara JC, DeCrease CH et Wakimoto BT. (2005) Evolution of heterochromatic genes of Drosophila. PNAS. 102 : 10958-10963.

- Yildiz A et Selvin PR. (2005) Kinesin: walking, crawling or sliding along? Trends in Cell Biology. 15 : 112-120. 


\title{
Chapitre 3 : MONTAGE EXPERIMENTAL ET PROTOCOLES
}

\author{
I> Introduction à la diffusion dynamique de la lumière par le noyau d'une \\ cellule vivante
}

\section{1) Méthodes actuelles pour l'analyse de la dynamique du noyau}

Nous avons pu voir que l'étude des compartiments du noyau de la cellule, aussi bien d'un point de vue fonctionnel que dynamique, était un enjeu majeur de la recherche en biologie. Le développement des techniques de microscopie a permis de recueillir un nombre important d'informations sur les mouvements des éléments du noyau, y compris à des échelles plus petites que le micromètre. L'évolution des connaissances dans ce domaine est conditionnée par le besoin constant d'outils d'analyse dont la résolution, spatiale et/ou temporelle, se doit d'être toujours plus fine. Ces outils doivent tous obéir à une contrainte fondamentale : être suffisamment non-invasifs pour ne pas modifier la structure ou le comportement de la cellule.

On peut penser que la diffusion dynamique de la lumière est une technique, noninvasive et non-destructrice, pouvant donner des informations sur la dynamique globale du noyau d'une cellule vivante. C'est la technique expérimentale que nous avons décidé de développer pour étudier la dynamique interne du noyau d'une cellule vivante au cours d'un processus biologique particulier : le cycle cellulaire. Cependant ce n'est pas la seule technique pouvant donner des informations sur les propriétés dynamiques du noyau. On peut penser à quatre méthodes de microscopie différentes : la spectroscopie à corrélation de fluorescence (Lamb et al., 2005 ; Vukojevic et al., 2005), la microscopie de fluorescence en temps réel, la microscopie par contraste interférentiel (Sonostseva et al., 2005) et enfin la microscopie à contraste de phase. Avant de décrire les avantages de la diffusion de la lumière, nous allons présenter succinctement ces autres techniques.

\section{1-1) Spectroscopie à corrélation de fluorescence}

La spectroscopie à corrélation de fluorescence (FCS) consiste à exciter grâce à un faisceau laser, bleu en général, la fluorescence de particules marquées se déplaçant dans un volume d'excitation de l'ordre de $1 \mu \mathrm{m}^{3}$, puis à collecter la fluorescence émise grâce à un compteur de photons. En se déplaçant dans le volume d'excitation, les particules provoquent des fluctuations de l'intensité lumineuse qui sont ensuite analysées grâce à un corrélateur. Cette méthode permet d'atteindre des résolutions temporelles de l'ordre de la microseconde (Lamb et al., 2005 ; Vukojevic et al., 2005). La FCS a, toutefois, plusieurs limites. Tout d'abord, cette technique ne peut pas donner une information globale sur la dynamique interne du noyau puisqu'elle ne peut suivre que des particules marquées. Une autre limite de la FCS est l'utilisation éventuelle de sonde fluorescente qui sont peut-être invasives dans les cas où l'on ne peut pas utiliser de GFP. Ensuite, il ne faut pas que deux particules traversent le volume d'excitation en même temps au risque de fausser l'analyse des fluctuations par le corrélateur. Cela implique que les particules suivies doivent être en régime dilué à l'échelle du volume d'excitation. Les concentrations dans le noyau de la plupart des éléments du noyau étant en général élevées, cette méthode ne peut s'appliquer dans le noyau que sur des volumes d'excitation très petits et donne donc des informations sur des dynamiques très locales des particules. Enfin, pour que le volume d'excitation soit petit, il faut que le laser soit très focalisé. Ceci pose un problème car si l'on focalise fortement le laser, on induira des dommages au noyau dans le volume d'excitation. En effet, les faisceaux lasers bleus 
provoquent des dommages au noyau, même à très faible puissance (de With et Greulich, 1995).

\section{1-2) Microscopie de fluorescence en temps réel}

La microscopie de fluorescence en temps réel consiste à suivre grâce à une caméra des protéines ou des régions d'intérêt fusionnées à des protéines fluorescentes. Pointons une première limite à cette technique : de même que pour la FCS, cette technique ne permet de suivre qu'un nombre limité d'objets marqués ${ }^{1}$. Cette technique ne permet pas d'obtenir des informations sur la dynamique globale du noyau. Comme pour la FCS, une autre limite de la microscopie de fluorescence est l'utilisation éventuelle de sondes fluorescentes qui peuvent être invasives dans les cas où l'on ne peut pas utiliser de GFP. Un autre problème vient de la limite en résolution temporelle induite par le mode d'acquisition. Les techniques de microscopie de fluorescence (FRAP, vidéomicroscopie time-lapse,...) utilisent des caméras rapides pour acquérir avec la meilleure résolution temporelle possible des séries d'images de l'échantillon. Les mouvements des protéines d'intérêt dans l'échantillon sont ensuite analysés grâce au « film » obtenu. Toutefois, la faible luminosité des protéines fluorescentes nécessite un certain temps d'exposition qui limite grandement la vitesse d'acquisition. Ainsi, les temps d'acquisition sont rarement inférieurs à la centaine de millisecondes. Si l'on veut améliorer ces temps d'acquisition, il faut augmenter la puissance du faisceau laser qui excite la fluorescence. Or en général, les faisceaux laser utilisés sont bleus ou verts et provoquent donc déjà des dommages au noyau, même à très faible puissance (de With et Greulich, 1995). Augmenter la puissance du faisceau induira encore plus de dommages.

\section{1-3) Microscopie par contraste interférentiel}

La microscopie par contraste interférentiel, consiste à mesurer grâce à un capteur CCD, le décalage de phase entre un faisceau laser balayant la cellule et un faisceau laser de référence. La résolution spatiale est de l'ordre du micromètre et la résolution temporelle de l'ordre de la dizaine de millisecondes. Sonostseva et al. (2005) étudient ainsi la dynamique intra-cellulaire d'un neurone de L. stagnalis. En analysant le décalage de phase, entre le laser balayant la cellule et le laser de référence, par une transformée en double-ondelettes, ils obtiennent deux gammes de fréquences caractéristiques. La plus lente des deux se situe entre 0,1 et $5 \mathrm{~Hz}$ et semble provenir des processus dynamiques se déroulant dans la membrane plasmique (réorganisation de la membrane, changement du potentiel de la membrane, oscillations de la membrane,...). La gamme de temps plus rapide, de 10 à $20 \mathrm{~Hz}$, semble, quant à elle, provenir de la superposition de plusieurs processus se déroulant dans la membrane et le cytoplasme (mouvements de complexes protéiques à l'intérieur du cytoplasme, brusques oscillations de la membrane plasmique...). Ils montrent également que les dynamiques à 0,1 et $0,3 \mathrm{~Hz}$ sont responsables de modulation de fréquence des autres processus, mettant ainsi en évidence la coordination de ces processus.

La microscopie par contraste interférentiel a donc l'avantage de permettre d'étudier la dynamique intra-cellulaire de façon plus globale que les précédentes méthodes présentées avec une excellente résolution temporelle. Toutefois, nous pointerons le fait que la puissance du faisceau laser utilisée doit être importante pour permettre au capteur CCD de capter correctement le faisceau décalé en phase. Cela pourrait donc provoquer des dommages potentiels au noyau, surtout si l'on veut réduire le volume analysé.

\footnotetext{
${ }^{1}$ La fusion de protéines à la GFP n'est pas considérée comme étant invasive. Toutefois, on pourrait remettre cela en cause si plus de quelques protéines différentes sont fusionnées.
} 


\section{1-4) Microscopie à contraste de phase}

Nous n'avons pas trouvé dans la littérature d'exemple d'utilisation de la microscopie à contraste de phase pour l'étude de la dynamique du noyau. On peut, toutefois, supposé qu'il est possible de développer une telle méthode. Elle serait fondée sur le même principe que la microscopie par contraste interférentiel : l'analyse des mouvements à l'intérieur du noyau en fonction des décalages de phase de la lumière captée par une caméra. Cette méthode serait non-invasive et non-destructive mais la faible luminosité imposerait un temps d'exposition important et limiterait fortement la gamme de temps accessible.

\section{1-5) Conclusion}

La quasi-totalité des connaissances actuelles sur la dynamique du noyau a été obtenue grâce aux techniques de microscopie de fluorescence. Toutefois, ces techniques ne permettent pas de suivre la dynamique du noyau dans son ensemble et propose une résolution temporelle assez limitée. Or, précisons une nouvelle fois que tous les éléments du noyau font partie d'un ensemble et que le rôle de leurs mouvements est de faire fonctionner cet ensemble. Nous avons d'ailleurs déjà montré que la dynamique des éléments du noyau s'étendait sur plusieurs ordres de grandeur tout en étant parfaitement coordonnée. La méthode développée par Sosnovtseva et al. (2005) permet d'observer une dynamique plus globale de la cellule mais est potentiellement dangereuse pour la cellule. La diffusion dynamique de la lumière (si on choisit correctement la longueur d'onde et la puissance d'irradiation) est une technique noninvasive et non-destructrice pour la cellule qui permet d'obtenir la dynamique interne du noyau dans sa globalité. Cependant, la diffusion dynamique de la lumière présente une limite importante : puisque les mesures sont globales et que l'on travaille dans l'espace de Fourier, il sera délicat d'établir quels sont les phénomènes physiologiques à l'origine des dynamiques observées. Nous pensons donc que la diffusion dynamique de la lumière est une technique complémentaire des techniques que nous venons de présenter car elle permet un suivi plus général de la dynamique du noyau sur des échelles de temps assez fines tout en étant noninvasive et non-destructive pour la cellule.

Dans la suite, nous allons présenter le principe de la diffusion de la lumière.

\section{2) Diffusion dynamique de la lumière : principe}

Brièvement, la technique de diffusion dynamique de la lumière (voir Annexe $\mathrm{A}$ ) consiste à envoyer un faisceau lumineux à travers un échantillon et à analyser les fluctuations de l'intensité de la lumière diffusée. La lumière diffusée a pour origine les modulations spatiotemporelles locales de l'indice de réfraction de l'échantillon (Bern et Pecora ; 1976). Dans le cas du noyau d'une cellule vivante, ces modulations peuvent avoir pour origine des variations locales de concentration des objets composant le noyau (mouvements de la chromatine, mouvements des macromolécules,...) ou des changements dans l'organisation spatiale de la chromatine ou des corps nucléaires. L'analyse des variations temporelles de l'intensité diffusée permet donc de remonter à la dynamique des processus à l'origine de ces fluctuations. Les avantages de cette méthode pour l'étude de la dynamique du noyau sont nombreux. Tout d'abord elle est non-invasive et non-destructive pour la cellule (si le faisceau lumineux est, toutefois, convenablement choisi). Ensuite, elle permet de mesurer la dynamique de processus sur une échelle de temps allant de la microseconde à la dizaine de seconde. Enfin, elle permet de sonder ces dynamiques sur différentes échelles spatiales, allant de la centaine de nanomètres à quelques micromètres, simplement en modifiant l'angle auquel la lumière est recueillie par rapport au faisceau incident. Il nous reste, maintenant, à définir ce que l'on espère obtenir par diffusion de la lumière dans le noyau d'une cellule vivante. 
La diffusion de la lumière est déjà utilisée en biologie, mais aucune expérience de ce type n'a été menée, à ce jour, sur la dynamique interne du noyau d'une cellule vivante. La plupart des expériences ont porté sur l'étude de propriétés morphologiques de la cellule, ou encore sur la structure de la chromatine (Bloomfield, 1985 ; Lowary et Widom, 1989)

La diffusion de la lumière a aussi été utilisée dans le but d'établir un diagnostique dans le cadre du dépistage du cancer. Mourant et al. (1998) ont ainsi mis en évidence des différences significatives entre les propriétés de la lumière diffusée par des fibroblastes de rat et par des fibroblastes tumorigéniques dérivés de la même lignée. Ces différences semblent dues à la taille plus importante de certaines particules de la lignée cancéreuse. Une autre expérience menée sur cette même lignée cancéreuse (Mourant et al., 2000) a consisté à comparer la contribution du noyau et de la cellule dans son ensemble à la diffusion de la lumière d'un faisceau lumineux incident. Il apparaît que la diffusion de la lumière est très sensible aux changements dans le noyau. 30 à $40 \%$ de la lumière diffusée par toute la cellule semblent ainsi provenir du noyau. Les mitochondries semblent également responsables d'une bonne partie de la lumière diffusée. Backman et al. (2000) ont également établi un méthode fondée sur la diffusion de la lumière pour repérer des cellules cancéreuses sur l'épithélium d'organes humains. Cette méthode consiste à éclairer les cellules épithéliales de l'organe avec une fibre optique délivrant la lumière provenant d'un brûleur au xénon puis à analyser le spectre de la lumière réfléchie. Ils sont ainsi en mesure d'établir la taille du noyau des cellules éclairées. La taille du noyau d'une cellule épithéliale cancéreuse étant 2 à 4 fois plus important que celle du noyau d'une cellule épithéliale normale, il est possible de repérer la présence de cellules cancéreuses. Enfin, la diffusion de la lumière a également été utilisée pour mesurer les variations de volumes de cellules adhérentes suite à un choc osmotique (Srinivas et al., 2003).

\section{3) Diffusion de la lumière par le noyau d'une cellule vivante.}

A l'intérieur du noyau, on peut dénombrer un nombre important d'évènements à même de modifier localement l'indice de réfraction.

Les fluctuations locales de l'indice de réfraction du noyau peuvent provenir des nombreux mouvements qui se produisent dans le noyau et qui, localement, vont modifier la composition, les concentrations respectives et l'organisation du noyau. Ils concernent la chromatine, les différents corps de l'espace interchromosomique et les macromolécules en suspension (voir chapitre 2).

Les mouvements à l'intérieur du noyau sont principalement induits par la transcription et la réplication (voir chapitre 2). Ces mouvements se déroulent à tous les niveaux dans le noyau. Les territoires chromosomiques bougent les uns par rapport aux autres et, plus localement, la chromatine change régulièrement de densité en se compactant et/ou se décompactant pour permettre les activités de transcription et/ou de réplication. Les compartiments de l'espace interchromosomiques changent également de densité en fonction des besoins de la cellule (voir chapitre 2) et certains d'entres eux peuvent se déplacer sur de grandes distances à l'échelle du noyau. Enfin, un nombre très important de macromolécules diffusent dans tout le noyau, comme les ARN messagers ou les ARN ribosomiques qui doivent atteindre le cytoplasme.

Les fluctuations locales de l'indice de réfraction du noyau peuvent également être engendrées par les nombreuses réactions chimiques qui se produisent à chaque instant à l'intérieur du noyau. Parmi ces réactions chimiques, on pourra citer l'hydrolyse des molécules d'ATP, la synthèse de brins d'ADN lors de la réplication, la synthèse des ARN... Ces réactions chimiques vont tout d'abord provoquer des fluctuations de concentration de leurs réactifs. De 
plus, les molécules issues de ces réactions n'ont pas, a priori, les mêmes caractéristiques optiques que les molécules d'origine.

La diffusion de la lumière nous offre la possibilité de sonder les variations de l'indice de réfraction sur différentes échelles de temps. Comme les processus à l'origine de ces variations sont caractéristiques de l'état de la cellule, nous espérons observer des différences notables dans les propriétés dynamiques du noyau entre les différentes phases du cycle cellulaire. En conclusion, nous espérons que la diffusion dynamique de la lumière nous permettra d'appréhender, de façon plus globale que les méthodes actuelles, la dynamique interne du noyau d'une cellule vivante à un instant donné.

Ici, il est important de mentionner que le noyau d'une cellule vivante est un système actif, dans lequel de l'énergie est produite et consommée, en permanence. C'est donc un système hors équilibre ce, qui va avoir plusieurs conséquences sur l'intensité lumineuse diffusée et donc sur les mesures que nous allons réaliser (voir chapitre 4).

Avant de décrire le montage expérimental, nous allons présenter le type cellulaire que nous avons utilisé pour toutes nos expériences.

\section{II> Cellules neuroblastomes de la lignée SHEP}

Les cellules que nous utilisons pour nos études sont des neuroblastomes de la lignée SHEP. Les neuroblastomes sont des cellules cancéreuses du système nerveux sympathique. Comme toutes les cellules cancéreuses, si les conditions physiologiques le leur permettent, elles ne s'arrêtent pas en phase G0 après la mitose, mais poursuivent le cycle cellulaire. Pour cette lignée de cellules, celui-ci est relativement rapide. Il dure environ 15 heures : la phase G1 dure environ 10 heures, la phase $S$ environ 2 heures et les phases G2/M environ 3 heures.

Nous avons remarqué, au cours de nos expériences, une autre caractéristique remarquable des SHEP : elles n'ont pas d'inhibition de contact. Autrement dit, si le milieu de culture est encore suffisamment bon, elles poussent les unes sur les autres si elles n'ont pas de place sur le substrat.

Il existe plusieurs lignées de neuroblastomes. La lignée SHEP se caractérise par sa sensibilité à des facteurs apoptotiques comme le ligand FAS (Goillot et al., 1997). Le choix de ce type de cellule se justifie pour nos expériences par diverses raisons. Tout d'abord les biologistes avec lesquelles nous avons collaboré ont une grande habitude de la culture de ce type cellulaire et disposaient de stock important. Ensuite, leurs robustesses et leurs grandes capacités prolifératives rendent leur utilisation plus aisée. Enfin, elles nous permettront d'étudier la dynamique du noyau lors de la phase préapoptotique.

\section{III> Principe du montage et contraintes expérimentales}

Pour étudier la dynamique du noyau d'une cellule SHEP vivante par diffusion dynamique de la lumière, il est nécessaire de réaliser un montage expérimental qui tienne compte de contraintes intrinsèques. Ces contraintes sont de deux ordres : physiques et physiologiques. Du point de vue de la physique, le montage doit permettre d'éclairer avec un faisceau laser le noyau d'une seule cellule, pendant un temps suffisamment long pour permettre un bon échantillonnage. Cela implique que la cellule doit rester quasi-immobile tout le long de l'expérience, que le faisceau laser soit suffisamment petit pour n'éclairer qu'un seul noyau et enfin que l'on puisse voir le faisceau laser et les cellules afin de pouvoir aligner le faisceau et le noyau d'une cellule. Ensuite, toujours du point de vue de la physique, il faut un système qui permette de récolter et d'analyser la lumière diffusée par le noyau dans une direction donnée. Du point de vue physiologique, les mesures effectuées n'auront d'intérêt que si les cellules sur lesquelles elles sont réalisées sont maintenues dans un environnement physiologique qui leur permet de se développer de façon normale. Il faut donc un système qui contrôle les 
paramètres physiologiques comme le milieu de culture, la température de ce milieu, son $\mathrm{pH}, \ldots$ Il sera également nécessaire de s'assurer que la longueur d'onde et le faisceau laser utilisé ne détériorent pas les cellules.

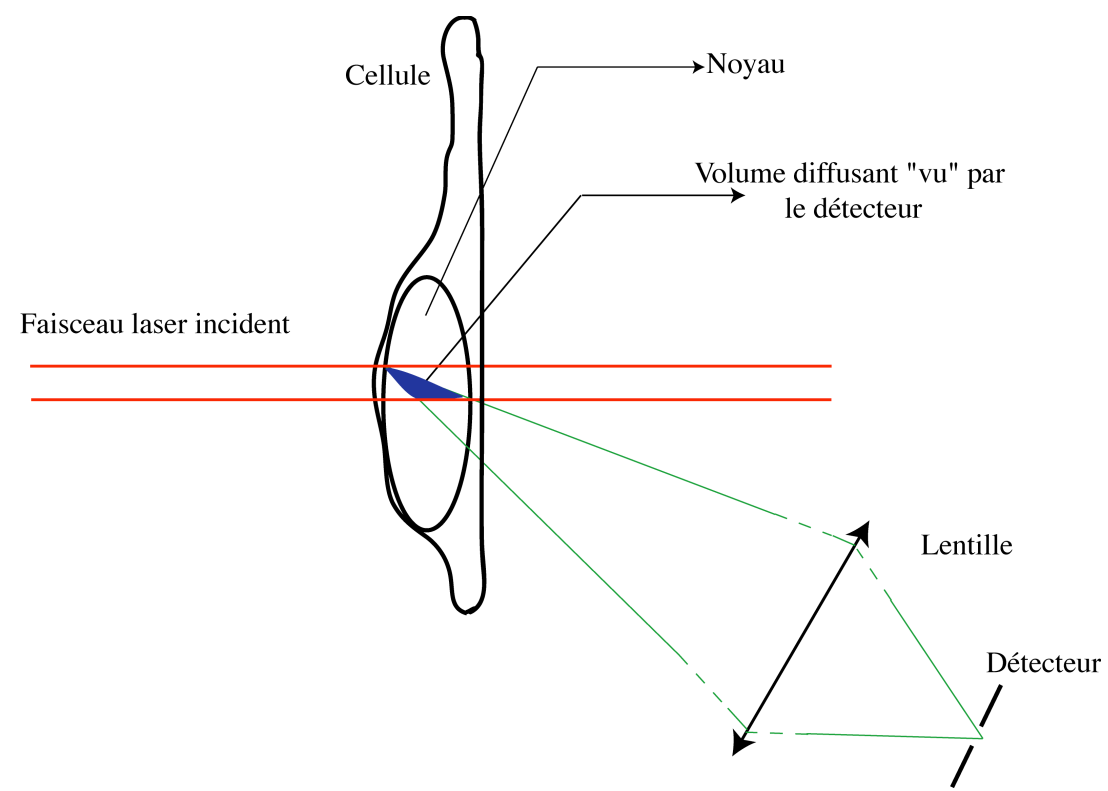

Figure 3-1: Principe de base de l'expérience. Elle consiste à "éclairer » le noyau d'une cellule avec un faisceau laser. La lumière diffusée est envoyée sur la surface photosensible d'un détecteur.

Le dispositif expérimental que nous avons développé pour réaliser nos expériences et que nous allons décrire en détail au paragraphe suivant est assez similaire aux dispositifs de diffusion de la lumière montés sur microscope tel que celui développé, par exemple, par Kaplan et al. (1999). Mais, contrairement aux dispositifs «classiques », nous avons préféré rebâtir un microscope sur une table optique plutôt que d'utiliser un microscope commercial. Ceci pour des raisons d'encombrement car il nous semblait intéressant d'avoir de la place accessible autour du montage expérimental, mais, aussi, pour pouvoir recueillir l'intensité diffusée vers l'avant à plusieurs angles. Donc, grâce à cette configuration expérimentale, nous allons pouvoir avoir accès à une gamme assez large de vecteurs d'onde de diffusion $\mathbf{q}^{2}$, ce que ne permet pas un montage installé sur un microscope. C'est un très gros avantage pour le type d'étude que nous souhaitons mener, car ainsi nous allons pouvoir regarder la dépendance en vecteur d'onde des processus que nous mesurons. Par contre, dans notre montage, les cellules sont placées verticalement et non plus horizontalement comme sur un microscope classique. Ceci aurait pu poser des problèmes, mais, nous avons vérifié que cette configuration n'avait strictement aucune incidence sur le comportement des cellules et qu'elles restaient accrochées sur la surface près de l'endroit où elles avaient adhéré. Il faut aussi noter que, dans notre montage, le faisceau laser traverse d'abord une épaisseur de milieu de culture avant de traverser le noyau d'une des cellules adhérées sur la surface.

${ }^{2}|\mathbf{q}|=(4 \pi n / \lambda) \sin (\theta / 2)$, où $n$ est l'indice du milieu diffusant, $\lambda$ la longueur d'onde du rayonnement et $\theta$ l'angle de diffusion, c'est-à-dire l'angle entre le faisceau laser incident et la direction de l'intensité diffusée. Pour $n$, on prend celui du verre ; $n=1,5, \lambda=632.8 \mathrm{~nm}$. 


\section{$\underline{\text { IV > Eclairer le noyau d'une cellule vivante avec un faisceau laser }}$}

\section{1) Immobilisation des cellules}

Le noyau de la cellule doit rester dans le faisceau laser qui l'éclaire pendant toute la mesure. La cellule doit donc être quasiment immobile pendant quelques minutes. Le moyen le plus simple de maintenir la cellule en place consiste à la faire adhérer sur une surface. En effet, les cellules adhérentes se déplacent à une vitesse qui se mesure en $\mu \mathrm{m}$ par heure. Ainsi, le déplacement de la cellule sur quelques minutes est inférieur au micromètre. Le support doit permettre une bonne adhésion des cellules, mais doit aussi nécessairement être transparent pour ne pas gêner la diffusion de la lumière. Les deux surfaces les plus couramment utilisées en culture cellulaire sont le verre et le plastique. Si le plastique est la surface sur laquelle les cellules adhèrent le mieux, le verre est plus transparent et sa structure, plus homogène, le rend plus adapté à un montage optique. Choisir ce dernier support permet de limiter l'intensité d'une éventuelle diffusion de la lumière parasite venant du support.

Les expériences seront donc menées sur des cellules adhérentes sur du verre afin que le noyau reste dans le faisceau laser pendant quelques minutes. Il est maintenant indispensable de s'assurer que le faisceau laser soit suffisamment petit pour être contenu dans le noyau d'une seule cellule.

\section{2) Taille du faisceau laser}

\section{2-1) Taille du faisceau, taille d'un noyau}

Puisque notre objectif est d'étudier la dynamique du noyau d'une seule cellule, le faisceau laser doit éclairer un seul noyau. Sa taille doit donc être inférieure à celle du noyau qui a un diamètre de l'ordre de 6-7 $\mu \mathrm{m}$ pour un neuroblastome. Le faisceau laser que nous utilisons est un $\mathrm{He}-\mathrm{Ne}$ (Coherent ; 632,8 $\mathrm{nm}$ de longueur d'onde). Le diamètre de ce faisceau mesure 0,65 mm (donnée constructeur), soit 100 fois plus que le diamètre d'un noyau. Il est donc nécessaire de réduire la taille du faisceau.

\section{2-2) Focalisation du faisceau laser}

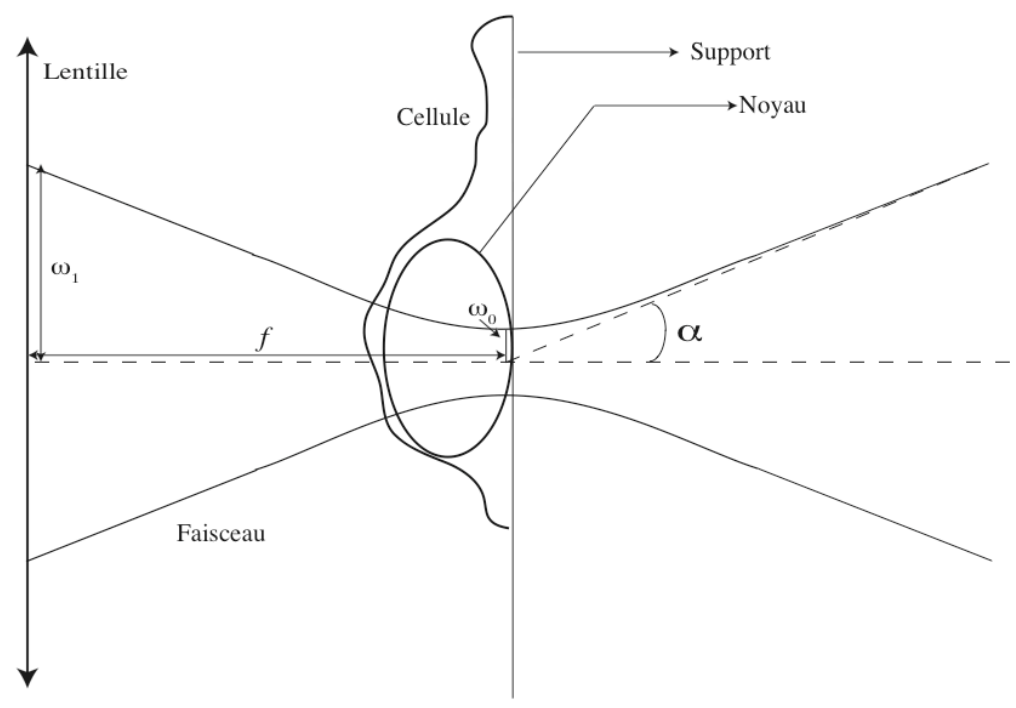

Figure 3-2 : Représentation schématique de la focalisation d'un faisceau laser dans le noyau d'une cellule. $\omega_{1}$ est le rayon du faisceau à l'entrée de la lentille, fla distance focale de la lentille, $\omega_{0}$ le rayon $d u$ waist et $\alpha$ l'angle de divergence du faisceau 
Pour réduire la taille du faisceau laser, il suffit de le focaliser grâce à une lentille. Pour notre montage, nous avons décidé d'utiliser à la place d'une lentille un objectif de microscope qui nous permettra en plus de pouvoir observer les cellules. Nous ferons, pour la suite, l'approximation consistant à assimiler cet objectif à une simple lentille. Le faisceau que nous utilisons est gaussien, il n'est pas focalisé en un point, mais a une section de taille minimale appelée beam waist (Figure 3-2) et le rayon, $\omega_{0}$, du waist dépend de la focale, $f$, de l'objectif, de la longueur d'onde, $\lambda$, du faisceau et de son rayon, $\omega_{1}$, à l'entrée de l'objectif. Il a pour expression :

$$
\omega_{0}=\frac{f \lambda}{\pi \omega_{1} n}(3-1)
$$

avec $n$ l'indice de réfraction du milieu où le faisceau est focalisé. Il est ainsi possible de régler la taille du waist en jouant sur les paramètres $f$ et $\omega_{1}{ }^{3}$. Pour l'objectif que nous utilisons, $f=5 \mathrm{~mm}$. Si nous ne modifions pas la taille du faisceau laser $(0,65 \mathrm{~mm})$, l'application numérique de l'équation (3-1) donne $\omega_{0} \approx 3 \mu \mathrm{m}$ soit un diamètre de $6 \mu \mathrm{m}$ pour le beam waist ce qui est à peu près équivalent à la taille du noyau. Cela correspond à ce que nous observons expérimentalement. Nous avons, toutefois, décidé de focaliser davantage le faisceau, afin de s'assurer qu'il reste toujours inclus dans le noyau pendant les mesures. Pour cela, nous élargissons $\omega_{1}$ d'un facteur 3 et on obtient ainsi, $\omega_{0} \approx 0,95 \mu \mathrm{m}$, soit un diamètre de $1,9 \mu \mathrm{m}$ pour le waist. Encore une fois, cela correspond à ce que nous pouvons voir à l'écran (Figure 3-4). Ce sont les grandeurs que nous avons conservées pour toutes nos expériences.

Remarque: Le faisceau laser a une puissance de $10 \mathrm{~mW}$. Cette intensité incidente conduit à des intensités diffusées trop importantes qui provoquent un disfonctionnement du système de détection. Cela peut être contrôlé en diminuant la puissance du faisceau laser. Pour cela, nous avons placé sur le chemin du faisceau un système composé d'une lame $\lambda / 2$ et d'un cube séparateur de faisceau (voir Figure 3-3). Ce système fonctionne de la manière suivante. Supposons que la polarisation du faisceau laser à la sortie du tube soit verticale. Soit $\psi$ l'angle entre l'axe principal de la lame $\lambda / 2$ et la verticale. A la sortie de la lame, la polarisation du laser aura un angle de $2 \psi$ avec cette dernière. Le cube séparateur de faisceau transmet la composante horizontale de la polarisation et réfléchit perpendiculairement la composante verticale. En conséquence le faisceau incident est polarisé horizontalement, c'està-dire dans le plan de diffusion. Si $I_{0}$ est l'intensité du faisceau, la composante transmise aura pour intensité $I=I_{0} \sin ^{2}(2 \psi)$. En pratique, selon la rotation de la lame $\lambda / 2$, ce dispositif peut ne transmettre que $2 \%$ de l'intensité du faisceau.

Un système de visualisation est, à présent, indispensable pour placer précisément le waist à l'endroit où se trouve le noyau de la cellule .

\section{3) Système de visualisation}

Pour pouvoir réaliser nos expériences, il faut illuminer le noyau d'une cellule, c'est-à-dire qu'il faut amener le noyau d'une des cellules adhérées sur la surface de verre au point de focalisation du faisceau laser. Pour ceci, nous avons monté un système composé d'un microscope optique en transmission à fond clair, qui permet de visualiser, à la fois, les cellules adhérées sur la surface de verre et la position du waist, et d'une platine de translation trois axes qui permet de déplacer l'échantillon. Ce dispositif nous permet d'amener

\footnotetext{
${ }^{3}$ La taille du faisceau à l'entrée de la lentille peut être modifiée en le faisant passer par un système afocal. Il se compose de deux lentilles respectivement de focale $f_{1}$ et $f_{2}$. En les plaçant à une distance de $f_{1}+f_{2}$ l'une de l'autre on multiplie le diamètre du faisceau par un facteur de $f_{2} / f_{1}$
} 
précisément le noyau d'une des cellules adhérées sur la surface de verre au waist du faisceau laser.

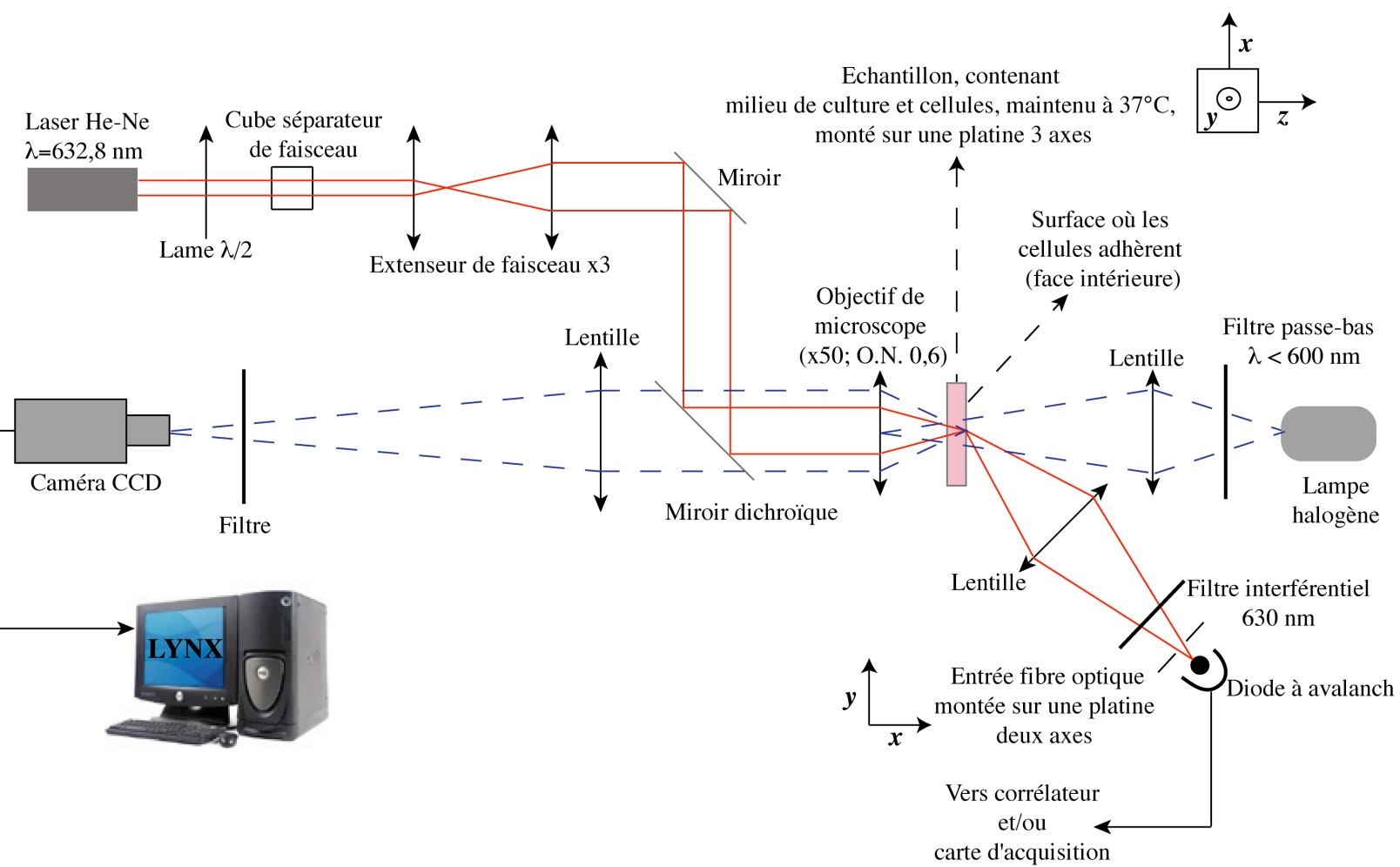

Figure 3-3 : Intégralité du montage expérimental de diffusion de la lumière. Les cellules sont visualisées en transmission par microscopie optique à fond clair. Le faisceau laser est visualisé par réflexion. L'échantillon qui contient les cellules est monté sur une platine 3 axes qui permet de positionner le noyau d'une cellule à l'endroit où se trouve le waist du faisceau laser.

Le microscope optique en transmission à fond clair est construit sur la table optique en utilisant l'objectif de microscope servant à focaliser le faisceau laser. C'est un objectif avec un grossissement de 50 et une ouverture numérique (O.N.) de 0,6. Cet objectif nous permet d'observer un champ d'environ $150 \times 150 \mu \mathrm{m}^{2}$. L'échantillon à visualiser, c'est-à-dire les cellules adhérées sur la surface de verre, est éclairé en lumière blanche par une lampe halogène située à l'opposé de l'objectif (la lumière blanche se propageant dans le sens inverse de la propagation du faisceau laser ; voir Figure 3-3). La lumière de la lampe halogène est focalisée sur la face d'entrée de l'objectif de microscope par une lentille placée entre les cellules et la lampe qui joue le rôle de condenseur. L'image de la surface donnée par l'objectif de microscope est formée sur le capteur d'une caméra CCD (caméra Kappa DX2H, pilotée par ordinateur par le logiciel Lynx de ClaraVision ; ce logiciel permet, entre autres, d'acquérir les images en différents formats, de faire de la vidéomicroscopie time-lapse,...) à l'aide d'une seconde lentille placée après l'objectif. La position et la focale de cette lentille ont été choisies pour que le grossissement soit conservé. Comme on peut le voir sur la Figure 3-4, avec les concentrations cellulaires typiques d'une de nos expériences, on observe, simultanément, une petite dizaine de cellules, tout en ayant une très bonne vision du noyau de chacune d'entre elles. On voit aussi très nettement la réflexion du faisceau laser sur la surface. Donc, en déplaçant la surface de verre sur laquelle les cellules sont adhérées grâce à une platine trois axes, nous pouvons positionner le noyau d'une cellule exactement à l'endroit où se trouve le waist du faisceau. 


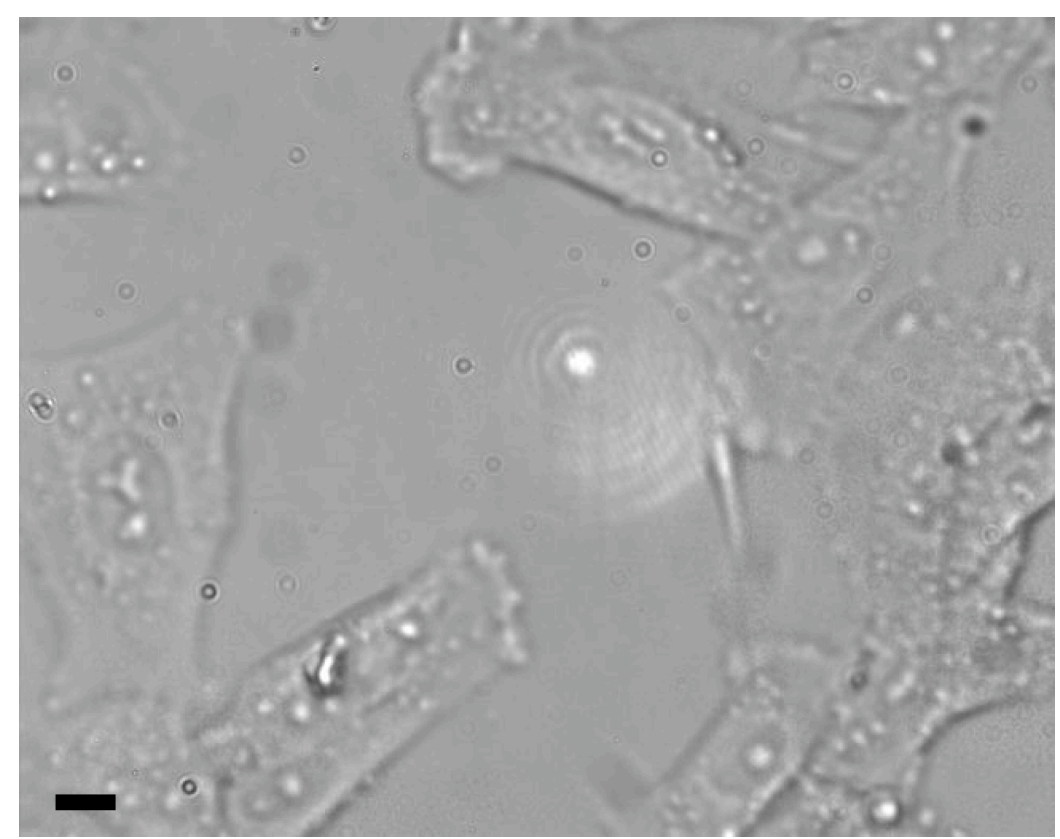

Figure 3-4 : Image des cellules et du waist du faisceau laser obtenue à l'écran de l'ordinateur.

La barre représente $5 \mu \mathrm{m}$.

Remarques : a) Le laser et la camera CCD ne pouvant être placés, tous les deux, dans l'axe de l'objectif, le laser est placé sur le côté et le faisceau laser est envoyé sur l'échantillon grâce à un miroir dichroïque, réfléchissant les longueurs d'onde supérieures à $630 \mathrm{~nm}$, placé sur l'axe de l'objectif (voir Figure 3-3).

b) Il peut être intéressant, lors d'une expérience de diffusion de la lumière, de faire varier la profondeur à laquelle se trouve le waist dans la cellule. Cela permettrait de sonder la dynamique du noyau sur sa profondeur. En pratique, il suffirait d'avancer ou de reculer l'échantillon par rapport à l'objectif. Ces déplacements s'effectuent avec la vis micrométrique qui contrôle l'axe $z$ de la platine (Figure 3-3). Toutefois, sonder le noyau de cette façon nécessite des déplacements de l'ordre du micromètre. Or, il est difficile d'atteindre cette précision en tournant la vis micrométrique «à la main ». C'est pourquoi nous avons décidé de remplacer la vis de l'axe $z$ par un dispositif piézoélectrique (ThorLabs Inc.). Ce dispositif va avancer ou reculer l'échantillon en fonction de la tension qui lui est appliquée (10 Volts pour un déplacement d'environ $1 \mu \mathrm{m}$ ). Il est piloté par un logiciel (ThorLabs Inc.) grâce auquel la tension peut être réglée au dixième de volts près $(10 \mathrm{~nm})$.

\section{V> Système de mesure de la lumière diffusée}

Une fois le faisceau laser focalisé dans le noyau d'une cellule, nous avons besoin d'un système optique pour récolter la lumière diffusée à un certain angle du faisceau incident et l'envoyer sur la surface photosensible d'un détecteur. Ensuite, un autre système est nécessaire pour permettre de transformer l'intensité de la lumière detectée en un signal éléctrique qui pourra être analysé pour nous donner accès à la dynamique du volume diffusant. 


\section{1) Système de collection de la lumière diffusée}

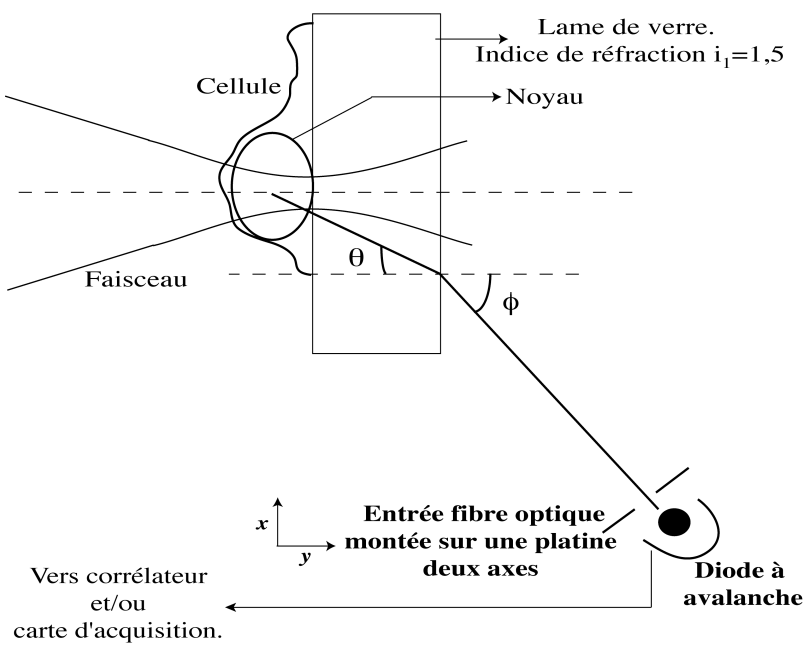

Figure 3-5 : Schéma représentatif de la détection. Les photons diffusés sont acheminés vers la surface photosensible de la diode à avalanche par une fibre optique. L'entrée de cette fibre optique est placée à un angle $\phi$ du faisceau incident. Du fait de l'important changement d'indice à l'interface verre/air les photons qui arrivent sur le détecteur sont, en fait, les photons diffusés à un angle $\theta$ du faisceau incident (équation (3-2)).

Le système de collection va non seulement servir à récolter la lumière diffusée, mais va également permettre de sélectionner la taille du volume diffusant. La lumière diffusée est simplement collectée par une lentille placée entre l'échantillon et le détecteur (Figure 3-3). La lentille focalise la lumière diffusée sur le cœur d'une fibre optique qui conduit la lumière jusqu'au détecteur. La fibre optique fait office de «trou d'aiguille» : plus la taille de son cœur est réduite, plus le volume diffusant vu par le détecteur sera petit. Nous utilisons une fibre optique monomode (O.N. 0,6) dont le cœur mesure $5 \mu \mathrm{m}$ de diamètre ${ }^{4}$ ce qui donne un volume diffusant d'environ $10 \mu \mathrm{m}^{3}$. Cette taille est comparable à celle occupée par un territoire chromosomique dans le noyau d'un SHEP-Neuroblastome.

Remarques : a) La direction dans laquelle on détecte la lumière diffusée fait un angle $\phi$ avec la direction du faisceau laser incident. Contrairement aux montages classiques de diffusion de la lumière, cet angle de détection $\phi$ n'est pas identique à l'angle de diffusion $\theta$ que nous avons défini au début de ce chapitre (voir Figure 3-5). En effet nous travaillons avec une interface verre-air plane et, d'après la loi de Descartes, un photon diffusé par le noyau avec un angle $\theta$ sortira dans une direction $\phi$ telle que :

$$
1,5 \times \sin (\theta)=\sin (\phi)
$$

La gamme d'angles de diffusion $\theta$ accessible pour les mesures est, environ : $13^{\circ}-42^{\circ}$. En effet, on ne peut pas descendre en dessous d'un angle $\theta=13^{\circ}$, car le système de collection ne peut pas faire un angle $\phi<20^{\circ}$ sans empêcher la bonne visualisation de l'échantillon. Audessus de $\theta=42^{\circ}$, nous sommes au-delà de la réflexion totale de la lumière à l'interface verre-air et il n'y a plus de lumière diffusée détectable pour ces angles (il faut noter que notre montage ne permet pas de faire des mesures de diffusion vers l'arrière). En prenant pour la valeur de l'indice de réfraction du noyau 1,5, la gamme de vecteurs d'onde accessibles avec notre montage est : $q_{\min } \approx 3,45 \cdot 10^{6} \mathrm{~m}^{-1}, q_{\max } \approx 1,2 \cdot 10^{7} \mathrm{~m}^{-1}$.

\footnotetext{
${ }^{4}$ La petite taille du cour de fibre rend toutefois assez fastidieux son alignement avec le point de focalisation de la lentille. Cet alignement se fait grâce à la platine de translation deux axes présentée sur la Figure 3-5.
} 
b) Pour éviter que la détection de l'intensité lumineuse diffusée (à $632.8 \mathrm{~nm}$ ) ne soit polluée par de la lumière parasite rentrant accidentellement dans la fibre, nous avons placé l'entrée de celle-ci au fond d'une boîte noire dont la face d'entrée est fermée par un filtre interférentiel centré sur $634 \mathrm{~nm}$ et de bande passante $10 \mathrm{~nm}$. Nous avons aussi enlevé toutes les longueurs d'ondes supérieures à $600 \mathrm{~nm}$ de la lumière blanche servant à éclairer les cellules. Nous nous sommes également aperçus que des photons en provenance de la lumière ambiante peuvent passer par le corps même de la fibre et atteindre le détecteur polluant ainsi les mesures. Ce phénomène est supprimé simplement en blindant la fibre (en l'entourant d'une gaine en papier aluminium). Le détecteur est, quant à lui, enfermé dans une boîte noire. De cette manière, aucun photon ne lui parvient directement. L'efficacité de ce montage a été testée en branchant la diode le laser éteint. Le nombre de photons comptés correspondait au bruit noir de notre détecteur indiqué par le constructeur (autour de 100 photons par seconde).

\section{2) Détecteur}

L'efficacité quantique du détecteur (nombre de photons détectés par rapport au nombre de photons reçus) dépend principalement de la longueur d'onde. Nous avons, ainsi, choisi d'utiliser une photodiode à avalanche (APD) dont l'efficacité quantique pour les longueurs d'onde proches de $640 \mathrm{~nm}$ est d'environ $90 \%$. Elle nous assure la meilleure détection possible pour notre montage ${ }^{5}$. Il est nécessaire pour la suite de comprendre comment marche une APD pour pouvoir traiter le signal en sortie. Les APD émettent une impulsion TTL à chaque fois qu'elles détectent un photon. L'intensité de la lumière diffusée se mesure alors comme le nombre de photons reçus pendant un temps d'échantillonnage donné. La grande efficacité des APD provient de leur mode de fonctionnement. Ce sont des dispositifs semi-conducteurs principalement composés d'une jonction PN polarisée en inverse. Dans des conditions « idéales », lorsqu'un photon pénètre l'APD il crée une paire électron-trou. La diode a une «zone d'accélération» parcouru par un fort courant électrique. Sous son effet, la paire électron-trou subie une accélération. Elle va acquérir suffisamment d'énergie pour créer d'autres paires électrons-trous par collision avec la structure cristallines du semi-conducteur. Elles vont, à leur tour, être accélérées et créer de nouvelles paires électrons-trous : c'est l'effet avalanche. On a ainsi un phénomène interne d'amplification du photocourant. Au delà d'un certain seuil, ce photocourant est transformé par l'électronique de l'APD en une impulsion TTL émise en sortie (largeur $30 \mathrm{~ns}$ ). La diode applique alors un temps mort de 50 ns pour éviter de compter deux fois le même photon. L'APD est donc un détecteur très sensible ${ }^{6}$.

Les impulsions TTL émises par l'APD doivent à présent être transformées en un signal contenant la dynamique du volume diffusant.

\section{3) Systèmes d'acquisition du signal}

Nous disposions au laboratoire d'une carte corrélateur BI9000AT (Brookhaven Instrument). Nous avons donc choisi de l'utiliser afin d'acquérir l'intensité de la lumière diffusée sous sa

\footnotetext{
${ }^{5}$ Ce type de détecteur a également été choisi dans l'éventualité d'une utilisation future avec un laser émettant dans l'infrarouge. En effet, nous ferons remarquer par la suite que les longueurs d'ondes les moins dangereuses pour les cellules se situent dans l'infrarouge et que, de plus, le laser He-Ne ne peut pas s'utiliser avec tous les types de cellules. Il se trouve que les APD ont la plus forte efficacité quantique pour les longueurs d'onde conseillées.

${ }^{6}$ Des paires électrons-trous peuvent être générées à l'intérieur de sa structure par des fluctuations thermiques. Ces paires se comporteront exactement de la même manière que celles qui sont générées par un photon. Une avalanche va alors se produire et un photon sera compté. C'est ce que l'on appelle le bruit noir. Ceci peut être grandement atténué par la géométrie de la diode et par un module interne à effet Peltier. L'amplitude maximale de ce bruit s'élève à 100 coups par seconde pour notre APD. Il est à noter que pour nos expériences de diffusion de la lumière par une cellule, l'intensité moyenne est de l'ordre de 200 kcoups par seconde. La qualité de la photodiode est donc suffisante pour que ce bruit soit négligeable lors de nos expériences.
} 
forme autocorrélée. Toutefois, le noyau étant le siège de nombreuses réactions biochimiques se produisant à chaque instant, le signal sera non-stationnaire. Dans ce cas, l'autocorrélation ne pouvant se faire que sur une portion donnée du signal, nous n'obtiendrons qu'un « instantané » de la dynamique du noyau. Cela nous obligera à répéter de nombreuses fois les mesures. Nous avons donc complété le montage par un système permettant l'acquisition du signal non traité que nous appellerons « signal brut ».

\section{3-1) Autocorrélateur}

Le principe de l'autocorrélation est décrit en Annexe A. Rappelons brièvement que l'autocorrélation consiste à comparer une fonction avec une version d'elle-même décalée d'un temps $\tau_{j}$. Les temps caractéristiques du signal seront donnés par les décroissances de la courbes d'autocorrélation. Pour réaliser cela, l'autocorrélateur échantillonne le temps $T$ en $N$ intervalles de temps dont le i-ème a une longueur $\Delta t_{i}$. Le signal délivré par l'APD étant une série d'impulsions, chacune d'entre elles signalant la détection d'un photon, l'intensité de la lumière diffusée pendant cet intervalle est $n_{i}$, nombre de photons comptés pendant $\Delta t_{i}$. Ainsi, la fonction d'autocorrélation du signal bâti par l'autocorrélateur est :

$$
\tilde{C}\left(\tau_{j}\right)=\lim _{N \rightarrow \infty} \frac{N_{j}}{N}=\lim _{N \rightarrow \infty} \frac{1}{N} \sum_{i=1}^{N} n_{i} n_{i-j}, j=1,2,3, \ldots, M(3-3)
$$

où $M$ est le nombre de temps de décalage. Chaque temps de décalage correspond à un canal. Le canal numéro $j$ contiendra au final la valeur $N_{j}$ présentée dans l'équation (3-3).

La carte de corrélation BI9000AT dispose de deux modes de fonctionnement pour réaliser $\tilde{C}\left(\tau_{j}\right)$ : le mode linéaire et le mode ratio.

\section{a) BI9000AT : mode linéaire.}

En mode linéaire, $\Delta t_{i}=\Delta t$ pour tout $i$ où $\Delta t$ est un temps d'échantillonnage choisi par l'utilisateur. Les temps de décalage $\tau_{j}$ sont tels que $\tau_{j}=j \times \Delta t$. Pour un temps $t$ donné, la quantité $n_{1}$ sera donc le nombre de photons comptés entre $t$ et $t+\Delta t, n_{2}$ sera le nombre de photons comptés entre $t$ et $t+2 \Delta t$ et ainsi de suite jusqu'à $n_{M}$, nombre de photons comptés entre $t$ et $t+M \Delta t$. Le corrélateur va ajouter la valeur du produit $n_{1} \times n_{1}$ à celle présente dans le canal $N_{1}$, la valeur du produit $n_{1} \times n_{2}$ à celle présente dans le canal $N_{2}$, et continuera ainsi jusqu'au canal $N_{M}$. La fonction d'autocorrélation se construit donc pendant tout le temps d'acquisition par accumulation. Notons que le corrélateur BI9000AT dispose d'un nombre maximum de 508 canaux. La gamme de temps que peut couvrir le mode linéaire est donc comprise entre 0 et $508 \Delta t$. Il appartient donc à l'utilisateur de choisir convenablement $\Delta t$. Il devra être suffisamment petit pour ne pas rater de l'information contenue dans le signal et suffisamment grand pour que le corrélateur en couvre toute la dynamique.

\section{b) BI9000AT : mode ratio.}

Le mode linéaire est satisfaisant si le signal ne contient qu'un seul temps caractéristique compris dans la gamme que peut couvrir le corrélateur. Par contre, si le signal mesuré contient plusieurs temps caractéristiques, il peut être assez difficile d'avoir toutes les décroissances correspondantes sur la courbe d'autocorrélation entre 0 et $508 \Delta t$. Il est alors nécessaire d'étendre la dynamique du corrélateur. Le nombre de canaux étant fixe, il suffit d'augmenter les temps de décalage non linéairement de façon à couvrir une plus grande gamme de temps. Le BI9000AT dispose d'un mode de répartition non-linéaire des canaux : le mode ratio. Dans ce mode, les temps de décalage ne dépendent plus directement de $\Delta t$. Ils dépendent surtout du nombre de canaux $M$, du premier et du dernier temps de décalage, respectivement $\tau_{1}$ et $\tau_{M}$, ces trois paramètres devant être choisis par l'utilisateur. Le BI9000AT choisi 
automatiquement $\Delta t$ en fonction de $\tau_{1}$ et $\tau_{M}$. Concernant les temps de décalages, ils sont calculés en fonction du ratio $R$ entre le premier et le dernier temps de décalage pondéré par $M$ de sorte que:

$$
\tau_{M}=\tau_{1} \times R^{M-1}(3-4)
$$

\begin{tabular}{|c|c|c|c|}
\hline $\begin{array}{c}\text { Numéro } \\
\text { canal } \\
\text { demandé }\end{array}$ & $\tau_{j}$ & $\tau_{\mathrm{j}}(\bmod \Delta \mathrm{t})$ & $\begin{array}{c}\text { Numéro } \\
\text { canal } \\
\text { attribué }\end{array}$ \\
\hline 1 & 5,00 & 5 & 1 \\
\hline 2 & 6,67 & 5 & \\
\hline 3 & 8,89 & 10 & 2 \\
\hline 4 & 11,86 & 10 & \\
\hline 5 & 15,81 & 15 & 3 \\
\hline 6 & 21,08 & 20 & 4 \\
\hline 7 & 28,12 & 30 & 5 \\
\hline 8 & 37,49 & 35 & 6 \\
\hline 9 & 50,00 & 50 & 7 \\
\hline 10 & 66,68 & 65 & 8 \\
\hline 11 & 88,91 & 90 & 9 \\
\hline 12 & 118,57 & 120 & 10 \\
\hline 13 & 158,11 & 160 & 11 \\
\hline 14 & 210,85 & 210 & 12 \\
\hline 15 & 281,17 & 280 & 13 \\
\hline 16 & 374,95 & 375 & 14 \\
\hline 17 & 500,00 & 500 & 15 \\
\hline 18 & 666,76 & 665 & 16 \\
\hline 19 & 889,14 & 890 & 17 \\
\hline 20 & 1185,69 & 1185 & 18 \\
\hline 21 & 1581,14 & 1580 & 19 \\
\hline 22 & 2108,48 & 2110 & 20 \\
\hline 23 & 2811,71 & 2810 & 21 \\
\hline 24 & 3749,47 & 3750 & 22 \\
\hline 25 & 5000,00 & 5000 & 23 \\
\hline
\end{tabular}

Tableau 3-1 : Exemple de répartition des canaux par le corrélateur BI9000AT. Ici l'utilisateur a choisi un nombre maximal de canaux égal à 25 , le premier temps de décalage à $5 \mu \mathrm{s}$ et le dernier à $5000 \mu \mathrm{s}$. Le ratio $R$ calculé vaut environ 1,33. Le corrélateur n'utilisera en réalité que 23 canaux, les canaux 2 et 4 étant respectivement redondants avec les canaux 1 et 3 .

Le temps de décalage $\tau_{j}$ est calculé en fonction de $R$ et arrondi au multiple de $\Delta t$ le plus proche :

$$
\tau_{j}=\tau_{1} \times R^{j-1}(\bmod \Delta t)(3-5)
$$

Evidemment, il se peut que $\tau_{j}(\bmod \Delta t)=\tau_{j+1}(\bmod \Delta t)$. Dans ce cas, le corrélateur utilisera 1 canal de moins et le canal $j+1$ correspondra en fait au canal numéro $k$, plus proche entier de $j$ tel que $\tau_{j}(\bmod \Delta t) \neq \tau_{k}(\bmod \Delta t)^{7}$. Le Tableau 3-1 donne un exemple de la répartition des

\footnotetext{
${ }^{7}$ Cela signifie que lorsque le corrélateur calculera la fonction d'autocorrélation il ne laissera pas un «trou » entre les canaux $j$ et $k$. Simplement, le temps de décalage qui correspondra au canal $j+1$ ne sera pas $\tau_{j+1}$ mais $\tau_{k}$.
} 
canaux si l'utilisateur choisi $M=25, \tau_{1}=5 \mu$ s et $\tau_{M}=5000 \mu$ s (on a alors $R \approx 1.33$ ). Au final, le corrélateur n'utilisera que 23 canaux. On fera attention au fait que plus $M$ est grand, plus sa différence avec le nombre de canaux réellement utilisé est importante.

c) BI9000AT : trois corrélateurs.

La mémoire des variables que le corrélateur utilise pour compter les impulsions TTL venant de la diode et effectuer les produits $n_{i} n_{i-j}$ est limité. En mode ratio, cela peut poser un problème de saturation mémoire lorsque ces valeurs sont très grandes, ce qui arrive lorsque la gamme des temps de décalage est très étendue et que le temps d'échantillonnage est très court. Pour pallier ce problème, le BI900AT utilise trois corrélateurs. Le premier dit « à vitesse rapide », utilise un temps d'échantillonnage très rapide (entre 25 et $100.10^{-9} \mathrm{~s}$ ) mais opère sur un nombre de temps de décalage très réduit (14 canaux) pour éviter la saturation. Le deuxième, à " vitesse moyenne », utilise des temps d'échantillonnage plus lents (entre 500.10' ${ }^{9} \mathrm{~s}$ et $100.10^{-6} \mathrm{~s}$ ) mais opère sur une gamme de temps plus étendu (de $500.10^{-9} \mathrm{~s}$ à $1.64 \mathrm{~s}$ ). Enfin, le troisième, à « vitesse lente », utilise des temps d'échantillonnage encore plus lents (entre $50.10^{-6} \mathrm{~s}$ et $400.10^{-3} \mathrm{~s}$ ) et opère sur une gamme de temps plus étendue que les deux autres (de $50.10^{-6} \mathrm{~s}$ à $1311 \mathrm{~s}$ ). Le raccordement entre les trois corrélateurs est rendu possible par le chevauchement partiel de leur gamme de temps.

Comme nous l'avons vu plus haut, nous utilisons, en plus de cet autocorrélateur, un dispositif pour acquérir le signal brut.

\section{3-2) Acquisition du signal brut}

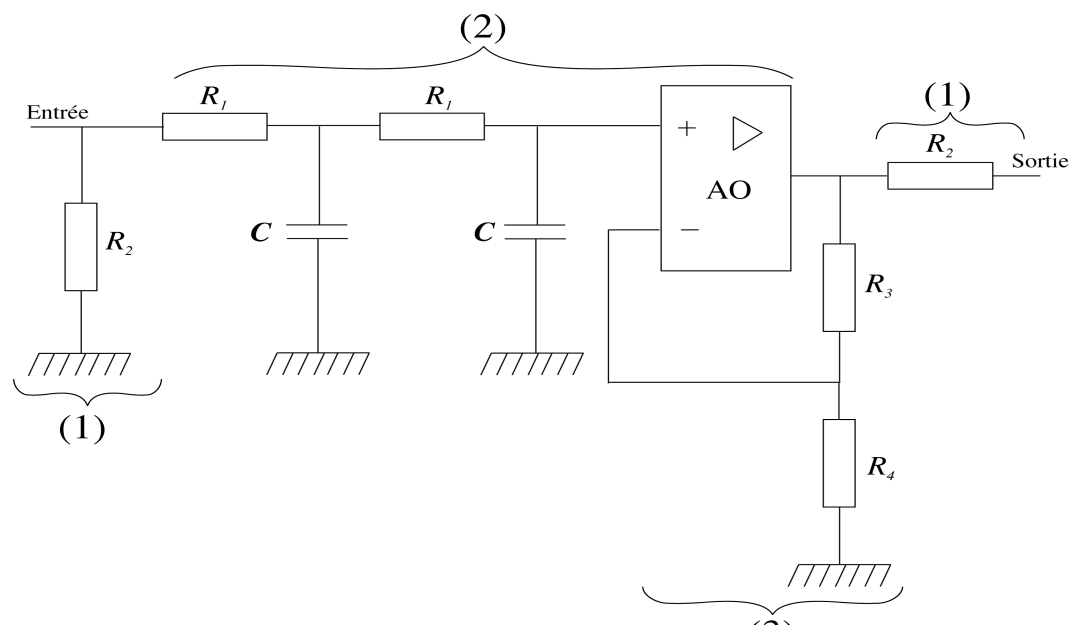

(3)

Figure 3-6 : Montage permettant de moyenner sur chaque milliseconde la cadence d'arrivée des impulsions TTL émises par l'APD. (1) Les résistances $R_{2}$ sont de $50 \Omega$ et servent à adapter l'impédance du circuit à celles de l'APD et de la carte d'acquisition. (2) Double circuit RC permettant de moyenner le signal. Les résistances $R_{1}$ ont pour valeur $1300 \Omega$, les

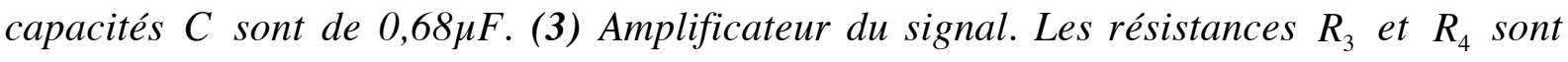
choisies pour amplifier le signal en sortie du double circuit $R C$ avec un gain de 10.

Le signal brut que nous cherchons à acquérir correspond en fait à l'historique du taux de comptage des photons par l'APD. La carte corrélateur BI900AT ne permet pas de récupérer cet historique. Nous avons donc monté un dispositif que nous avons utilisé en parallèle du corrélateur comprenant une autre carte d'acquisition pouvant nous donner accès au signal brut. Nous disposions au laboratoire d'une carte d'acquisition DT322 (Data Translation). Cette carte permet de compter les photons émis par l'APD, mais son taux d'échantillonnage 
maximal est d'environ $100.10^{3} \mathrm{~Hz}$. Or le compteur de photons du corrélateur nous indique que, lors de nos expériences, l'APD peut compter en moyenne 200-300.10 $0^{3}$ photons par secondes. La carte DT322 est donc beaucoup trop lente. Nous avons, alors, décidé de la coupler à un montage qui permet de lui envoyer une tension proportionnelle à la cadence d'arrivée des impulsions TTL pour chaque milliseconde. Pour cela, il suffit de prendre en compte le fait que, chaque impulsion ayant une hauteur et une largeur fixe (respectivement $5 \mathrm{~V}$ et $30 \mathrm{~ns}$ ) la tension moyenne, $U$, générée par l'ensemble des impulsions émises pendant un temps $\Delta t$ est :

$$
U \approx 5 V \times \frac{N}{\Delta t} \times 30 n s(3-6),
$$

où $N$ est le nombre d'impulsions émises pendant $\Delta t$. Cette tension moyenne est donc proportionnelle à la cadence d'arrivée des photons : $N / \Delta t$. Il suffit donc de réaliser un montage capable de moyenner la tension générée par les impulsions TTL sur chaque milliseconde pour obtenir le signal brut.

Le montage que nous avons utilisé est un montage double RC présenté en Figure 3-6. Une simple application de la loi des nœuds permet d'établir la fonction de réponse du double circuit RC qui relie la tension d'entrée $U_{E}$ à la tension de sortie $U_{S}$. Cette fonction de réponse dépend de la fréquence $\omega$ du signal d'entrée selon :

$$
U_{S}=\frac{1}{(j \omega \tau)^{2}+3 j \omega \tau+1} U_{E}(3-7),
$$

où $\tau=R_{1} C$ et $j$ est tel que $j^{2}=-1$.

D'après l'équation (3-7), le double circuit RC joue donc le rôle de filtre passe-bas en atténuant les fréquences supérieures à $1 / \tau$. Le circuit transmettra, donc, en sortie, la composante continue du signal soit, ici, le signal moyenné sur $\tau$. Il suffit donc de choisir $R_{1}$ et $C$ de sorte que $\tau \approx 1 \mathrm{~ms}$ (choisi respectivement à $1300 \Omega$ et $0,68 \mu F$ ) pour envoyer à la carte DT 322 un signal proportionnel à la cadence d'arrivée des photons pendant ce même temps et obtenir ainsi les variations du signal brut en fonction du temps.

Maintenant que tous les éléments du montage de diffusion de la lumière sont réunis nous allons valider expérimentalement notre montage

\section{4) Validation et géométrie du montage expérimental}

Dans cette partie, nous allons vérifier la validité de notre montage, c'est-à-dire vérifier que l'on mesure une fonction d'autocorrélation adéquat. Pour cela, nous allons comparer les résultats obtenus avec notre montage sur une solution de billes de latex diluées, avec ceux obtenus avec un banc de diffusion de la lumière classique sur le même échantillon. Cette expérience va également nous permettre de déterminer la géométrie de notre montage. La géométrie d'un montage expérimental de diffusion dynamique de la lumière est déterminée par la lumière qui est envoyée sur la surface photosensible du détecteur. Deux géométries sont possibles : homodyne et hétérodyne. En géométrie homodyne, seul le faisceau diffusé par le volume diffusant atteint le détecteur tandis qu'en géométrie hétérodyne, une partie du faisceau incident est superposée au faisceau diffusé pour servir de référence ${ }^{8}$. Notre montage est initialement prévu pour fonctionner en géométrie homodyne, il est toutefois possible qu'une partie du faisceau incident (pouvant, par exemple, provenir des reflets sur la lame de verre) atteignent le détecteur. Les différences concernant les deux géométries sont expliquées en

\footnotetext{
${ }^{8}$ Plusieurs conditions sont toutefois nécessaires. Tout d'abord il faut que l'intensité du faisceau incident soit nettement supérieure à celle du faisceau diffusé. Ensuite les fluctuations temporelles de l'intensité du faisceau incident doivent être négligeables par rapport à celles du faisceau diffusé. Enfin ces fluctuations ne doivent pas être corrélées.
} 
détail dans Bern et Pecora (1976). Brièvement, dans le cas homodyne, on mesure le carré du module des variations d'indice de l'échantillon, tandis que dans le cas hétérodyne on ne mesure que la partie réelle de ces variations. Donc, les deux géométries permettent d'aboutir aux mêmes résultats si ces variations n'ont pas de composantes complexes.

La solution que nous utilisons est composée de billes de latex de $220 \mathrm{~nm}$ de diamètre dans de l'eau à température ambiante. Nous avons veillé à ce que la concentration en billes de latex soit suffisamment faible de façon à ce que l'on soit en régime dilué (la dynamique de chaque bille est indépendante de celle des autres). Dans ce cas, la dynamique des billes provient de leur seule agitation thermique. Il s'agit donc d'une diffusion brownienne. Ainsi, la fonction d'autocorrélation de l'intensité de la lumière diffusée est une monoexponentielle décroissante dont le taux de relaxation vaut $2 \omega$ dans le cas où la géométrie du montage est homodyne et $\omega$ dans le cas où la géométrie du montage est hétérodyne, avec :

$$
\omega=D \mathbf{q}^{2}(3-8)
$$

$\mathbf{q}$ étant le vecteur d'onde de diffusion et $\boldsymbol{D}$ le coefficient de diffusion des billes latex. Ce dernier est donné par la relation de Stokes-Einstein :

$$
D=\frac{k_{B} T}{6 \pi \eta R}(3-9)
$$

où $T$ est la température de l'eau, $\eta$ la viscosité dynamique de l'eau et $R$ le rayon des billes de latex.

Le banc de diffusion de la lumière (Figure 3-7 ) a une géométrie homodyne. Il comprend un laser à Argon (Coherent) dont on utilise la raie verte $(\lambda=514 \mathrm{~nm})$. La lumière diffusée par l'échantillon est recueillie par un photomultiplicateur monté sur un goniomètre, qui permet de faire varier l'angle de détection de 10 à $150^{\circ}$ par rapport au faisceau incident. La cadence d'arrivée des photons est analysée grâce à une carte corrélateur Malvern dont le fonctionnement est sensiblement différent de celui du BI9000AT notamment en ce qui concerne la répartition des canaux en mode non-linéaire (pour une description détaillée se reporter à Chu (1991)). Toutefois cela n'empêche pas la comparaison des résultats obtenus grâce aux deux corrélateurs.

Laser Ar

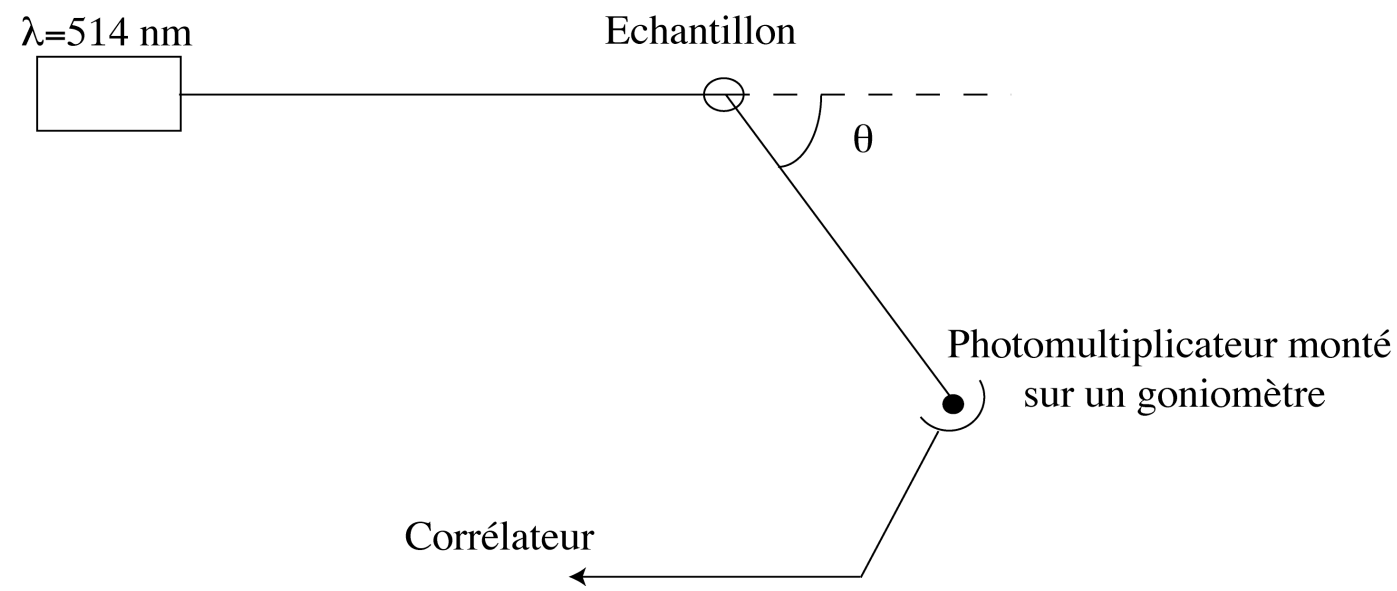

Figure 3-7 : Schéma du banc de diffusion de la lumière.

Pour effectuer la comparaison entre les deux montages, nous commençons par mesurer, pour plusieurs vecteurs d'onde $\mathbf{q}$, la fonction d'autocorrélation de l'intensité diffusée par cette solution sur le montage classique de diffusion de la lumière. Le coefficient de diffusion des 
billes de latex $\boldsymbol{D}$ est extrait des résultats expérimentaux en mesurant le coefficient directeur de la droite obtenue en traçant la variation du taux de relaxation $\omega$ en fonction de $\mathbf{q}^{2}$. Nous trouvons : $D=2,43 \cdot 10^{-12} \mathrm{~m}^{2} \cdot \mathrm{s}^{-1}$. Ensuite, nous mesurons la fonction d'autocorrélation de l'intensité diffusée par cette même solution sur notre montage pour un angle de diffusion unique d'environ $21^{\circ 9}$, soit : $\mathbf{q}^{2}=2,21.10^{13} \mathrm{~m}^{-2}$, ce qui donne un taux de relaxation $\boldsymbol{D q ^ { 2 }} \approx 54 \mathrm{~s}^{-1}$. La solution est introduite dans la chambre, puis placée sur le montage. L'étau qui maintient la chambre de culture n'est pas chauffé puisque l'expérience est réalisée à température ambiante. Le faisceau laser est focalisé de la même manière que lors des expériences réalisées avec les cellules et le waist du faisceau est placé à environ $2 \mu \mathrm{m}$ de la lame de verre.) L'ajustement des courbes d'autocorrélation obtenues, par une monoexponentielle décroissante, nous donne des fréquences de relaxation caractéristiques, $\omega_{1}$, se situant, en moyenne, autour de $105 \mathrm{~s}^{-1}$ avec une très faible dispersion entre les différentes mesures (voir Figure 3-8). Or, comme $D \mathbf{q}^{2} \approx 54 \mathrm{~s}^{-1}$, on peut en conclure que $\omega_{1}=2 D \mathbf{q}^{2}$ et donc que la géométrie de notre expérience est homodyne.
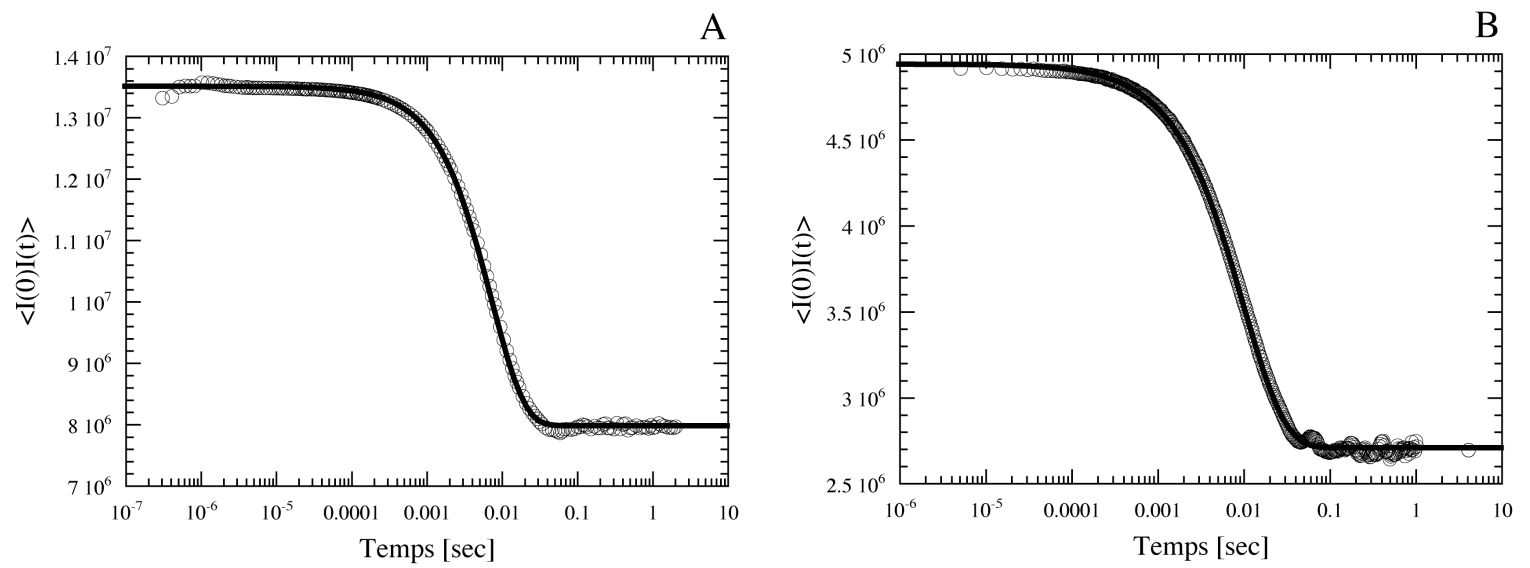

Figure 3-8: Fonctions d'autocorrélation de l'intensité de la lumière diffusée par un échantillon composé d'un mélange suffisamment dilué d'eau et de billes de latex ( $\varnothing$ $220 \mathrm{~nm})$, représentées sur une échelle semi-logarithmique. A. Courbe obtenue avec le banc de diffusion de la lumière. L'angle de détection est situé à $20^{\circ}$ du faisceau incident. L'ajustement est fait grâce au carré d'une monoexponentielle décroissante. Le temps caractéristique obtenu est de $66 \mathrm{~s}^{-1}$. B. Courbe obtenue avec le montage de diffusion de la lumière sur les cellules. L'angle de diffusion est situé à environ $21^{\circ}$ du faisceau incident.

Ces résultats valident notre montage expérimental et confirment que la géométrie du montage est homodyne. Toutefois, avant d'utiliser ce montage pour effectuer des mesures sur le noyau d'une cellule vivante, il faut nous assurer que nous pouvons maintenir les cellules dans un bon état physiologique.

\section{VI> Environnement physiologique des cellules}

Les cellules eucaryotes humaines peuvent être cultivées dans un environnement artificiel. Cet environnement doit alors répondre à des exigences strictes, nécessaires au bon développement des cellules. Il doit leur apporter les éléments indispensables à leur survie (acides aminés, facteurs de croissance, ions minéraux,...) et être maintenu à la température physiologique de $37^{\circ} \mathrm{C}$. Cet environnement doit également être stérile afin d'éviter toute contamination par des

\footnotetext{
${ }^{9}$ Ce qui signifie que l'angle de détection est d'environ $33^{\circ}$ (équation (3-2)).
} 
agents (bactéries, levures, champignons,...) susceptibles d'altérer la croissance, les caractéristiques ou encore les fonctions des cellules. Si nous voulons étudier la dynamique du noyau d'une cellule lors de différents stades de la vie cellulaire, il nous faut trouver un moyen de reproduire cet environnement dans notre montage. D'un autre coté, il sera également indispensable de s'assurer que le laser que nous utilisons ne détériore pas les cellules.

\section{1) Environnement physiologique}

\section{1-1) Chambre de culture}

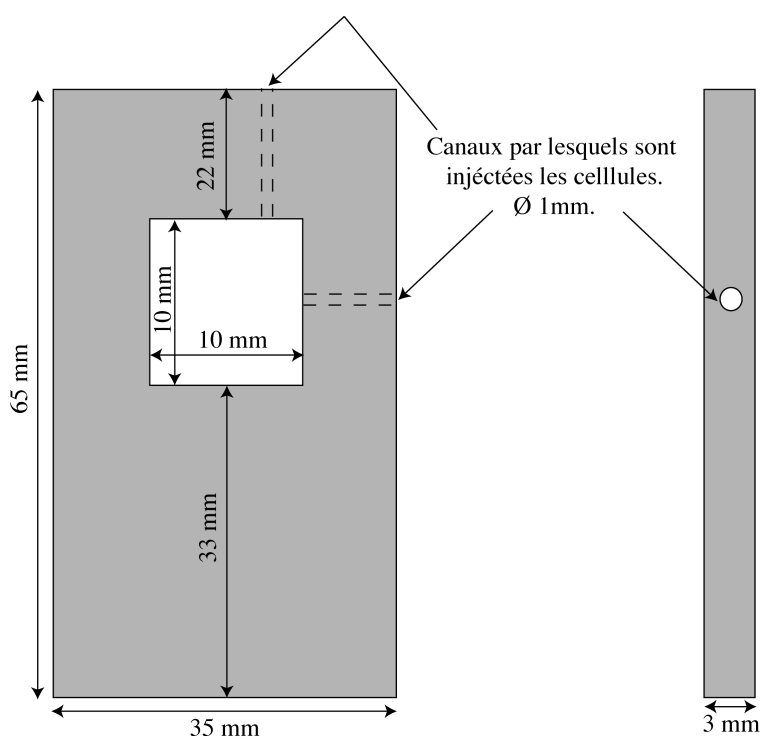

Figure 3-9 : Vu de face et de profil de la pièce en acier inoxydable servant au maintien des cellules dans de bonnes conditions physiologiques tout au long de l'expérience. Les cellules sont introduites avec leur milieu de culture entre deux lames de verre scellées de chaque côté du trou carré. Une fois les cellules adhérées sur l'une des lames, cette pièce est placée dans le montage de diffusion de la lumière, à la verticale, dans un étau chauffé à $37^{\circ} \mathrm{C}$. Le milieu de culture chauffe par conduction de la chaleur.

La pièce qui nous permettra de reproduire un environnement adéquat pour les cellules doit donc obéir à un cahier des charges bien précis. En premier lieu, les cellules doivent adhérer sur une lame de verre, comme nous l'avons expliqué au début de ce chapitre, et doivent baigner dans suffisamment de milieu de culture pour que les cellules puissent se développer normalement pendant plusieurs heures, voire quelques jours. Le volume contenant les cellules et le milieu doit être hermétiquement clos pour conserver la stérilité de l'environnement des cellules puisque l'expérience ne se déroule pas dans une salle stérile. Ensuite, la température du milieu de culture doit être à $37^{\circ} \mathrm{C}$. Pour obéir à ce cahier des charges, nous avons réalisé la pièce présentée en Figure 3-9. C'est une pièce métallique de 3 millimètres d'épaisseur comprenant un trou carré de 1 centimètre de côté. Une lame de verre est scellée par un joint de silicone de chaque côté de ce trou. L'épaisseur de $3 \mathrm{~mm}$ assure aux cellules une réserve de milieu suffisante. Les cellules sont introduites avec leur milieu de culture dans la chambre ainsi formée, par les canaux présentés en Figure 3-9. En mettant cette pièce à plat dans incubateur à $37^{\circ} \mathrm{C}$, les cellules sédimentent sur la lame de verre du bas et y adhérent en s'étalant (le processus prend environ 3 heures). Une fois les cellules adhérées la pièce est placée sur le montage de diffusion de la lumière, la surface de verre sur laquelle se trouve les 
cellules placée la plus loin de l'objectif de microscope. Sur le montage, la pièce est enchâssée dans un étau métallique (voir Figure 3-10) qui est chauffé à $37^{\circ} \mathrm{C}$ par une résistance chauffante (une sonde est placée dans l'étau et est reliée à un PID qui contrôle la résistance chauffante). La chambre de culture est ainsi chauffée, à $37^{\circ} \mathrm{C}$, par conduction de la chaleur. A l'aide d'une sonde de température placée à l'intérieur de la chambre de culture remplie d'eau, nous avons observé que les variations de température autour de $37^{\circ} \mathrm{C}$ étaient de l'ordre de $0,2^{\circ} \mathrm{C}$. Ces variations sont sans conséquences sur le développement des cellules. De cette façon, la chambre de culture assure aux cellules un réservoir de milieu stérile, maintenu à la bonne température. Il faut noter que sur le montage de diffusion de la lumière, la lame de verre sur laquelle adhèrent les cellules est placée verticale et perpendiculaire à la direction de propagation du faisceau laser (Figure 3-10). Comme nous l'avons dit au paragraphe III >, nous avons pu observé que cette position verticale des cellules ne perturbait en rien leur développement. L'étau est, quant à lui, placé sur la platine de translation trois axes placée derrière l'objectif de microscope (voir la Figure 3-3) ce qui permet de déplacer la surface de verre sur laquelle sont adhérées les cellules par rapport au faisceau laser.

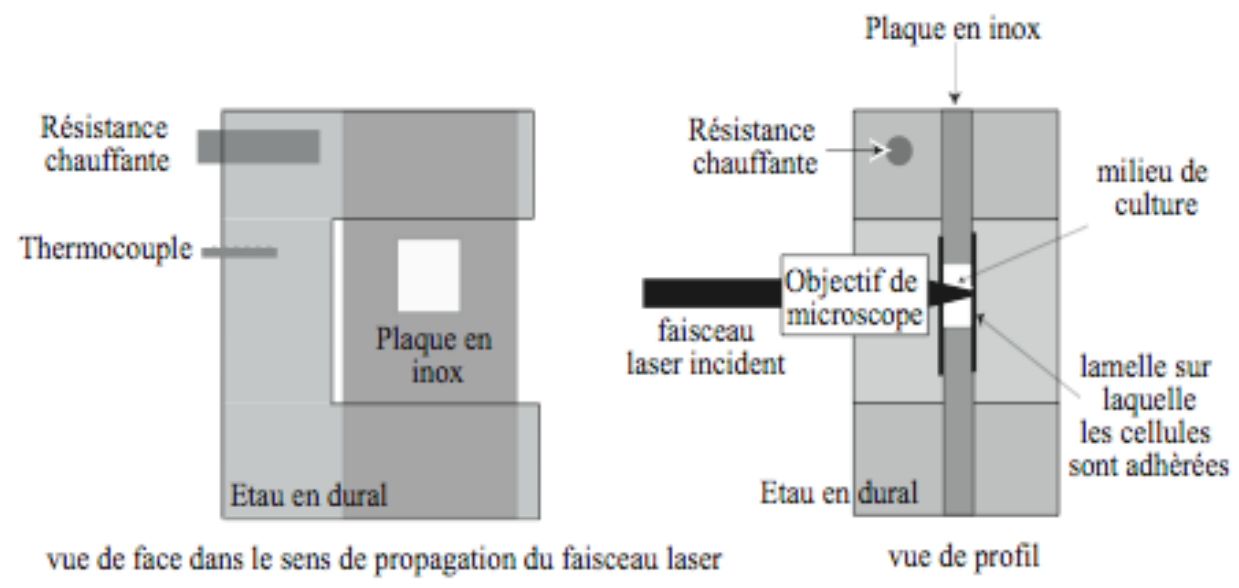

Figure 3-10 : Vu de face et de profil de l'étau maintenant la chambre de culture. Cet étau est monté sur la platine trois axes présentée sur la Figure 3-3.

\section{1-2) Métal composant la chambre de culture}

Nous nous sommes rapidement rendu compte que le choix du métal qui compose la pièce n'était pas anodin. Nous avons dû mener plusieurs essais avant de trouver le métal qui convenait le mieux à la réalisation de la chambre de culture. Les premiers étaient en dural. Cet alliage d'aluminium a pour avantages son coût raisonnable et sa faible dureté. Il peut ainsi être usiné sans difficulté. Toutefois il s'est avéré qu'il était oxydé par le milieu. Le résultat était la formation de petits cristaux sur les rebords de la chambre de culture. Ces petits cristaux passaient dans le milieu sous forme de particules colloïdales. Cela n'entraînait pas de modifications visibles du comportement cellulaire, mais le passage de ces particules dans le faisceau laser, près de la cellule étudiée, perturbait les expériences de diffusion de la lumière. Nous avons donc essayé d'utiliser un matériau ne présentant pas cet inconvénient. Le choix s'est porté sur le laiton. C'est un alliage de cuivre et de zinc. Celui-ci est également facile à travailler et coûte encore moins cher que le dural. Nous avons, malheureusement, remarqué dès les premiers essais que les cellules mourraient dans les premières heures qui suivaient leur introduction dans la chambre de culture (tandis que des cellules en provenance du même lot se développaient normalement dans une chambre de culture en dural). L'explication de ce phénomène est, toutefois, assez simple. Lorsque les cellules et le milieu sont introduits dans la chambre de culture, des ions $\mathrm{Zn}^{2+}$ et $\mathrm{Cu}^{2+}$ sont relargués dans le milieu suite à l'oxydation du 
laiton par ce dernier. Ces ions métalliques inhibent l'action des facteurs de croissance et provoquent l'apoptose des cellules (Ross et al., 1997 ; Wang et al., 1999 ; Ross et al., 2001). Nous avons alors décidé d'utiliser de l'acier inoxydable. Nous avions jusque-là évité ce matériau du fait de son coût élevé et de sa grande dureté qui rend la fabrication de la pièce plus difficile qu'avec du dural ou du laiton. Malgré tout, il a pour avantage une très grande résistance à l'oxydation et surtout il ne relargue aucun ion métallique ou autres substances toxiques pour les cellules dans le milieu. Les essais menés dans une chambre de culture en acier inoxydable ont montré une grande propreté de l'échantillon et une excellente survie des cellules.

\section{2) Milieu de culture}

En plus des besoins décrits au début de ce paragraphe, le milieu de culture que nous allons utiliser pour conserver nos cellules doit prendre en compte certaines contraintes supplémentaires imposées par la chambre de culture. La contrainte principale est l'absence de $\mathrm{CO}_{2}$ élément normalement indispensable pour contrôler le $\mathrm{pH}$ du milieu. La composition de notre milieu est donc la suivante :

- la base de notre milieu est du DMEM (Gibco). Celui-ci contient des ions minéraux et du glucose.

- les facteurs de croissance sont apportés par l'ajout de Sérum de Fœtus de Veau à hauteur de $10 \%$ du mélange total. Celui-ci contient également de l'insuline pour permettre l'assimilation du glucose par les cellules et des protéines d'adhésion pour faciliter l'adhésion des cellules sur leur support.

- de la L-Glutamine, acide aminé essentiel au développement des cellules, doit être ajouté au mélange.

- la base du milieu contient également une solution tampon $\left(\mathrm{HCO}_{3} \mathrm{Na}\right)$ servant normalement à maintenir le $\mathrm{pH}$ à 7,4 par équilibre avec le $\mathrm{CO}_{2}$ atmosphérique. Toutefois, le porte-échantillon étant hermétiquement clos, cela n'est pas possible dans notre montage. Nous devons donc ajouter dans notre milieu une autre solution tampon, n'ayant pas besoin de dioxyde de carbone, l'HEPES (N-2-[Hydroxyethyl]piperazine]N'-[2ethansulfonicacid]; Gibco). La concentration efficace est de $25 \mathrm{mM}$, soit $2,5 \% \mathrm{du}$ mélange total pour une solution d'HEPES à $1 \mathrm{M}$.

Le milieu de culture utilisé avec la chambre de culture, selon les protocoles présentés en Annexe B, nous permet d'observer des cellules qui poursuivent leur cycle pendant plusieurs jours après leur introduction dans la chambre de culture. Toutefois, il faut à présent s'assurer que ce développement n'est pas perturbé par le laser que nous utilisons pendant nos expériences.

\section{3) Choix du faisceau laser}

La littérature montre que l'illumination d'une cellule par un faisceau laser peut provoquer des dommages ou des modifications de son comportement. Ces dommages sont principalement fonction de deux paramètres. Le premier paramètre est la puissance du faisceau, qui si elle est trop importante entraînera la mort de la cellule. Dans notre cas, il faut également prendre en compte le fait qu'une fois le faisceau focalisé, l'énergie par unité de surface du faisceau qui passera par le noyau de la cellule sera fortement augmentée. Les effets calorifiques qui en résultent pourraient provoquer des dommages au noyau. Le deuxième paramètre qui peut être à l'origine de dommages causés au noyau de la cellule est la longueur d'onde du faisceau.

\section{3-1) Choix de la longueur d'onde}

Pour trouver la longueur d'onde la plus adaptée à notre montage, nous nous sommes fondé sur les travaux menées par Ashkin et al. (1987) et Neuman et al. (1999), pour les longueurs 
d'onde se situant dans l'infrarouge, et sur ceux de de With et Greulich (1995), pour des longueurs d'onde allant de l'ultraviolet au rouge. Les résultats concordent pour différents types cellulaires et montrent que celles qui provoquent le moins de dommages aux cellules se situent dans l'infrarouge autour de 830 et de $970 \mathrm{~nm}$. Toutefois, il est nettement plus facile de travailler avec un faisceau laser visible, notamment pour s'assurer qu'il est bien dans le noyau de la cellule. De With et Greulich (1995) montrent que les longueurs d'onde dans le visible qui créent le plus de dommages se situent autour de $400 \mathrm{~nm}$ (bleu). A l'inverse, ils notent beaucoup moins de dommages pour une longueur d'onde de $640 \mathrm{~nm}$ (rouge). Nous avons donc, naturellement, était amené à utiliser un laser rouge pour nos expériences. Nous avons choisi d'utiliser un laser He-Ne (Coherent) avec une longueur d'onde de 632,8 nm.

\section{3-2) Effet de l'irradiation d'une cellule par un laser He-Ne}

Plusieurs travaux semblent, toutefois, montrer que les lasers He-Ne peuvent induire des mutations pour certains types cellulaires. Ainsi, Schkorbatov (1999) note une décondensation de la chromatine chez des cellules épithéliales après irradiation pendant 1 seconde à une puissance de $1 \mathrm{~mW} . \mathrm{cm}^{-2}$, soit un temps d'exposition et une puissance relativement faible. L'exposition de globules rouges à ce type de laser provoque un changement dans leurs propriétés rhéologiques (Mi et al., 2004). D’autres expériences (Stein et al., 2005) mettent en évidence l'augmentation des capacités prolifératives des ostéoblastes toujours suite à une irradiation avec un He-Ne. A l'inverse, les fibroblastes ont plutôt tendance à rester en G0/G1, voire à apoptoser, après exposition (Shu et al., 2002). Une autre étude (Morales et al., 1995) montre que, pour des puissances pouvant dépasser les $10 \mathrm{~mW}$, ces lasers n'ont aucun effet sur les adénocarcinomes. Les effets sont donc très variables d'une lignée cellulaire à une autre. Les cellules que nous utilisons sont de la lignée SHEP-Neuroblastomes. A notre connaissance, l'effet de l'illumination par un laser He-Ne sur ce type de cellule n'a encore jamais été observé. Nous avons donc mené plusieurs expériences afin de s'assurer que ce type de laser ne modifie pas le comportement des cellules. Elles ont consisté à irradier, avec une puissance de $10 \mathrm{~mW}$, le noyau de plusieurs cellules pendant différents temps puis à observer leur comportement par vidéomicroscopie time-lapse. Pour chaque expérience, nous avons veillé à ce que les conditions soient à chaque fois identiques. Ainsi :

- les cellules étaient maintenues durant tout le test dans du milieu de culture à $37^{\circ} \mathrm{C}$. Nous avons également fait en sorte que la confluence des cellules ne soit pas trop importante (typiquement moins de 60\%) au début de l'expérience. Cela afin de s'assurer qu'elles soient dans des conditions de croissance optimale.

- concernant l'observation, nous avons veillé à ce qu'au moins une dizaine de cellules soient dans le champ du microscope. Seule une d'entre elles était irradiée. Les autres ont servi de témoin. Les observations ont été menées jusqu'à 24 heures après irradiation.

A chaque expérience correspondait un temps d'irradiation. Celui-ci pouvait varier de une demi-heure à 6 heures. Chacun de ces temps a été testé plusieurs fois. L'irradiation était considérée comme sans effet lorsque la cellule irradiée ne présentait aucune différence du point de vue du comportement ou du développement avec les autres. Nous avons alors pu déterminer les temps d'irradiation dangereux pour la cellule. C'est ainsi que les irradiations ayant duré moins de trois heures ont été considérées comme sans effet. Par contre une irradiation de trois heures et plus entraînait l'apoptose de la cellule.

Le laser que nous utilisons ne semble provoquer de dommages aux SHEP-Neuroblastomes que pour des temps largement supérieurs aux quelques minutes que durent nos mesures. De plus, rappelons que nous pouvons encore réduire la puissance du laser grâce à la lame $\lambda / 2$ et au cube séparateur de faisceau (Figure 3-3). Typiquement, la puissance de travail que nous avons utilisée se situe entre 0,1 et $0,5 \mathrm{~mW}$. Les cellules ne devraient donc pas subir de dommages pendant nos mesures. 


\section{VII> Contrôle du cycle cellulaire}

Nous utilisons le montage de diffusion de la lumière que nous avons construit pour étudier la dynamique interne du noyau lors d'un processus biologique particulier: le cycle cellulaire. L'objectif de cette étude est de voir si la dynamique interne du noyau est liée aux phases du cycle cellulaire.

On voit tout de suite que le problème majeur va être de mener les expériences sur des cellules dont on connaît la phase du cycle cellulaire à l'instant de la mesure. Pour cela, nous avons du établir un protocole qui nous permet de « contrôler » le cycle cellulaire des SHEP et donc de connaître, à un instant donné, la phase du cycle dans laquelle se trouvent les cellules.

\section{1) Répartition des cellules SHEP dans le cycle cellulaire}

Dans un premier temps, nous avons cherché à connaître la répartition dans le cycle cellulaire d'une population «normale » de cellules SHEP. Nous avons étudié cette répartition par des expériences de cytométrie en flux (CMF ; voir Annexe C). Pour cela, nous avons utilisé des cellules cultivées en boîtes de Pétri dans un incubateur à $\mathrm{CO}_{2}$. Pour s'assurer qu'elles étaient en phase de croissance exponentielle, nous avons réalisé l'expérience avant qu'elles n'occupent plus de $60 \%$ de la surface de la boîte (taux d'occupation évalué par microscopie optique). L'analyse par CMF a été réalisée sur une population de 20000 cellules et montre qu'environ $64 \%$ des cellules sont en G0/1, $14 \%$ en S et $22 \%$ en G2+M (Figure 3-11). Nous avons cherché un moyen d'augmenter significativement ces statistiques.

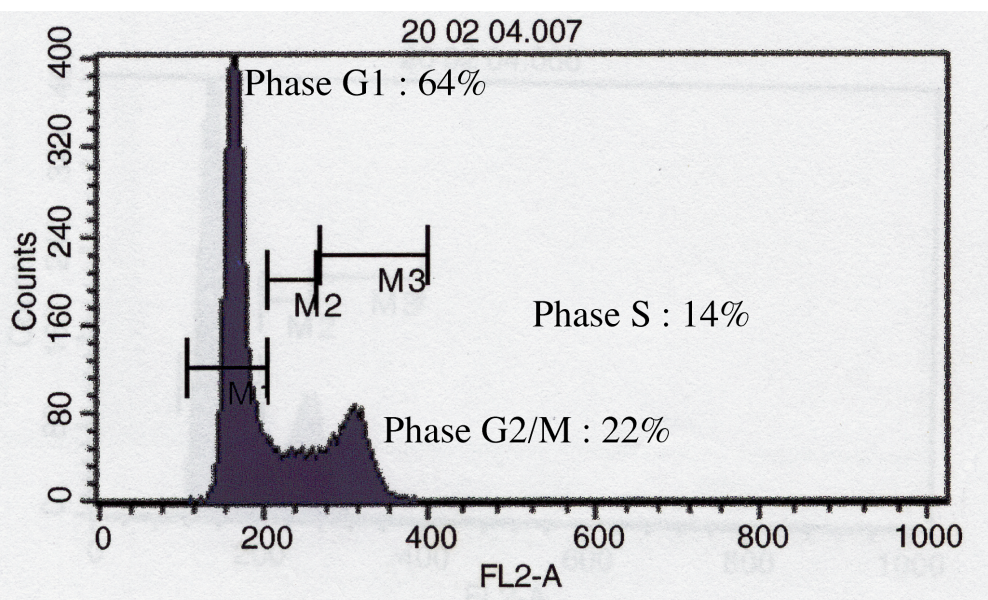

Figure 3-11 : Analyse par cytométrie en flux (voir Annexe C) de la répartition d'une population de SHEP-Neuroblastomes dans les différentes phases du cycle cellulaire; histogramme représentant le nombre de cellules en fonction de la fluorescence émise par leur noyau (unités arbitraires). Expérience réalisée sur une population de 20000 cellules, cultivées en boîte de Pétri. Le pourcentage de cellules dans chaque phase du cycle est déterminé par la surface de chaque pic défini par des zones d'intérêt.

\section{2) Blocage du cycle cellulaire par un agent pharmacologique cytobloquant : HU}

Un moyen simple et efficace d'augmenter le pourcentage de cellule dans chaque phase du cycle consiste à induire l'accumulation des cellules dans une phase donnée, puis à leur permettre de repartir dans le cycle. On peut ainsi espérer qu'elles restent synchronisées sur plusieurs heures. La manière la plus courante de bloquer une population de cellules dans une phase donnée du cycle cellulaire consiste à ajouter au milieu de culture un agent pharmacologique cytobloquant. Fulda et al. (1995) ont testé l'effet de 19 de ces agents sur 
différentes lignées de neuroblastomes (ne comprenant toutefois pas les SHEP). Nous nous sommes intéressés à l'hydroxyurée (HU). Elle fait partie de celles qui sont considérées comme les plus efficaces pour bloquer le cycle des cellules. De plus son utilisation est relativement bien maîtrisée par le laboratoire de biologie avec lequel nous avons collaboré. Ajoutée à une concentration adaptée au milieu de culture, cette drogue inhibe une enzyme essentielle au démarrage de la réplication de l'ADN (Jong et al., 1998 ; Danielle et al., 2003 ; Koc et al. 2004) bloquant, ainsi, les cellules à la transition entre la phase G1 et la phase S. Les cellules bloquées vont, alors, s'accumuler dans la phase G1. L'effet de HU est réversible après lavage des cellules et remise en culture dans du milieu neuf. Les cellules entrent alors de façon synchronisée en phase S (Mutomba et Wang, 1996). Notons, toutefois, que les effets de HU peuvent être très différents en fonction des cellules et de la concentration utilisée. Bien qu'ils utilisent des lignées de la même famille de cellules, des neuroblastomes, Fulda et al. (1995) notent des résultats assez variables sur l'action des agents cytobloquants d'une lignée à l'autre. De même, Mutomba et Wang (1996), montrent que pour certains types de cellules HU n'inhibe pas la synthèse d'ADN. Elle les bloque plutôt à la transition G2+M ou M/G1. Il est également important de remarquer que HU peut avoir un effet toxique sur certaines cellules selon les concentrations utilisées (Danielle et al., 2003). Il est donc nécessaire d'établir un protocole précis pour son utilisation sur nos cellules.

\section{3) Effet de HU sur les cellules SHEP}

Nous avons mené plusieurs séries d'expériences afin de trouver le bon protocole d'utilisation de HU sur nos cellules. Ces expériences ont concerné deux paramètres clés de l'utilisation de HU :

- la concentration dans le milieu de culture : nous avons déjà fait état d'une certaine toxicité de HU: une concentration trop importante pourrait provoquer la mort des cellules (Danielle et al., 2003). D'un autre coté, une concentration trop faible n'aurait pas d'effet suffisant sur le cycle cellulaire des SHEP.

- le temps d'exposition avant changement de milieu: rappelons que l'effet de HU est supprimé en remplaçant le milieu de culture par du milieu neuf. Il est nécessaire d'éliminer HU pour plusieurs raisons. Tout d'abord, il convient d'éliminer d'éventuels effets sur la dynamique du noyau, ce qui pourrait fausser les résultats des expériences de diffusion de la lumière. Ensuite, l'élimination de HU permet de relâcher les cellules de façon synchronisée dans le cycle cellulaire. Enfin, il ne faut pas négliger d'éventuels effets toxiques sur le long terme.

Les tests de ces deux paramètres ont été menés en parallèle de deux façon différentes :

- $\operatorname{par} C M F$ : la CMF nous a servi à établir avec exactitude la manière dont les cellules sont bloquées dans le cycle et leur synchronisation suite à l'inhibition de HU.

- par vidéomicroscopie time-lapse dans notre montage : les mesures par CMF étant réalisées sur des cellules cultivées en boîte de Pétri dans un incubateur à $\mathrm{CO}_{2}$, il est essentiel de s'assurer que le comportement des cellules est identique dans notre montage où elles ne sont plus sous $\mathrm{CO}_{2}$ et où elles adhèrent sur du verre.

Le protocole de culture des cellules avant l'ajout de HU a été établi de sorte à optimiser l'effet de HU sur les cellules. Pour cela, les cellules sont cultivées en boîte de Pétri dans un incubateur à $\mathrm{CO}_{2}$ jusqu'à atteindre $80 \%$ de confluence ${ }^{10}$ (taux d'occupation du fond de la boîte de Pétri par les cellules). Ensuite, elles sont remises en culture au 5/10 (voir Annexe B) dans une boîte de Pétri. Après 48 heures, les cellules sont arrivées à un tel niveau de confluence que le milieu de culture s'appauvrit très rapidement. Les cellules arrêtent alors leur prolifération, et se multiplient de nouveau après leur remise en culture. En les remettant

${ }^{10}$ Le taux de confluence de la boîte est établi par visualisation au microscope. 
en culture au 4/10 on s'assure qu'une large majorité reprendra le cycle en phase G1. Selon l'expérience que l'on veut mener, les cellules sont remises en culture :

- en boîtes de Pétri pour les analyses par CMF,

- dans la chambre de culture pour le suivi par vidéomicroscopie dans notre montage.

HU est ajouté 3 heures après avoir remis en culture les cellules au 4/10 (temps nécessaire aux cellules pour adhérer correctement au support), à la concentration souhaitée, dans les boîtes de Pétri ou dans la chambre de culture. HU bloquant les cellules à la transition G1/S, quelques heures après son ajout, la plupart des cellules auront atteint ce stade.

\section{3-1) Concentration efficace de $\mathrm{HU}$}

La littérature montre un large panel d'expériences sur le comportement des cellules en fonction de la concentration en HU du milieu de culture. Ainsi, Fulda et al. (1995) notent une baisse de $50 \%$ de l'activité proliférative de différentes lignées de neuroblastomes pour des concentrations de HU variant entre $10^{-2}$ et $8.10^{-2} \mathrm{mM}$. Rappelons, toutefois, que les effets peuvent être très différents d'une lignée à une autre. Dans le même temps, Jong et al. (1998) remarquent une baisse significative de l'activité des enzymes inhibées par HU avec des concentrations variant entre 0,2 et $1 \mathrm{mM}$. D'un autre coté, Olmos et al. (2005) montrent qu'une concentration légèrement supérieure à $1 \mathrm{mM}$ entraîne l'apoptose de cellules de type lymphomes (lignée DA-1). Afin de faire un premier tri dans le choix de la concentration la plus adaptée aux SHEP-Neuroblastomes, nous avons observé leur développement par vidéomicroscopie time-lapse, dans le montage de diffusion de la lumière, pour trois concentrations différentes de HU dans le milieu de culture : 0,1, 0,2 et 0,5 mM. Le facteur déterminant était le temps au bout duquel un nombre élevé de mitoses (plus de $80 \%$ des cellules visualisées) était observé. Ainsi, pour une concentration de $0,1 \mathrm{mM}$, ce temps était d'environ 16 heures, pour une concentration de $0,2 \mathrm{mM}$ ce temps était d'environ 20 heures et enfin, ce temps était d'environ 48 heures pour une concentration de $0,5 \mathrm{mM}$. Cette dernière concentration semble donc être la plus efficace. De plus elle ne semble pas toxique pour les cellules puisque non seulement on n'observe pas un nombre significatif de cellules en apoptoses, mais surtout les cellules finissent par se diviser. Nous avons alors comparé ces observations avec les résultats obtenus par CMF pour une population de cellules cultivées dans une boîte de Pétri sous incubateur à $\mathrm{CO}_{2}$. Les résultats obtenus nous ont également permis d'observer le développement des cellules pour cette concentration de HU.

Ainsi, les cellules ont été cultivées en boîte de Pétri selon le protocole de culture avant l'ajout de HU présenté plus haut. Au temps $t=0$, le milieu de culture est remplacé par un milieu contenant une concentration de $0,5 \mathrm{mM}$ de $\mathrm{HU}$. Une première mesure nous a permis d'établir que le taux de cellules en G0/1 est alors d'environ $90 \%$, le taux de cellules en S d'environ $4 \%$ et le taux de cellules en G2+M d'environ 6\%. Les boîtes sont, ensuite, analysées par CMF 6 heures, 10 heures, 15 heures, 18 heures, 21 heures, 24 heures, 36 heures et 48 heures après l'addition de HU. Leur évolution est comparée à celle de cellules témoins, toujours préparées selon le même protocole. La Figure 3-12 montre l'évolution comparée des cellules témoins et des cellules traitées par HU. 
A

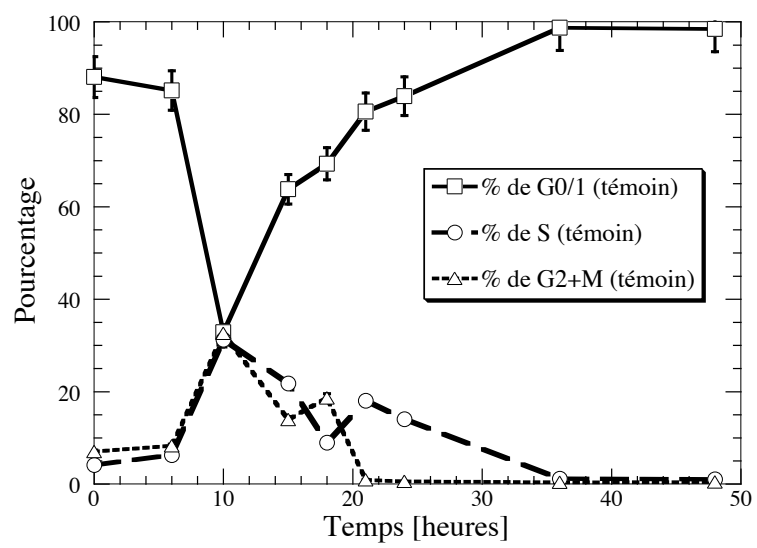

B

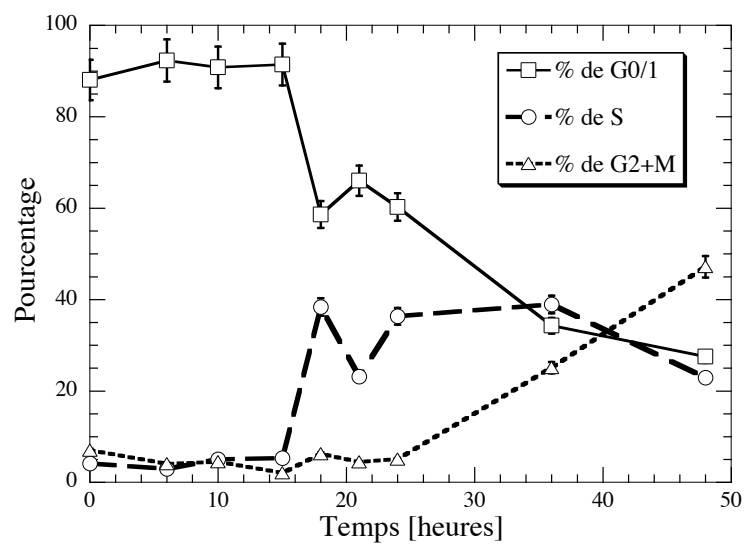

Figure 3-12 : Observation par CMF de l'évolution dans le cycle cellulaire d'une population de cellules sous $H U$ (concentration 0,5 $\mathrm{mM}$ ). HU est ajouté à $t=0$ et n'est pas éliminé tout le long de l'expérience. Chaque mesure est réalisée sur 20000 cellules dont environ 3/4 servent à établir les statistiques. A. Evolution des cellules témoins (sans HU). B. Evolution des cellules sous HU 0,5 $\mathrm{mM}$.

Concernant les cellules témoins, nous observons que :

- $90 \%$ des cellules sont en G0/16 heures après le début de l'expérience. A 10 heure, elles ne sont plus qu'environ $30 \%$ en $\mathrm{G} 0 / 1$.

- à 15 heure, on note une croissance rapide du nombre de cellules en G0/1 et une décroissance du nombre de cellule en $\mathrm{S}$ et en $\mathrm{G} 2+\mathrm{M}$.

- la croissance du taux de cellules en G0/1 se poursuit jusqu'à la $36^{\text {ème }}$ heure. Puis il se stabilise à plus de $90 \%$. Les résultats observés à 15 heures sont typiques d'un grand nombre de mitoses. Ces mitoses entraînent une surpopulation de la boîte et par conséquence un ralentissement du cycle des cellules d'où le grand nombre de cellules en G0/1 jusqu'à 24 heures. La stabilisation du taux de cellules en G0/1 à plus de $90 \%$ à partir de 36 heures pourrait signifier que les cellules sont devenues quiescentes (cycle cellulaire quasiment arrêté).

Si le comportement des cellules sous HU est comparable jusqu'à la $6^{\text {ème }}$ heure, il devient radicalement différent par la suite. On remarque alors que :

- les cellules sous HU sont à plus de $90 \%$ en G0/1 jusqu'à environ 15 heures après l'ajout de HU.

- dès la $18^{\text {ème }}$ heure on observe une décroissance du taux de cellules en G0/1 et une croissance du nombre de cellules en phase S. La décroissance du taux de G0/1 continue jusqu'à la fin de l'expérience tandis que l'on note une croissance très nette du taux de G2.

Nous pouvons déduire que dès la $18^{\text {ème }}$ heure, les effets de HU commencent à se dissiper. Toutefois, le taux toujours élevé de cellule en G2+M à 48 heures (proche de 50\%) et la décroissance du taux de cellules en G0/1 montrent qu'aucune mitose n'a encore eu lieu à ce moment. Ces résultats semblent donc parfaitement en accord avec les observations que nous avons mené par vidéomicroscopie time-lapse. Ainsi, même si HU ne bloque plus le cycle des cellules à partir de 15-18 heures, il le ralentit considérablement. Il faut, à présent, établir le comportement des cellules suite à différents temps d'exposition à HU à 0,5 mM. 


\section{3-2) Temps d'exposition à $H U$}

Après avoir déterminé la concentration la plus efficace de HU, nous souhaitons maintenant synchroniser les cellules dans un cycle cellulaire normal. Nous allons donc déterminer le moment où l'inhibition de HU nous garantit la meilleure synchronisation pendant la plus longue durée. Nous nous sommes fondés sur les résultats de l'expérience où nous avons laissé les cellules sous HU pendant 48 heures, pour établir les temps susceptibles d'être les plus adaptés. Nous avons ainsi choisi d'inhiber HU 10 heures et 15 heures après ajout. En effet, 10 heures après ajout, les cellules sont à plus de $90 \%$ en G0/1 et ne passent en S qu'entre 5 et 8 heures plus tard. Eliminer HU à ce moment doit permettre de conserver un maximum de cellules en G0/1 pendant un temps relativement long. Ensuite les cellules passant en S entre 15 et 18 heures, nous pouvons déduire que la majorité des cellules doit avoir atteint la limite G1/S autour de 15 heures. En éliminant HU, à ce moment, on peut s'attendre à avoir la meilleure synchronisation possible pour le reste du cycle cellulaire. Nous avons mené plusieurs séries d'expériences pour lesquelles HU a été respectivement rincé à chacun de ces temps $t$. Avant l'ajout de HU, les cellules ont toutes été cultivées selon le protocole décrit au début du paragraphe. Nous avons, à chaque fois, analysé par CMF la répartition des cellules dans le cycle à $t+1$ heure, $t+4$ heures, $t+7$ heures et $t+10$ heures. Le Tableau 3-2 et le Tableau 3-3 présentent les résultats obtenus lors de ces expériences. Dans le même temps, un lot identique de cellules est observé par vidéomicroscopie time-lapse dans le montage de diffusion de la lumière.

\begin{tabular}{|r||r|r|r|}
\hline $\begin{array}{c}\text { Temps après } \\
\text { HU (Heures) }\end{array}$ & $\begin{array}{c}\text { \% de cellules en } \\
\text { phase G0/1 }\end{array}$ & $\begin{array}{c}\text { \% de cellules en } \\
\text { phase S }\end{array}$ & $\begin{array}{c}\text { \% de cellules en } \\
\text { phase G2+M }\end{array}$ \\
\hline \hline $1: 00$ & 88 & 7 & 5 \\
\hline $4: 00$ & 66 & 28 & 6 \\
\hline $7: 00$ & 43 & 45 & 12 \\
\hline $10: 00$ & 41 & 45 & 14 \\
\hline
\end{tabular}

Tableau 3-2 : Analyse par CMF de la répartition dans le cycle cellulaire d'une population de cellules restée pendant 10 h00 sous HU. Chaque mesure est réalisée sur 20000 cellules dont environ 3/4 servent à établir les statistiques.

\begin{tabular}{|r||r|r|r|}
\hline $\begin{array}{c}\text { Temps après } \\
\text { HU (Heures) }\end{array}$ & $\begin{array}{c}\text { \% de cellules en } \\
\text { phase G0/1 }\end{array}$ & $\begin{array}{c}\text { \% de cellules en } \\
\text { phase S }\end{array}$ & $\begin{array}{c}\text { \% de cellules en } \\
\text { phase G2+M }\end{array}$ \\
\hline \hline $1: 00$ & 92 & 6 & 2 \\
\hline $4: 00$ & 30 & 54 & 16 \\
\hline $7: 00$ & 26 & 29 & 45 \\
\hline $10: 00$ & 79 & 14 & 7 \\
\hline
\end{tabular}

Tableau 3-3 : Analyse par CMF de la répartition dans le cycle cellulaire d'une population de cellules restée pendant 15 h00 sous HU. Chaque mesure est réalisée sur 20000 cellules dont environ 3/4 servent à établir les statistiques.

Ainsi :

- lorsque HU est inhibé à $t=10$ heures, on observe une période de 7 heures pendant laquelle la phase G0/1 domine nettement les autres. 7 heures après l'inhibition, la phase $\mathrm{S}$ devient légèrement dominante par rapport la phase G0/1. Dans le même temps, on n'observe aucune mitose dans le montage de diffusion de la lumière.

- lorsque HU est inhibé à $t=15$ heures, les cellules sont à près de $60 \%$ en $\mathrm{S}$ au bout de trois heures. Trois heures après une majorité des cellules (près de 55\%) sont en phase G2+M. Le pic de cellules en phase G0/1 (80\%) et la baisse significative du taux de 
cellules en $\mathrm{G} 2+\mathrm{M}$ (moins de 10\%) 10 heures après l'inhibition indique que les cellules ont pour la plupart déjà effectué leur mitose à ce moment. Concernant l'observation dans le montage de diffusion de la lumière, on observe un grand nombre de mitoses entre 9 et 10 heures après l'ajout de HU.

Les analyses menées par CMF permettent, ainsi, d'appréhender au mieux les effets de HU sur les cellules SHEP. L'observation en parallèle de cellules dans la chambre de culture, placé dans le montage de diffusion de la lumière, montre que l'évolution des cellules est similaire à celle obtenue en cultivant les cellules en boîte de Pétri dans un incubateur à $\mathrm{CO}_{2}$. Nous sommes en mesure de maintenir, dans notre montage, une majorité de cellules pendant plusieurs heures dans n'importe quelle phase du cycle. Ainsi :

- pour la phase G0/1 : en éliminant HU après 10 heures, pendant 7 heures le taux de cellules en G0/1 est nettement majoritaire par rapport à celui des autres phases du cycle. Nous disposons ainsi d'une fenêtre relativement longue pour étudier la phase $\mathrm{G} 0 / 1$.

- pour la phase $\mathrm{S}$ : en éliminant HU après 15 heures, nous disposons d'une fenêtre de 3 heures durant laquelle plus de $60 \%$ des cellules sont en phase $\mathrm{S}$ ce qui est suffisant pour pouvoir étudier cette phase. Nous avons également une majorité de cellules en phase $\mathrm{S}, 7$ heures après avoir inhibé HU à $t=10$ heures.

- pour la phase G2 : à partir de 6 heures après élimination de HU à $t=15$ heures, nous disposons d'une fenêtre de 2-3 heures durant laquelle la grande majorité des cellules est en phase G2.

- pour la phase M : il suffit d'attendre les nombreuses mitoses que l'on observe entre 9 et 10 heures après élimination de HU à $t=15$ heures.

\section{VIII> Conclusion}

Nous disposons, à présent d'un montage expérimental qui nous permet de focaliser un faisceau laser sur le noyau d'une cellule vivante. Nous pouvons ensuite récupérer et analyser l'intensité de la lumière diffusée. Les cellules sont maintenues dans un bon état physiologique et nous sommes également capable de contrôler la phase du cycle dans laquelle elles se trouvent. Nous pouvons à présent observer la dynamique du noyau en fonction du cycle cellulaire.

\section{BIBLIOGRAPHIE}

- Ashkin A, Dziedzic JM et Yamane T. (1987) Optical trapping and manipulation of single cells using infrared laser beams. Nature. 330 : 769-771.

- Backman V, Wallace MB, Perelman LT, Arendt JT, Gurjar R, Müller MG, Zhang Q, Zonios G, Kline E, McGillican T, Shapshay S, Valdez T, Badizadegan K, Crawford JM, Fitzmaurice M, Kabani S, Levin HS, Seiler M, Dasari RR, Itzkan I, Van Dam J, Feld MS. (2000) Detection of preinvasive cancer cells. Nature. 406 : 35-36.

- Bern BJ et Pecora R. Dynamic Light Scattering. Wiley \& Sons, New York. 1976.

- Bloomfield VA. Biological Applications dans Dynamic Light Scattering (Chapitre 9). Edité par Pecora R. Plenum Press. New York. 1985.

- Chu B. Laser Light Scattering. Basic Principles and Practice. Academic Press, London. 1991.

- Danielle Lima de Lima P, Cerqueira Dos Santos Cardoso P, Khayat AS, de Oliveira Bahia M et Burbano RR. (2003) Evaluation of mutagenic activity of Hydroxyurea on the G1-S- 
G2 phases of the cell cycle : an in vitro study. Genetics and Molecular Research. 2 : 328 333.

- de With A et Greulich KO. (1995) Wavelength dependence of laser-induced DNA damage in lymphocytes observed by single-cell gel electrophoresis. Journal of photochemistry and photobiology B. 30 : 71-76.

- Fulda S, Honer M, Menke-Moellers I et Berthold F. (1995) Antiproliferative potential of cytostatic drugs on neuroblastoma cells in vitro. European Journal of Cancer. 31A : 616621.

- Goillot E, Raingeaud J, Ranger A, Tepper RI, Davis RJ, Harlow E et Sanchez I. (1997) Mitogen-activated protein kinase-mediated Fas apoptotic signaling pathway. PNAS. 94 : 3302-3307.

- Jong AY, Yu K, Zhou B, Frgala T, Reynolds CP et Yen Y. (1998) A simple and sensitive ribonucleotide reductase assay. Journal of Biomedical Science. 5 : 62-68.

- Kaplan PD, Trappe V et Weitz DA. (1999) Light-scattering microscope. Applied Optics. 38 : 4151-4157.

- Koc A, Wheeler LJ, Mathews CK et Merrill GF. (2004) Hydroxyurea arrests DNA replication by a mechanism that preserves basal dNTP pools. Journal of Biological Chemistry. 279 : 223-230.

- Lamb DC, Müller BK et Bräuchle C. (2005) Enhancing the sensitivity of fluorescence correlation spectroscopy by using time-correlated single photon counting. Current Pharmaceutical Biotechnology. 6 : 405-414.

- Lowary PT et Widom J. (1989) Higher-order structure of Saccharomyces cerevisiae chromatin. PNAS. $86: 8266-8270$.

- Mi XQ, Chen JY, Liang ZJ, Zhou LW. (2004) In vitro effects of helium-neon laser irradiation on human blood: blood viscosity and deformability of erythrocytes. Photomedicine and Laser Surgery. 22 : 477-482.

- Morales JA, Ruiz-Gomez MJ, Gil-Carmona L, Souviron A et Martinez-Morillo M. (1995) He-Ne laser has no effect on cell cycle phases of human colon adenocarcinoma cells. Revista Española de Fisiología (en anglais). 51 : 43-47.

- Mourant JR, Hielscher AH, Eick AA, Johnson TM et Freyer JP. (1998) Evidence of intrinsic differences in the light scattering properties of tumorigenic and nontumorigenic cells. Cancer. 84 : 366-374.

- Mourant JR, Canpolat M, Brocker C, Esponda-Ramos O, Johnson TM, Matanock A, Stetter K et Freyer JP. (2000) Light scattering from cells: the contribution of the nucleus and the effects of proliferative status. Journal of Biomedical Optics. 5 : 131-137.

- Mutomba MC et Wang CC. (1996) Effects of aphidicolin and hydroxyurea on the cell cycle and differentiation of Trypanosoma brucei bloodstream forms. Molecular and Biochemical Parasitology. 80 : 89-102.

- Neuman KC, Chadd EH, Liou GF, Bergman K et Block SM. (1999) Characterization of photodamage to escherichia coli in optical traps. Biophysical Journal. 77 : 2856-2863.

- Olmos G, Prieto A, Herraez A, Tejedor MC, Alvarez-Mon M et Diez JC. (2005) Quantitation of apoptosis induction by etoposide or hydroxyurea in mouse interleukin 3dependent lymphoma cells. In Vivo. 19 : 455-464.

- Ross GM, Shamovsky IL, Lawrance G, Solc M, Dostaler SM, Jimmo SL, Weaver DF et Riopelle RJ. (1997) Zinc alters conformation and inhibits biological activities of nerve growth factor and related neurotrophins. Nature Medicine. 3 : 872-878.

- Ross GM, Shamovsky IL, Woo SB, Post JI, Vrkljan PN, Lawrance G, Solc M, Dostaler SM, Neet KE et Riopelle RJ. (1998) The binding of zinc and copper ions to nerve growth factor is differentially affected by $\mathrm{pH}$ : implications for cerebral acidosis. Journal of Neurochemistry. 78 : 515-523. 
- Shckorbatov YG. (1999) He-Ne laser light induced changes in the state of chromatin in human cells. Naturwissenschaften (en anglais). $86: 452-453$.

- Shu B, Wu Z, Hao L, Zeng D, Feng G et Lin Y. (2002) Experimental study on He-Ne laser irradiation to inhibit scar fibroblast growth in culture. Chinese journal of traumatology. $\mathbf{5}$ : 246-249.

- Sosnovtseva OV, Pavlov AN, Brazhe NA, Brazhe AR, Erokhova LA, Maksimov GV et Mosekilde E. (2005) Interference microscopy under double-wavelet analysis: a new approach to studying cell dynamics. Physical Review Letters. 94 : 218103.

- Srinivas SP, Bonanno JA, Lariviere E, Jans D et Van Driessche W. (2003) Measurement of rapid changes in cell volume by forward light scattering. Pflügers Archiv : European journal of physiology. $447:$ 97-108.

- Stein A, Benayahu D, Maltz L et Oron U. (2005) Low-level laser irradiation promotes proliferation and differentiation of human osteoblasts in vitro. Photomedicine and Laser Surgery. 23 : 161-166.

- Vukojevic V, Pramanik A, Yakovleva T, Rigler R, Terenius L et Bakalkin G. (2005) Study of molecular events in cells by fluorescence correlation spectroscopy. Cellular and Molecular Life Sciences. 62 : 535-550.

- Wang W, Post JI, Dow KE, Shin SH, Riopelle RJ et Ross GM. (1999) Zinc and copper inhibit nerve growth factor-mediated protection from oxidative stress-induced apoptosis. Neuroscience Letters. 259 : 115-118. 


\section{Chapitre 4 : RESULTATS ET DISCUSSION}

Dans ce chapitre, nous allons décrire les expériences que nous avons réalisées ainsi que les résultats que nous avons obtenus. Nous finirons ce chapitre par une discussion dans laquelle nous décrirons les hypothèses pouvant expliquer nos résultats puis nous aborderons les nombreuses questions qu'ils soulèvent.

\section{I> Forme général du signal}

Nous commencerons par exposer la forme générale des signaux : nous commenterons la forme générale du signal brut, puis la forme générale des courbes d'autocorrélation ainsi que les paramètres auxquels ces dernières permettent d'accéder. Puis, dans un deuxième temps, nous analyserons ces résultats en fonction de la phase du cycle cellulaire dans laquelle se trouvent les cellules.

\section{1) Signal non-stationnaire}

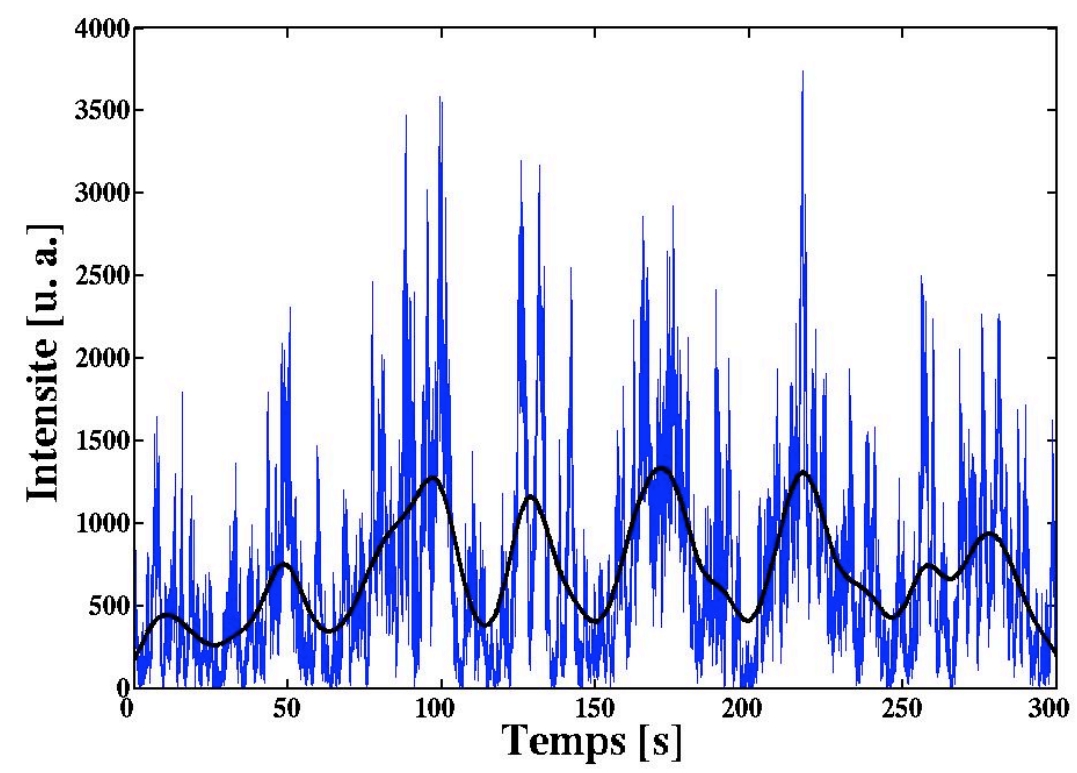

Figure 4-1 : Intensité de la lumière diffusée par le noyau d'une cellule en phase G0/1 en fonction du temps. Le temps d'échantillonnage de la carte d'acquisition est de $1 \mathrm{~ms}$. L'acquisition a été réalisée sur 5 minutes. En trait foncé : les modulations du signal sur des temps longs (courbe obtenue en moyennant le signal sur $30 \mathrm{~s}$ ).

\section{1-1) Signal brut}

L'intensité de la lumière diffusée par le noyau d'une cellule en phase G0/1 en fonction du temps est représentée en Figure 4-1. Le signal est caractéristique des signaux obtenus avec un temps d'échantillonnage d' $1 \mathrm{~ms}$. Cet enregistrement correspond à une mesure de 5 minutes, temps volontairement plus long que ceux que nous avons utilisés lors de la plupart des expériences, afin de pouvoir observer clairement ses variations sur des temps longs. Grâce au système de visualisation présenté au chapitre 3, nous avons vérifié pendant l'acquisition de tous les signaux que les mouvements des cellules étaient infimes et qu'aucun objet à l'intérieur de l'échantillon (cellules mortes, particules du milieu,...) n'était passé entre le 
faisceau laser et le noyau de la cellule, ce qui aurait pu provoquer de brusques bonds de l'intensité de la lumière diffusée.

A
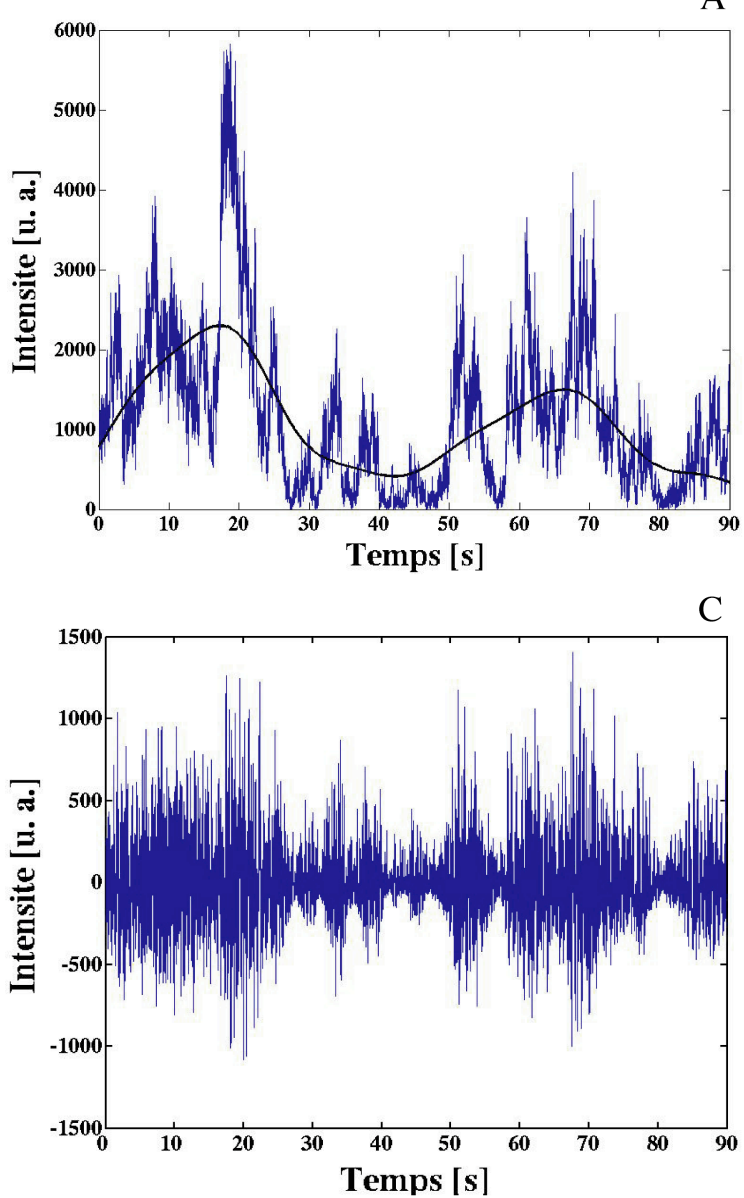

$\mathrm{B}$
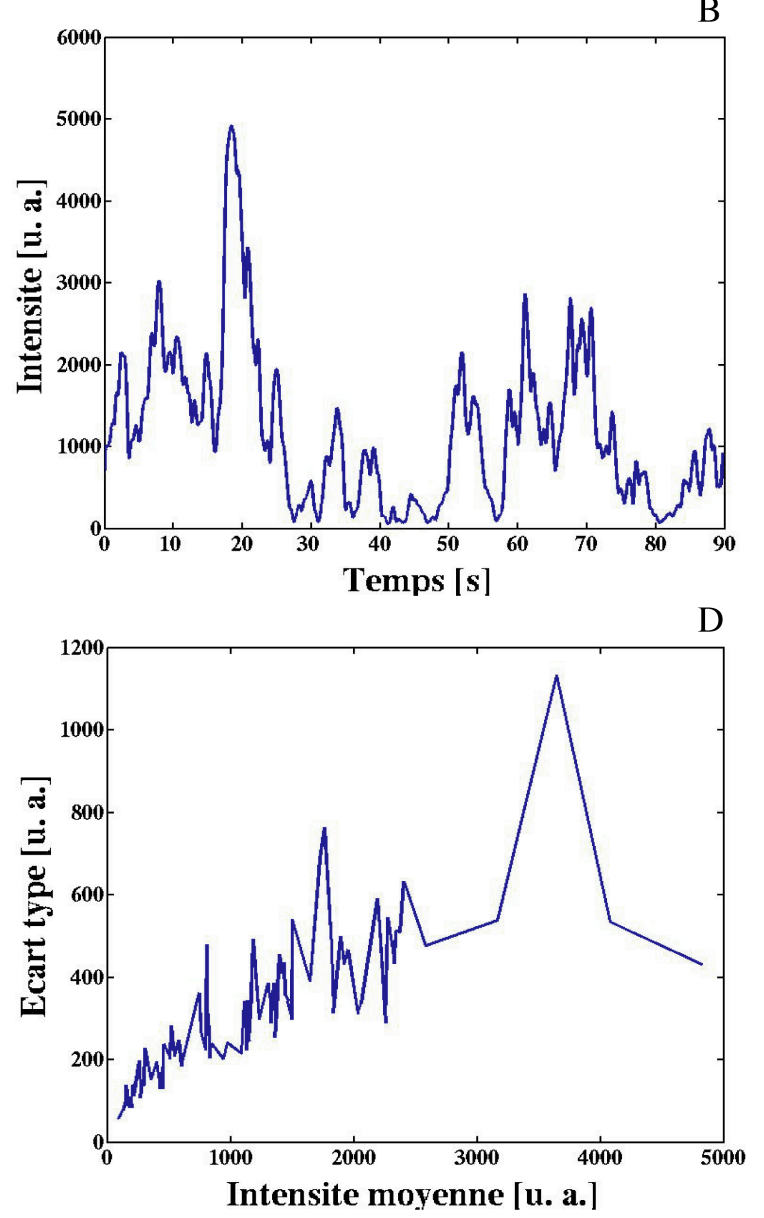

Figure 4-2 : Moyenne et bruit du signal correspondant à l'intensité de la lumière diffusée par le noyau d'une cellule vivante, en phase G0/1, en fonction du temps. Le temps d'échantillonnage de la carte d'acquisition est de $1 \mathrm{~ms}$. Les mesures ont été effectuées pendant 90 s. A. Signal brut sur 90 s et modulation du signal sur temps longs (courbe obtenue en moyennant le signal sur $30 \mathrm{~s})$. B. Signal brut moyenné sur $1 \mathrm{~s} . \boldsymbol{C}$. Bruit autour de la moyenne (Signal-Moyenne). D. Ecart type en fonction de la moyenne de l'intensité sur chaque seconde.

Nous pouvons immédiatement remarquer que les signaux sont non-stationnaires, ce qui est en accord avec le fait que le noyau de la cellule est un système hors-équilibre (voir chapitre 3). A chaque fois, on observe une modulation sur des temps longs du signal dont le temps caractéristique semble être d'environ 30-40 s. On observe également des pics d'intensité toutes les 8 à $10 \mathrm{~s}$ (qui sont plus aisément observables sur le signal moyenné sur 1 s comme présenté en Figure 4-2 B). Sur ces variations du signal s'ajoute du bruit (variations de l'intensité sur des temps très courts). Pour éviter de générer des fichiers trop volumineux, nous avons limité le temps d'acquisition à $90 \mathrm{~s}$. La Figure 4-2 A montre un signal type pour une acquisition de $90 \mathrm{~s}$, toujours sur une cellule en phase G0/1. On retrouve les mêmes caractéristiques que nous avons décrites pour l'acquisition sur 5 min (Figure 4-2). La Figure 4-2 B présente le signal moyenné sur $1 \mathrm{~s}$. On observe clairement les modulations à temps long ainsi que les pics d'intensité. La Figure 4-2 C représente le bruit autour de la moyenne (moyenne sur $1 \mathrm{~s}$ soustraite au signal brut). Il est essentiellement composé de variations 
rapides dont l'amplitude varie fortement. On remarque que l'amplitude du bruit est liée à l'intensité du signal comme on peut le voir sur la Figure 4-2 D qui montre clairement que l'intensité du bruit (écart type autour de la moyenne) croît en fonction de la moyenne. Une analyse du bruit par une simple transformée de Fourier ne permet pas d'extraire des fréquences ou des temps caractéristiques particuliers.

Ces premières observations montrent que l'ensemble du signal, aussi bien la moyenne du signal brut que le bruit, contient des informations sur la dynamique du volume diffusant. A l'heure actuelle le traitement du signal brut est en cours : nous nous orientons vers un traitement en ondelettes pour déterminer les temps caractéristiques du signal, ce qui est une analyse relativement complexe. Il était, donc, beaucoup plus direct et plus simple de commencer à travailler à partir des mesures des fonctions d'autocorrélation du signal.

\section{1-2) Informations données par la fonction d'autocorrélation du signal}

Comme le signal brut est non-stationnaire chaque mesure de la fonction d'autocorrélation du signal ne donne pas l'ensemble de la dynamique du noyau, mais correspond à un « instantané» de ses propriétés dynamiques à l'instant de la mesure. De ce fait, pour obtenir l'ensemble de la dynamique du noyau, il est nécessaire de répéter les mesures de la fonction d'autocorrélation un grand nombre de fois.

Les informations que nous obtenons grâce aux fonctions d'autocorrélation du signal ne concernent qu'une partie des informations contenues dans le signal brut. Comme la gamme de temps de décalage (voir chapitre 3) sur laquelle le corrélateur est efficace se situe entre $10^{-5}$ et $10 \mathrm{~s}$, il ne sera donc pas possible d'analyser les modulations sur des temps longs que nous observons sur les signaux bruts (dont les temps caractéristiques semblent être de plusieurs dizaines de secondes).

Ensuite, pour les temps de décalage proches de $10 \mathrm{~s}$, pour que la statistique de la fonction d'autocorrélation soit satisfaisante, la mesure devrait être faite pendant un temps de l'ordre de $1000 \mathrm{~s}$. Mais, sur cette durée, la statistique est fortement perturbée par les modulations du signal sur les temps de l'ordre de $30 \mathrm{~s}$, ce qui demande des temps de mesures encore plus longs (bien supérieurs à l'heure). Lors des mesures que nous avons effectuées sur des durées supérieures ou égales à 5 minutes (Figure 4-1), nous avons rencontré des problèmes car, dans à peu près un tiers des cas, les mouvements de la cellule faisaient sortir le noyau du faisceau laser avant la fin de la mesure. Il n'est, de ce fait, pas envisageable de faire des mesures sur des temps plus longs que 5 minutes. En conséquence, nous ne pourrons pas obtenir des informations fiables sur les pics observés toutes les 8-10 s. Par contre, les fonctions d'autocorrélation nous permettent d'accéder aux informations contenues dans le bruit (Figure 4-2 C), c'est-à-dire, sur les dynamiques plus rapides du signal.

\section{2) Autocorrélation du signal}

La mesure de la fonction d'autocorrélation du signal est effectuée par la carte corrélateur BI9000AT présentée au chapitre 3. Dans un premier temps, nous verrons de quelle façon nous avons paramétré la carte. Puis, nous regarderons la forme générale de la fonction d'autocorrélation obtenue pour toutes les mesures. Nous expliciterons alors les paramètres auxquels elle nous donne accès.

\section{2-1) Paramétrage de l'autocorrélateur}

Comme nous venons de l'expliquer, il est très difficile de faire des mesures sur des temps très longs. Il n'est donc pas raisonnable, pour des raisons expérimentales, de choisir une gamme de temps dont la limite supérieure est $10 \mathrm{~s}$. D'un autre coté, des mesures préliminaires ont montré qu'une limite supérieure, pour les temps de décalage, inférieurs à la seconde n'était pas appropriée à cause de l'existence d'un temps caractéristique de l'ordre de la seconde (voir 
Figure 4-3). Nous avons donc choisi de fixer cette limite supérieure à $1 \mathrm{~s}$. Le plus petit temps de décalage a été fixé, dans un premier temps, à $10^{-5} \mathrm{~s}$. Nous couvrons ainsi 5 décades en temps. Nous paramétrons le BI9000AT de sorte que le nombre de canaux demandés $M$ soit égal à 500 (voir chapitre 3). Dans cette configuration, le corrélateur n'utilise en fait que 399 canaux, soit 101 canaux de moins que le nombre demandé. Il utilise le corrélateur à vitesse moyenne, avec un temps d'échantillonnage de $10^{-6} \mathrm{~s}$, sur tous les temps de décalage compris entre $10^{-5} \mathrm{~s}$ et $11,63.10^{-2} \mathrm{~s}$ soit 256 canaux. Le reste des canaux est traité avec le corrélateur lent. Il utilise un temps d'échantillonnage de $1 \mathrm{~s}$, sur les 143 canaux restants. Par la suite, nous nous sommes aperçus qu'il n'était pas nécessaire de réaliser l'autocorrélation sur une gamme de temps aussi étendue. Nous avons donc utilisé une gamme de temps de décalage allant de $10^{-4} \mathrm{~s}$ à $1 \mathrm{~s}$, ne couvrant ainsi que 4 décades de temps caractéristiques. Dans cette configuration, le corrélateur utilise 453 canaux, soit 27 canaux de moins que le nombre demandé. Il utilise le corrélateur à vitesse moyenne, avec un temps d'échantillonnage de $10^{-6}$ $\mathrm{s}$, sur tous les temps de décalage compris entre $10^{-5} \mathrm{~s}$ et $2,63.10^{-2} \mathrm{~s}$ soit 256 canaux. Le reste des canaux est traité avec le corrélateur lent. Il utilise un temps d'échantillonnage de $200.10^{-3}$ s, sur les 143 canaux restants. Le changement de gamme de temps n'entraînant pas de modifications des résultats nous ne préciserons pas par la suite les mesures ayant été faites avec l'une ou l'autre gamme.

\section{2-2) Temps de mesure}

Concernant le temps pendant lequel nous avons effectué l'autocorrélation, il est choisi en fonction de plusieurs contraintes. Le signal étant non-stationnaire, même pour une gamme de temps de décalage allant jusqu'à la seconde, la durée de la mesure doit être d'au moins un quart d'heure pour espérer obtenir une bonne statistique pour les plus grands temps de décalage. Une telle durée de mesure est toujours trop grande. Nous avons fait des tests pour voir l'influence du temps de mesures sur les fonctions d'autocorrélation. Nous avons fait varier le temps de mesure entre 30 et 300 s. Nous n'avons pas remarqué de différences significatives entre les mesures effectuées pendant $60 \mathrm{~s}$ et celles effectuées sur $300 \mathrm{~s}$. Il est plus judicieux de choisir le temps de mesure le plus court possible. En effet, plus le temps de mesure est petit par rapport au temps d'évolution du système plus la « résolution » de nos résultats sera meilleure. De plus, la probabilité que se produise un incident (passage d'un objet devant le faisceau laser, déplacement de la cellule,...) pouvant « détruire » la fonction d'autocorrélation lors de sa construction par le corrélateur est évidemment plus faible pour un temps de mesure plus court. Enfin, comme les mesures doivent être répétées un grand nombre de fois, si l'on veut pouvoir faire des mesures sur plusieurs noyaux au cours de la même phase du cycle cellulaire, il est beaucoup plus pratique de faire les mesures sur un temps court. Nous avons donc choisi d'effectuer les mesures sur $60 \mathrm{~s}$.

Les informations sur la dynamique du volume diffusant seront obtenues grâce à l'ajustement de la fonction d'autocorrélation.

\section{2-3) Forme générale de la courbe d'autocorrélation}

Les fonctions d'autocorrélation de l'intensité lumineuse diffusée par les noyaux des cellules vivantes ont toutes les mêmes caractéristiques. L'allure de ces fonctions est identique pour toutes les expériences effectuées, que ce soit pour les mesures dans différentes phases du cycle cellulaire, mais aussi pour les mesures effectuées sur des cellules en contact avec HU. 
A

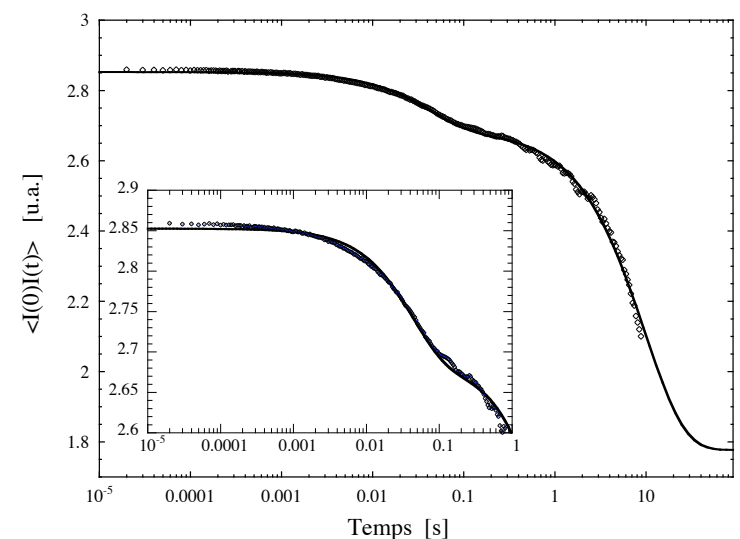

$\mathrm{B}$

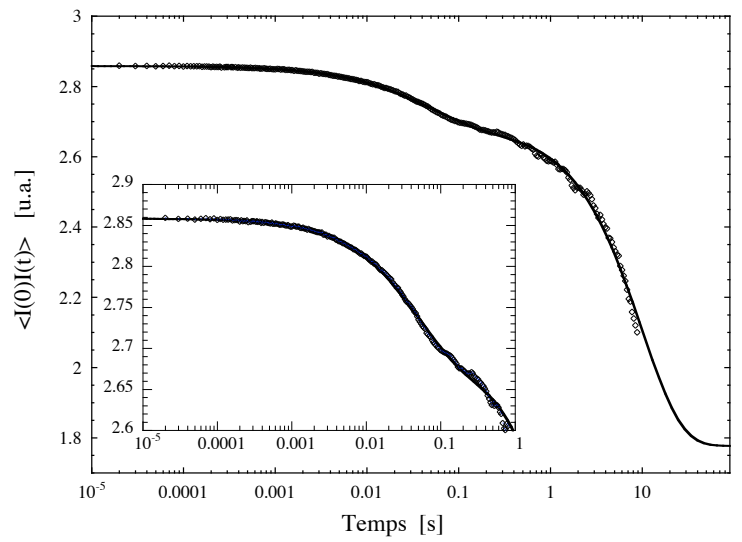

Figure 4-3 : Forme générale de la fonction d'autocorrélation de l'intensité de la lumière diffusée présentée sur une échelle semi-log. A. La fonction est ajustée par une somme d'exponentielle décroissante dont l'équation est de la même forme que l'équation (4-1). L'encart représente un agrandissement de la première décroissance et de son ajustement. $\boldsymbol{B}$. La fonction est ajustée par une somme d'exponentielle décroissante dont l'équation est de la même forme que l'équation (4-2). L'encart représente un agrandissement de la première décroissance et de son ajustement.

La forme générale de la fonction d'autocorrélation retournée par la carte corrélateur est présentée en Figure 4-3. Cette fonction présente clairement deux taux de relaxation différents et ne rejoint pas de ligne de base, comme l'on pouvait d'ailleurs s'y attendre. En effet, la ligne de base est difficilement mesurée car le signal est non-stationnaire (à titre de comparaison, on pourra regarder la ligne de base obtenue lors de l'expérience sur les billes de latex en Figure 3-8). La plupart des fonctions d'autocorrélation obtenues peuvent s'ajuster, assez correctement, par une somme de deux exponentielles décroissantes et d'une ligne de base. Puisque la géométrie de notre montage est homodyne, la fonction d'ajustement est :

$$
\langle I(0) I(t)\rangle=\left(A_{1} \exp \left(-\frac{1}{\tau_{1}} t\right)+A_{2} \exp \left(-\frac{1}{\tau_{2}} t\right)\right)^{2}+C(4-1)
$$

où $\tau_{1}$ et $\tau_{2}$ sont les deux temps caractéristiques du signal correspondant chacun à un taux de relaxation, $A_{1}$ et $A_{2}$ les amplitudes respectives des deux exponentielles et $\boldsymbol{C}$ la ligne de base. Cependant, nous nous sommes rapidement aperçus que l'ajustement était bien meilleur pour toutes les fonctions d'autocorrélation mesurées lorsque la première exponentielle était étirée (ce qui signifie que la première exponentielle décroît moins rapidement qu'une exponentielle normale). Donc, plutôt que d'ajuster la fonction d'autocorrélation par la fonction (4-1) nous avons utilisé la fonction suivante :

$$
\langle I(0) I(t)\rangle=\left(A_{1} \exp \left(-\left(\frac{1}{\tau_{1}} t\right)^{\alpha}\right)+A_{2} \exp \left(-\frac{1}{\tau_{2}} t\right)\right)^{2}+C(4-2)
$$

où $\alpha<1$ est le coefficient d'étirement.

Nous trouvons donc deux temps de relaxation. Le premier, $\tau_{1}$, le plus rapide des deux, est toujours de l'ordre de quelques dizaines de millisecondes. Le deuxième, $\tau_{2}$, est entre 10 et 100 fois plus lent que $\tau_{1}$ et varie, donc, autour de $1 \mathrm{~s}$. Pour toutes les mesures, l'amplitude du mode rapide est toujours inférieure à l'amplitude du mode lent. Typiquement, suivant les fonctions d'autocorrélation mesurées, $\boldsymbol{A}_{1}$ représente entre 10 et $30 \%$ de la partie dynamique 
de la fonction d'autocorrélation. Le mode lent est donc nettement dominant. Les problèmes pour le calcul de la ligne de base font que l'estimation de $\boldsymbol{C}$ est assez approximative. Toutefois, si nous faisons différentes estimations pour un même signal, seul le temps de relaxation du mode lent, ainsi que son amplitude relative dans le signal dynamique, semblent réellement affectés (selon les estimations de la ligne de base, on peut observer des variations allant jusqu'à un facteur deux dans l'estimation du temps de relaxation $\tau_{2}$ ).

En résumé, l'ajustement des fonctions d'autocorrélation de l'intensité diffusée donne accès à 6 paramètres, dont 5 peuvent, a priori, contenir des informations pertinentes sur la dynamique du volume diffusant ${ }^{1}$ :

- $A_{1}, 1$ 'amplitude du mode rapide,

- $\tau_{1}$, temps de relaxation du mode rapide,

- $\alpha$, coefficient d'étirement de la première exponentielle,

- $A_{2}$, l'amplitude du mode lent,

- $\tau_{2}$, temps de relaxation du mode lent (qui peut être relativement imprécis à cause de l'estimation de la ligne de base).

Un sixième paramètre, qui peut-être lui aussi pertinent, nous est donné par la carte corrélateur. Il s'agit du nombre moyen de photons détectés par seconde par l'APD (voir chapitre 3) pendant la durée de la mesure : $\langle N\rangle$. $\langle N\rangle$ est donné en milliers de coups par seconde (kcps/s). Ce paramètre varie d'une mesure à l'autre à cause de la mauvaise statistique due aux variations du signal à temps long. De fait, lors d'une expérience, les variations de $\langle N\rangle$ nous renseignent indirectement sur les variations à temps long de l'intensité diffusée. Cependant $\langle N\rangle$ dépend de la puissance du laser que nous envoyons sur le noyau, paramètre contrôlé comme nous l'avons expliqué au chapitre 3, mais dépend, aussi, fortement du réglage, c'est à dire de la position du volume diffusant vu par le détecteur (Figure 3-1) qui est réglée par l'utilisateur. Pour chaque nouvelle expérience, les réglages doivent être refaits afin de s'assurer que le volume diffusant est bien dans le noyau de la cellule. Pour pouvoir comparer les variations de $\langle N\rangle$ sur différentes expériences, nous prenons comme référence le nombre moyen de photons détectés $\left\langle N_{\text {milieu }}\right\rangle$ lorsque le faisceau laser est focalisé à un endroit où il n'y a pas de cellule (diffusion uniquement due aux fluctuations de l'indice de réfraction du milieu de culture qui est le même pour chaque expérience).

\section{2-4) Propriétés des résultats, invariables au cours du cycle cellulaire}

Une fois toutes les fonctions d'autocorrélation ajustées, nous avons commencé par regarder si les 6 paramètres présentaient des corrélations, afin de savoir si nous pouvions les étudier indépendamment les uns des autres (il est, par exemple, important de savoir si $\tau_{1}$ et $\tau_{2}$ sont les temps caractéristiques de deux processus distincts ou d'un seul processus). Les figures présentées ici, correspondent aux résultats obtenus sur une expérience pour des cellules à majorité en $\mathrm{G} 0 / 1$. Les observations sont identiques pour toutes les expériences effectuées dans toutes les phases du cycle cellulaire, ainsi que pour les mesures effectuées sur des cellules sous HU.

En traçant les temps de relaxation rapides et lents en fonction du nombre moyen de photons détectés pendant une seconde (Figure 4-4 A et B), il apparaît qu'il n'y a aucune corrélation entre $\tau_{1}$ et $\langle N\rangle$ ni entre $\tau_{2}$ et $\langle N\rangle$. De même, on montre (Figure 4-4 C et D) qu'il n'y a pas de corrélation entre les temps de relaxations $\tau_{1}$ et $\tau_{2}$ et leurs contributions respectives à la partie dynamique de la fonction d'autocorrélation, respectivement:

\footnotetext{
${ }^{1} \boldsymbol{C}$ n'est pas un paramètre directement important dans l'étude de la dynamique du volume diffusant et rappelons, une nouvelle fois, que son estimation est très approximative. Il n'est donc pas inclus dans les paramètres étudiés.
} 
$A_{1} /\left(A_{1}+A_{2}\right)$ et $A_{2} /\left(A_{1}+A_{2}\right)$. Nous arrivons à la même conclusion en ce qui concerne les paramètres $A_{1} /\left(A_{1}+A_{2}\right)$, respectivement $A_{2} /\left(A_{1}+A_{2}\right)$, et $\langle N\rangle$ (Figure 4-4 E et F).
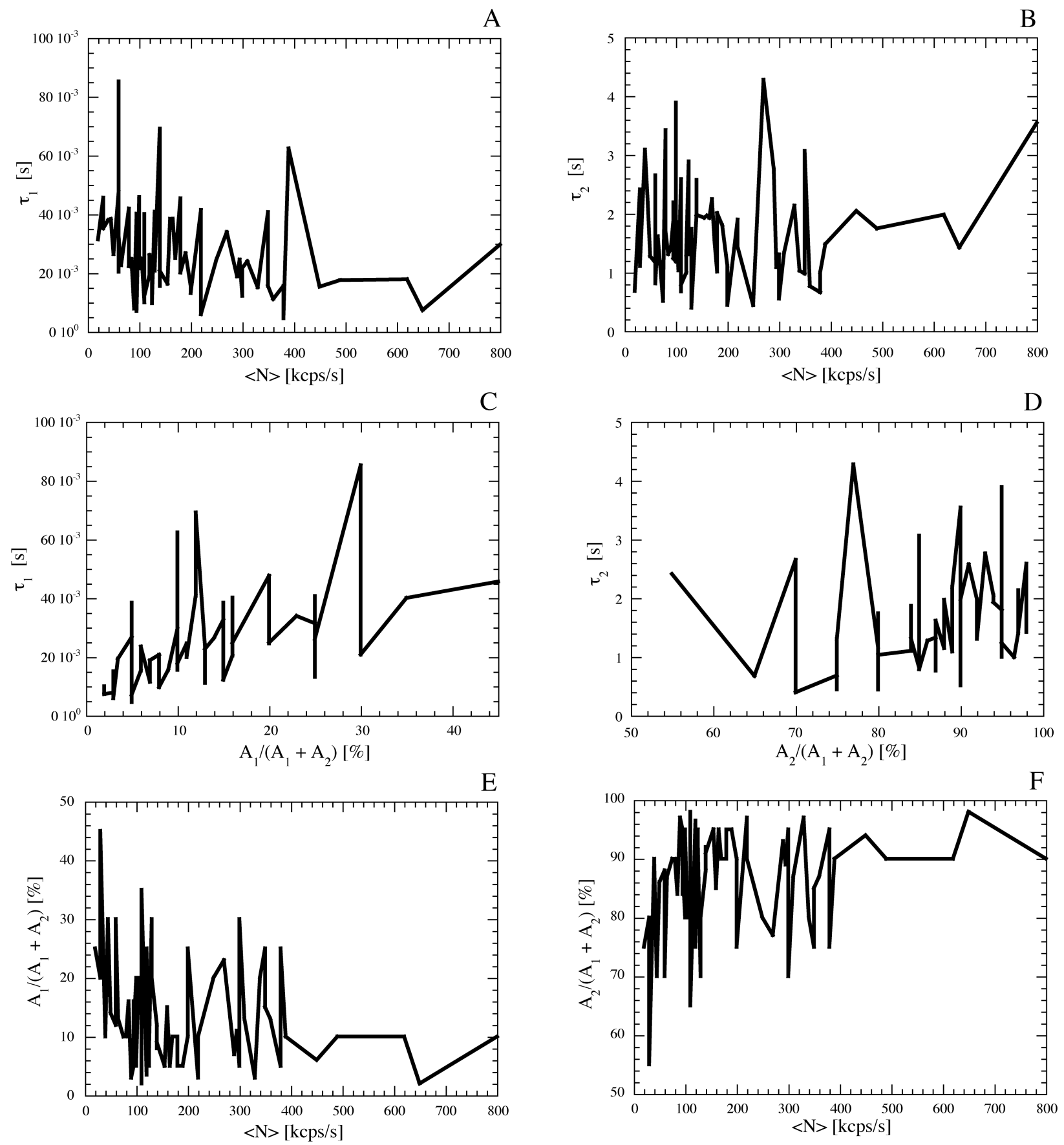

Figure 4-4 : Figures établies à partir d'environ 70 mesures, sur 10 noyaux différents, effectuées sur des cellules en G0/1 (même culture cellulaire pour toutes les mesures). $\boldsymbol{A}$ et $\boldsymbol{B}$. Respectivement, temps de relaxation $\tau_{1}$ et $\tau_{2}$ en fonction de $\langle N\rangle$. C et $\boldsymbol{D}$. Respectivement, temps de relaxation $\tau_{1}$ et $\tau_{2}$ en fonction de leur contribution dans la partie dynamique de la fonction d'autocorrélation. $\boldsymbol{E}$ et $\boldsymbol{F}$. Respectivement, contribution des temps de relaxation $\tau_{1}$ et $\tau_{2}$ en fonction de $\langle N\rangle$. 


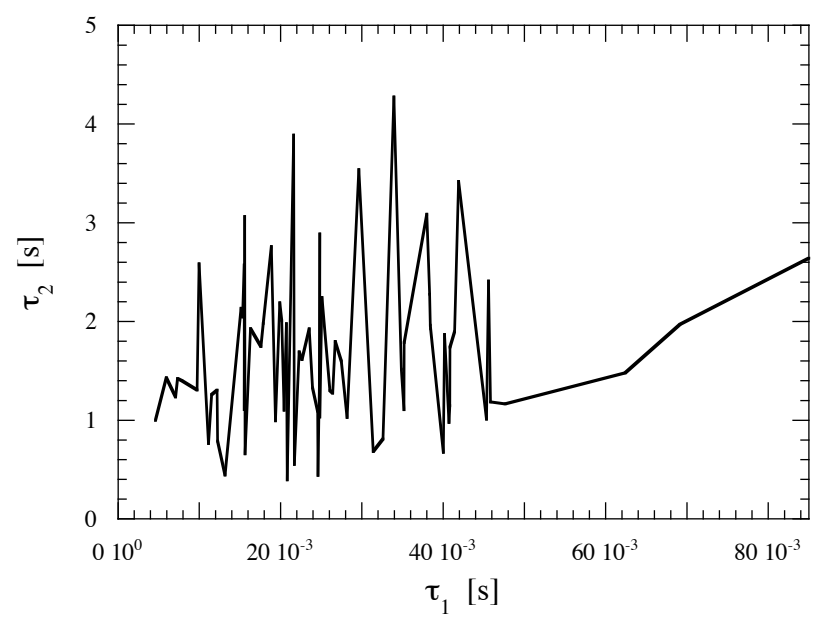

Figure 4-5 : $\tau_{2}$ en fonction de $\tau_{1}$. Figure établie à partir d'environ 70 mesures, sur 10 noyaux différents, effectuées sur des cellules en G0/1 (même culture cellulaire pour toutes les mesures).

Ensuite, nous avons tracé $\tau_{2}$ en fonction de $\tau_{1}$. Là encore, le graphe obtenu (Figure 4-5) montre clairement qu'il n'y a aucune dépendance entre ces deux paramètres et nous pouvons en conclure que nous sommes donc bien en présence de deux processus de relaxation indépendants l'un de l'autre. Enfin, la Figure 4-6 montre qu'il n'y a aucune dépendance entre le coefficient d'étirement $\alpha$ et $\tau_{1}$.

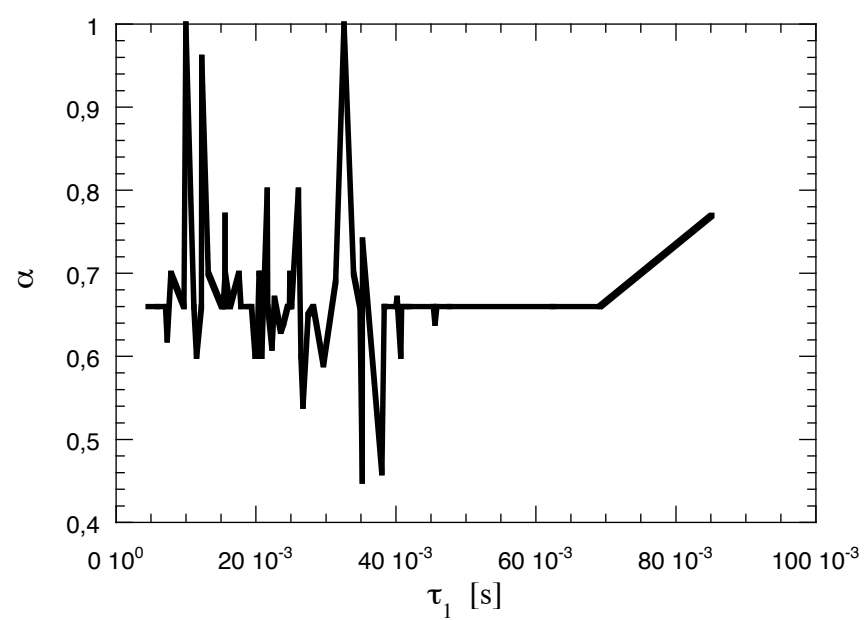

Figure 4-6 : $\alpha$ en fonction de $\tau_{1}$. Etabli à partir d'environ 70 mesures, sur 10 noyaux différents, effectuées sur des cellules en G0/1 (même culture cellulaire pour toutes les mesures).

Les 6 paramètres sont donc indépendants quelles que soient les expériences effectuées. Nous allons, à présent, nous intéresser plus en détail à leurs valeurs respectives lors des différentes phases du cycle cellulaire. 


\section{II> Valeurs des paramètres sous HU}

Les premières expériences que nous avons menées ont été réalisées sur des cellules sous HU. En commençant nos expériences sur ce système expérimental, notre but était, surtout, de "s'entraîner » et de voir si les propriétés dynamiques du noyau d'une cellule vivante dépendaient bien de la phase du cycle cellulaire dans laquelle la cellule se trouvait, comme nous en avions fait l'hypothèse. Pour cela, nous pensions qu'une population de cellules évoluant lentement au cours du temps était un système expérimental idéal. En effet, nous avons vu au chapitre 3 que placées sous HU, le cycle cellulaire des cellules se ralentissait considérablement. Pour résumer les résultats déjà discutés au chapitre 3 , nous rappelons que pour une population initiale avec près de $80 \%$ de cellules en phase $\mathrm{G} 0 / 1$, placée dans un milieu de culture contenant $0,5 \mathrm{mM}$ de $\mathrm{HU}$, nous observons que le taux de cellules en phases G0/1 dépasse $90 \%$ au bout de 6 heures et que ce pourcentage reste constant pendant plus de 10 heures (voir Figure 3-10, chapitre 3). Après 16 heures sous HU, nous observons que le taux de cellules en phase G0/1 commence à diminuer doucement alors que ceux des cellules en phases S et G2 augmentent. Après 33-34 heures sous HU, le nombre de cellules en phases $\mathrm{S}$ et $\mathrm{G} 2$ est supérieur au nombre de cellules en phase G0/1 (environ $35 \%$ de cellules en phase G0/1 et de $40 \%$ en phases $\mathrm{S}$ et $25 \%$ en phase G2).

Nous voyons ainsi qu'entre la $6^{\text {ème }}$ et la $16^{\text {ème }}$ heure, nous avons 10 heures pour réaliser des expériences sur des cellules qui sont à plus de $90 \%$ en phase G0/1. Alors qu'après la $34^{\text {ème }}$ heure, nous avons, là encore, 10 heures pour réaliser des expériences sur une population de cellules qu'on pourrait qualifier de asynchrone, dans laquelle les cellules en phase G0/1 sont minoritaires. Du fait de ces évolutions très lentes, il est possible, sur une même culture cellulaire, de faire beaucoup de mesures et d'avoir ainsi, rapidement, une statistique suffisante pour voir des tendances se dessiner.

Contrairement, aux expériences réaliser sur des cellules «libres » (sans HU dans le milieu) pour lesquelles nous avons regardé l'évolution de tous les paramètres auxquels nos mesures nous donnent accès, nous ne nous intéresserons, ici, qu'aux résultats concernant l'évolution des temps de relaxation $\tau_{1}$ et $\tau_{2}$. Pour toutes les expériences présentées dans cette partie, l'angle de diffusion était d'approximativement $21^{\circ}$ (soit environ $33^{\circ}$ pour l'angle de détection).

\section{1) Cellules en phase G0/1 sous HU}

Comme nous l'avons expliqué au chapitre 3 , les cellules sont introduites dans la chambre de culture avec un milieu de culture contenant $0,5 \mathrm{mM}$ de HU. La chambre est immédiatement bouchée hermétiquement, pour éviter tout contact avec l'extérieur, et laissée 3 heures en position horizontale dans un incubateur, pour permettre aux cellules d'adhérer sur la surface du bas, avant d'être montée sur le montage de diffusion de la lumière. Nous commençons nos expériences 9 heures après que les cellules ont été mises en contact avec HU.

Pour cette première étude, nous avons effectué 3 expériences différentes (c'est-à-dire sur des cultures cellulaires différentes). Pour chaque culture, entre 5 et 10 noyaux ont pu être utilisés. Nous avons ainsi mesuré 106 fonctions d'autocorrélation sur 23 noyaux différents.

\section{1-1) Temps $\tau_{1}$}

Le temps $\tau_{1}$ est extrait des ajustements des fonctions d'autocorrélation par l'équation (4-2), suivant la procédure que nous avons décrite un peu plus haut. L'exposant d'étirement $\alpha$ est toujours compris entre 0,6 et 0,9 . Pour chaque noyau étudié, nous obtenons une distribution $\tau_{1}$ et nous remarquons que ces mesures sont presque toutes comprises entre $5.10^{-3}$ et $70.10^{-3} \mathrm{~s}$ ( $87 \%$ des mesures sont comprises entre $15 \cdot 10^{-3}$ et $55.10^{-3} \mathrm{~s}$ ). Nous montrons ces résultats Figure 4-7 où, pour chaque noyau, nous donnons la gamme dans laquelle se situent les valeurs 
de $\tau_{1}$ mesurées. On remarque, tout de suite, que pour approximativement la moitié des noyaux, les valeurs de $\tau_{1}$ mesurées sont comprises entre $30.10^{-3}$ et $70.10^{-3} \mathrm{~s}$, alors que, pour l'autre moitié, les valeurs de $\tau_{1}$ mesurées sont comprises entre $15.10^{-3}$ et $40.10^{-3} \mathrm{~s}$. Seulement deux cellules présentent des temps $\tau_{1}$ inférieurs à $15.10^{-3} \mathrm{~s}$; dans la gamme $5.10^{-3}-20.10^{-3} \mathrm{~s}$.

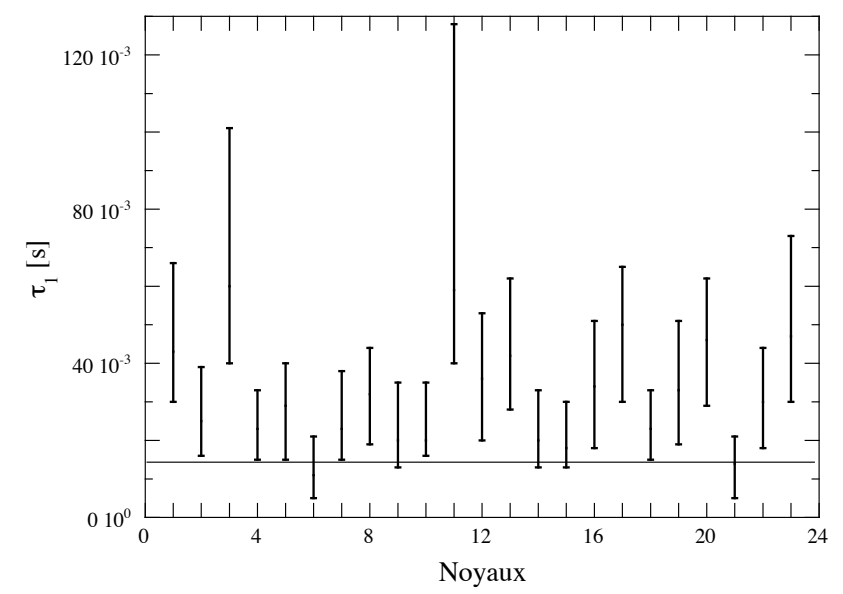

Figure 4-7 : Echelles sur lesquelles s'étendent les temps $\tau_{1}$ pour chaque noyau, pour des cellules en phase G0/1 sous $H U$.

A

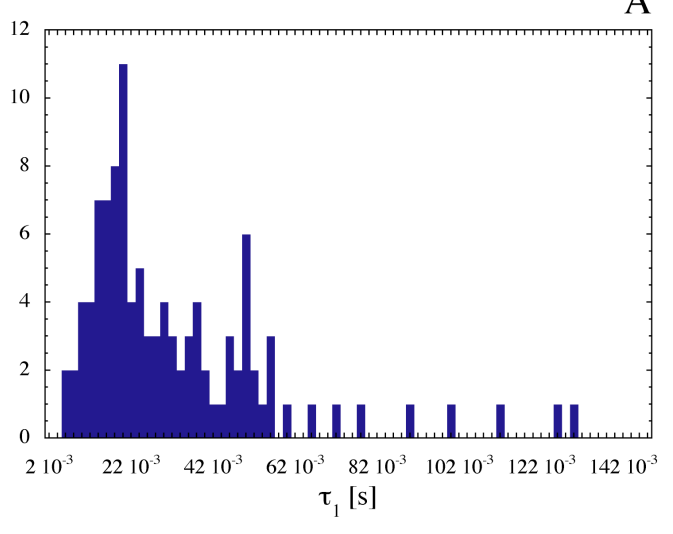

$\mathrm{C}$

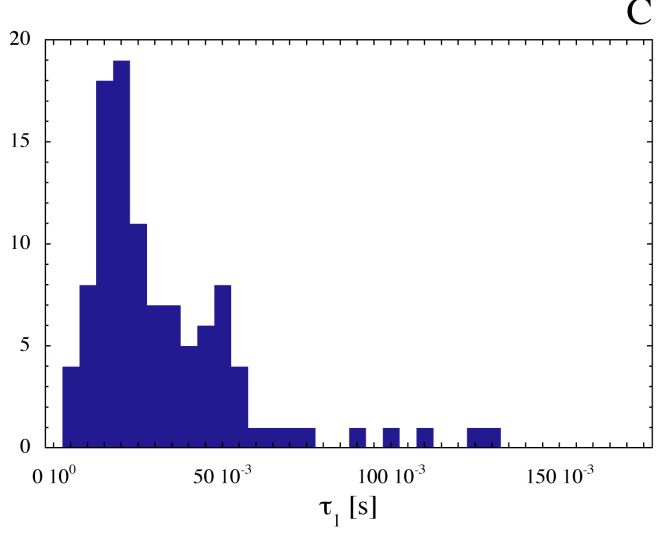

B

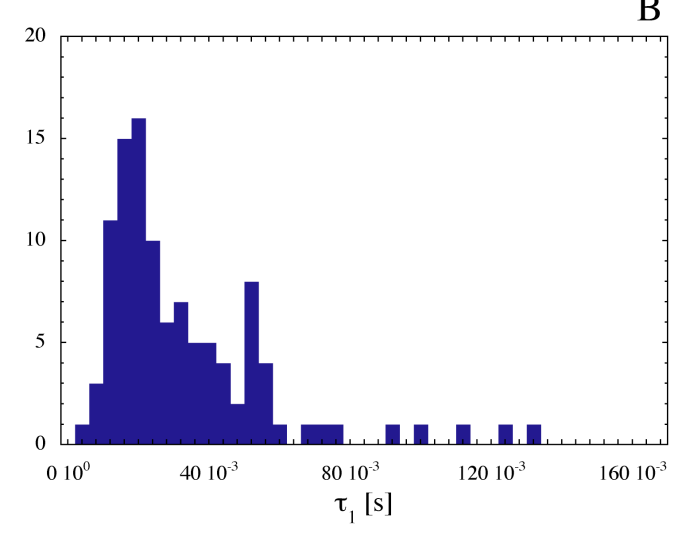

$\mathrm{D}$

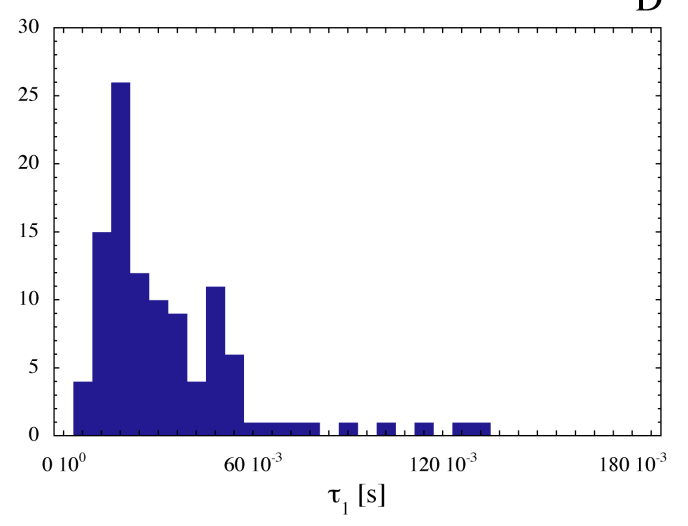

Figure 4-8 : Histogrammes sur la totalité des mesures du temps $\tau_{1}$ pour différents pas de temps $\delta t . A . \delta t=2 \cdot 10^{-3}$ s. $B . \delta t=4 \cdot 10^{-3}$ s. $C . \delta t=5 \cdot 10^{-3}$ s. $D . \delta t=6 \cdot 10^{-3} \mathrm{~s}$. 
La Figure 4-8 montre l'histogramme des mesures du temps $\tau_{1}$ réalisé en utilisant la totalité des 106 mesures. Nous avons réalisé plusieurs histogrammes en utilisant différents pas de temps (respectivement : $2.10^{-3}, 4.10^{-3}, 5.10^{-3}$ et $6.10^{-3} \mathrm{~s}$, Figure 4-8 A-D) pour voir l'effet de ce paramètre sur l'allure de la distribution du temps $\tau_{1}$. Nous voyons que l'allure de cette distribution ne change pas dramatiquement quand on change le pas de temps. Ainsi, on observe toujours deux « pics », l'un autour de $20.10^{-3} \mathrm{~s}$ et l'autre autour de $50.10^{-3} \mathrm{~s}$, ainsi qu'un «épaulement » autour de $30-35 \cdot 10^{-3} \mathrm{~s}$. Au début de cette discussion, nous avons déjà fait remarquer qu'il semblait y avoir deux types de noyaux avec des dynamiques rapides différentes. Ici, il nous semble intéressant de noter que, seulement, environ $13 \%$ des noyaux étudiés contribuent aux deux pics, tandis qu'environ $43 \%$ d'entre eux contribuent au pic à $20.10^{-3} \mathrm{~s}$ et $35 \%$ au pic à $50.10^{-3} \mathrm{~s}$. Ceci semble suggérer l'existence de deux types différents de dynamiques rapides pour les noyaux des cellules en phase G0/1 sous HU.

Dans la suite, pour pouvoir comparer les distributions obtenues sur les différentes phases du cycle cellulaire et ayant des statistiques différentes, nous utiliserons la distribution en probabilité (courbe représentative du poids des différentes valeurs possibles: taux de comptage donné par l'histogramme divisé par l'aire totale de l'histogramme). Dans toute la suite, pour l'analyse des distributions de $\tau_{1}$, nous utiliserons toujours l'histogramme obtenu avec un pas de temps de $4.10^{-3} \mathrm{~s}$ (on estime l'erreur sur la mesure de $\tau_{1}$ à $\pm 2.10^{-3} \mathrm{~s}$ ). Cette distribution en probabilité est présentée Figure 4-9.

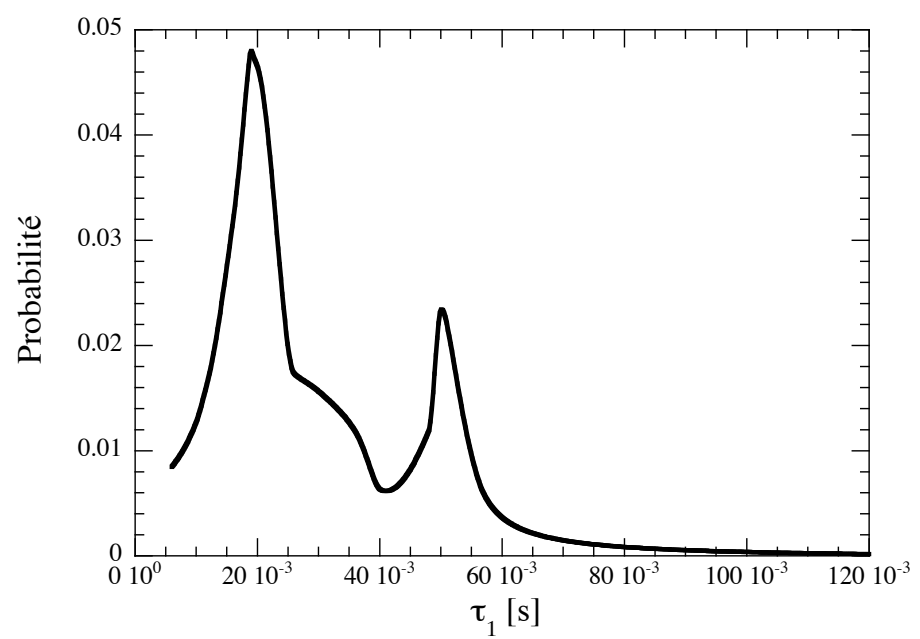

Figure 4-9 : Distribution en probabilité des temps $\tau_{1}$ pour des mesures réalisées sur des cellules en phase G0/1 sous $H U$.

\section{1-2) Temps $\tau_{2}$}

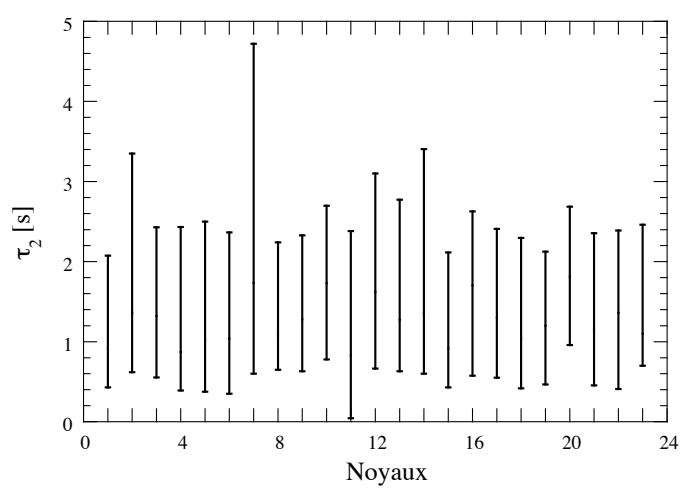

Figure 4-10 : Echelles sur lesquelles s'étendent les temps $\tau_{2}$ pour chaque noyau, pour des cellules en phase G0/1 sous $H U$. 
La Figure 4-10 montre les gammes dans lesquelles se trouvent les mesures du temps $\tau_{2}$ pour les différents noyaux. On observe que les valeurs mesurées se situent principalement entre 0,3 et $2,5 \mathrm{~s}$ (environ $86 \%$ des mesures). Comme nous l'avions indiqué au début de ce chapitre, elles sont au moins un ordre de grandeur au-dessus des valeurs observées pour le temps $\tau_{1}$. De plus, contrairement à ce que nous observons pour le temps $\tau_{1}$, pour chaque cellule, les mesures de $\tau_{2}$ balayent l'ensemble de la distribution.

La Figure 4-11 A montre l'histogramme du temps $\tau_{2}$ sur la totalité des 106 mesures avec un pas de temps de $0,25 \mathrm{~s}$. Pour $\tau_{2}$ aussi, prendre un pas de temps de $0,25 \mathrm{~s}$, ou de $0,5 \mathrm{~s}$, ne change pas, dramatiquement, l'allure de la distribution. Dans tous les cas, nous observons un pic unique centré sur 0,5 s avec une «queue » pour les temps longs. La Figure 4-11 B présente la distribution en probabilité obtenue à partir de l'histogramme de la Figure 4-11 A. Cette distribution en probabilité peut être ajustée (Figure 4-11 B) par la fonction densité d'une loi log-normale d'équation :

$$
f(x)=\frac{1}{x \sigma \sqrt{2 \pi}} \exp \left(\frac{1}{2 \sigma^{2}} \ln \left(\frac{x}{M}\right)^{2}\right)(4-3)
$$

où $\boldsymbol{M}$ et $\sigma$ sont telles que la moyenne de la distribution est égale à $M \exp \left(\frac{\sigma^{2}}{2}\right)$ et l'écart type à $\sqrt{M^{2} \exp \left(\sigma^{2}\right)\left(\exp \left(\sigma^{2}\right)-1\right)}$. Nous obtenons, ainsi, une moyenne $1,35 \mathrm{~s}$ et un écart type autour de la moyenne de $0,9 \mathrm{~s}$.

A

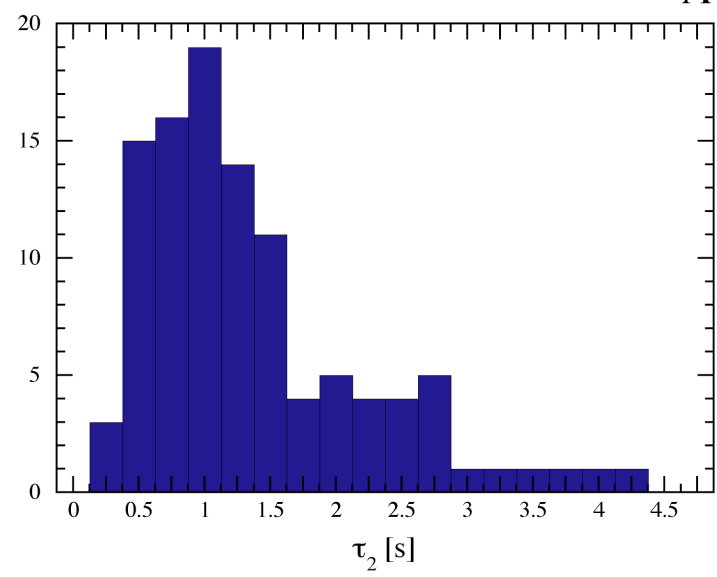

B

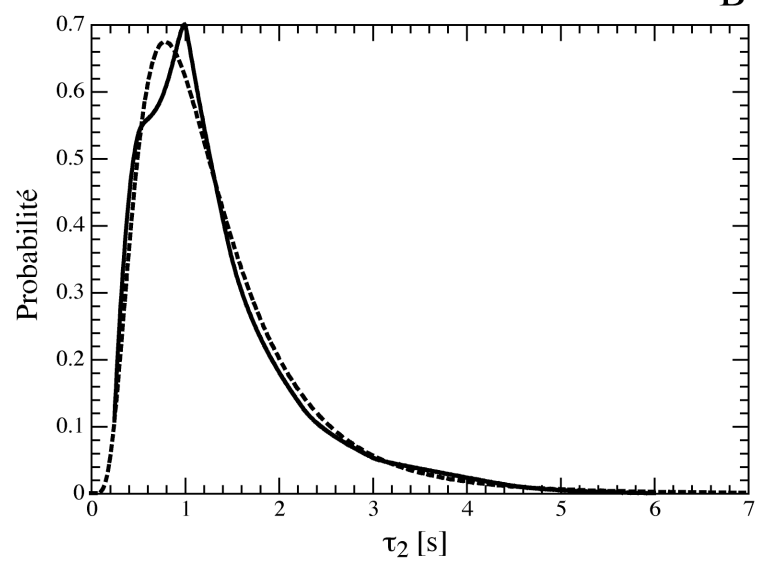

Figure 4-11 : Temps $\tau_{2}$ obtenus sur toutes les mesures réalisées en phase G0/1 sous HU. A. Histogramme. B. Distribution en probabilité (trait plein) et ajustement par la fonction densité d'une loi log-normale selon l'équation (4-3) (pointillés).

\section{2) Cellules en phase $\mathrm{S}-\mathrm{G} 2$ sous HU}

Nous avons effectué 3 expériences différentes sur des cellules asynchrones sous HU. Chacune de ces expériences a été réalisée avec une culture cellulaire différente ( 2 ont été faites à la suite des expériences conduites sur des cellules en phase G0/1). Pour chaque culture, entre 5 et 10 noyaux ont pu être utilisés. Nous avons ainsi mesuré 104 fonctions d'autocorrélation sur 19 noyaux différents. 


\section{2-1) Temps $\tau_{1}$}

Le temps $\tau_{1}$ est extrait des ajustements des fonctions d'autocorrélation par l'équation (4-2) et, là encore, l'exposant d'étirement $\alpha$ est toujours compris entre 0,6 et 0,9 . Pour chaque noyau étudié, nous obtenons une distribution $\tau_{1}$ et nous remarquons que contrairement à ce que nous avons observé pour des cellules quasiment toutes en phases G0/1, maintenant, plus de la moitié des noyaux présentent des valeurs du temps $\tau_{1}$ inférieures à $15.10^{-3} \mathrm{~s}$; dans la gamme $5.10^{-3}-30.10^{-3} \mathrm{~s}$ (Figure 4-12). Pour les autres noyaux, les mesures du temps $\tau_{1}$ sont presque toutes comprises entre $15.10^{-3}$ et $70.10^{-3} \mathrm{~s}$.

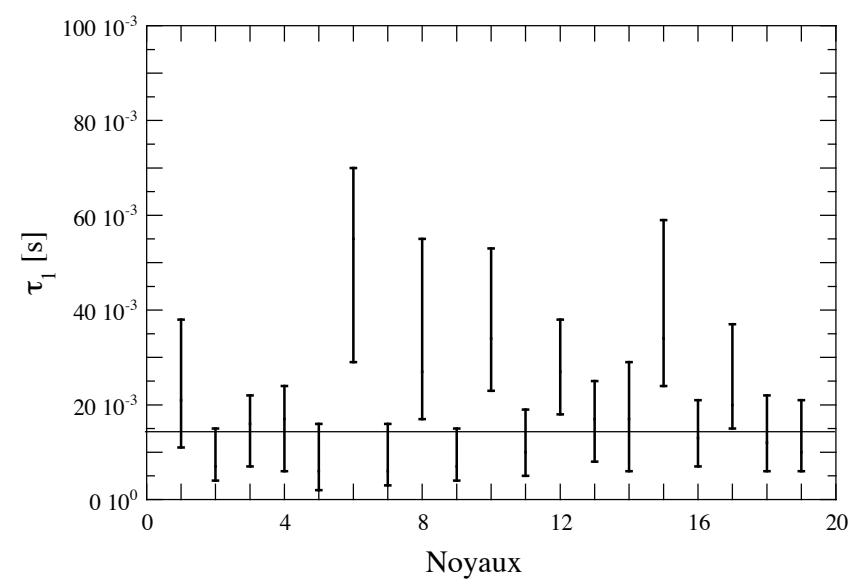

Figure 4-12 : Echelles sur lesquelles s'étendent les temps $\tau_{1}$ pour chaque noyau, pour des cellules en phase "mixée » sous $H U$.

Nous présentons l'histogramme de ces mesures en Figure 4-13 A (avec un pas de temps de $4.10^{-3} \mathrm{~s}$ ). L'allure de cette distribution est très différente de celle que nous avons obtenue sur des cellules en phase G0/1. La distribution est déplacée vers les temps courts, avec beaucoup plus de temps en dessous de $15.10^{-3} \mathrm{~s}$. Environ $92 \%$ des mesures sont comprises entre $5.10^{-3}$ et $55.10^{-3} \mathrm{~s}$. Nous observons deux pics, un vers $15.10^{-3} \mathrm{~s}$ et un autre vers $50.10^{-3} \mathrm{~s}$, ainsi que deux épaulements, un autour de $22.10^{-3} \mathrm{~s}$, l'autre autour de $32.10^{-3} \mathrm{~s}$. Les différences entre la distribution de temps $\tau_{1}$ mesurée pour des cellules en phase G0/1 et la distribution de temps $\tau_{1}$ mesurée pour des cellules « mixées » apparaît encore plus clairement si l'on montre sur la même figure les deux distributions en probabilité (Figure 4-13 B). Nous interprétons ces différences comme étant la signature d'une dynamique rapide différente pour les cellules en phase G0/1 et les cellules en phases S, ou G2. La dynamique rapide est, manifestement, plus rapide dans les phases $S$, ou G2, que dans la phase G0/1. Nous supposons que les 7 cellules pour lesquelles les valeurs de $\tau_{1}$ mesurées sont comprises entre $15.10^{-3}$ et $70.10^{-3} \mathrm{~s}$ sont en phase G0/1 (on peut remarquer que, sur ces sept cellules, on retrouve les 2 «populations » dont nous avons parlé précédemment). Nous retirons ces sept cellules et, avec uniquement les valeurs de $\tau_{1}$ mesurées sur les 12 cellules restantes, nous construisons la distribution en probabilité du temps $\tau_{1}$ pour des noyaux de cellules en phase S, ou G2 (insert de la Figure 4-13 B). Cette distribution montre un pic vers $15 \cdot 10^{-3} \mathrm{~s}$ et un épaulement autour de $22 \cdot 10^{-3} \mathrm{~s}$. 


\section{A}
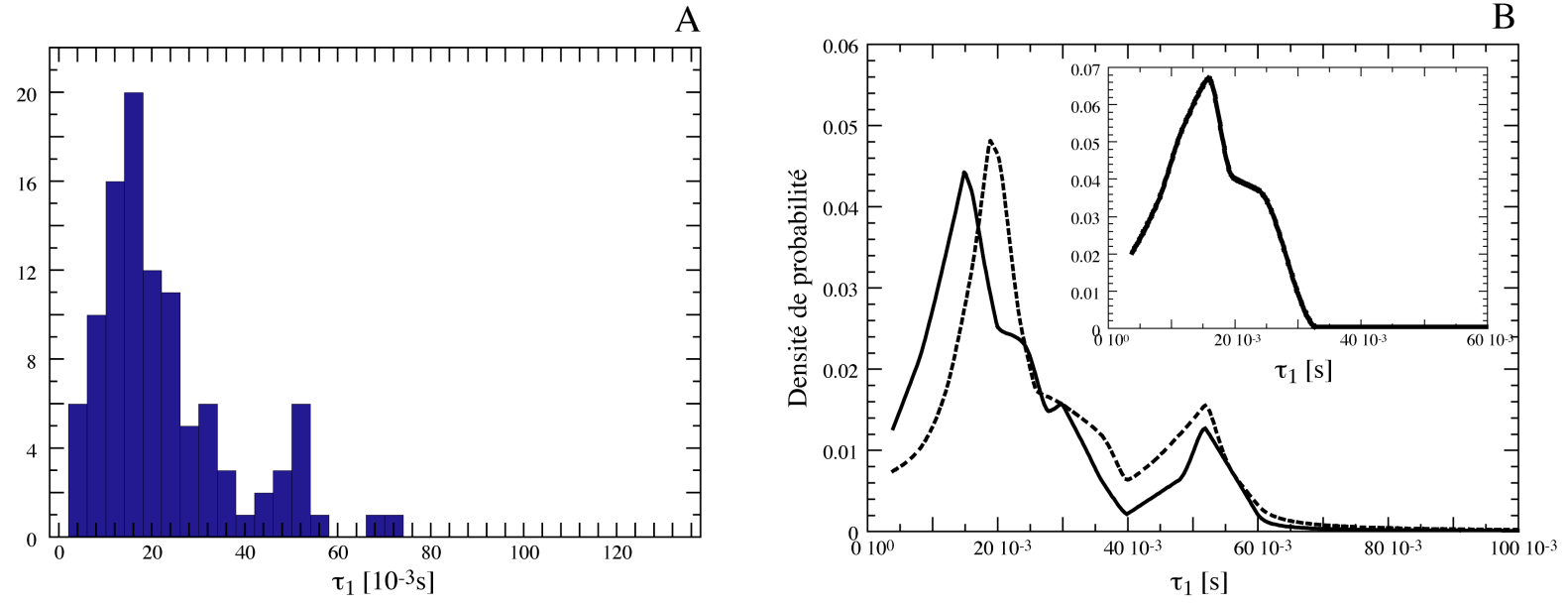

Figure 4-13 : A. Histogramme des valeurs du temps de relaxation $\tau_{1}$ sur l'ensemble des mesures réalisées en phase "mixée " sous HU. B. Comparaison entre les distributions obtenues en phase "mixée » sous HU (trait plein) et en phase G0/1 sous HU (trait pointillé, voir Figure 4-9). L'insert représente la distribution obtenue lorsque l'on enlève des mesures réalisées en phase "mixée », les mesures effectuées sur des cellules supposées en phase G0/1 (pour lesquelles les valeurs de $\tau_{1}$ mesurées sont comprises entre $15.10^{-3}$ et $70.10^{-3} \mathrm{~s}$ ).

\section{2-2) Temps $\tau_{2}$}
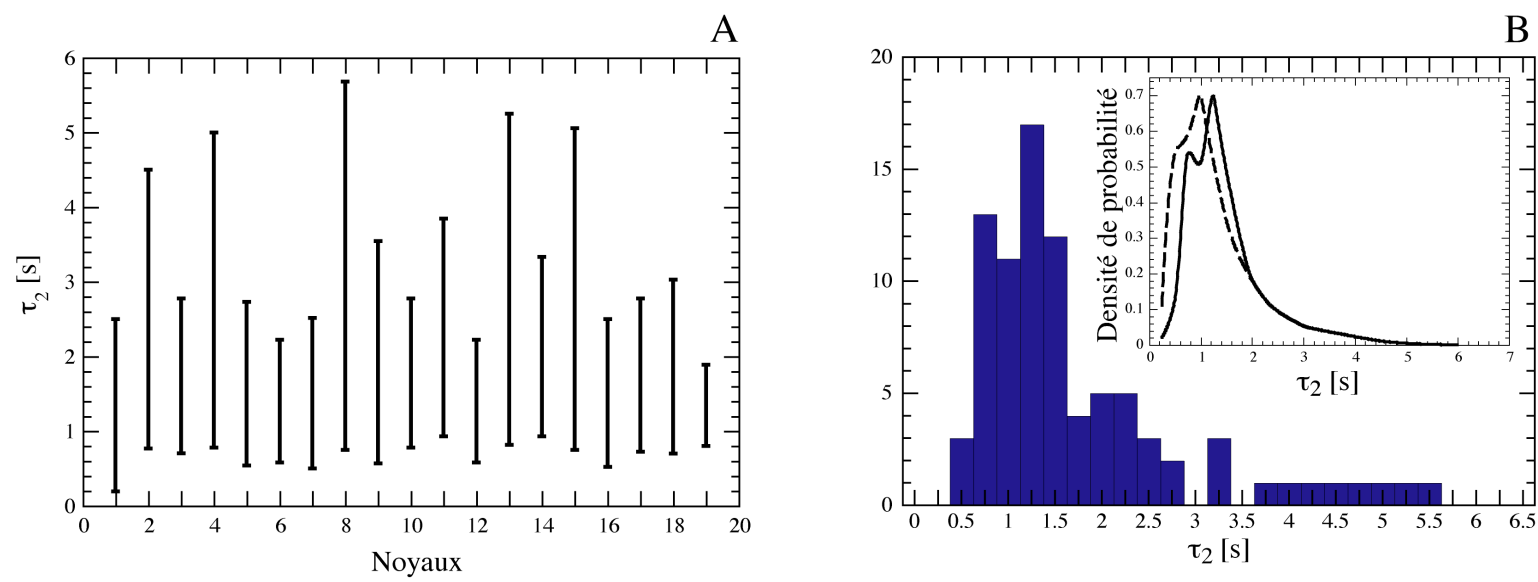

Figure 4-14: A. Pour chaque noyau échelle de temps des mesures du temps $\tau_{2}$ pour des cellules asynchrones sous $H U$. B. Histogramme des valeurs du temps de relaxation $\tau_{2}$ sur l'ensemble des mesures réalisées sur des cellules asynchrones sous HU. En insert, distribution de probabilité obtenue à partir de cet histogramme (trait plein) et distribution de probabilité des temps $\tau_{2}$ pour des mesures réalisées en phase G0/1 sous $H U$ (pointillés; voir Figure 4-11 B)

La Figure 4-14 A montre les gammes dans lesquelles se trouvent les mesures du temps $\tau_{2}$ pour les différents noyaux. Comme pour les cellules en phase G0/1, on observe que les valeurs mesurées se situent principalement entre 0,3 et $2,5 \mathrm{~s}$ (environ $83 \%$ des mesures). De plus, contrairement à ce que nous observons pour le temps $\tau_{1}$, on peut remarquer que pour chaque cellule étudiée, les mesures de $\tau_{2}$ balayent l'ensemble de la distribution. On ne peut pas faire de différence entre les cellules en phase G0/1 et les cellules en phase $S$, ou G2, comme on peut le faire en regardant le temps $\tau_{1}$. La distribution en probabilité du temps $\tau_{2}$ 
obtenue à partir de l'histogramme des données expérimentales, avec un pas de temps de 0,25 s, est présentée Figure 4-14 B. Comme pour les figures en phase G0/1, nous observons un pic unique centré sur $0,5 \mathrm{~s}$ avec une «queue » pour les temps longs. Cette distribution en probabilité peut être, elle aussi, ajustée par la fonction densité d'une loi log-normale (équation (4-3)). Nous obtenons, ainsi, une moyenne de 1,42 s et un écart type autour de la moyenne de $0,74 \mathrm{~s}$. Les valeurs de cet ajustement sont très similaires à celles que l'on avait trouvées pour les cellules en phase G0/1. Dans l'insert de la Figure 4-14 B, nous présentons, ensemble, les distributions en probabilités du temps $\tau_{2}$ pour les cellules en phase G0/1 et les cellules « mixées », ces deux distributions sont quasiment identiques.

\section{3) Conclusion des expériences menées sur des cellules sous HU}

La conclusion de ces premières expériences est que l'on peut mesurer la dynamique interne du noyau d'une cellule vivante grâce à des expériences de diffusion dynamique de la lumière. Cette dynamique est bimodale, avec un temps court de l'ordre de quelques dizaines de millisecondes et un temps long de l'ordre de la seconde. Le résultat principal est que la dynamique rapide des noyaux varie en fonction de la phase du cycle cellulaire alors que le temps long semble, lui, indépendant de la phase du cycle. La dynamique rapide semble assez complexe avec l'existence manifeste de plusieurs temps caractéristiques ; 3 pour les cellules en phases G0/1, à : $20.10^{-3}, 32.10^{-3}$ et $50.10^{-3}$ s et 2 pour les cellules en phases $S-G 2$, à : $15.10^{-3}$ et $22.10^{-3} \mathrm{~s}$. De plus, en phase G0/1, il semble qu'il existe deux dynamiques différentes, ces deux dynamiques reflétant, très probablement, deux états différents de la cellule dans la phase G0/1. La distribution des temps longs est plus simple et semble suivre une loi de distribution de type log-normale.

Ces résultats ont été obtenus pour des cellules en contact avec une drogue cytobloquante, de ce fait, leur intérêt «biologique » peut sembler limiter. Néanmoins, ces expériences nous ont appris à travailler avec ces systèmes et donc, nous ont permis de réaliser ensuite des expériences sur des cultures cellulaires sans HU. De plus les résultats obtenus nous ont donnés des pistes, qui se sont avérées utiles, pour analyser les résultats que nous avons obtenus lors des expériences sur ces cultures cellulaires sans HU. La présentation et la discussion des expériences et des résultats obtenus sur les cultures cellulaires sans HU font l'objet de la partie suivante.

\section{III> Valeurs des paramètres en fonction du cycle cellulaire}

Nous nous sommes servis des résultats présentés au chapitre 3 sur le contrôle du cycle cellulaire grâce à HU pour avoir le maximum de cellules dans la phase du cycle que nous souhaitions étudier. Nous avons ainsi pu suivre l'évolution des 6 paramètres présentés cidessus, en fonction de l'état du noyau, lors des phases G0/1, S, G2 et M. Pour les expériences menées sur toutes les phases, l'angle de diffusion était d'approximativement $21^{\circ}$ (soit environ $33^{\circ}$ pour l'angle de détection).

\section{1) Evolution de la contribution du mode rapide à la fonction d'autocorrélation au cours du cycle cellulaire}

Des paramètres décrits plus haut, les contributions respectives du mode lent et du mode rapide à la partie dynamique des fonctions d'autocorrélation sont probablement ceux qui nous apportent le moins d'informations. La Figure 4-15, montre l'ajustement de la distribution des contributions du mode rapide, $A_{1} /\left(A_{1}+A_{2}\right)$, pour les phases $\mathrm{G} 0 / 1, \mathrm{~S}$ et $\mathrm{G} 2$. Les distributions de chacune de ces contributions sont ajustées par une loi log-normale. La moyenne des distributions est alors d'environ $27 \%$ pour la phase G0/1 avec un écart-type de $21 \%$. Pour la phase $\mathrm{S}$, la moyenne est d'environ $21 \%$ avec un écart type de $15 \%$. Enfin, pour la phase G2 
on trouve une moyenne d'environ $17 \%$ avec un écart type de $12 \%$. Tout d'abord la moyenne diminue légèrement tout au long du cycle cellulaire. On peut également remarquer que ces distributions sont très larges (l'écart-type correspond à, environ, 70\% de la moyenne de chaque distribution).

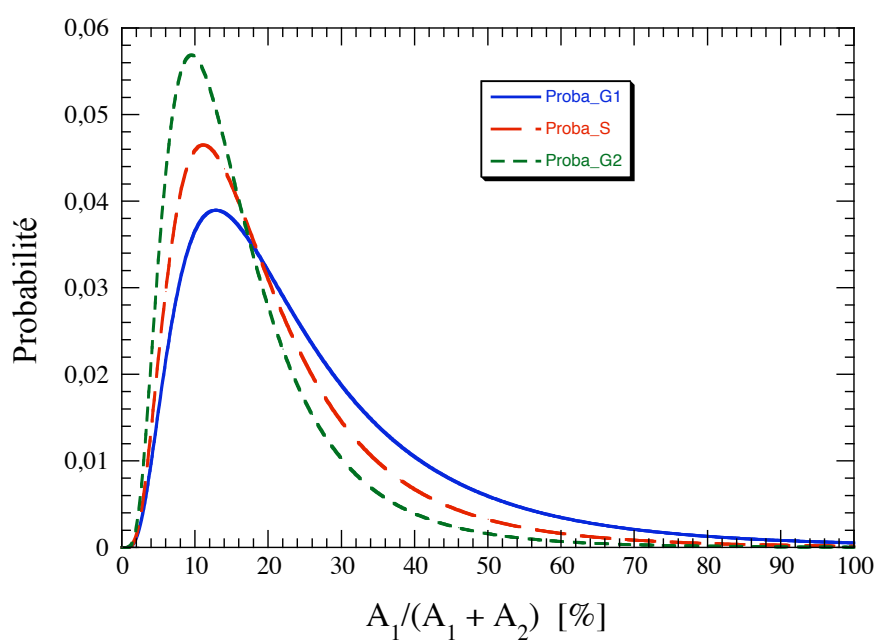

Figure 4-15: Distributions en probabilité de la contribution du temps $\tau_{1}$ à la partie dynamique de la fonction d'autocorrélation pour les phases G0/1, S, G2.

Dans la suite, nous allons nous intéresser à l'évolution des 4 autres paramètres pour chacune des phases du cycle cellulaire.

\section{2) Distributions des valeurs des 4 paramètres pour la phase G0/1}

\section{2-1) Protocole}

Pour pouvoir étudier la dynamique du noyau pendant la phase G0/1, les cellules ont été laissées, 10 ou 15 heures sous HU. Les résultats présentés au chapitre 3, montrent que la phase G0/1 est, alors, nettement dominante (voir Tableau 3-2 et 3-3 Chapitre 3) respectivement pendant 6 heures et 2 heures après retrait de HU du milieu de culture. Les fonctions d'autocorrélation ont été mesurées pendant $60 \mathrm{~s}$ et ajustées par la fonction (4-2). Nous avons mené 4 expériences différentes, en utilisant à chaque fois une culture cellulaire différente. Pour chaque culture, entre 5 et 10 noyaux ont pu être utilisés. Nous avons ainsi effectué 182 mesures sur 24 noyaux différents. Nous commencerons par nous intéresser aux variations de $\langle N\rangle$ puis, aux temps $\tau_{1}, \tau_{2}$ et au coefficient d'étirement $\alpha$.

\section{2-2) Nombre moyen $\langle N\rangle$ de photons détectés au cours d'une mesure}

Les mesures de $\langle N\rangle$ effectuées pendant la phase G0/1, montre que ce paramètre peut varier assez brutalement d'une mesure à l'autre, pour le même noyau. Toutefois, pour la plupart des mesures, $\langle N\rangle$ est comprise entre 100 et $600 \mathrm{kcps} / \mathrm{s}$ (Figure 4-16 A). L'histogramme de $\langle N\rangle$ sur la totalité des 182 mesures montre un pic très net entre 150 et $200 \mathrm{kcps} / \mathrm{s}$ (Figure 4-16 B). L'histogramme peut s'ajuster par une loi log-normale. Nous trouvons ainsi une moyenne d'environ $260 \mathrm{kcps} / \mathrm{s}$ pour un écart type d'environ 190 (Figure 4-16 B). La distribution est donc très large (l'écart-type correspond à, environ, $70 \%$ de la moyenne de la distribution). 
A
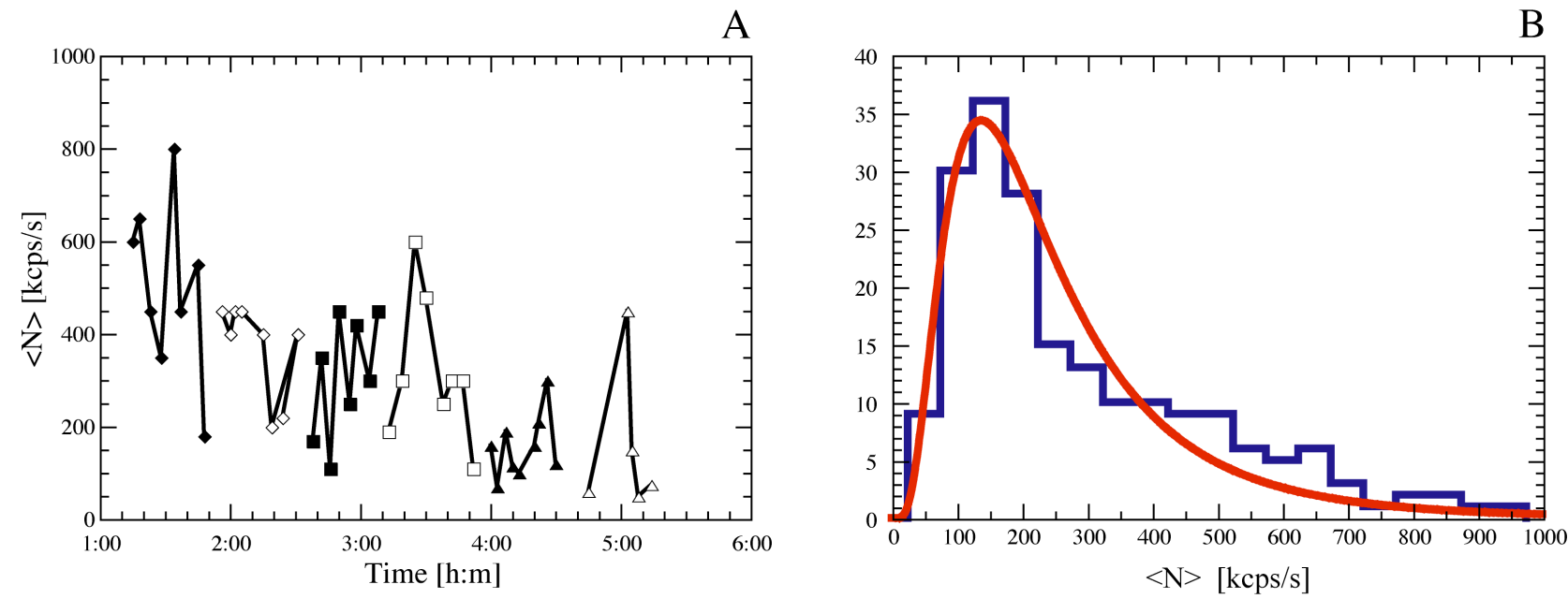

Figure 4-16 : Nombre moyen de photons détectés pendant une mesure, $\langle N\rangle$, au cours de la phase G0/1. A. Variations de $\langle N\rangle$ sur une expérience comprenant environ 45 mesures sur 6 noyaux différents (le changement de symbole indique un noyau différent; même culture cellulaire pour toutes les mesures). B. Histogramme établi sur la totalité des mesures effectuées pendant la phase G0/1. Ajustement par une loi log-normale (équation (4-3)) de moyenne 260 et d'écart type 190.

\section{2-3) Temps $\tau_{1}$}

A

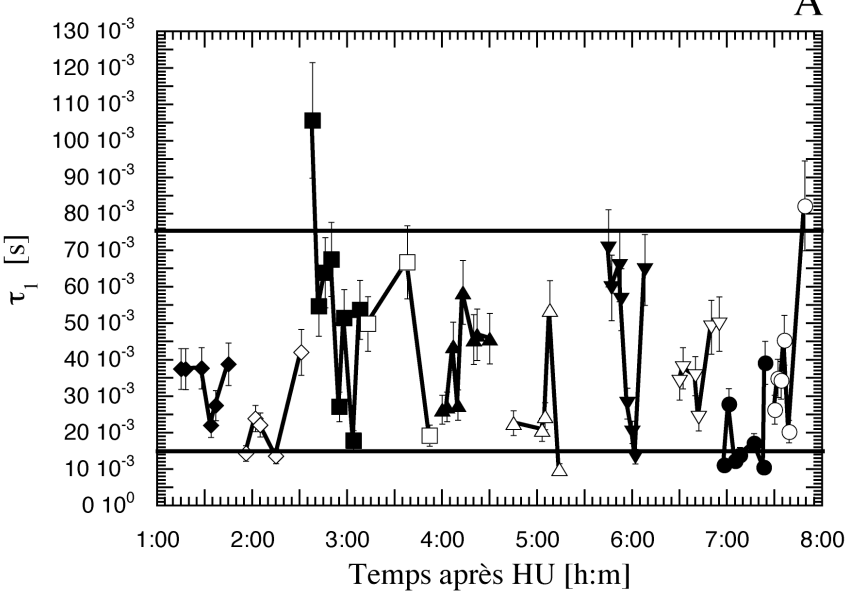

B

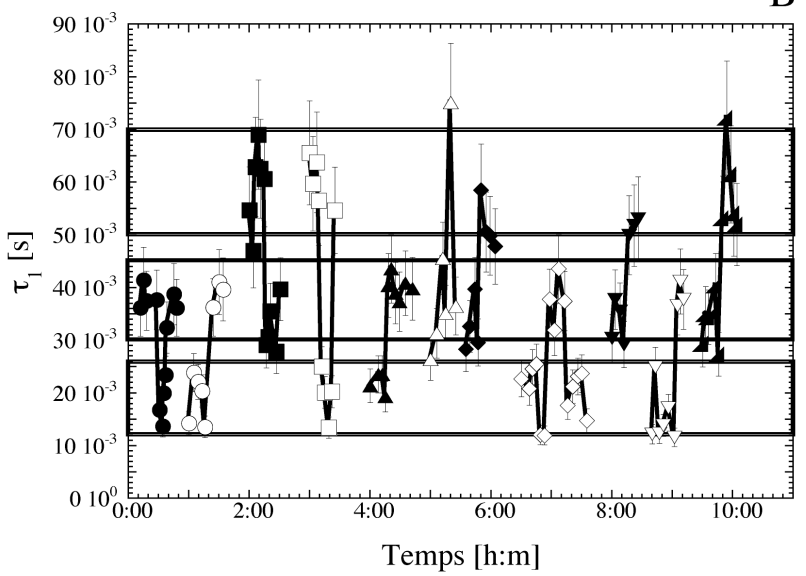

Figure 4-17 : Mesures, sur des cellules en G0/1, du temps de relaxation $\tau_{1}$. A. Evolution des valeurs de $\tau_{1}$ sur une expérience (60 mesures sur 10 noyaux; le changement de symbole indique un noyau différent). $\boldsymbol{B}$. Valeurs de $\tau_{1}$ provenant de toutes les expériences réalisées en phase G0/1. Sur ce graphe, le temps auquel débute la mesure de chaque noyau (le changement de symbole indique un noyau différent) est arbitraire.

Concernant le temps $\tau_{1}$, l'observation de son évolution sur une même expérience (Figure 4-17 A), c'est-à-dire une même culture cellulaire (60 mesures sur 10 noyaux ), montre des temps principalement compris entre $15.10^{-3}$ et $70.10^{-3} \mathrm{~s}$. On remarque que pour la moitié des noyaux, le temps $\tau_{1}$ se situe entre $15.10^{-3}$ et $40.10^{-3} \mathrm{~s}$ tandis que pour l'autre moitié $\tau_{1}$ se situe plutôt entre $30.10^{-3}$ et $70.10^{-3} \mathrm{~s}$. Ce résultat rejoint ceux que l'on a déjà observés pour les mesures 
réalisées sur des cellules en phase G0/1 sous $\mathrm{HU}$ (voir paragraphe II > de ce chapitre). La Figure 4-17 B a été réalisée en utilisant des résultats provenant de toutes les expériences faites sur des cellules en phase G0/1 sans HU. Pour clarifier la figure, et éviter que les points de plusieurs noyaux se superposent, on fixe l'heure de début de la première mesure de chaque noyau. Le seul élément significatif est, donc, l'écart en temps entre les différentes mesures réalisées sur un même noyau (la première mesure du noyau 2 n'est pas faite 50 minutes après le début de l'expérience mais l'écart avec la deuxième mesure est bien d'environ 3 minutes). On voit sur cette figure que quelque soit l'expérience, $\tau_{1}$ est, toujours, principalement compris entre $15.10^{-3}$ et $70.10^{-3} \mathrm{~s}$, et qu'il existe manifestement deux types de cellules, celles dont la dynamique rapide est comprise entre $15.10^{-3}$ et $40.10^{-3} \mathrm{~s}$ et celles dont la dynamique rapide est comprise entre $30.10^{-3}$ et $70.10^{-3} \mathrm{~s}$. Ce qui est en accord avec la Figure 4-17 A. De plus, avec cette figure, on peut voir que pour un même noyau, on a deux «paliers » pour le temps $\tau_{1}$. Pour les cellules dont la dynamique rapide est comprise entre $15.10^{-3}$ et $40.10^{-3} \mathrm{~s}$, on observe un palier autour de $20.10^{-3} \mathrm{~s}$ et un autour de $35.10^{-3} \mathrm{~s}$. Pour les cellules dont la dynamique rapide est comprise entre $30.10^{-3}$ et $70.10^{-3} \mathrm{~s}$, on a de nouveau un palier autour de $35.10^{-3} \mathrm{~s}$ et un autour de $55.10^{-3} \mathrm{~s}$. On note que lorsqu'une mesure donne un temps $\tau_{1}$ sur l'un de ces paliers, il y a $80 \%$ de chance que le temps $\tau_{1}$ donné par la mesure suivante soit sur le même palier.

A

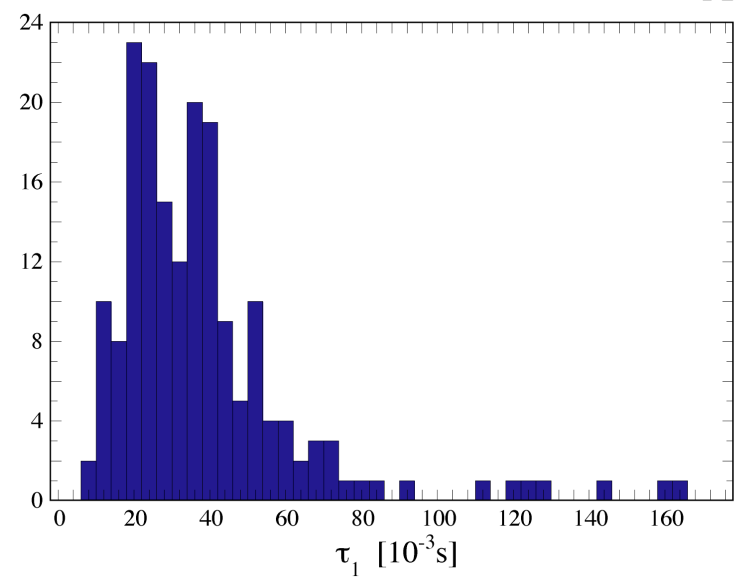

B

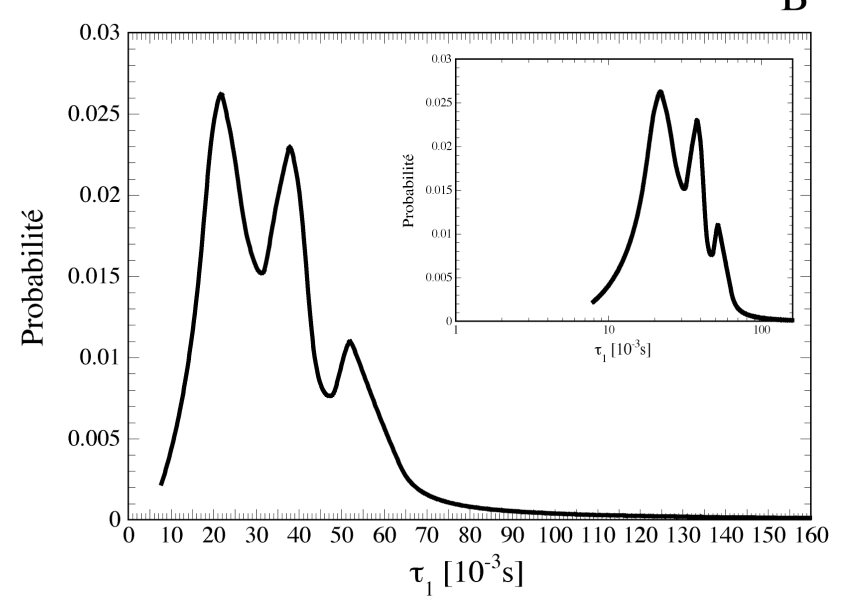

Figure 4-18 : Histogramme $(\boldsymbol{A})$ et distribution en probabilité (B ; échelle semi-log pour l'insert) du temps $\tau_{1}$ sur la totalité des mesures effectuées pendant la phase G1. La distribution en probabilité est obtenue en divisant l'amplitude de l'histogramme par l'aire totale de l'histogramme.

L'histogramme de la totalité des mesures du temps $\tau_{1}$ (Figure 4-18 A) montre que 87\% des mesures sont effectivement comprises entre $15.10^{-3}$ et $70.10^{-3} \mathrm{~s}$. On observe deux « pics », l'un autour de $20-22.10^{-3} \mathrm{~s}$ et l'autre autour de $35-38 \cdot 10^{-3} \mathrm{~s}$, ainsi qu'un « épaulement » autour de $55.10^{-3} \mathrm{~s}$. De même que pour les résultats obtenus sous $\mathrm{HU}$, changer légèrement le pas de temps ne change pas fondamentalement l'histogramme (cela affine ou élargit légèrement les pics et l'épaulement que l'on observe). La Figure 4-18 B représente la distribution en probabilité de $\tau_{1}$ pour des cellules en phase G0/1.

\section{2-4) Temps $\tau_{2}$}

Concernant le temps $\tau_{2}$ (Figure 4-19), l'histogramme et la distribution en probabilité montrent que la plupart des mesures se situe entre 0,5 et $2 \mathrm{~s}$. Contrairement à $\tau_{1}$ qui présente une distribution « compliquée », pour $\tau_{2}$ on observe un pic unique centré sur 0,5 s. Comme 
sous HU, pour chaque cellule, les mesures de $\tau_{2}$ balayent l'ensemble de la distribution. Cette distribution peut être ajustée par la fonction densité d'une loi log-normale de moyenne $0,95 \mathrm{~s}$ et d'écart type 0,7 .
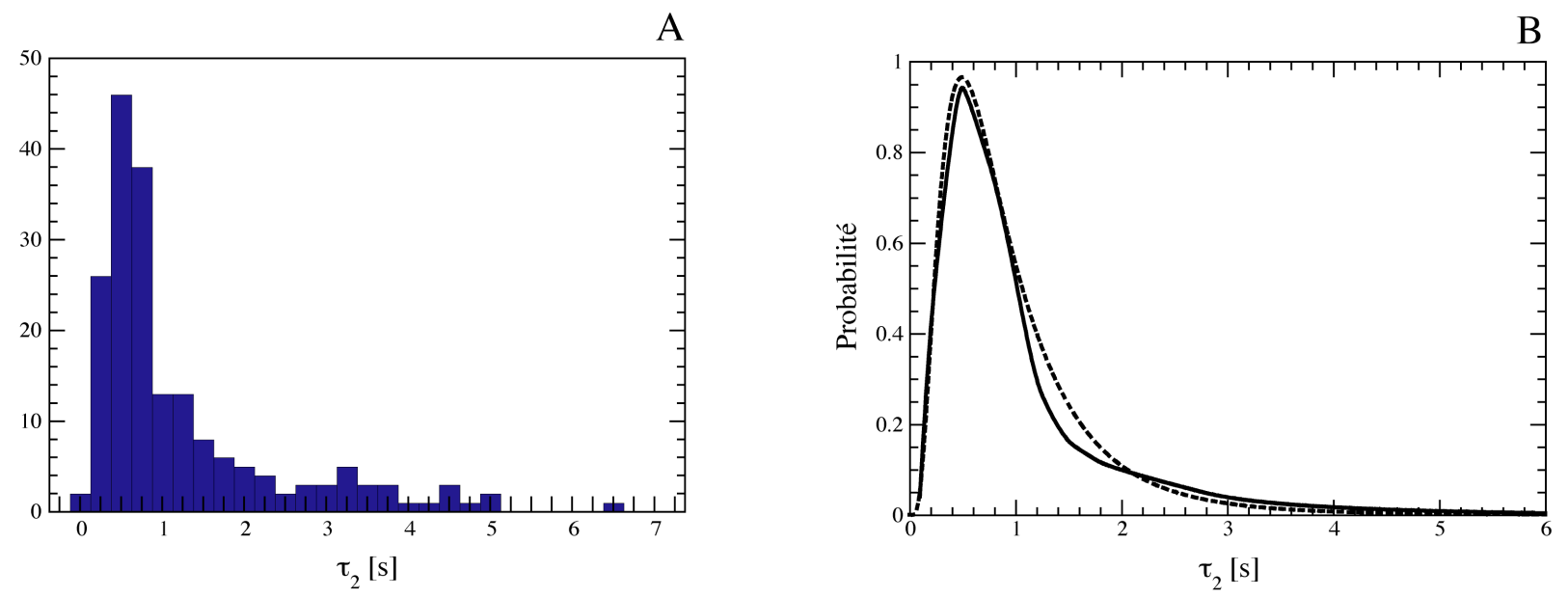

Figure 4-19: Histogramme (A) et distribution en probabilité $(B)$ du temps $\tau_{2}$ pour des cellules à majorité en phase G0/1. La distribution (trait plein) est ajustée par une loi lognormale de moyenne 0,95 s et d'écart-type 0,7 (trait pointillé).

\section{2-5) Coefficient d'étirement $\alpha$}

Concernant les coefficients d'étirement $\alpha$, l'histogramme présenté en Figure 4-20 montre qu'ils sont tous compris entre 0,35 et 1 . On note un pic entre 0,55 et 0,7 ( $60 \%$ des mesures). La distribution en probabilité peut s'ajuster par la fonction densité d'une loi normale de moyenne 0,62 et d'écart type 0,1 . La distribution est donc plutôt centré.

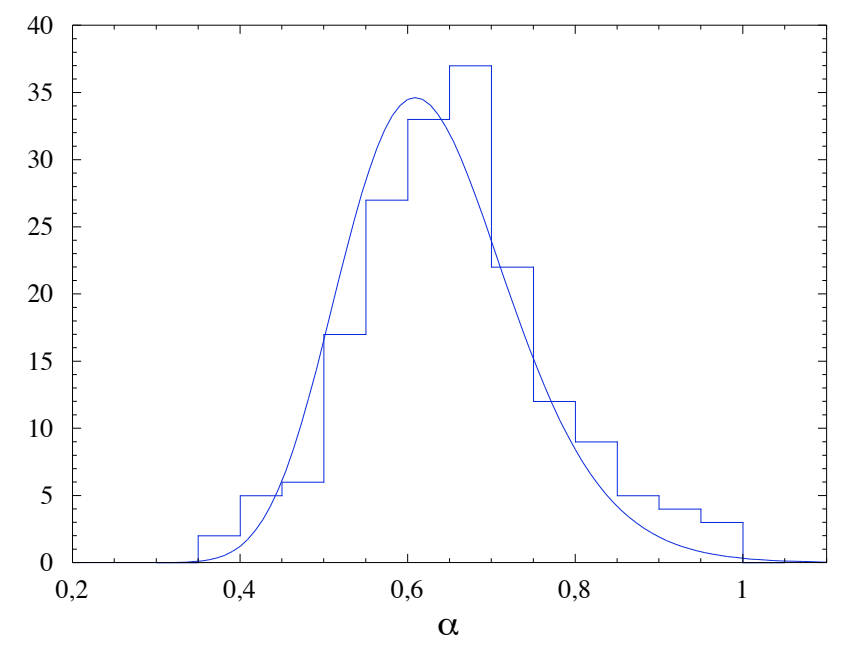

Figure 4-20 : Histogramme des coefficients d'étirement $\alpha$ pour la phase G0/1.

\section{2-6) Conclusion}

Lors de la phase G0/1, $\langle N\rangle$ se situe aux alentours de $260 \mathrm{kcps} / \mathrm{s}$. L'écart type autour de cette valeur est relativement élevé, ce qui signifie que les modulations de l'intensité diffusée sur des temps longs sont relativement importantes au cours de cette phase.

Toutes les valeurs du temps $\tau_{1}$ semblent comprises entre $15.10^{-3}$ et $70.10^{-3} \mathrm{~s}$. Nos résultats semblent montrer qu'il existe deux «types » de dynamiques différentes; une 
comprise entre $15.10^{-3}$ et $40.10^{-3} \mathrm{~s}$ et une autre comprise entre $30.10^{-3}$ et $70.10^{-3} \mathrm{~s}$. La distribution des temps $\tau_{1}$, montre trois gammes de temps caractéristiques respectivement centrées autour de $20.10^{-3}, 37.10^{-3}$ et $55.10^{-3}$ s. Ces résultats sont assez similaires à ceux obtenus sur des cellules en phase G0/1 sous HU ; même gamme de temps caractéristiques, même répartition en deux populations de cellules. Par contre, sous HU, le pic autour de 35$37.10^{-3} \mathrm{~s}$ devient un épaulement tandis que l'épaulement autour de $55.10^{-3} \mathrm{~s}$ devient un pic (voir Figure 4-9 et Figure 4-18).

Pour le temps de relaxation $\tau_{2}$, les valeurs sont comprises principalement entre 0,5 et 2 $\mathrm{s}$ avec un pic très net à $0,5 \mathrm{~s}$. La distribution peut être ajustée par une loi log-normale. Il convient toutefois de prendre ces valeurs avec précaution à cause des erreurs possibles sur l'estimation de la ligne de base.

La distribution des coefficients d'étirement $\alpha$ est ajustée par une gaussienne de moyenne 0,62 .

\section{3) Distributions des valeurs des 4 paramètres pour la phase $S$ majoritaire}

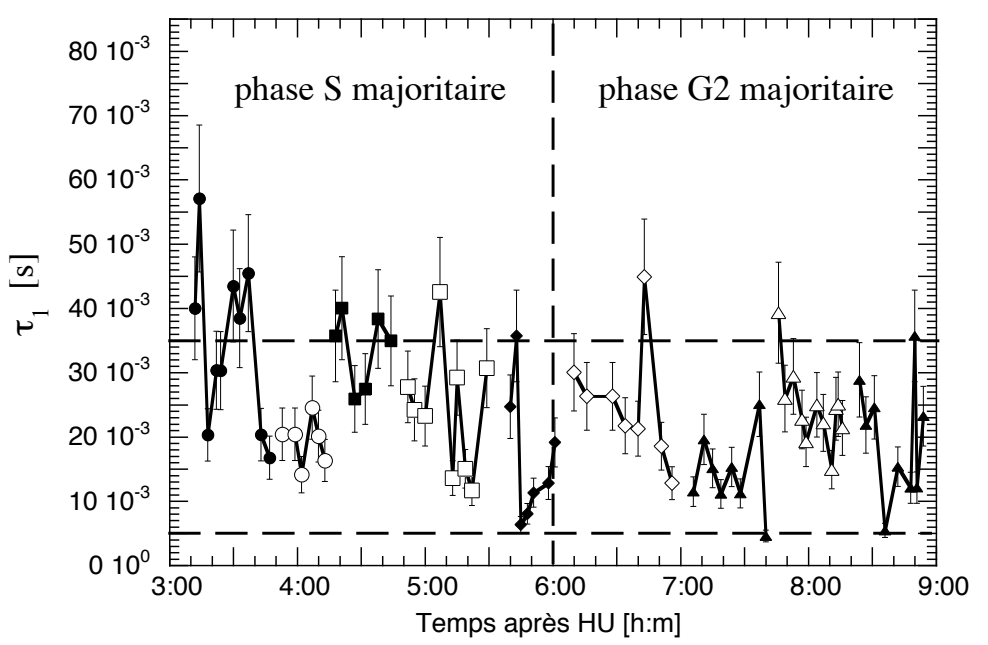

Figure 4-21 : Evolution sur une expérience (84 mesures sur 9 noyaux différents) des temps de relaxation $\tau_{1}$.

\section{3-1) Protocoles}

Pour obtenir une majorité de cellules en S, nous avons laissé les cellules pendant 15 heures sous HU avant de le rincer. En commençant l'expérience 3 heures plus tard, nous avons une fenêtre d'environ 3-4 heures pendant laquelle la phase $S$ est nettement dominante (au moins $60 \%$ de la population ; voir Tableau 3-3 Chapitre 3). Nous avons également effectué quelques mesures sur des cellules, laissées pendant 10 heures sous HU avant d'être rincées, 8-9 heures après le rinçage (à ce moment au moins $55 \%$ de la population en phase $\mathrm{S}$; voir Tableau 3-2 Chapitre 3). Dans toutes ces expériences, la phase $\mathrm{S}$ est majoritaire mais, contrairement aux mesures faites en phase G0/1, où les autres phases étaient très minoritaires, ici, le taux de cellules en phases G0/1 et G2 n'est pas négligeable. La Figure 4-21 présente les temps $\tau_{1}$ pour une expérience réalisée sur des cellules laissées 15 heures sous HU. On remarque que pour la plupart des cellules, $\tau_{1}$ est compris entre $5.10^{-3}$ et $35-40.10^{-3} \mathrm{~s}$. Toutefois, on peut voir que certaines mesures présentent des temps $\tau_{1}$ plus lents, se situant dans la gamme des résultats obtenus en phase $\mathrm{G} 0 / 1$ avec et sans HU. Cette observation est similaire à ce que l'on a pu voir pour des cellules à majorité en S-G2 sous HU (voir paragraphe II >). On suppose que les noyaux montrant une dynamique rapide similaire à celle observée pour les cellules en phase G0/1 appartiennent à des cellules en phase G0/1. Donc, nous ne tenons pas compte des 
mesures faites sur ces noyaux pour établir les distributions des différents paramètres pour des cellules en phase $\mathrm{S}$. Cela résulte en la suppression d'environ $15 \%$ des noyaux mesurés. A la fin, il reste 44 cellules supposés être majoritairement en phase $\mathrm{S}$ (les résultats de FACS montrent que la répartition est d'environ $75 \%$ en phase $\mathrm{S}$ et $25 \%$ en phase G2). Cela nous fait un total de 252 mesures. Encore une fois, les expériences ont été menées sur 6 cultures cellulaires différentes (une culture cellulaire par expérience).

Une nouvelle fois, nous commencerons par regarder les variations de $\langle N\rangle$, puis nous nous intéresserons aux temps $\tau_{1}$ et $\tau_{2}$ ainsi qu'au coefficient d'étirement $\alpha$.

\section{3-2) Nombre moyen $\langle N\rangle$ de photons détectés au cours d'une mesure}

Pour ces cellules, on note que les mesures de $\langle N\rangle$, pour une cellule donnée, varient beaucoup moins brutalement d'une mesure à l'autre que pour les cellules en phase G0/1. Les valeurs de $\langle N\rangle$ semblent principalement comprises entre 50 et $300 \mathrm{kcps} / \mathrm{s}$ (Figure 4-22 A). L'histogramme de $\langle N\rangle$ sur la totalité des mesures peut également s'ajuster par la fonction densité d'une loi log-normale (équation (4-3)). La distribution a une moyenne de $150 \mathrm{kcps} / \mathrm{s}$ (Figure 4-22 B). L'écart-type autour de cette moyenne est d'environ 120. On note donc une nette diminution par rapport à la phase G0/1 de la moyenne mais également de l'écart-type. La distribution est donc plus resserrée qu'en G0/1.

A

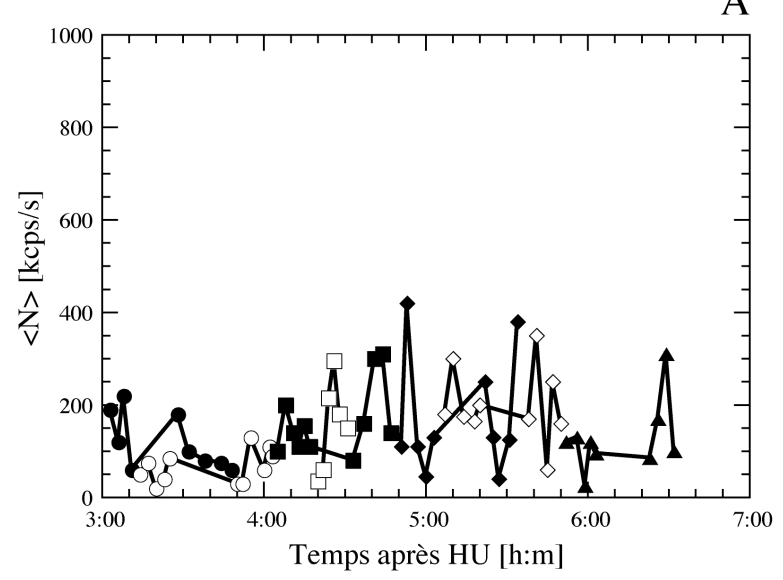

B

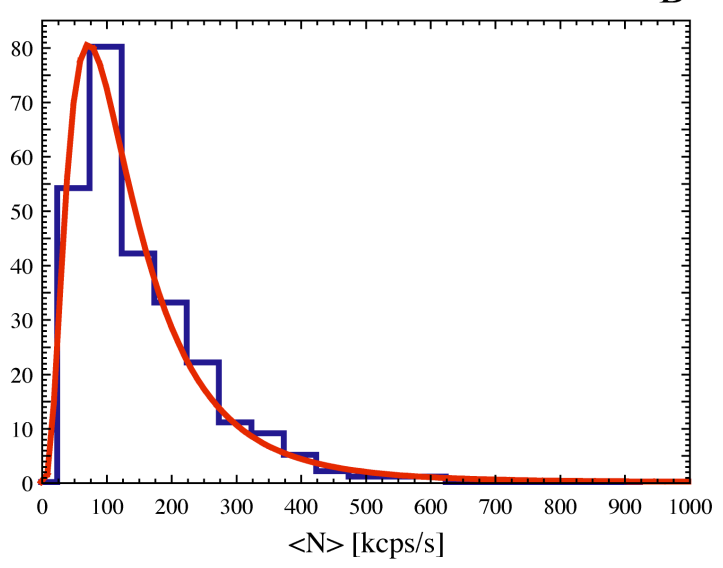

Figure 4-22 : Nombre moyen de photons détectés $\langle N\rangle$ au cours de la phase S. A. Variations de $\langle N\rangle$ sur une expérience comprenant 70 mesures sur 8 noyaux différents (même culture cellulaire pour toutes les mesures). B. Histogramme établi sur la totalité des mesures effectuées pendant la phase S. Ajustement par une loi log-normale de moyenne 150 et d'écart type 120.

\section{3-3) Temps $\tau_{1}$}

La Figure 4-23 (même remarque pour l'échelle de temps que pour la Figure 4-17 B) est en accord avec la Figure 4-21 concernant la gamme des valeurs obtenues pour le temps $\tau_{1}$ : entre $5.10^{-3}$ et $35-40.10^{-3} \mathrm{~s}$. On peut déjà noter, par rapport à la phase $\mathrm{G} 0 / 1$, un tassement des valeurs du temps $\tau_{1}$ vers des temps plus courts. De plus, contrairement à ce qui a été observé dans la phase G0/1, il semble que l'on observe qu'un seul type de dynamique rapide et l'on ne retrouve pas les variations du temps $\tau_{1}$ par paliers. La différence entre 2 mesures successives du temps $\tau_{1}$, réalisées sur un même noyau, est bien plus importante que pour la phase G0/1. 


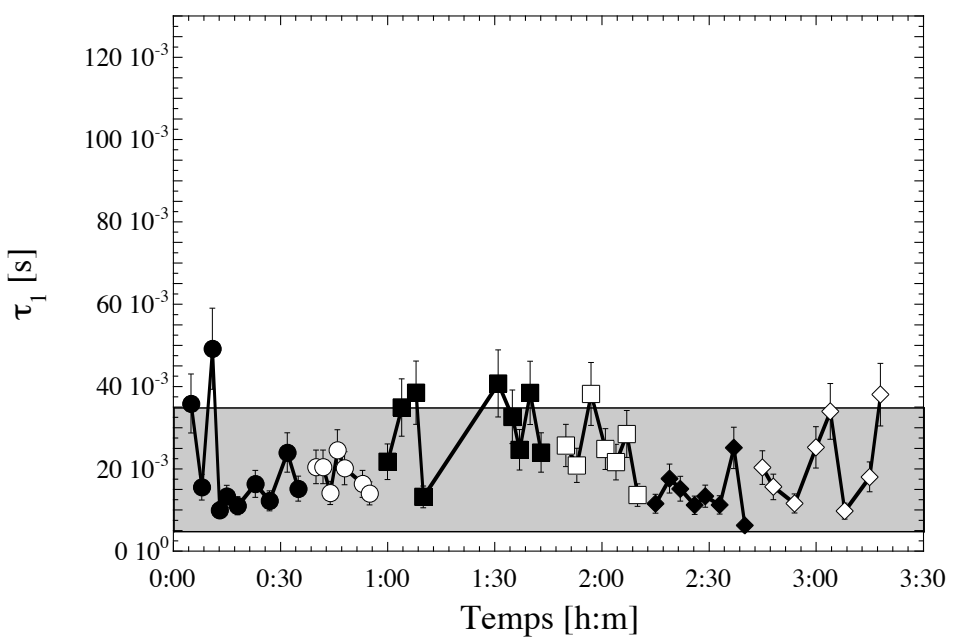

Figure 4-23 : Evolution sur plusieurs expériences (50 mesures sur 6 noyaux) des temps $\tau_{1}$ avec une majorité de cellules en phase S. Sur ce graphe, le temps auquel débute la mesure de chaque noyau est arbitraire (le changement de symbole indique un noyau différent).

Le tassement des temps $\tau_{1}$ vers les temps plus court est confirmé par toutes les mesures effectuées en S comme le montre l'histogramme de la Figure 4-24. L'histogramme montre principalement deux pics : le premier vers $10.10^{-3} \mathrm{~s}$, le deuxième autour de $20.10^{-3} \mathrm{~s}$ et un épaulement entre $35-40 \cdot 10^{-3} \mathrm{~s}$. La distribution en probabilité se retrouve singulièrement différente de celle obtenue en G0/1.
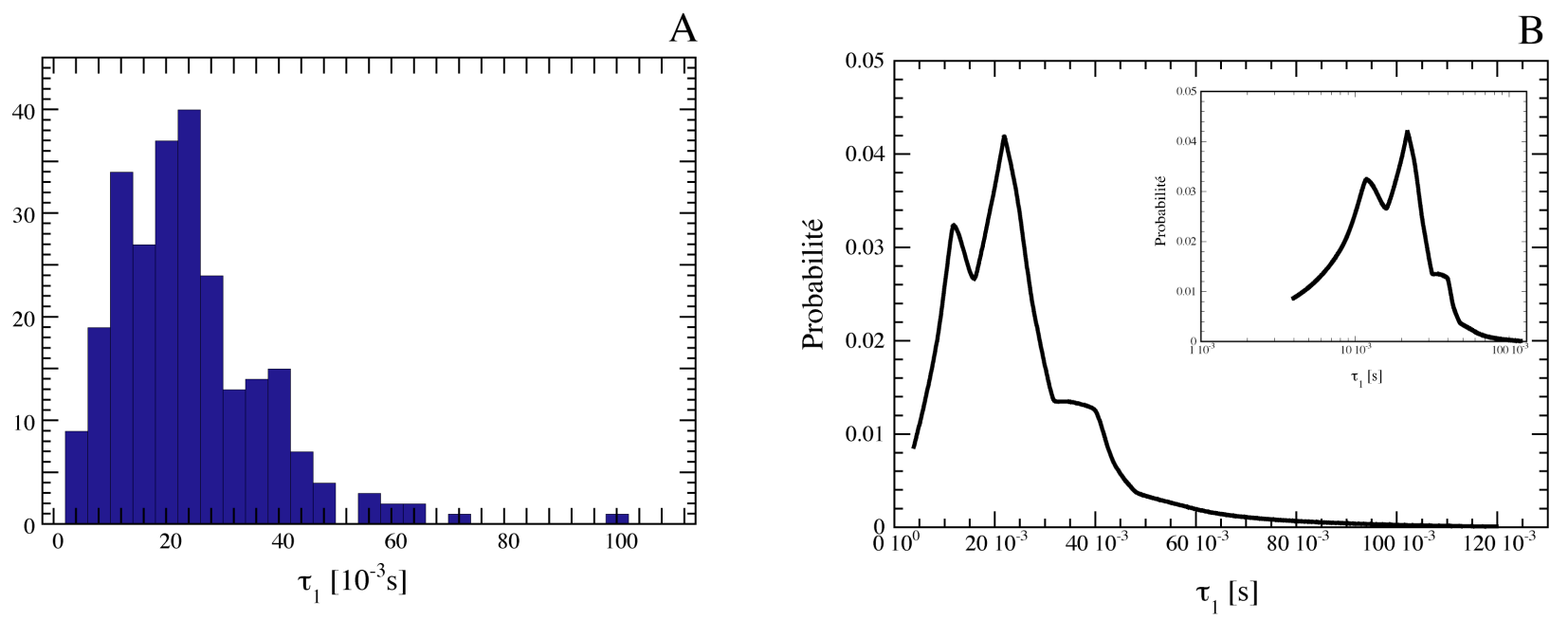

Figure 4-24 : Histogramme $(\boldsymbol{A})$ et distribution en probabilité (B ; échelle semi-log en insert) du temps $\tau_{1}$ sur la totalité des mesures effectuées pendant la phase $S$. 


\section{3-4) Temps $\tau_{2}$}
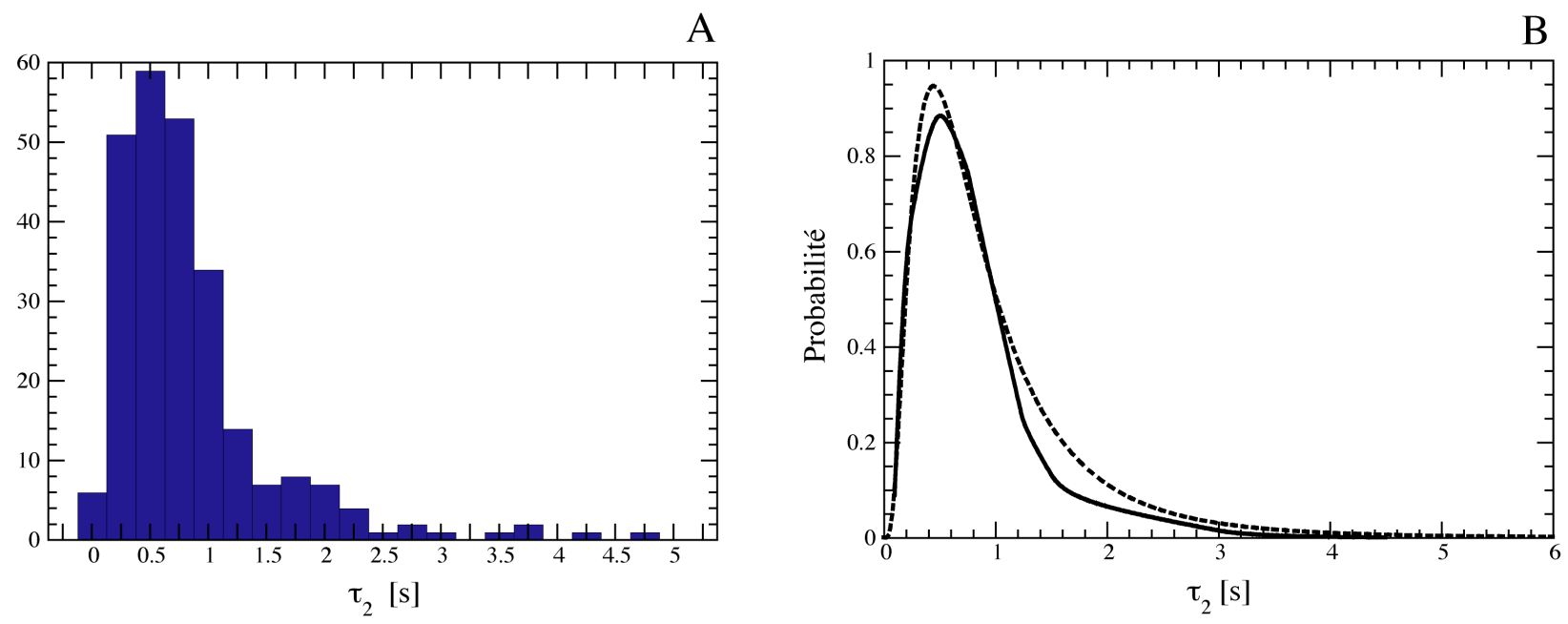

Figure 4-25 : Histogramme (A) et distribution en probabilité (B) du temps $\tau_{2}$ pour des cellules à majorité en phase $S$. La distribution (trait plein) est ajustée par une loi log-normale de moyenne 0,98 s et d'écart-type 0,8 (trait pointillé).

Pour le temps $\tau_{2}$ (Figure 4-25), l'histogramme et la distribution en probabilité montrent que la plupart des mesures se situe entre 0,2 et $2 \mathrm{~s}$, avec un pic centré sur 0,5 s. La distribution de probabilité des temps $\tau_{2}$ est ajustable par une loi log-normale de moyenne $0,98 \mathrm{~s}$ et d'écarttype 0,8 . Encore une fois, la distribution est très large et pour chaque cellule, les mesures de $\tau_{2}$ balayent l'ensemble de la distribution. On notera que cette distribution en probabilités est très similaire à celle obtenue en G0/1.

\section{3-5) Coefficient d'étirement $\alpha$}

Concernant les coefficients d'étirement $\alpha$, l'histogramme présenté en Figure 4-26 montre qu'ils sont tous compris entre 0,35 et 1 . On note un pic entre 0,55 et 0,75 (environ $80 \%$ des mesures). La distribution en probabilité peut s'ajuster par la fonction densité d'une loi normale de moyenne 0,66 et d'écart type 0,074. La distribution est donc plutôt centrée, sa moyenne est semblable à celle de la phase G0/1, mais elle est plus resserrée.

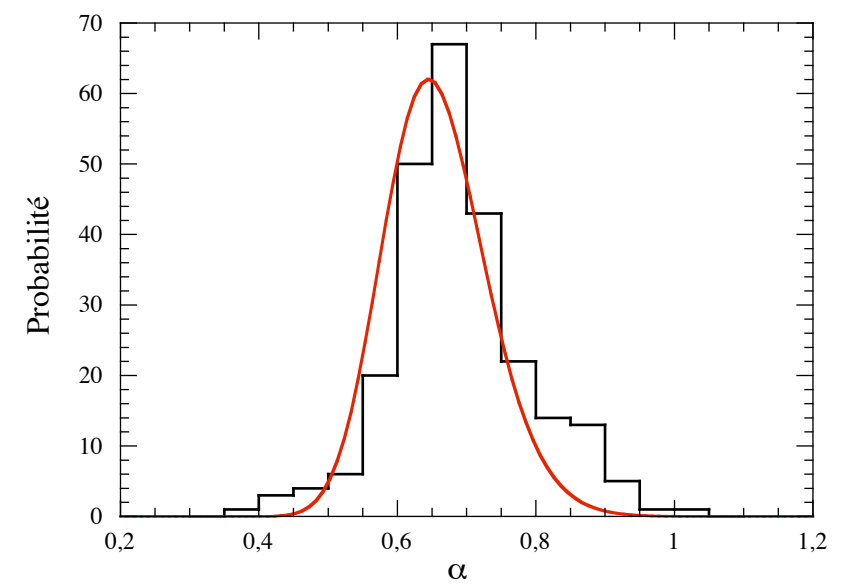

Figure 4-26 : Histogramme des coefficients d'étirement $\alpha$ pour la phase S. L'ajustement est fait par une gaussienne de moyenne 0,6 et d'écart-type 0,074. 


\section{3-6) Conclusions}

Les valeurs des paramètres pour des cellules majoritairement en phase $\mathrm{S}$ présentent des différences avec la phase G0/1. Ainsi, on observe une intensité moyenne $\langle N\rangle$ d'environ 150 $\mathrm{kcps} / \mathrm{s}$. L'écart type autour de cette moyenne, 120, étant plus resserré qu'en G0/1, on peut en déduire que les modulations de l'intensité diffusée sur des temps longs sont moins importantes.

Le temps de relaxation du mode rapide $\tau_{1}$ se situe principalement entre $5.10^{-3}$ et 35 $40.10^{-3} \mathrm{~s}$ avec des pics pour $10.10^{-3}, 20.10^{-3} \mathrm{~s}$ et un épaulement pour $35-40.10^{-3} \mathrm{~s}$. Encore une fois, nous insistons sur le fait que la dynamique rapide présentée par chaque cellule, ainsi que la distribution en probabilité du temps $\tau_{1}$ sont très différentes de celles observées en phase G0/1.

Concernant le temps de relaxation du mode lent $\tau_{2}$, il se situe plutôt entre 0,2 et $2 \mathrm{~s}$ avec un pic important à $0,5 \mathrm{~s}$. Cette distribution s'ajuste par une loi log-normale. Contrairement à celle des temps $\tau_{1}$, la distribution des temps $\tau_{2}$ semble équivalente à celle obtenue pour la phase G0/1.

Comme pour la phase G0/1, la distribution de probabilité du coefficient d'étirement $\alpha$, s'ajuste par une gaussienne. Cette distribution est plus resserrée que dans la phase G0/1.

\section{4) Distributions des valeurs des 4 paramètres pour la phase G2 majoritaire}

\section{4-1) Protocole}

Pour obtenir une majorité de cellules en G2, nous avons laissé les cellules pendant 15 heures sous HU avant de l'enlever. Nous avons laissé les cellules reprendre leur cycle et les expériences ont été menées entre 7 et 9 heures après avoir levé les effets de HU (voir Tableau 3-3 Chapitre 3), moment où le taux de G2 est supérieur à $50 \% .9$ heures après avoir retiré $\mathrm{HU}$, on voit qu'environ 9 cellules sur 10 entrent en mitose. On en déduit que le taux de cellules en phase G2 augmentent rapidement entre 7 et 9 heures pour passer de $50 \%$ à $90 \%$. Comme nous l'avons fait pour la phase $\mathrm{S}$, nous avons essayé de repérer les cellules en phase G0/1 (en se fondant, une nouvelle fois, sur les mesures du temps $\tau_{1}$ ). Par contre, la différence entre la dynamique rapide de la phase $S$ et celle de la phase G2 n'est pas suffisamment flagrante pour permettre de retirer les cellules qui sont en phase S. Sachant cela et prenant en compte les résultats des mesures par FACS (voir chapitre 3), on peut estimer qu'environ $75 \%$ de nos mesures sont effectuées sur les noyaux de cellules en phase G2. 5 cultures cellulaires ont été utilisées pour réaliser l'ensemble des mesures; une culture correspondant à une expérience. Pour chaque expérience, les mesures ont été réalisées sur 5-10 noyaux. Une fois les cellules supposées en phase G0/1 retirées, nous avons un total de 138 mesures sur 18 noyaux différents.

Ici encore, nous commencerons par présenter les variations de $\langle N\rangle$, puis celles des temps de relaxation $\tau_{1}$ et $\tau_{2}$. Nous terminerons par les valeurs du coefficient d'étirement $\alpha$.

\section{4-2) Nombre moyen $\langle N\rangle$ de photons détectés au cours d'une mesure}

Comme pour les cellules majoritairement en phase $\mathrm{S}$, les valeurs de $\langle N\rangle$ pour un même noyau varient moins brutalement d'une mesure à l'autre que lors de la phase G0/1. Les valeurs de $\langle N\rangle$ observées pendant la phase G2 sont principalement comprises entre 100 et $400 \mathrm{kcps} / \mathrm{s}$. Encore une fois, on peut ajuster la distribution de $\langle N\rangle$ par une loi log-normale. Cet ajustement nous donne une moyenne autour de $220 \mathrm{kcps} / \mathrm{s}$ et un écart type d'environ 160 (Figure 4-27). 


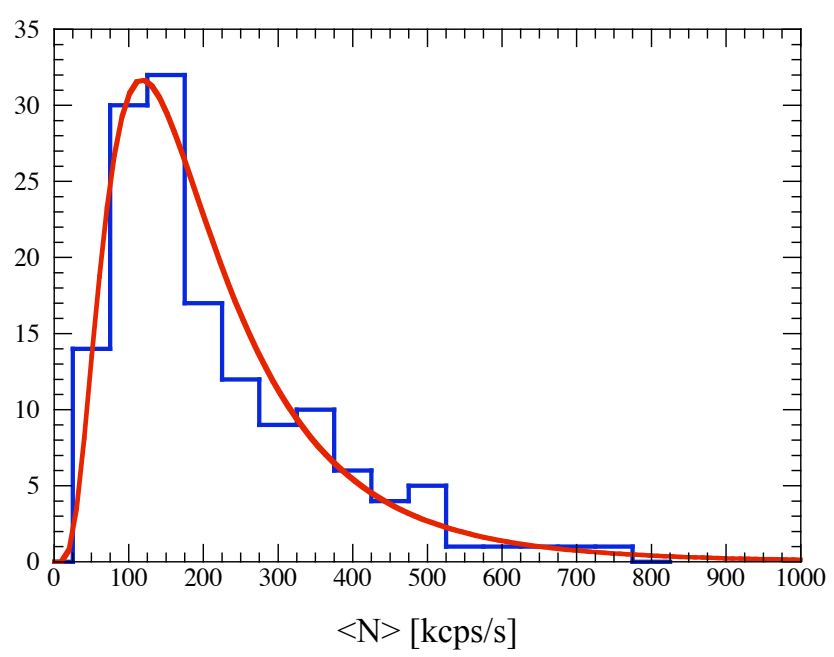

Figure 4-27 : Histogramme du nombre moyen $\langle N\rangle$ de photons détectés pendant une mesure au cours de la phase G2, établi sur la totalité des mesures effectuées pendant la phase G2. Ajustement par une loi log-normale de moyenne 220 et d'écart type 160.

\section{4-3) Temps $\tau_{1}$}

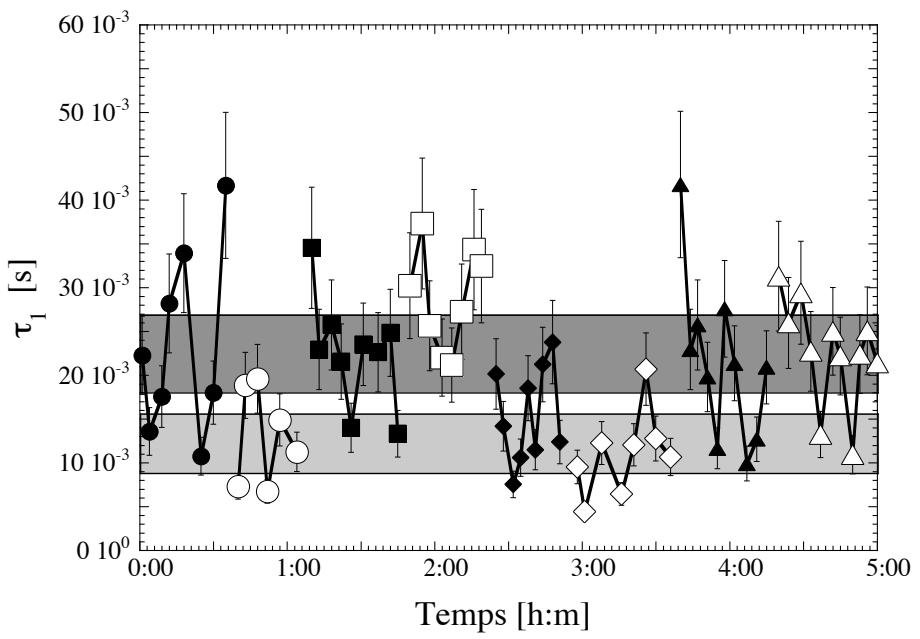

Figure 4-28 : Evolution sur plusieurs expériences (74 mesures sur 8 noyaux différents) des temps $\tau_{1}$ pour des cellules majoritairement en phase G2. Sur ce graphe, le temps auquel débute la mesure de chaque noyau (le changement de symbole indique un noyau différent) est arbitraire.

Nous pouvons observer sur la Figure 4-28 que les mesures du temps $\tau_{1}$ sont comprises entre $5.10^{-3}$ et $30.10^{-3} \mathrm{~s}$. La Figure 4-28 (même remarque pour l'échelle de temps que pour la figure 4-19 B) est en accord avec la Figure 4-21 concernant la gamme des valeurs obtenues pour le temps $\tau_{1}$ : entre $5.10^{-3}$ et $30.10^{-3} \mathrm{~s}$. On observe, ici, une seule « catégorie » de cellules, comme pour la phase $S$. Par contre, les mesures de $\tau_{1}$ semblent se répartir sur deux paliers : un autour de $20-22.10^{-3} \mathrm{~s}$ et l'autre un peu plus rapide autour $10 \cdot 10^{-3} \mathrm{~s}$. Néanmoins, contrairement à la phase G0/1, 2 mesures successives sur le même noyau sont souvent assez différentes.

Si l'on fait l'histogramme sur l'ensemble des mesures du temps $\tau_{1}$ effectuées pour la phase G2 (Figure 4-29 A), on remarque la présence de deux pics centrés sur les deux paliers 
présentés ci-dessus. On peut noter que $86 \%$ des mesures sont comprises entre $5.10^{-3}$ et $30.10^{-3}$ s. On note également un léger épaulement autour de $35.10^{-3} \mathrm{~s}$. La Figure 4-29 B présente la distribution en probabilité tirée de cet histogramme. On notera qu'elle est très différente des distributions obtenues pour les phases G0/1 et S.

A
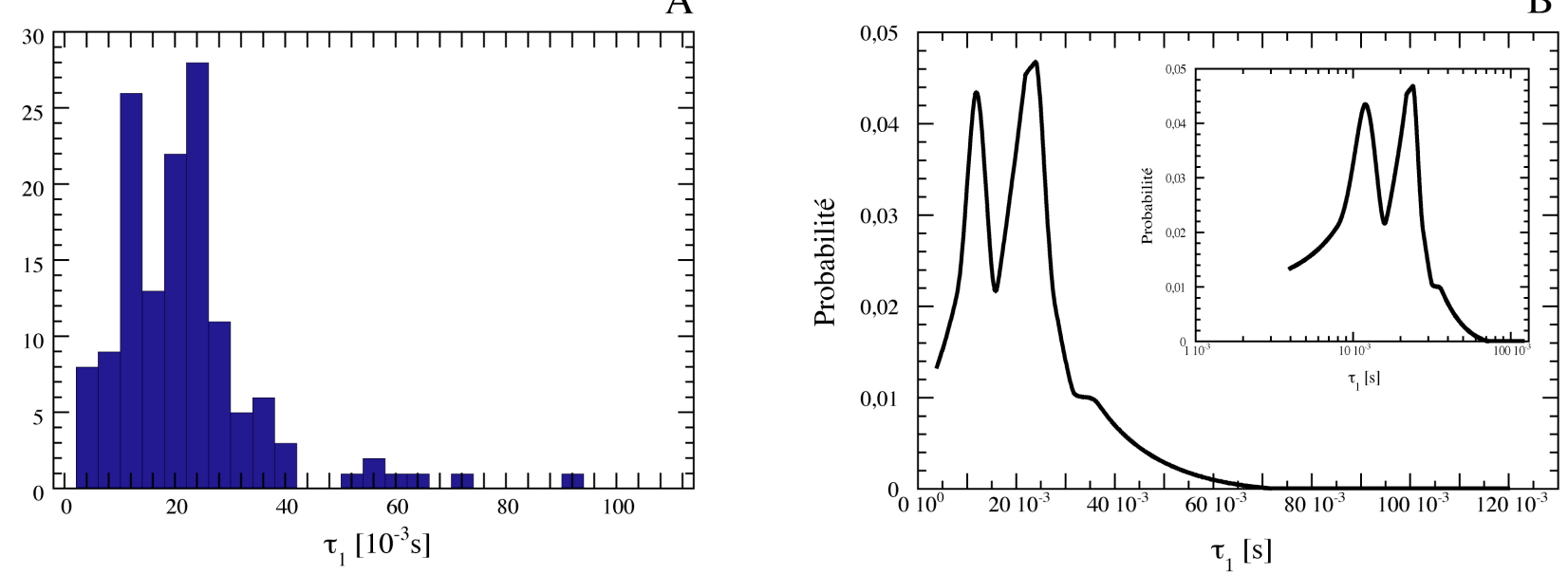

Figure 4-29 : Histogramme (A) et distribution en probabilité ( $B$; échelle semi-log en insert) du temps $\tau_{1}$ sur la totalité des mesures effectuées pendant la phase G2.

\section{4-4) Temps $\tau_{2}$}
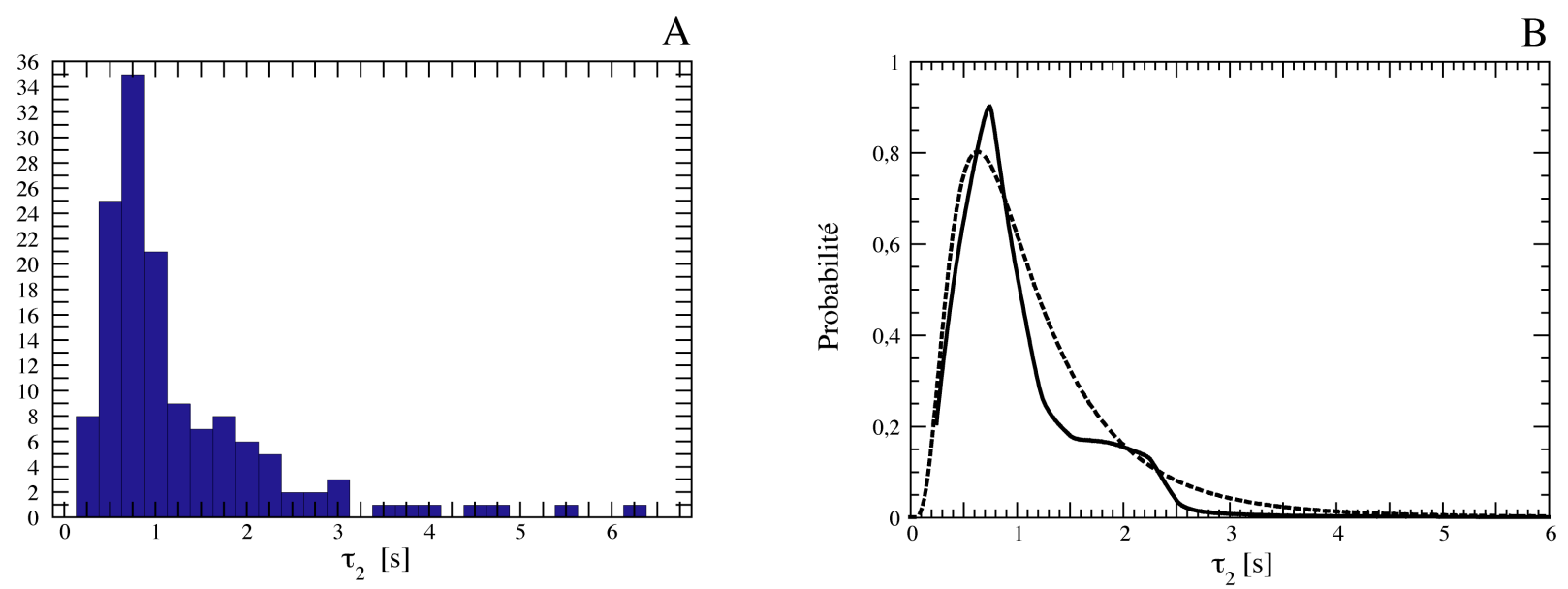

Figure 4-30 : Histogramme (A) et distribution en probabilité $(B)$ du temps $\tau_{2}$ pour de cellules à majorité en phase G2. La distribution (trait plein) est ajustée par une loi log normale de moyenne 1,2 s et d'écart-type 0,84 (trait pointillé).

La majorité des temps de relaxation $\tau_{2}$ (Figure 4-30) est là encore comprise entre 0,5 et $2 \mathrm{~s}$. Toutefois, la distribution semble différente de celles observées pour les phases G0/1 et $\mathrm{S}$. Ainsi, cette distribution présente un pic autour de $0,7 \mathrm{~s}$ et un épaulement entre 1,5 et 2,5 s.

Comme pour les autres phases nous avons essayé d'ajuster cette distribution par une loi log-normale. Du fait de l'épaulement, cet ajustement est moins bon que pour les phases G0/1 et S. L'ajustement donne une moyenne de $1,2 \mathrm{~s}$ et un écart-type de 0,84 s. Cette analyse semble confirmer que cette distribution des temps de relaxation $\tau_{2}$ est différente des distributions du temps $\tau_{2}$ pour les phases G0/1 et $\mathrm{S}$ qui semblaient identiques. Cependant, il 
faut considérer cette différence avec précaution, du fait de l'incertitude sur l'estimation des valeurs de $\tau_{2}$ (voir paragraphe I $>$ ).

\section{4-5) Coefficients d'étirement $\alpha$}

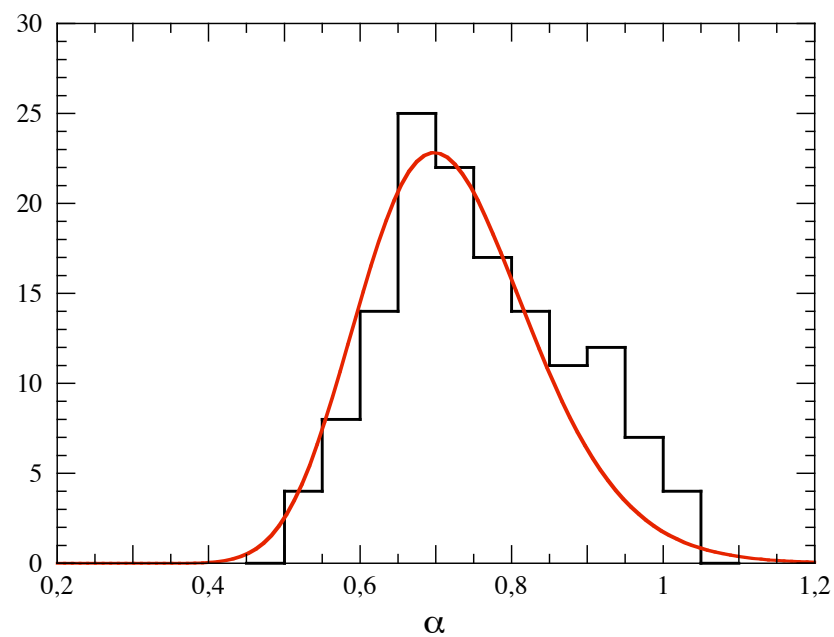

Figure 4-31 : Histogramme des coefficients d'étirement $\alpha$ pour des cellules majoritairement en phase G2. L'ajustement est fait par une loi log-normale de moyenne 0,72 et d'écart-type 0.12 .

La majorité des coefficients d'étirement $\alpha$, est compris entre 0,45 et 1 (Figure 4-31). Toutefois, contrairement aux autres phases, on note un nombre plus important de mesures audessus de 0,7. Ici, la distribution de probabilité est mieux ajustée par une loi log-normale que par une gaussienne. Cet ajustement nous donne une moyenne de 0,72 pour un écart-type de 0,12 . La distribution des coefficients semble donc différente de celles observées pour les phases $\mathrm{G} 0 / 1$ et $\mathrm{S}$.

\section{4-6) Conclusions}

Les distributions des paramètres pour la phase G2 sont clairement différentes de celles observées pour les phases G0/1 et S. Ainsi, $\langle N\rangle$ est moyenné par environ $220 \mathrm{kcps} / \mathrm{s}$ avec un écart type de 160. La moyenne est à peu près équivalente à celle obtenue en G0/1 par contre la distribution est plus resserrée, ce qui implique des modulations sur des temps longs moins importantes qu'en G0/1, mais qui restent plus importantes qu'en S.

Le temps de relaxation du mode rapide $\tau_{1}$ se situe principalement entre $5.10^{-3}$ et $30.10^{-3}$ $\mathrm{s}$ avec des pics pour $10.10^{-3}$ et $20.10^{-3} \mathrm{~s}$.

Concernant le temps de relaxation du mode lent $\tau_{2}$, il se situe plutôt entre 0,5 et $2 \mathrm{~s}$ avec un pic autour $0,7 \mathrm{~s}$ et un épaulement entre 1,5 et 2,5 s. L'ajustement de cette distribution par une loi log-normale donne une moyenne de $1,2 \mathrm{~s}$ avec un écart-type de $0,84 \mathrm{~s}$. La distribution de $\tau_{2}$ semble donc sensiblement différente de celles obtenues en phases G0/1 et $\mathrm{S}$.

Le coefficient d'étirement $\alpha$ est principalement compris entre 0,45 et 1 . Contrairement aux autres phases, on note un nombre important de valeur de $\alpha$ au-dessus de 0,7. La distribution de $\alpha$ semble elle aussi sensiblement différente de celles obtenues en phases G0/1 et $\mathrm{S}$. 


\section{5) Distributions des valeurs des 4 paramètres pour la phase $M$}

La phase M ne peut être distinguée de la phase G2 sur les mesures de FACS. On ne peut donc pas prédire à partir de quel moment la majorité des cellules est en M. Nous avons déjà expliqué, au chapitre 3, qu'après avoir laissé les cellules sous HU pendant 15 heures, on observe un nombre important de cellules en phase $M$ entre 9 et 10 heures après avoir retiré HU (environ 9 cellules sur 10 entrent en mitose). On reconnaît à l'écran que les cellules sont en phase $\mathrm{M}$ uniquement lorsque l'enveloppe nucléaire est dissoute et que le noyau n'est plus distinguable du reste de la cellule. On ne peut dire que les mesures correspondent à la phase $M$ qu'à ce moment là. L'important état de condensation de la chromatine rend les chromosomes visibles par notre système de visualisation. Il est donc possible, surtout pendant la métaphase où les chromosomes sont bien alignés au centre de la cellule, de focaliser le faisceau laser sur ces derniers et d'observer le signal qui en résulte. Toutefois, les mitoses arrivant relativement tardivement après le début de l'expérience et les mesures étant difficile à réaliser correctement, nous ne disposons que de 42 mesures sur 6 noyaux. Cela est toutefois déjà suffisant pour tirer des premières conclusions.

\section{5-1) Nombre moyen $\langle N\rangle$ de photons détectés au cours d'une mesure}

Tout d'abord l'intensité moyenne $\langle N\rangle$ semble beaucoup plus importante que pour les autres phases du cycle cellulaire. En général, l'intensité diffusée devient très grande et elle devient même tellement importante que pour éviter de saturer le corrélateur, nous devons baisser la puissance du faisceau laser incident.

\section{5-2) Temps $\tau_{1}$}

$88 \%$ des mesures du temps de relaxation $\tau_{1}$ sont comprises entre $5.10^{-3}$ et $35.10^{-3} \mathrm{~s}$. L'histogramme sur l'ensemble des mesures montre un seul pic centré sur $12.10^{-3} \mathrm{~s}$ (Figure 4-32 A) et une queue vers les temps longs. La distribution (Figure 4-32 B) peut donc s'ajuster par une loi log-normale de moyenne $20.10^{-3} \mathrm{~s}$ et d'écart-type $12,4.10^{-3} \mathrm{~s}$. Cette distribution est très différente de celles des phases G0/1, S et G2.
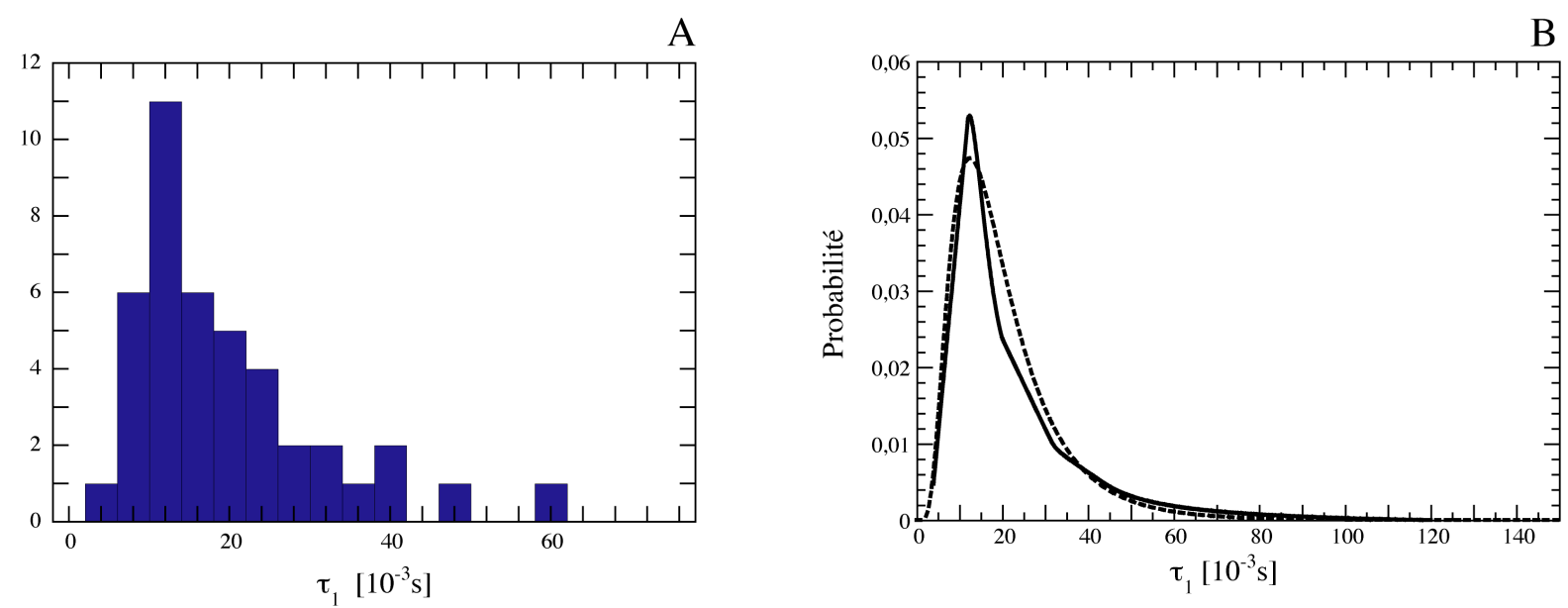

Figure 4-32 : Histogramme $(\boldsymbol{A})$ et distribution en probabilité $(\boldsymbol{B})$ du temps $\tau_{1}$ sur la totalité des mesures effectuées pendant la phase $M$. . La distribution (trait plein) est ajustée par une loi log-normale de moyenne $20.10^{-3} \mathrm{~s}$ et d'écart type $12,4.10^{-3} \mathrm{~s}$ (trait pointillé). 


\section{5-3) Temps $\tau_{2}$}
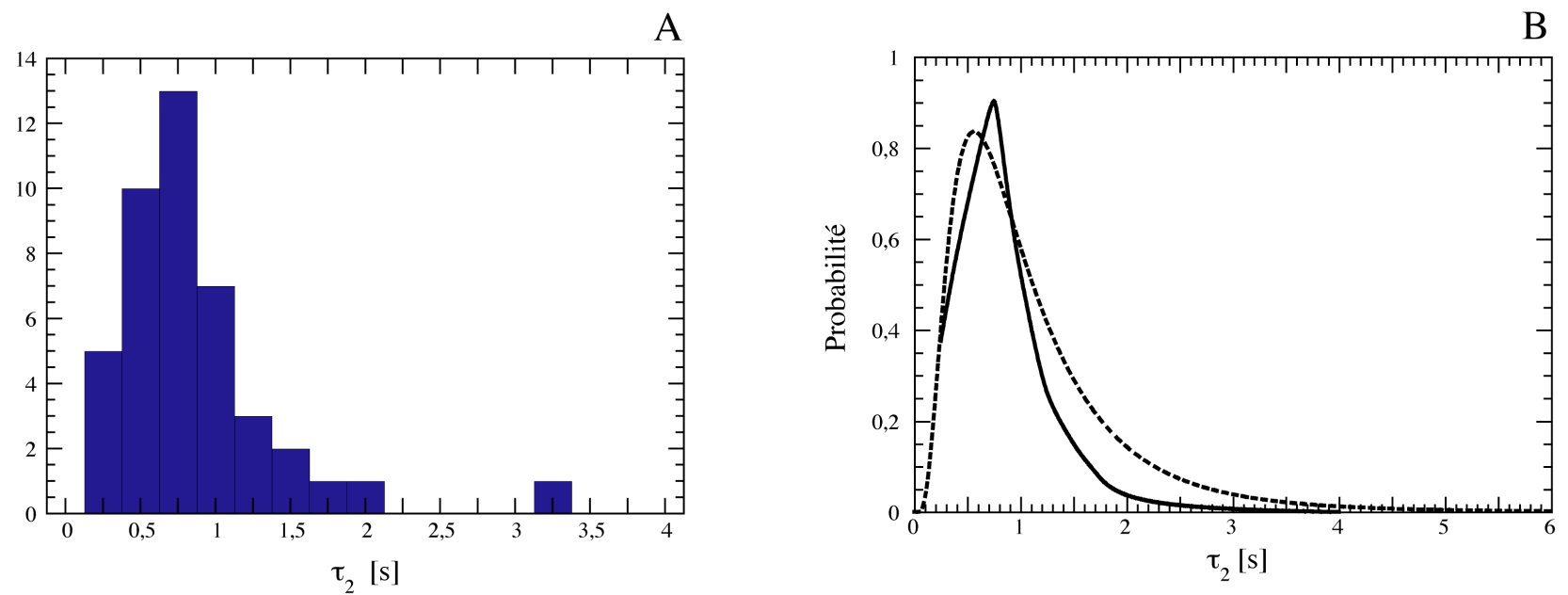

Figure 4-33 : Histogramme $(\boldsymbol{A})$ et distribution en probabilité $(\boldsymbol{B})$ du temps $\tau_{2}$ pour des cellules à majorité en phase $M$ (trait plein). La distribution est ajustée par une loi lognormale (trait pointillé).

Concernant le temps de relaxation $\tau_{2}$, la plupart du temps les valeurs se situe entre 0,3 et 1,5 s (86\% des mesures). L'histogramme (Figure 4-33 A) est très piqué autour de $0,7 \mathrm{~s}$. Du fait de la mauvaise statistique, la distribution (Figure 4-33 B) s'ajuste moins bien que pour les autres phases avec une loi log-normale. Cependant, on peut tirer de cet ajustement une valeur moyenne de $1,12 \mathrm{~s}$ avec un écart-type de $0,85 \mathrm{~s}$. Cette distribution semble assez différente de celles trouvées en G0/1 et S, mais semble plutôt proche de celle trouvée en G2.

\section{5-4) Coefficient d'étirement $\alpha$}

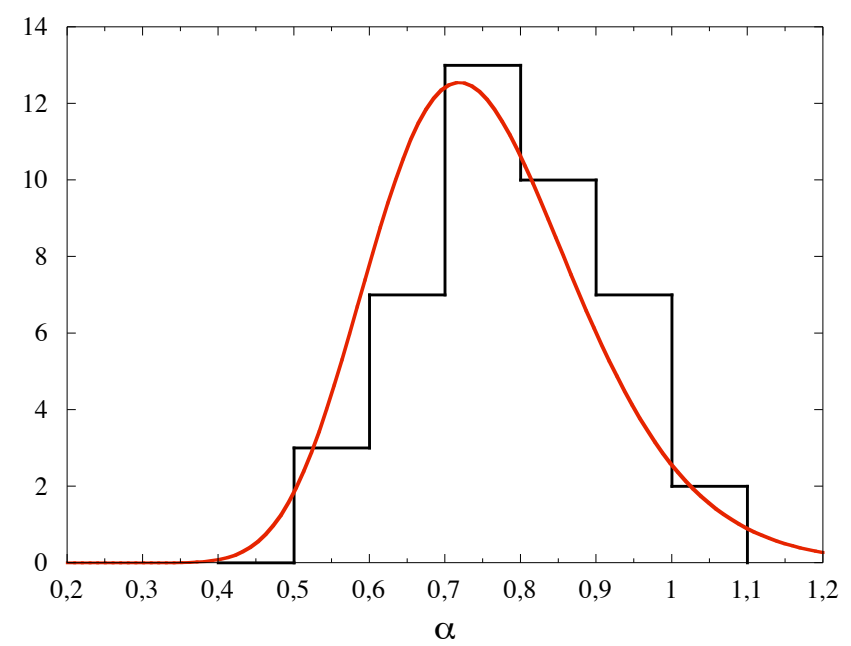

Figure 4-34 : : Histogramme des coefficients d'étirement $\alpha$ pour des cellules en phase $M$. L'ajustement est fait par une loi log-normale de moyenne 0,75 et d'écart type 0,14.

La majorité des coefficients d'étirement $\alpha$, est compris entre 0,5 et 1 (Figure 4-34). Comme pour la phase G2 on note un nombre plus important de mesures au-dessus de 0,7. La distribution de probabilité est également ajustée par une loi log-normale. Cet ajustement nous 
donne une moyenne de 0,72 pour un écart-type de 0,12 . La distribution des coefficients semble donc assez proche de celle observée pour des cellules majoritairement en phase G2.

\section{5-5) Conclusions}

Malgré le peu de mesure que nous avons, entraînant une moins bonne statistique que dans les autres phases, nous pouvons conclure que les distributions des différents paramètres semblent être caractéristiques de la phase $\mathrm{M}$.

Déjà, l'intensité diffusée est bien plus importante que dans les autres phases, ce qui peut s'expliquer par la forte condensation de la chromatine, entraînant localement un changement important de concentration, et également par l'importante réorganisation de l'ensemble de la cellule en préparation à la division.

Le temps de relaxation du mode rapide, $\tau_{1}$, a une gamme de valeurs principalement comprise entre $5.10^{-3}$ et $35.10^{-3} \mathrm{~s}$ et présente une distribution très différentes de celles de autres phases. Cette distribution peut être ajustée par une loi log-normale de moyenne $20.10^{-3}$ $\mathrm{s}$ avec un écart-type de $12,4.10^{-3} \mathrm{~s}$.

Le temps de relaxation du mode lent, $\tau_{2}$, semble principalement compris entre 0,3 et 1,5 s. Malgré plus de difficultés pour ajuster la distribution par une loi log-normale, on trouve une moyenne de $1,12 \mathrm{~s}$ avec un écart-type de $0,85 \mathrm{~s}$.

Le coefficient d'étirement $\alpha$ est principalement compris entre 0,5 et 1 . Comme pour la phase G2, on note un nombre important de valeur de $\alpha$ au-dessus de 0,7 . La distribution de $\alpha$ semble assez proche de celle obtenue pour des cellules majoritairement en phase G2.

\section{$\underline{\text { IV }>\text { Discussion }}$}

Dans cette partie, nous allons essayer d'apporter les premiers éléments d'explication (les plus simples) concernant l'évolution des paramètres mesurés, $\langle N\rangle, \alpha, \tau_{1}$ et $\tau_{2}$, au cours du cycle cellulaire, de présenter les différentes questions que soulèvent nos résultats et, aussi, de proposer certaines hypothèses.

\section{1) Valeurs du paramètre $\langle N\rangle$ au cours du cycle cellulaire}

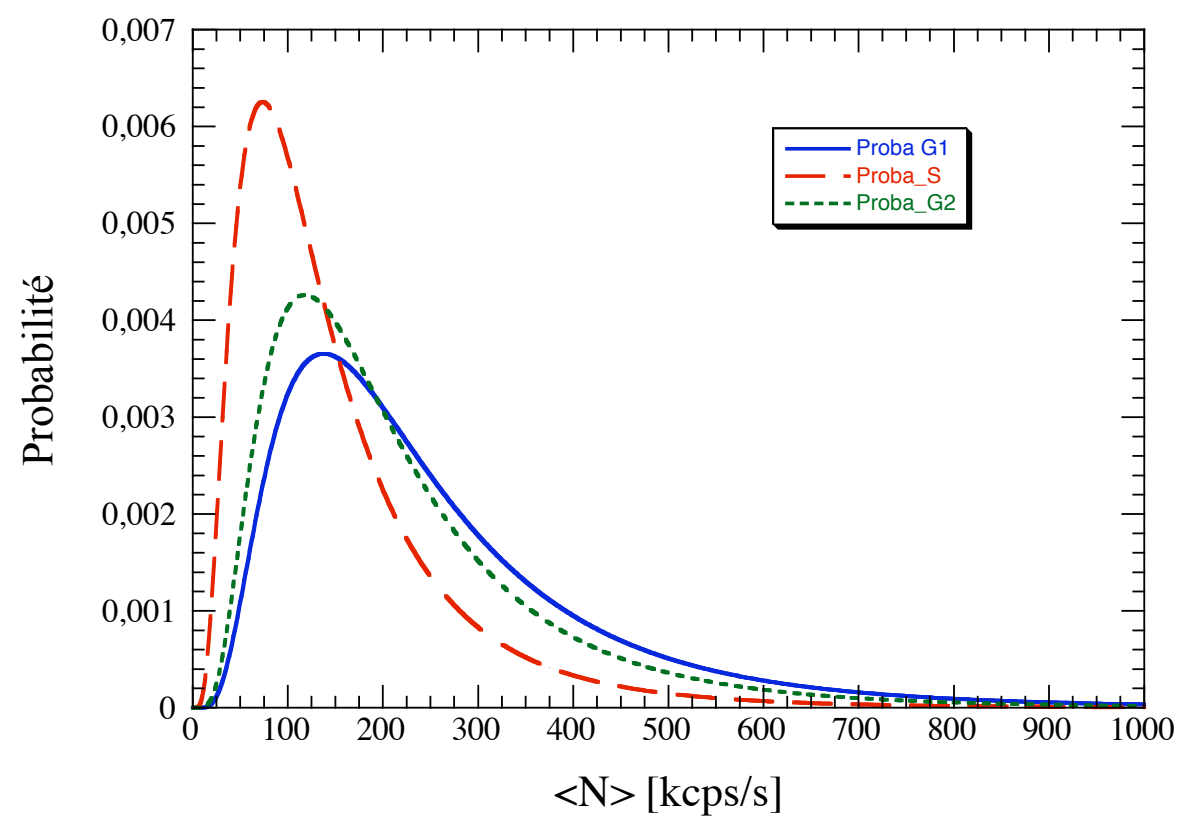

Figure 4-35 : Distributions en probabilité de $\langle N\rangle$ pour les phases G0/1, S, G2. 
Comme le montre la Figure 4-35, que les mesures soient réalisées pendant les phases G0/1, S ou G2, la distribution en probabilité du nombre moyen de photons détectés par seconde au cours d'une mesure, $\langle N\rangle$, peut toujours s'ajuster par une loi log-normale. La moyenne et l'écart-type de ces distributions sont différents pour chaque phase. Ainsi la moyenne de la distribution de $\langle N\rangle$ pour phase G0/1 (260 kcps/s) est plus importante, et la largeur de cette distribution plus grande (écart type de $190 \mathrm{kcps} / \mathrm{s}$ ) que pour la phase $\mathrm{S}$ (moyenne de 150 $\mathrm{kcps} / \mathrm{s}$ et écart type de $120 \mathrm{kcps} / \mathrm{s}$ ) et la phase G2 (moyenne de $220 \mathrm{kcps} / \mathrm{s}$ et écart-type de 190 $\mathrm{kcps} / \mathrm{s})$.

Comme nous l'avons expliqué au début de ce chapitre, les fluctuations de $\langle N\rangle$ sont dues à des problèmes de statistique et proviennent des modulations de l'intensité diffusée sur des temps qui ne sont pas négligeables devant la durée de la mesure. Ainsi, une distribution large de $\langle N\rangle$ indique des variations importantes de l'intensité diffusée pendant la durée de la mesure, tandis qu'une distribution plus serrée signifie des variations moins importantes. L'importante valeur de l'écart-type de la distribution de $\langle N\rangle$ en phase G0/1 est donc significative de variations importantes de l'intensité diffusée sur des temps longs (variations que l'on observe sur le signal brut). Ces variations sont moins importantes en phase $S$ et en phase G2 puisque, dans ces deux cas, l'écart-type est plus faible que pour la phase G0/1. On peut donc en conclure que les processus qui sont à l'origine de ces variations lentes de l'intensité diffusée sont très probablement modifiés au cours du cycle cellulaire. Cependant, à l'heure actuelle, nous n'avons pas vraiment d'idées sur l'origine de cette dynamique très lente. Une hypothèse est qu'elle pourrait être due aux mouvements des territoires chromosomiques, en effet, il a été montré (Tumbar et Belmont, 2001) que les mouvements de ces territoires dans à l'intérieur du noyau sont plus importants en phase G0/1 qu'en phases $S$, ou G2.

Les valeurs moyennes des distributions de $\langle N\rangle$ représentent très certainement les valeurs moyennes de l'intensité diffusée par le noyau que l'on obtiendrait si on faisait les mesures sur des temps très longs. Ce dernier paramètre est donc caractéristique de l'état du noyau (c'est la diffusion statique). L'angle de diffusion étant petit, on peut faire l'hypothèse que l'intensité de la lumière diffusée est proche de celle qui est diffusée à vecteur d'onde nul. Cette valeur est donc fortement liée à l'amplitude des fluctuations de concentration de grandes longueurs d'onde dans le noyau, mais, aussi à la concentration d'objets diffusants dans le volume sondé, ainsi qu'à leur masse et taille (diffusion de Mie; van de Hulst, 1981). Ceci signifie que l'interprétation de ce paramètre n'est pas aisée. L'intensité diffusée est généralement plus forte en phase G0/1 qu'en phases S et G2, et l'intensité diffusée en phase G2 est plus forte qu'en phase $\mathrm{S}$. La concentration en ADN augmentant significativement entre les phases $\mathrm{S}$ et G2, ceci pourrait expliquer l'augmentation de l'intensité entre les phases $S$ et G2. L'importance de la moyenne de $\langle N\rangle$ pour la phase G0/1 pourrait s'expliquer par deux importants facteurs provenant de la forte activité transcriptionnelle du noyau lors de la phase G0/1 : une augmentation importante de la concentration en ARN dans le noyau et un nombre important de mouvements de particules à grande échelle (migration des ARNm vers le cytoplasme,...). Enfin, notons que lors de la phase S, les mouvements de particules et les changements de concentration dans le noyau sont principalement engendrés par la réplication de l'ADN et sont donc très localisés et moins importants que pour les autres phases.

\section{2) Valeurs du coefficient d'étirement $\alpha$ au cours du cycle cellulaire}

La décroissance exponentielle étirée en fonction du temps du processus de relaxation rapide, pourrait en fait décrire une distribution large de temps de relaxations. Selon Castaing et Souletie (1991), dans les systèmes qui ne sont pas à l'équilibre thermodynamique, une distribution large de temps caractéristiques peut provenir de l'existence d'un ensemble de 
processus hiérarchisés qui gouverne l'évolution en fonction du temps d'un phénomène, d'une étape vers la suivante, chaque étape ayant son propre temps caractéristique (comme dans le cas d'un processus de vieillissement). Dans ce cas, la distribution des temps de relaxation du phénomène suit une loi log-normale. Le paramètre $\boldsymbol{M}$ de cette loi log-normale (voir équation (4-3)) correspond au taux de relaxation $\tau_{1}$ de l'exponentielle étirée. Le paramètre $\sigma$ de cette loi log-normale (voir équation (4-3)) est relié à l'exposant $\alpha$ par la relation (Castaing et Souletie, 1991) :

$$
\alpha=\frac{1}{\sqrt{1+\sigma^{2}}}
$$

Un tel comportement est typique de nombreux phénomènes biologiques dont l'évolution au cours du temps est le fait d'une succession ordonnée de différents processus, chacun de ces processus ayant son propre temps caractéristique. Il n'est alors pas surprenant, dans nos expériences, d'observer un processus de relaxation donnant une décroissance exponentielle étirée en fonction du temps.

Pour les cellules en phase G0/1, les coefficients d'étirement $\alpha$ sont tous compris entre 0,35 et 1 . La distribution en probabilité des coefficients $\alpha$ suit une loi gaussienne de moyenne 0,62 avec un écart type de 0,1 . Pour la phase $S$, toutes les valeurs du coefficient d'étirement $\alpha$ se situent également entre 0,35 et 1 . La distribution en probabilité de $\alpha$ suit également une loi gaussienne de moyenne 0,66 et d'écart type 0,074. Cette distribution est de moyenne semblable, mais plus resserrée, que celle qui est obtenue pour la phase G0/1. Pour la phase G2, les coefficients $\alpha$ sont compris entre 0,45 et 1 . Cette fois, la distribution en probabilité suit une loi log-normale de moyenne 0,72 et d'écart type 0,12. La probabilité d'obtenir un coefficient $\alpha$ supérieur à 0,7 est donc plus important pour la phase G2 que pour les phases $\mathrm{G} 0 / 1$ et $\mathrm{S}$; la distribution est légèrement différente. Pour la phase $\mathrm{M}$, les coefficients $\alpha$ sont compris entre 0,5 et 1 et environ $65 \%$ des mesures sont au-dessus de 0,7. Cette distribution en probabilité peut s'ajuster par une loi log-normale de moyenne 0,75 et d'écart type 0,14. Comme le montre la Figure 4-36 qui représente, ensemble, les distributions en probabilité des coefficients d'étirement $\alpha$, mesurés sur des cellules en phases G0/1, S, G2 et M, nous observons au cours de l'évolution dans le cycle cellulaire que ces distributions se déplacent vers 1 (leur moyenne augmente). De plus, on remarque que la distribution en phase $\mathrm{S}$ est beaucoup plus resserrée que dans les autres phases. Suivant l'hypothèse que nous avons faite au-dessus, cette évolution des valeurs moyennes des distributions pourrait signifier que les distributions des temps caractéristiques de relaxations contribuant à la valeur obtenue pour le temps $\tau_{1}$ lors d'une mesure sont moins larges en phases G2, ou M, qu'en phases G0/1, ou S. Il est cependant difficile d'aller beaucoup plus loin dans la discussion sans plus d'informations sur les processus biologiques à l'origine de la dynamique rapide.

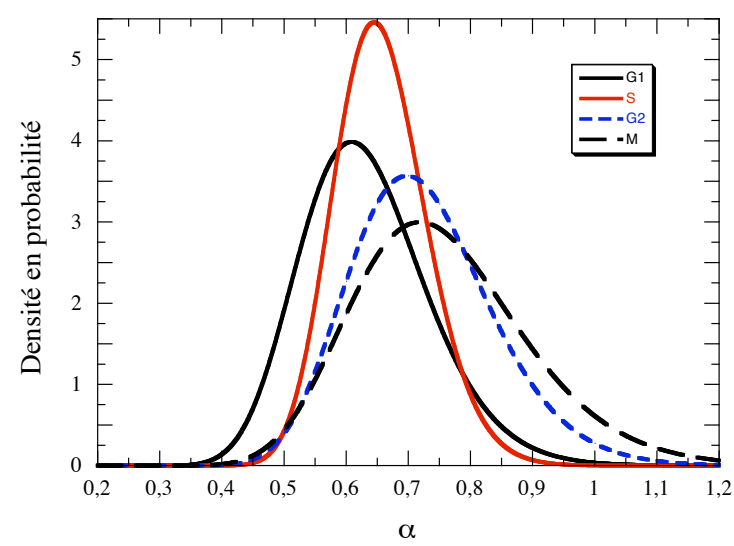

Figure 4-36 : Comparaison des distributions en probabilité des coefficients d'étirement $\alpha$ mesurés sur des cellules en phases G0/1, S, G2 et M. 


\section{3) Valeurs du temps de relaxation $\tau_{1}$ au cours du cycle cellulaire}

\section{3-1) Cellules en phase G0/1 avec et sans HU.}

Pour une cellule en phase G0/1, avec ou sans HU dans le milieu de culture, les temps de relaxations $\tau_{1}$ sont principalement compris entre $15.10^{-3}$ et $60.10^{-3} \mathrm{~s}$ (autour de $85 \%$ des mesures). Le taux de cellules en phase G0/1 étant, en général, supérieur à $90 \%$ lors des mesures réalisées pour cette phase, que ce soit avec ou sans HU, ces résultats nous donnent un « profil » assez précis de la distribution du temps de relaxation $\tau_{1}$ pour les cellules en phase G0/1. Avec et sans HU, la distribution en probabilité des temps $\tau_{1}$ montre trois gammes de temps caractéristiques différents respectivement centrées autour de $20.10^{-3}, 35.10^{-3}$ et $55.10^{-3}$ s. L'existence de ces trois gammes de temps semble confirmée par l'existence de «paliers » (voir Figure 4-17) pour les cellules sans HU (pour les cellules avec HU, on a moins de données pour chaque cellule et donc il est plus difficile de voir ces paliers). Cependant, on remarque qu'il existe une différence nette entre la distribution obtenue pour les cellules sous HU et celle qui est obtenue pour les cellules sans HU (voir Figure 4-37). La présence de HU dans le milieu de culture à l'air de favoriser les temps courts, l'allure de la distribution pour les cellules sans HU est beaucoup plus écrasée que celle pour les cellules avec HU et, le " pic » à $35.10^{-3} \mathrm{~s}$ que nous observons dans la distribution des temps $\tau_{1}$ obtenue pour des cellules sans HU s'effondre pour ne donner qu'un épaulement dans la distribution des temps $\tau_{1}$ obtenue pour des cellules sous HU. Donc, on peut dire que, très probablement, la présence de HU dans le milieu de culture change la dynamique rapide interne du noyau des cellules en phase G0/1, mais, on ne sait pas expliquer comment. A ce point de notre étude, nous ne pouvons pas associer les distributions obtenues à un phénomène biologique particulier, ou à un ensemble de phénomènes. En particulier, nous ne pouvons pas dire si les trois temps caractéristiques observés à environ $20.10^{-3}, 35.10^{-3}$ et $55.10^{-3} \mathrm{~s}$ sont reliés au même processus biologique, ou, au contraire à des processus biologiques différents qui ont lieu à des moments différents dans les cellules en phases G0/1.

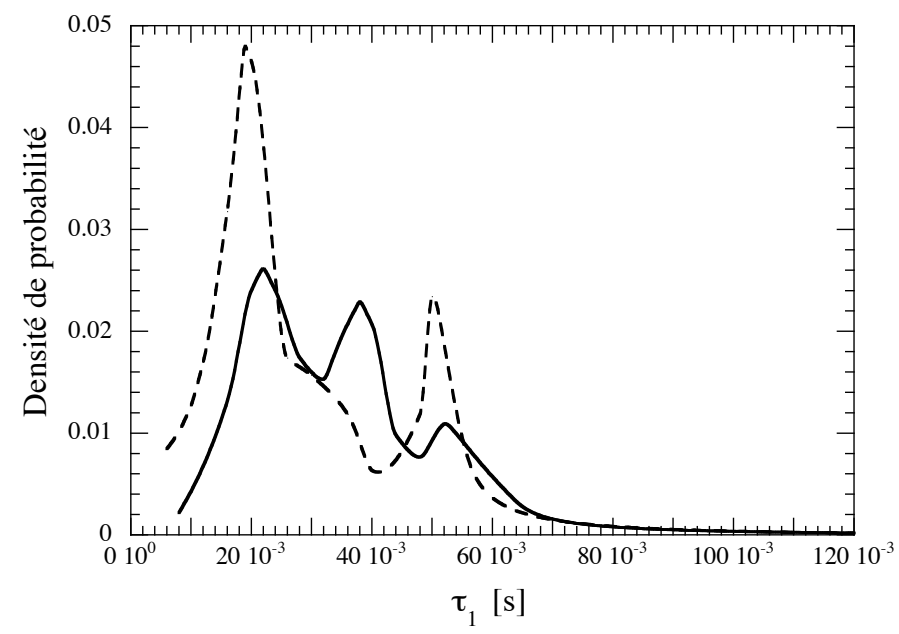

Figure 4-37 : Comparaison des densités de probabilité des temps $\tau_{1}$ mesurés sur des cellules en phase G0/1 sans $H U$ (trait plein) et avec HU (pointillé).

Un autre résultat intéressant obtenu sur les cellules en phase G0/1 est qu'en général (dans 90\% des cas), une série de mesures consécutives sur le même noyau (donc sur une durée totale de 25-30 minutes) donne soit des temps $\tau_{1}$ compris entre $15.10^{-3}$ et $40.10^{-3} \mathrm{~s}$, soit compris entre $30.10^{-3}$ et $70.10^{-3} \mathrm{~s}$. Ceci suggère l'existence de deux types de dynamiques 
différentes pour les noyaux des cellules en phase G0/1 (avec, probablement, la possibilité de passage d'un état à l'autre suggérée par les $10 \%$ de cellules pour lesquelles les mesures de $\tau_{1}$ sont comprises entre $15.10^{-3}$ et $70.10^{-3} \mathrm{~s}$ ). Ces deux types de dynamiques reflétant probablement deux états différents de la phase $\mathrm{G} 0 / 1$.

\section{3-2) Cellules en phases $S$ et $G 2$.}

Lorsque les mesures sont réalisées sur une population composée majoritairement de cellules en phase $\mathrm{S}$, ou $\mathrm{G} 2$, nous avons essayé d'affiner nos résultats en retirant les mesures effectuées sur des cellules pour lesquelles nous retrouvions le profil du temps de relaxation $\tau_{1}$ de la phase G0/1 (environ 20\% des cellules pour les « systèmes » expérimentaux majoritairement en phase S sans HU, 5\% pour ceux en phase G2 sans HU et 35\% pour ceux sous HU). Dans tous les cas, pour la majorité des mesures restantes, les temps caractéristiques se situent principalement entre $5.10^{-3}$ et $35-40.10^{-3} \mathrm{~s}$. On obtient donc des temps de relaxations $\tau_{1}$ plus rapides que pour la phase G0/1. Il faut noter ici, que jusqu'à présent, les différentes mesures du temps $\tau_{1}$ réalisées, ne nous ont pas permis de différencier clairement les cellules en phase $\mathrm{S}$ des cellules en phase G2. Sous HU, une fois les cellules en G0/1 enlevées, on a environ $50 \%$ de cellules en phase $\mathrm{S}$ et $50 \%$ en phase G2. On observe un « pic » autour de $15.10^{-3} \mathrm{~s}$ et un épaulement vers $22.10^{-3} \mathrm{~s}$. Pour les «systèmes » expérimentaux majoritairement en phase S sans HU (typiquement, environ $75 \%$ de cellules en phase $\mathrm{S}$ et $25 \%$ en phase G2), la distribution en probabilité présente deux pics pour $12.10^{-3}$ et $22.10^{-3} \mathrm{~s}$ (voir Figure 4-24). Concernant les «systèmes » expérimentaux majoritairement en phase G2 (typiquement, environ $75 \%$ de cellules en phase $\mathrm{G} 2$ et $25 \%$ en phase S), la distribution en probabilité du temps $\tau_{1}$ montre aussi deux pics centrés autour de $12.10^{-3}$ et $22.10^{-3} \mathrm{~s}$. Mais, bien que ces valeurs soient assez semblables à celles qui sont obtenues pour la phase $S$, on peut cependant noter quelques différences notables. En particulier, quand on regarde la répartition des valeurs mesurées pour chaque cellule, pour les populations de cellules majoritairement en phase G2, on observe deux «paliers » (voir Figure 4-28), ce qui n'est pas le cas pour les populations de cellules majoritairement en phase $S$ (voir Figure 4-23). Nous noterons, aussi, que les pics à $12.10^{-3}$ et $20.10^{-3} \mathrm{~s}$ sont beaucoup plus prononcés pour la phase $\mathrm{G} 2$ et l'épaulement que l'on observe autour de $35.10^{-3} \mathrm{~s}$ sur la distribution pour la phase $\mathrm{S}$ est très nettement atténué sur la distribution pour la phase G2. Les deux distributions de temps $\tau_{1}$ présentent donc des différences significatives et il semble que la dynamique rapide en phase G2 soit plus rapide qu'en phase $\mathrm{S}$.

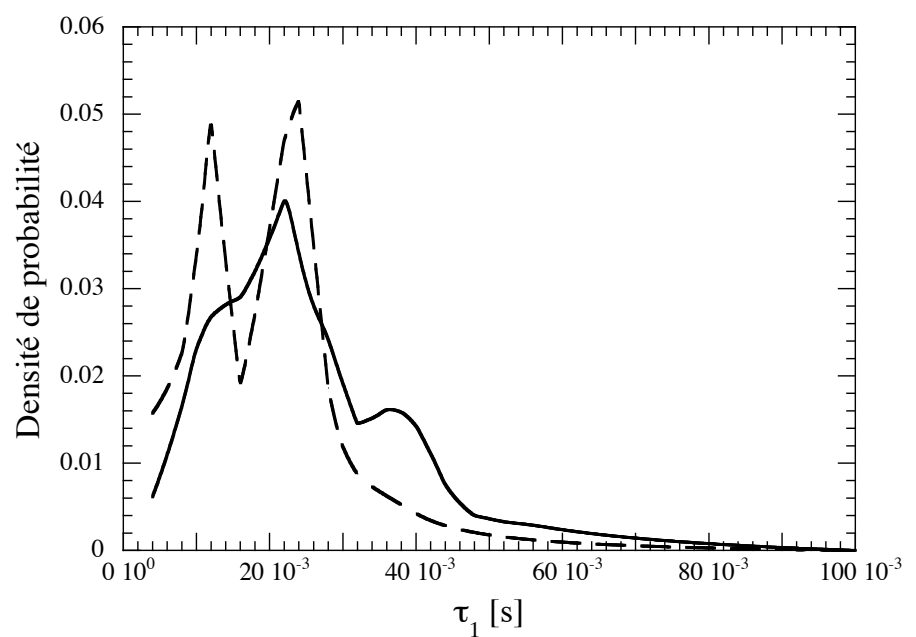

Figure 4-38: Comparaison des distributions de probabilité des temps $\tau_{1}$ estimées pour la phase $S$ (trait plein) et la phase G2 (pointillés). 
On utilise les deux distributions obtenues sur des cellules sans HU, pour extraire une allure un peu plus représentative des distributions en probabilité du temps $\tau_{1}$ pour les phases $\mathrm{S}$ et $\mathrm{G} 2$. On suppose que la distribution, $s$, obtenue sur des populations de cellules majoritairement en phase $S$ peut s'écrire : $s=(0,75 S+0,25 G 2)$, où $S$ et $G 2$ sont les distributions respectives pour les phases $\mathrm{S}$ et G2. De même, pour la distribution, $g_{2}$, obtenue sur des populations de cellules majoritairement en phase G2, on peut écrire : $g_{2}=(0,75 G 2$ $+0,25 S)$. De là, on en déduit que la distribution en probabilité du temps $\tau_{1}$ pour les phases $S$ est égale à : $S=\left(3 s-g_{2}\right) / 2$ et celle pour la phase G2 à : $G 2=\left(3 g_{2}-s\right) / 2$. Les distributions $\mathrm{S}$ et G2 ainsi obtenues sont présentées en Figure 4-38. Ces deux distributions sont clairement différentes. La distribution pour la phase $\mathrm{S}$ est assez large, de $5.10^{-3}$ à $50.10^{-3} \mathrm{~s}$ avec qu'un seul « pic » vraiment marqué autour de $22.10^{-3} \mathrm{~s}$ (ce qui peut expliquer que l'on ne voit pas de «paliers » quand on analyse les résultats cellule par cellule). Ce «pic » est encadré par deux épaulements à $15.10^{-3}$ et $35.10^{-3} \mathrm{~s}$. La distribution pour la phase G2 est plus étroite, de $5.10^{-3}$ à $30.10^{-3} \mathrm{~s}$, avec deux « pics », assez fins, autour de $12.10^{-3}$ et $22.10^{-3} \mathrm{~s}$ (centrés sur les paliers observés ; voir Figure 4-28). Les questions sont les mêmes que pour la phase G0/1 ; quels sont les phénomènes biologiques à l'origine de ces dynamiques ? Les temps caractéristiques observés dans ces deux phases sont-ils reliés à un seul processus biologique, ou, au contraire à des processus biologiques différents ayant lieu à des instants différents dans les cellules pendant ces phases?

Sur la Figure 4-39, nous montrons, ensemble, la distribution obtenue sur des populations de cellules sous $\mathrm{HU}$ avec une répartition 50-50 sur les phases $\mathrm{S}$ et G2 (résultats de la partie II >2-1) et la distribution estimée pour une telle population sans HU, en utilisant les distributions $S$ et $G 2$. Ces deux distributions sont différentes et suggère que la présence de HU dans le milieu de culture modifie la dynamique rapide des cellules en phases $\mathrm{S}$ et $\mathrm{G} 2$, comme elle le fait pour les cellules en phase G0/1. La présente de HU dans le milieu de culture semble conduire à une dynamique plus rapide.

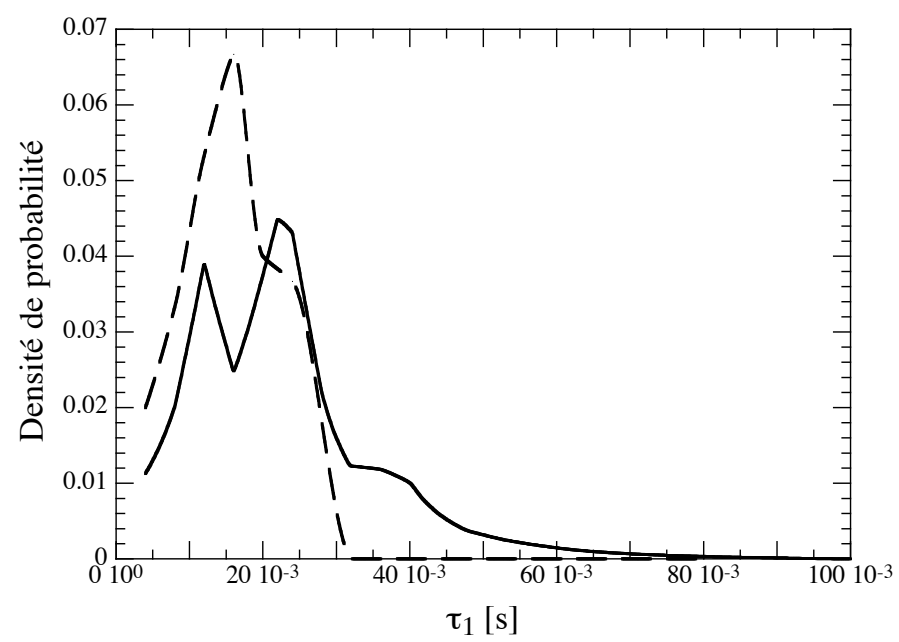

Figure 4-39 : Comparaison entre la distribution de probabilité des temps $\tau_{1}$ mesurés sur des cellules à moitié en phases $S$ et en phase G2 sous HU (insert de la Figure 4-13), et la distribution de probabilité des temps $\tau_{1}$ estimée pour une population à moitié en phases $S$ et en phase G2 sans HU (distribution réalisée à partir des données de la Figure 4-38). 


\section{3-3) Cellules en phase $M$.}

Les mesures effectuées pour la phase $M$ montre que, pour cette phase, les temps de relaxations $\tau_{1}$ sont principalement compris entre $5.10^{-3}$ et $35.10^{-3}$ s. Contrairement aux autres phases, la distribution en probabilité ne présente qu'un seul pic autour de $12.10^{-3} \mathrm{~s}$ et peut même s'ajuster par une loi log-normale de moyenne $35.10^{-3} \mathrm{~s}$. Cette dynamique rapide est donc très différente de celle que l'on a observée dans les autres phases du cycle cellulaire. Là encore, nous ne savons pas relier cette dynamique à des processus biologiques.

\section{3-4) Conclusion}

En conclusion, comme l'avait déjà suggéré nos premières expériences sur des cellules sous $\mathrm{HU}$, la distribution des temps de relaxations $\tau_{1}$ évolue au cours du cycle cellulaire. Cette évolution est illustrée en Figure 4-40, où l'on présente ensemble les distributions en probabilité des temps de relaxations $\tau_{1}$ pour les 4 phases du cycle cellulaire. On peut remarquer que pour les phases $\mathrm{G} 0 / 1, \mathrm{~S}$ et $\mathrm{G} 2$, ces distributions présentent toujours un «pic » autour de $20-22.10^{-3} \mathrm{~s}$. En présence de HU, la dynamique interne rapide des noyaux semble modifiée : elle semble plus rapide.

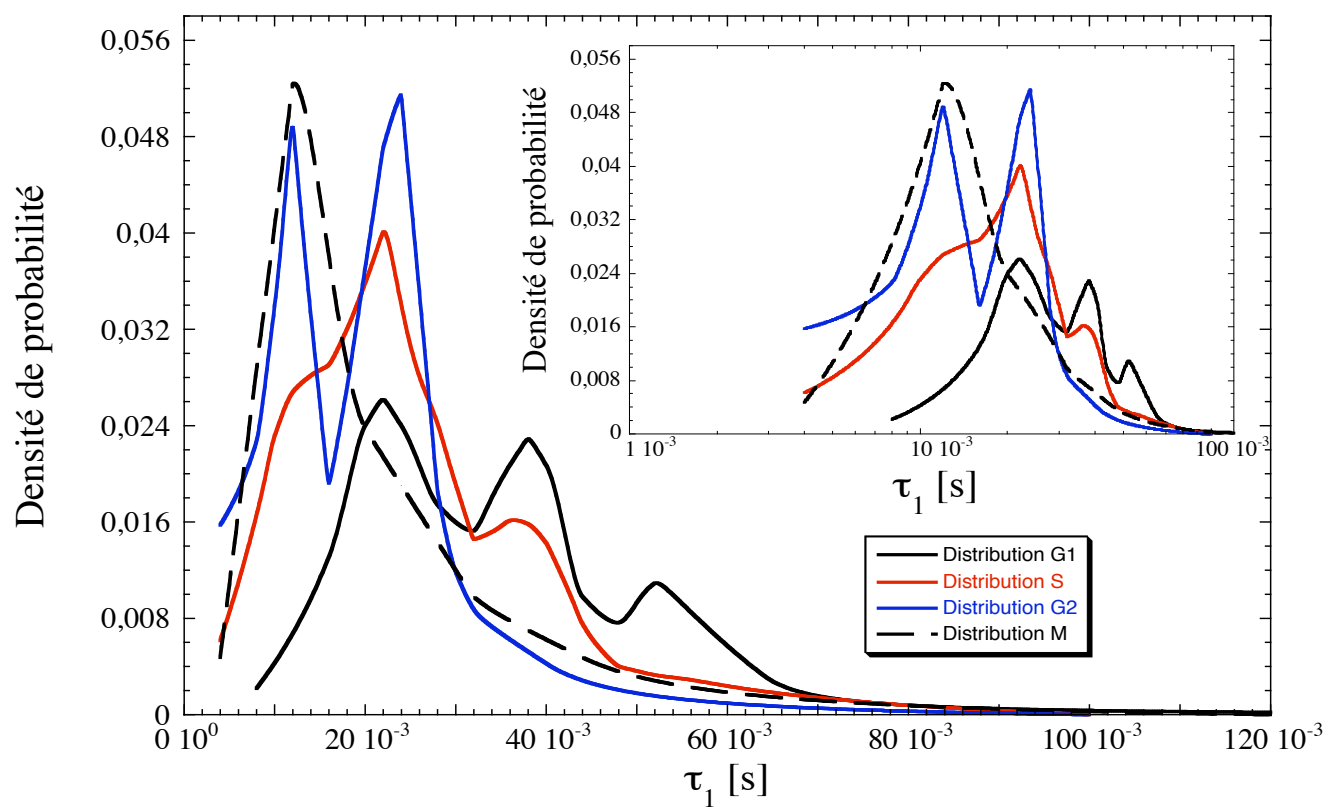

Figure 4-40 : Distributions en probabilité des temps de relaxation $\tau_{1}$ pour les phases $G 0 / 1$, $S, G 2$ et $M$.

\section{4) Valeurs du paramètre $\tau_{2}$ au cours du cycle cellulaire.}

Contrairement à ce que l'on a pu observer pour le temps de relaxation $\tau_{1}$, les temps de relaxations du mode lent $\tau_{2}$ mesurés pour un même noyau balayent l'ensemble de la distribution, quelque soit la phase du cycle cellulaire pendant laquelle les mesures ont été réalisées. De plus, la distribution en probabilité du temps de relaxation $\tau_{2}$ obtenus pour les différentes phases du cycle cellulaire peut toujours s'ajuster par une loi log-normale. On peut, toutefois noter quelques différences dans ces distributions en fonction de la phase du cycle dans laquelle les mesures sont réalisées. 


\section{4-1) Cellules en phase G0/1 avec et sans $H U$.}

Pour les cellules en phase G0/1 sous HU, la plupart des valeurs du temps $\tau_{2}$ se situe entre 0,3 et 2,5 s. La distribution de probabilité montre un pic autour de $1 \mathrm{~s}$. La moyenne de cette distribution est de $1,35 \mathrm{~s}$ avec un écart type de 0,9 . Pour les cellules en phase G0/1 sans HU, les valeurs de $\tau_{2}$ se situent plutôt entre 0,2 et $2 \mathrm{~s}$. La distribution en probabilité montre un pic autour de $0,5 \mathrm{~s}$, avec une moyenne de 0,95 et un écart type $0,7 \mathrm{~s}$. La distribution du temps $\tau_{2}$ lorsque les cellules sont en G0/1 sous HU présente donc un décalage significatif vers des temps plus longs par rapport à la distribution des temps $\tau_{2}$ mesurés sur des cellules en phase G0/1 sans HU. Il se peut donc que, de même que pour la dynamique rapide, la présence de HU dans le milieu modifie la dynamique lente interne du noyau des cellules en phase G0/1. Il est surprenant de noter qu'en présence de HU, la dynamique rapide devient plus rapide et la dynamique lente plus lente.

\section{4-2) Cellules en phase $S$}

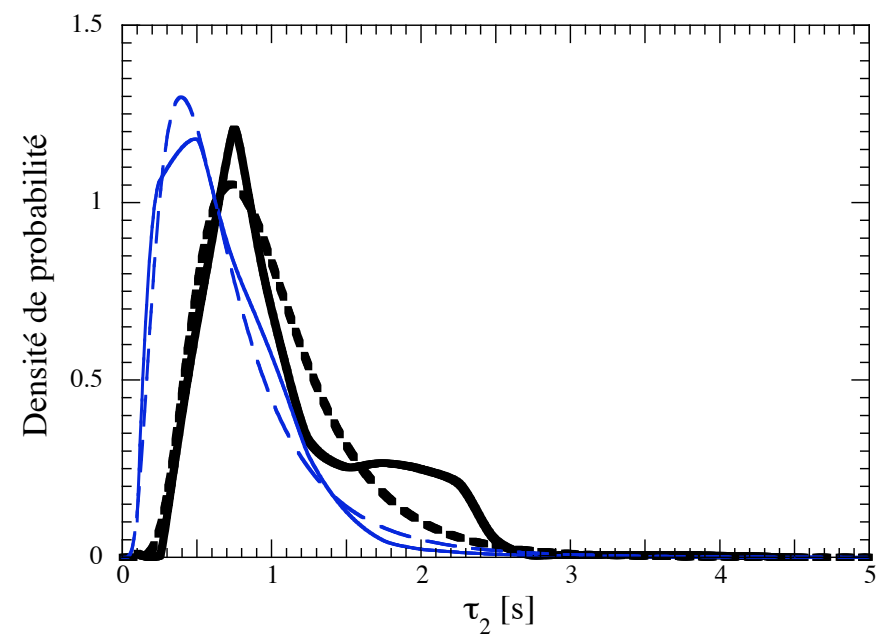

Figure 4-41 : Distribution en probabilité (trait plein) des temps $\tau_{2}$ estimée pour la phase $S$ (trait fin) et pour la phase G2 (trait fort). Ces distributions sont ajustée par des loi lognormale (trait pointillé).

Comme pour la dynamique rapide, en utilisant les données pour les distributions de temps $\tau_{2}$ respectivement sur une population de cellules majoritairement en $S$ (voir Figure 4-25) et sur une population de cellules majoritairement en G2 (voir Figure 4-30), on peut estimer, grossièrement, les distributions de temps $\tau_{2}$ pour les phases $S$ et $\mathrm{G} 2$ seules, en l'absence d'HU (voir Figure 4-41). On observe que les temps de relaxations $\tau_{2}$ se situe principalement entre 0,2 et $1,2 \mathrm{~s}$. Cette distribution en probabilité montre un pic centré sur $0,4 \mathrm{~s}$ et a une moyenne de $0,75 \mathrm{~s}$ pour un écart-type de $0,5 \mathrm{~s}$. Elle est donc légèrement différente de la distribution de temps $\tau_{2}$ obtenue en phase G0/1 sans HU; elle semble un peu plus rapide.

\section{4-3) Cellules en phase G2.}

La distribution en probabilité des temps de relaxations $\tau_{2}$ estimée pour des cellules en phase G2 est présentée à la Figure 4-41. Les temps de relaxations $\tau_{2}$ sont alors principalement compris entre 0,5 et $2 \mathrm{~s}$. Cette distribution en probabilité présente un pic assez fin centré à $0,75 \mathrm{~s}$ et un épaulement assez marqué entre $1,5 \mathrm{~s}$ et $2,5 \mathrm{~s}$. Cet épaulement n'est pas observable sur les distributions obtenues dans les autres phases du cycle cellulaire. Cette distribution diffère donc très fortement de celles qui ont été obtenues en phases G0/1, S et M. Cependant, 
cette distribution peut s'ajuster, assez correctement, par une loi log-normale de moyenne 1,0 s et d'écart-type 0,6 s. La dynamique lente semble donc un peu plus lente en phase G2 qu'en phases $\mathrm{G} 0 / 1$ et $\mathrm{S}$.

\section{4-4) Effets de $H U$}

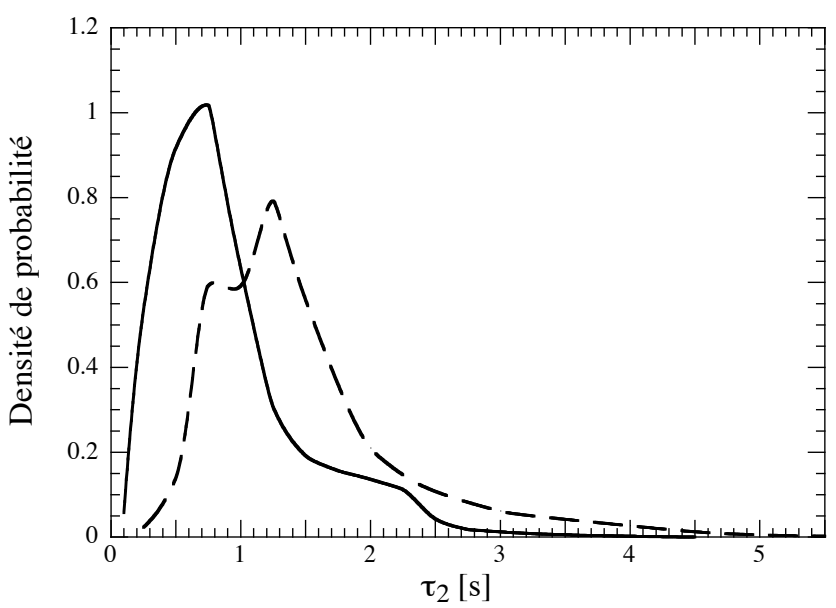

Figure 4-42 : Comparaison des distributions de probabilité, des temps $\tau_{2}$, estimées pour une population de cellules réparties dans différentes phases du cycle cellulaire avec $H U$ (trait pointillé) et sans HU (trait plein).

La Figure 4-42 montre la distribution en probabilité des temps $\tau_{2}$ mesurée pour un mélange de cellules dans différentes phases sous HU (voir Figure 4-14) et la distribution en probabilité des temps $\tau_{2}$ estimée pour une population identique. Manifestement, la présence de HU semble ralentir la dynamique lente, et ceci quelle que soit la phase du cycle cellulaire (alors que la présence de HU semble, au contraire, accélérer la dynamique rapide).

\section{4-5) Cellules en phase $M$.}

Pour les cellules en phase $\mathrm{M}$, les temps de relaxations $\tau_{2}$ sont principalement compris entre 0,3 et 1,5 s. La distribution en probabilité des temps $\tau_{2}$ présente un pic autour de $0,75 \mathrm{~s}$ et peut s'ajuster par une loi log-normale de moyenne $1,12 \mathrm{~s}$ avec un écart-type de $0,85 \mathrm{~s}$. Si la moyenne et l'écart-type de la distribution sont proches de ceux de la phase G2, on peut toutefois noter la disparition de l'épaulement observé dans la distribution du temps $\tau_{2}$ pour la phase G2.

\section{4-6) Conclusion}

On peut remarquer (voir Figure 4-43) que les différences entre les distributions des temps $\tau_{2}$ pour les différentes phases du cycle cellulaire sont moins importantes (et moins flagrantes) que celles observées pour les distributions en probabilité des temps $\tau_{1}$. Comme pour le temps $\tau_{1}$, pour le moment, nous ne savons pas quel sont les processus à l'origine de la dynamique lente. De ce fait, nous ne pouvons pas non plus expliquer les différences observées dans les distributions en probabilité des temps $\tau_{2}$ lors des différentes phases du cycle cellulaire. On peut néanmoins remarquer que la diffusion brownienne des complexes mRNP dans le noyau, observée par Shav-Tal et al. (2004) est caractérisée par des coefficients de diffusion compris entre $1.10^{-14}$ et $9.10^{-14} \mathrm{~m}^{2} / \mathrm{s}$. En diffusion dynamique de la lumière, de tel processus diffusif donnerait un temps caractéristique de relaxation égal à : $\tau=1 / D \mathbf{q}^{2}$, ou $D$ est le coefficient de diffusion du processus et $\mathbf{q}$ le vecteur d'onde correspondant à l'angle de diffusion pour lequel 
les mesures ont été réalisées $\left(21^{\circ}\right)$. Pour $D$ compris dans la gamme donné par Shav-Tal et al., on aurait un temps caractéristique compris entre 0,5 et $4 \mathrm{~s}$, donc compatibles avec les temps caractéristiques $\tau_{2}$ que nous avons mesurés. Nous pouvons donc émettre l'hypothèse que le temps de relaxation $\tau_{2}$ correspond à la diffusion brownienne «d'objets » tel que les complexes protéiques. Pour confirmer cette hypothèse, il faudrait vérifier que $1 / \tau_{2}$ varie linéairement en fonction de $\mathbf{q}^{2}$. Nous avons commencé à étudier l'effet du vecteur d'onde de diffusion sur les propriétés dynamiques du noyau (sur des cellules en G0/1 sous HU); pour le moment cette étude est en cours et nous ne pouvons pas encore confirmer, ou infirmer, notre hypothèse sur l'origine du temps $\tau_{2}$.

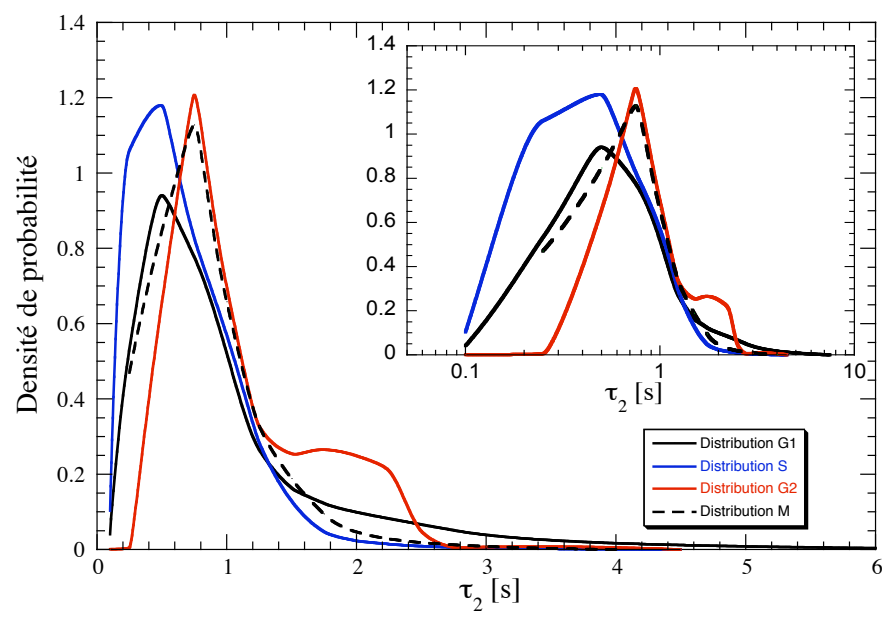

Figure 4-43 : Distributions en probabilité des temps de relaxation $\tau_{2}$ pour les phases $G 0 / 1$, $S, G 2$ et $M$.

\section{5) Influence de la taille et de la constitution du volume diffusant sur les paramètres}

Pour terminer cette discussion, il nous semble important de discuter l'effet possible de la taille du volume diffusant sur nos résultats. Comme nous l'avons indiqué au chapitre 3 , le volume diffusant est de l'ordre d'une dizaine de $\mu \mathrm{m}^{3}$, soit un volume comparable à celui qui est occupé par un territoire chromosomique dans le noyau. Bien sûr, il est plutôt probable que le volume diffusant est composé de petites «parties » de plusieurs territoires (intuitivement, de 2 à 4) et de domaine interchromosomique. Les variations des paramètres $\tau_{1}, \alpha$ (la dynamique rapide) et $\tau_{2}$ (la dynamique lente) observées d'une mesure à l'autre, sur le même noyau, pourraient venir du fait que, d'une mesure à l'autre, «l'activité » de la zone sondée a changé. Mais, comme le noyau bouge au cours de l'expérience et que les territoires chromosomiques bougent les uns par rapport aux autres, il est évident, qu'au cours des mesures réalisées sur le même noyau, nous n'allons pas toujours sonder la même «zone » du noyau. L'activité à l'intérieur des différents territoires chromosomiques n'est pas exactement la même ; il peut se passer simultanément et à très faible distance (de l'ordre quelques microns) deux activités complètement différentes. Par exemple, il y a toujours dans le noyau à la fois des activités de transcription et de réparation ainsi que d'autres activités dans les différents foci (amas) nucléaires. On peut donc imaginer que la dynamique a l'intérieur de ces territoires n'est pas identique et donc, que suivant la zone du noyau sondée on pourra avoir des temps différents. Ainsi, les variations des paramètres $\tau_{1}, \alpha$ et $\tau_{2}$ observées d'une mesure à l'autre, sur le même noyau, pourraient venir du fait que, d'une mesure à l'autre, la constitution du volume diffusant a changé. 
Nous avons également utilisé pour collecter la lumière diffusée, une fibre multimode avec un cœur de $50 \mu \mathrm{m}$ de diamètre à la place de la fibre monomode (diamètre : $5 \mu \mathrm{m}$ ). Une taille de détecteur plus grande signifie un volume diffusant plus important. L'information obtenue est donc une moyenne sur un plus grand nombre de territoires chromosomiques. Expérimentalement, le rapport signal sur bruit de la fonction d'autocorrélation est beaucoup moins bon lorsque nous utilisons la fibre multimode, probablement à cause de l'augmentation du nombre d'aires de cohérence. De ce fait, l'ajustement est, généralement, un peu moins bon. Néanmoins, les résultats que nous obtenons alors, pour les paramètres $\tau_{1}$, $\alpha$ et $\tau_{2}$ (non présentés), sont similaires à ceux que nous avons présentés dans ce chapitre. Dans ce cas, on peut juste remarquer que les variations d'une mesure à l'autre semblent moins importantes ; probablement à cause de la moyenne sur un plus gros volume.

Comme on ne regarde qu'un petit volume du noyau, on peut se poser la question de savoir si on fait vraiment une mesure globale de la dynamique de l'ensemble du noyau. Au cours de l'ensemble des mesures sur une même phase, il est certain que nous avons sondé toutes les différentes zones du noyau ; ceci à cause des mouvements du noyau, mais, aussi, parce que lors de nos mesures, il nous est arrivé de déplacer volontairement la cellule étudiée par rapport au faisceau, aussi bien en profondeur que latéralement. De plus, il est impossible que les mesures réalisées, pour une même phase, sur les différents noyaux soient toutes réalisées sur les mêmes territoires chromosomiques. Donc, on peut, sans problème, croire que les distributions obtenues reflètent la dynamique globale de l'ensemble du noyau. À partir de ces considérations, on peut faire l'hypothèse que les propriétés dynamiques du noyau sont dues à la superposition de plusieurs processus «biologiques » n'ayant pas forcément de lien entre eux (il est à noter que cette hypothèse rejoint celle que nous avons déjà formulée plus haut concernant les origines de la dynamique rapide).

Cependant, les paramètres $\tau_{1}, \alpha$ et $\tau_{2}$ obtenus pour les différentes mesures réalisées, dans une même phase du cycle, ne sont pas très différents. En suivant l'hypothèse formulée au-dessus, ceci signifie que les propriétés dynamiques (les temps caractéristiques) associées aux différents processus qui ont lieu dans le noyau lors d'une même phase du cycle ne sont pas très différents.

\section{V>Conclusion}

Les expériences que nous avons menées nous donnent de nombreux résultats sur la dynamique interne du noyau. Comme attendu, cette dynamique est très riche et très complexe, avec un très grand nombre de temps caractéristiques s'étalant de quelques millisecondes à quelques dizaines de secondes. Nos expériences nous ont permis de sonder, plus particulièrement, la dynamique du noyau entre la milliseconde et la seconde. Cette dynamique montre deux distributions de temps de relaxations qui semblent totalement indépendantes l'une de l'autre. Une distribution de temps « rapides », compris dans la gamme : $5.10^{-3}$ $70.10^{-3} \mathrm{~s}$ et qui est fortement modifiée au cours du cycle cellulaire. Pour le moment, nous ne sommes pas capable d'associer cette dynamique à des phénomènes biologiques particuliers. Néanmoins, ces temps semblent être la signature de relaxations s'effectuant par un ensemble de processus hiérarchisés. Une distribution de temps «lents », compris dans la gamme : 0,25 - $2 \mathrm{~s}$ et qui est moins modifiée au cours du cycle cellulaire que la distribution des temps « rapides ». Par comparaison avec des résultats existant dans la littérature (en particulier Shav-Tal et al., 2003) nous émettons l'hypothèse que ce temps de relaxation lent, $\tau_{2}$, correspond à la diffusion brownienne « d'objets » comme les complexes protéiques.

Nous avons aussi pu observer que la présence d'une drogue cytobloquante (HU) modifiait la dynamique interne du noyau. La présence de cette drogue semble accélérer la dynamique rapide et ralentir la dynamique lente. 


\section{BIBLIOGRAPHIE :}

- Castaing B et Souletie J. (1991) Dynamic scaling and non exponential relaxations in the presence of disorder. Application to spin glasses. Journal of Physics I. 1 : 403-414.

- Shav-Tal Y, Darzacq X, Shenoy SM, Fusco D, Janicki SM, Spector DL et Singer SH. (2004) Dynamics of single mRNPs in nuclei of living cells. Science. 304 : 1797-1800.

- Tumbar T et Belmont AS. (2001) Interphase movements of a DNA chromosome region modulated by VP16 transcriptional activator. Nature Cell Biology. 3 : 134-139.

- $\quad$ van de Hulst HC. Light scattering by small particles. New York, Dover. 1981. 


\section{Chapitre 5 : TRANSMISSION DE L'APOPTOSE}

\section{I> Remarques préliminaires}

Les expériences que nous présenterons dans ce chapitre ne concernent plus la diffusion de la lumière. Elles découlent d'une observation que nous avons faite lors des expériences au cours desquelles nous avons testé l'effet de l'irradiation par le laser He-Ne du noyau des cellules neuroblastomes de la lignée SHEP (chapitre 3). Nous avons montré (chapitre 3), qu'une irradiation du noyau sur plus de trois heures, avec une puissance de $10 \mathrm{~mW}$, entraînait la mort par apoptose de la cellule irradiée. Lors des observations que nous avons faites suite à l'irradiation de la cellule cible, nous avons noté que les cellules voisines de la cellule irradiée entraient également en apoptose peu après celle-ci. Ensuite, l'apoptose semble s'étendre aux cellules environnantes puis le phénomène s'arrête. La place laissée vacante par les cellules mortes est alors occupée par d'autres cellules qui prolifèrent normalement et envahissent l'espace libéré. Nous avons immédiatement exclu l'hypothèse selon laquelle ces phénomènes périphériques d'apoptose seraient directement provoqués par le faisceau laser. En effet, rappelons que le faisceau laser est focalisé dans le noyau de la cellule sur une surface de moins de $3 \mu \mathrm{m}$ de diamètre (voir chapitre 3 ) tandis que le diamètre de la cellule varie en moyenne entre 20 et $40 \mu \mathrm{m}$. L'effet de l'irradiation par le faisceau laser est donc très local à l'échelle de la population cellulaire. Il est donc très peu probable que les cellules voisines de la cellule irradiée subissent des dommages. Nous avons alors émis l'hypothèse qu'il devait y avoir, entre la cellule irradiée et ses voisines, «transmission » de l'apoptose qui pourrait se faire par la libération d'un ligand provoquant la mort des cellules avoisinantes après interaction avec son récepteur.

Nous commencerons ce chapitre par une brève introduction sur la mort cellulaire par apoptose et sur les différents mécanismes qui permettent de l'activer. Puis nous tenterons, en utilisant le montage présenté au chapitre 3, de répondre à deux questions fondamentales soulevées par l'hypothèse d'une transmission d'un facteur apoptotique. La première question concerne le mode de transmission: cette transmission se fait-elle par contact cellule-cellule ou par diffusion d'un agent apoptotique dans le milieu ? Pour répondre cette question, nous devons provoquer l'apoptose d'une cellule au sein d'une population cellulaire et regarder comment la mort par apoptose se transmet. La deuxième question concerne l'arrêt de la transmission : pourquoi est-ce que la transmission ne semble atteindre que les premières et deuxièmes couches concentriques de cellules voisines situées autour de la cellule irradiée et ne s'étend pas à toute la population cellulaire ?

\section{II> L'apoptose}

\section{1) Définition}

L'apoptose est un mécanisme ubiquitaire de mort programée de la cellule (par opposition à la nécrose qui est une mort cellulaire accidentelle). L'apoptose a été réellement définie pour la première fois par Carl Vogt en 1842, puis remis en lumière et nommée ainsi par Kerr, Willye et Currie au début des années 1970 (Kerr et al., 1972). Ils se sont fondés sur plusieurs travaux de recherche mettant en évidence les similarités morphologiques, observés par microscopie électronique, de différents types cellulaires lors d'un type de mort cellulaire qui semblait jouer un rôle important dans l'élimination de cellules devenues indésirables (Kerr, 2002). Ainsi, d'un point de vue morphologique (Figure 5-1), un des premiers signes de l'apoptose est la 
réduction du volume de la cellule : le cytoplasme et le noyau se condensent. Après cela, il se forme des corps apoptotiques qui vont se séparer de la cellule. Ils sont composés d'éléments de la cellule (organites, fragments de noyau,...) englobés par de la membrane plasmique. In vivo, ces corps apoptotiques seront ensuite rapidement phagocytés par les macrophages dans les tissus ou encore par des cellules environnantes. La conservation de l'intégrité de la membrane des corps apoptotiques évite une réaction inflammatoire qui serait déclenchée par le relargage du contenu cytoplasmique dans le milieu environnant. Ces modifications morphologiques que l'on observe sont dues à de nombreuses réactions biochimiques à l'intérieur de la cellule. Ces réactions aboutissent principalement :

- à la coupure de l'ADN contenue dans le noyau : la chromatine se condense avant d'être finalement coupée en petits fragments de tailles comparables à celle du nucléosome (Earnshaw, 1995),

- à la perméabilisation de la membrane des mitochondries,

- à la destruction par coupure enzymatique des protéines contenues dans la cellule.

A
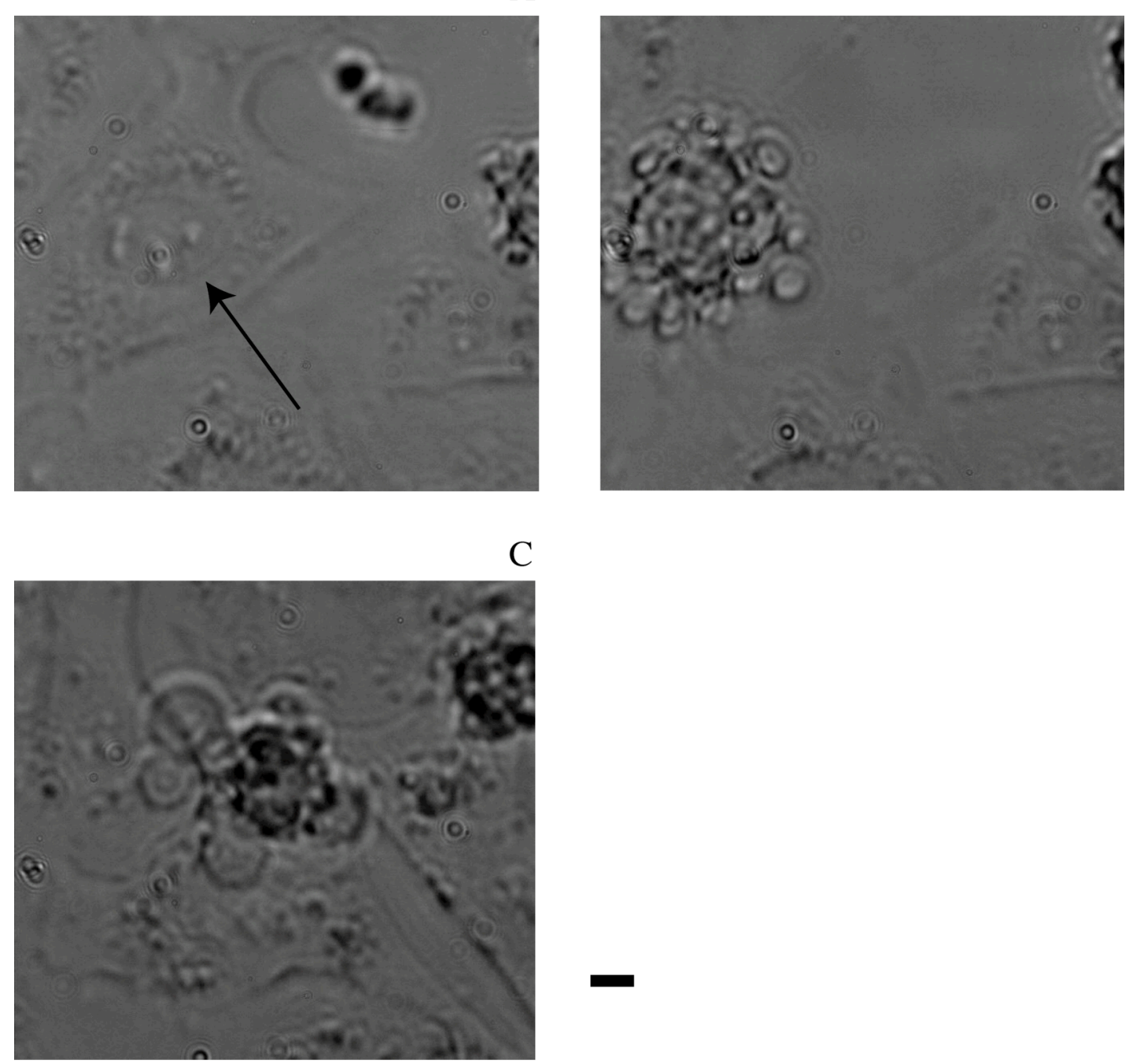

Figure 5-1 : Observation du processus d'apoptose d'une cellule SHEP en microscopie optique à fond clair (la barre représente $5 \mu \mathrm{m}$ ). A. La cellule (indiquée par la flèche) est étalée sur le support et en contact avec les cellules voisines. $\boldsymbol{B}$. A $t=0 \mathrm{~min}$, la cellule se contracte, perd de l'adhérence avec le substrat et les cellules voisines et de nombreuses protubérances membranaires apparaissent. C. A $t=40 \mathrm{~min}$, l'apoptose est complètement achevée, la membrane de la cellule morte présente de nombreux renflements qui, in vivo, se détacheront progressivement les uns des autres, ce sont les corps apoptotiques. Des cellules environnantes " envahissent » la place qui était occupée par la cellule morte. 
Comme nous l'avons déjà expliqué, l'apoptose peut être induite par la cellule ellemême, mais peut également être provoquée par des facteurs extérieurs. Dans tous les cas, il s'agit d'un processus actif durant lequel de nombreuses protéines interagissent de façon complexe (Kiechle et Zhang, 2002; Fadeel et Orenius, 2005) suite à un événement déclencheur. Nous allons présenter les deux principales voies d'activation de l'apoptose : l'activation par des récepteurs membranaires de mort et l'activation par dommages causés à l'ADN.

\section{2) Activation de l'apoptose par les récepteurs membranaires}

\section{2-1)Récepteurs membranaires à l'origine de l'apoptose}

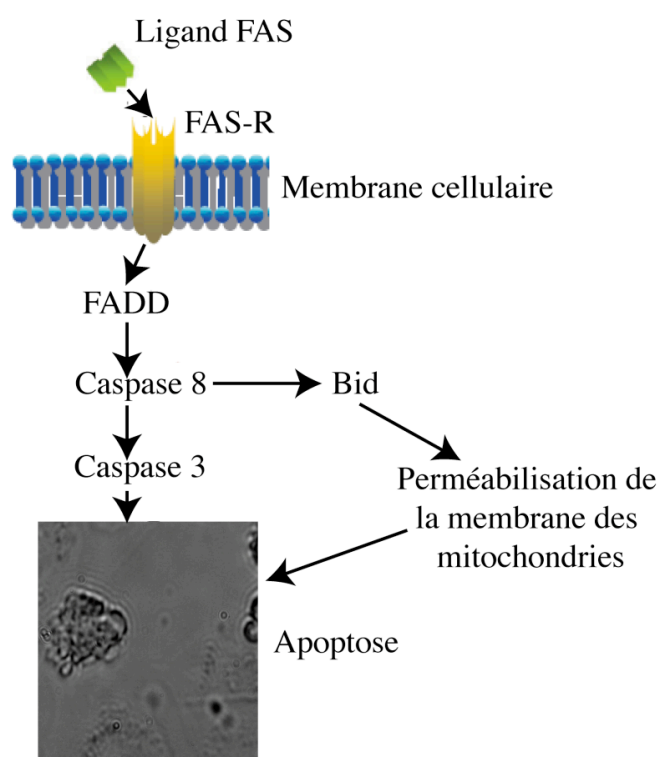

Figure 5-2 : Schéma représentatif de l'activation de l'apoptose par fixation d'un ligand FAS sur un récepteur FAS (FAS-R) de la cellule.

L'apoptose peut-être déclenchée par la stimulation de nombreux récepteurs transmembranaires. Ces récepteurs sont un sous-groupe de la superfamille des récepteurs TNF (Tumor Necrosis Factor)/NGF (Nerve Growth Factor) (Peter et al., 1997 ; Lüschen et al., 2000 ; Sartorius et al., 2001). Les récepteurs membranaires de la famille des NGF entraînent l'apoptose de la cellule lorsqu'ils ne sont plus liés à leur ligand. C'est notamment le cas des récepteurs p75 qui entraînent l'apoptose de la cellule lorsqu'il ne sont plus liés à des facteurs de croissance (Bergeron et Yuan, 1998). A l'inverse, les éléments de la famille des TNF induisent l'apoptose de la cellule lorsqu'ils sont liés à leur ligand. Parmi les éléments de cette famille de récepteurs, nous retiendrons tout particulièrement la protéine FAS-R (FASRécepteur) (Peter et al., 1997 ; Goillot et al., 1997; Sartorius et al., 2001), également appelée CD95, qui peut être simplement stimulée par le ligand FAS, notamment présent sur les lymphocytes $\mathrm{T}$, ou par des anticorps anti-FAS-R. Cette activation entraîne l'agrégation des récepteurs Fas. Ces récepteurs possèdent un domaine cytoplasmique, appelé « domaine de mort » ou DD (Death Domain), directement impliqué dans le recrutement de protéines proapoptotique. La stimulation de FAS (Figure 5-2) entraîne une cascade protéique parfaitement organisée et coordonnée. Cette cascade commence par le recrutement de la protéine FADD (FAS-Associated Death Domain) (Chinnaiyan et al., 1995), par l'intermédiaire des DD, qui vont déclencher l'activation en série d'enzymes de la famille des caspases (Figure 5-2; Fadeel 
et Orrenius, 2005). Cette famille contient 14 membres dont la plupart joue un rôle actif dans l'apoptose (Fadeel et Orrenius, 2005). Ce sont des protéases zymogènes (activées par coupure peptidique) dont les principales fonctions consistent à inhiber les différents moyens de protection de la cellule, à activer des molécules jouant un rôle dans la destruction cellulaire et à cliver certaines protéines essentielles à la survie de la cellule. La première caspase recrutée est la caspase 8 qui à son tour active la caspase 3 entraînant l'apoptose de la cellule (la caspase 3 est, notamment, à l'origine des changements morphologiques de la cellule durant l'apoptose par le clivage de certaines protéines du cytosquelette (Khotakota et al., 1997)). De nombreuses protéines permettent la régulation de l'activité des caspases et peuvent ainsi inhiber ou activer l'apoptose. La famille des protéines inhibitrices de l'apoptose (IAP) est l'une des principales régulatrices de l'activité des caspases (Hays et al., 2002 ; Holley et al., 2002 ; Yoo et al. 2002).

La caspase 8 va également cliver une protéine zymogène du cytosol, nommée Bid (Figure 5-2) qui a pour rôle d'amplifier le signal apoptotique en ciblant les mitochondries.

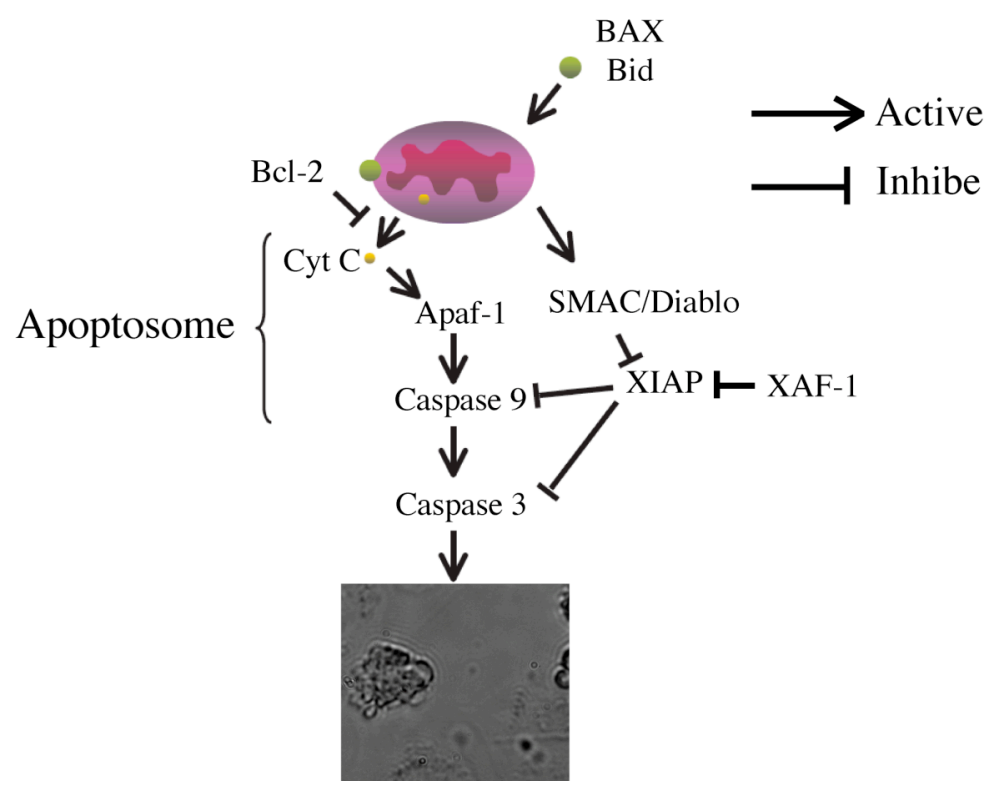

Figure 5-3 : (tiré de Fadeel et Orrenius (2005)) Schéma de l'activation de l'apoptose par voie mitochondriale caspase-dépendante.

\section{2-2) Rôle des mitochondries dans l'apoptose}

Les mitochondries ne servent pas seulement «d'usine d'énergie » pour la cellule. Elle joue également un rôle important dans l'apoptose. Le processus fondamental de l'activation de l'apoptose par les mitochondries est la perméabilisation de leur membrane. Les protéines de la famille des $\mathrm{Bcl}-2$ ont une fonction importante dans la régulation de ce processus et des processus qui en découle. Cette famille de protéines se divise en deux sous-groupes, l'un proapoptotique (contenant les protéines Bid, BAX,...) et l'autre anti-apoptotique (contenant les protéines $\mathrm{Bcl}-2, \mathrm{Bcl}-\mathrm{XL}, \mathrm{Bcl}-\mathrm{W}, \ldots)$. La perméabilisation de la membrane des mitochondries est entraînée par des protéines du sous-groupe proapoptotique de la famille des Bcl-2 comme Bid ou BAX (Li et al., 1998). Cette perméabilisation a pour effet la libération du cytochrome c (Cyt c) dans le cytosol (Figure 5-3). Le Cyt c va permettre l'activation d'une protéine du cytosol, Apaf-1 (Apoptotis protease-activator factor 1) qui va à son tour recruter de la caspase 9 (van Loo et al., 2002). La combinaison de ces trois protéines forme un complexe d'activation des caspases appelé apoptosome (Figure 5-3). L'apoptosome va permettre l'activation de la caspase 3 qui entraînera, in fine, l'apoptose de la cellule. 
Toutefois, l'apoptosome contient également une IAP, la XIAP (X-linked IAP), qui est un inhibiteur de la caspase 3 et de la caspase 9 (Shiozaki et Shi, 2004 ; Fadeel et Orrenius, 2005). L'activation de la caspase 3 est, alors, permise par Smac/DIABLO (Second Mitochondrial Activator of Caspases ou Direct IAP Binding protein with LOw pI) et XAF1 (XIAPAssociated Factor-1) un inhibiteur de la XIAP libérée par la mitochondrie en même temps que le Cyt c (Figure 5-3 ; Shiozaki et Shi, 2004 ).

\section{3) Activation par dommages causés à l'ADN}

Les dommages causés directement à l'ADN peuvent provenir d'une irradiation du noyau par un faisceau laser (Kulms et al., 2002), par rayons X ou encore par certaines molécules chimiques (thérapies anti-cancéreuses, intoxication chimique). L'activation ou non de l'apoptose suite à ces dommages dépend principalement d'une seule protéine, p53, qui est une protéine suppresseur de tumeur. En effet, des expériences menées sur des souris mutées pour le gène de p53 ont montré qu'elles pouvaient se développer normalement mais qu'elles étaient beaucoup plus sujettes à des tumeurs que les souris témoins (Ryan et al., 2001). On estime d'ailleurs qu'environ $50 \%$ des cancers chez l'homme contiennent une mutation du gène codant cette protéine (Levine, 1997 ; Ryan et al., 2001). p53 est normalement présente en très faible quantité dans la cellule. La transcription de cette protéine est toutefois très élevée lorsque l'ADN est endommagé. L'intensité de cette transcription dépend de l'étendue des dommages causés à l'ADN (Levine, 1997). p53 a pour premier effet de bloquer le cycle cellulaire. Puis en fonction des dommages, elle va activer une ribonucleotide reductase, la p53R2 (Tanaka et al., 2000 ; Ryan et al., 2001), qui va initier la réparation de l'ADN, ou alors, si les dommages sont trop importants, provoquer la transcription de gène comme BAX qui entraînera la libération du Cyt $c$ par la mitochondrie (Ryan et al., 2001). p53 permet également l'expression des récepteurs membranaires comme le FAS-R (Ryan et al., 2001) qui permettront d'activer l'apoptose comme nous l'avons décrit plus haut.

L'ADN est également clivée par le facteur AIF (Apoptosis Inducing Factor), une molécule proapototique libérée lors de la perméabilisation de la membrane de la mitochondrie. Une fois libérée, l'AIF passe du cytosol au nucléoplasme, où il semble se lier à l'ADN pour provoquer la condensation puis la fragmentation à grande échelle de la chromatine par un mécanisme moléculaire encore inconnu mais indépendant des caspases (Ye et al., 2002).

\section{4) Conclusion}

L'apoptose est donc un phénomène complexe disposant de plusieurs voies d'activation. C'est aussi un phénomène fondamental qui joue un rôle crucial au cours du développement et de l'apparition de nombreuses maladies. Ainsi, les cancers, par exemple, sont en fait dues à une dégradation de la capacité des cellules à entrer en apoptose (Peter et al., 1997). L'apoptose est également impliquée dans d'autres types de maladies où l'on en note un fort taux parmi certains types cellulaires (SIDA, diabète de type I,...). Dans notre travail, nous avons utilisé les deux principaux types de stimuli de l'apoptose : les dommages causés à l'ADN et l'activation de l'apoptose par les récepteurs FAS-R de la membrane cellulaire.

\section{III> Mode de transmission du facteur apoptotique}

\section{1) Expériences d'irradiations}

Pour analyser le mode de transmission du signal apoptotique, nous avons réalisé des expériences d'irradiation d'une seule cellule, dans une population de cellules, avec le montage présenté au chapitre 3 . A chaque fois, la population de cellules introduites dans la chambre de culture était suffisamment peu concentrée (concentration de départ $2 / 5$; voir annexe) pour 
qu'une fois les cellules adhérées sur le verre, elles soient réparties en petits groupes séparés par des espaces de longueur inférieur à $10 \mu \mathrm{m}$ (cette échelle de longueur est confirmée par les observations menées lors de nos expériences). Nous avons, alors, irradié une cellule au cœur de l'un de ces groupes puis nous avons observé la propagation de l'apoptose. Nous avons mené 20 expériences similaires. 12 de ces expériences ont abouti à des résultats équivalents à ceux présentés dans la Figure 5-4.

A

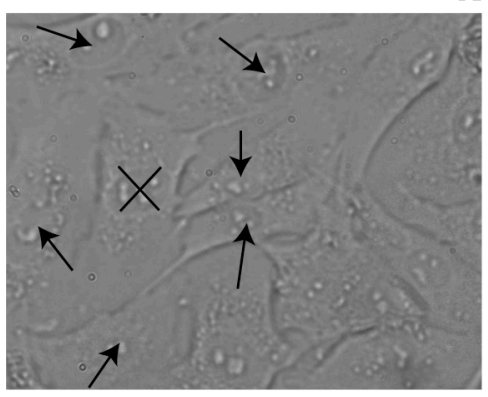

$\mathrm{D}$

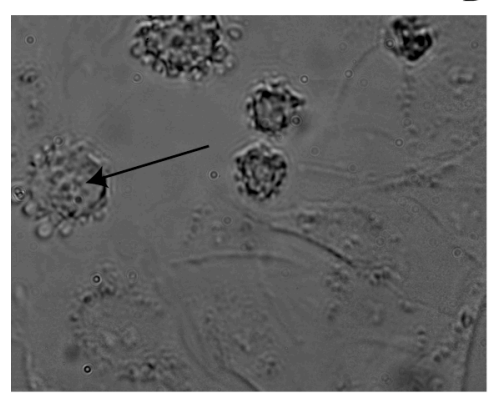

G
B

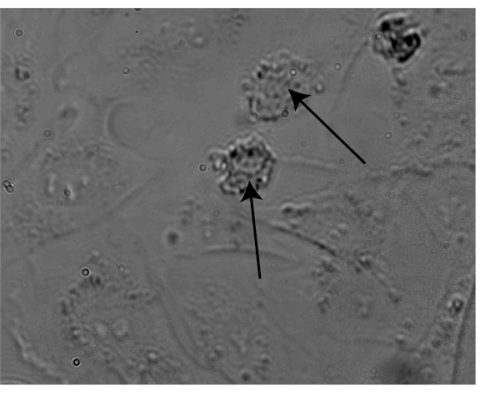

E

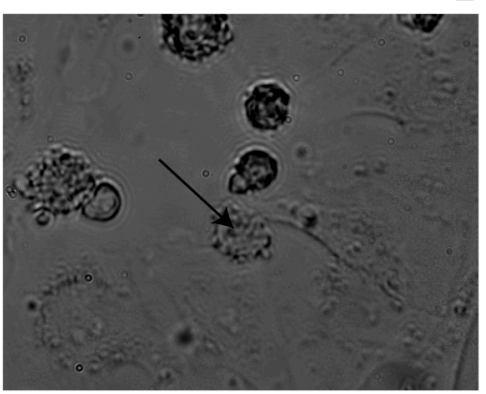

(3)

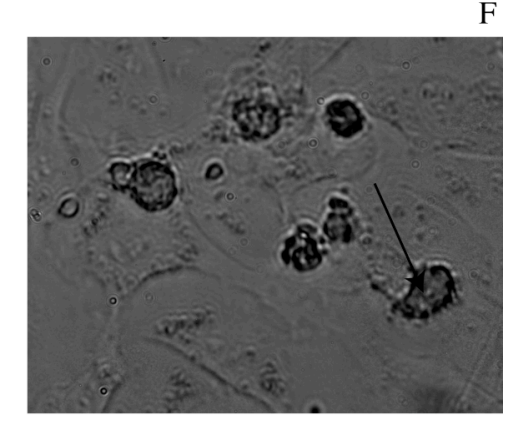

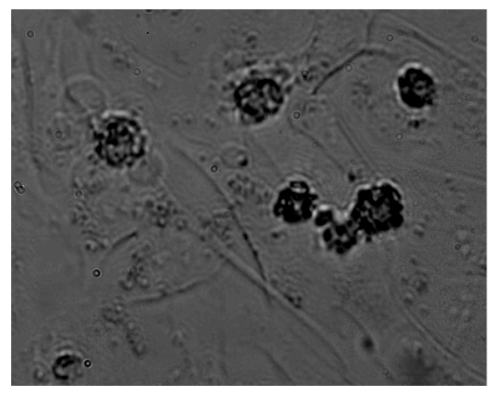

Figure 5-4: Transmission de l'apoptose suite à l'irradiation d'une cellule (la barre représente $5 \mathrm{\mu m})$. A. Photographie prise avant l'irradiation. La cellule irradiée est marquée d'une croix. Les cellules en contact avec la cellule irradiée sont marquées d'une flèche. Nous considèrerons que la cellule irradiée a terminé son apoptose à $t=0$. Dans les photos suivantes, nous marquons par une flèche les cellules voisines de la cellule irradiée qui entrent en apoptose. B. $t=15 \mathrm{~min} . \boldsymbol{C} . t=20 \mathrm{~min} . \boldsymbol{D} . t=30 \mathrm{~min} . \boldsymbol{E} . t=1 \mathrm{~h} 05 \mathrm{~min} . \boldsymbol{F} . t=5 \mathrm{~h}$. Une cellule voisine de l'une des cellules voisines de la cellule irradiée entre alors en apoptose. Elle n'était pas en contact direct avec la cellule irradiée. $G . t=6 \mathrm{~h}$. On ne note plus d'apoptose. La place laissée par les cellules mortes est envahie par d'autres cellules.

Cette figure montre la propagation de l'apoptose dans un groupe de cellules suite à l'irradiation d'une des cellules du groupe. Au moment où la cellule irradiée entre en apoptose, elle est au contact de 6 cellules. On peut remarquer que les premières cellules à entrer en apoptose étaient toutes en contact avec la cellule irradiée. Très rapidement, deux de ces cellules voisines sont entrées en apoptose. Au bout d'environ 1 heure, sur les 6 cellules 
voisines, 5 sont entrées en apoptose, une heure après la fin de l'apoptose de la cellule irradiée. Par la suite, on note qu'une cellule de l'une de ces voisines entre également en apoptose. La transmission semble donc se propager principalement aux premières cellules voisines, puis touche quelques cellules voisines de ces dernières et s'arrête.

Ces observations tendent à confirmer l'hypothèse d'une transmission par contact. En effet, si la transmission se faisait par diffusion, le facteur de transmission devrait se propager rapidement du fait de mouvements de convection qui ont lieu dans l'échantillon ${ }^{1}$. Ainsi, des cellules qui ne sont pas au contact de la cellule irradiée devraient pouvoir entrer en apoptose avant les voisines de la cellule irradiée. Or, nous n'avons jamais observé cela. Pour affiner ces observations, nous avons établi une méthode de motifs cellulaires, nous permettant de séparer des groupes de cellules par des espaces de longueur fixe.

\section{2) Motifs cellulaires}

Les expériences de motifs cellulaires consistent à traiter la surface sur laquelle vont adhérer les cellules de sorte à contrôler leurs sites d'adhérence. La principale difficulté consiste à imprimer et ainsi délimiter la surface sur laquelle les cellules vont adhérer. Nous commencerons donc par présenter les méthodes existantes avant d'expliciter la méthode que nous avons choisie. Enfin, nous présenterons les résultats que nous avons obtenus.

\section{2-1) Etat de la recherche}

Ces dernières années, les motifs cellulaires ont connu un large développement, grâce, notamment, aux résultats qu'ils permettent d'obtenir sur l'étude de l'adhérence cellulaire ou encore pour leurs implications possibles dans l'élaboration de capteurs biologiques (Park et Schuler, 2003). La plupart des méthodes utilisées sont fondées sur la softlitographie et la photolithographie. Les méthodes les plus courantes sont :

- la méthode dite de microcontact printing ( $\mu \mathrm{CP}$ ) (Mrksich et al., 1997 ; Kane et al., 1999; Zhang et al., 1999 ; Chang et al ., 2003). Cette méthode consiste à réaliser un tampon de PDMS (PolyDiMethylSyloxane, un polymère souple) pour imprimer le motif sur la lame de verre. Le tampon est réalisé en moulant le PDMS sur un patron réalisé par photolithographie. Les tampons ainsi obtenus peuvent avoir une résolution de l'ordre de la dizaine de micromètres. La surface sur laquelle ils seront utilisés est, en général, du verre sur lequel une fine couche d'or ou d'argent, d'environ $10 \mathrm{~nm}$ d'épaisseur, a été préalablement déposée ${ }^{2}$ (Mrksich et al., 1997). Le tampon de PDMS est alors trempé dans une solution de SAM (Self Assembled-Monolayer), comme l'alkanethiol $\left(\mathrm{SH}\left(\mathrm{CH}_{2}\right)_{15} \mathrm{CH}_{3}\right)$. Le tampon est ensuite appliqué sur la surface de verre et d'or. L'or permettra aux SAM d'adhérer parfaitement sur la surface via la fonction thiol (SH) de la SAM (Mrksich et al., 1997). La surface est ensuite enduite de fibronectine, une glycoprotéine extra-cellulaire ubiquitaire nécessaire à l'adhésion des cellules, qui va adhérer préférentiellement sur les SAM (du fait de la grande hydrophobicité de la partie non adhérente sur l'or). Eventuellement, avant l'ajout de fibronectine, la surface peut-être trempé dans une autre SAM qui, après adsorption sur l'or (elle ne peut pas être adsorbée sur la première SAM utilisée), présente en surface

\footnotetext{
${ }^{1}$ Lors de l'introduction des cellules et du milieu de culture dans le porte-échantillon, il est pratiquement impossible d'éviter la présence de petites bulles d'air. Ces bulles d'air se logent en haut du porte-échantillon lorsque celui-ci est placé à la verticale dans l'étau chauffé (chapitre 3). L'air contenu dans les bulles d'air chauffant moins rapidement que le milieu, il se crée un gradient de température dirigée du haut vers le bas dans l'échantillon. Cela résulte en un mouvement de convection dans l'échantillon.

${ }^{2}$ Rappelons qu'une couche d'or ne devient réfléchissante qu'à partir d'une épaisseur de $50 \mathrm{~nm}$. Ici, la couche reste donc optiquement transparente. La visualisation de la surface peut donc se faire aussi bien avec un microscope normal qu'un microscope inversé.
} 
des oligomères du groupe des éthylène glycol (par exemple $\left[-\mathrm{CH}_{2} \mathrm{CH}_{3}-\right]_{7} \mathrm{CH}_{3}$ ). Ces oligomères rendent ce type de SAM très résistant à l'adsorption de protéines (Mrksich et al., 1997 ; Kane et al., 1999). Les cellules sont ensuite placées sur la lame où elles vont adhérer sur la fibronectine. Les motifs cellulaires ainsi obtenus peuvent donc avoir une résolution de l'ordre de $10 \mu \mathrm{m}$ et les cellules restent dans les motifs pour des temps pouvant aller de quelques heures à quelques jours.

- la méthode dite de système microfluidique (microfluidic system ou $\mu \mathrm{FS}$ ) (Chiu et al., 2000; Anderson et al., 2000). Cette méthode consiste à créer un réseau de microcanaux à l'intérieur d'un tampon en PDMS. Le tampon est posé sur la surface où devront adhérer les cellules. Les canaux permettent alors de faire passer les protéines, les SAM ou même les cellules directement sur la lame de verre. L'intérêt d'une telle méthode est qu'elle permet, par exemple, de faire adhérer séparément différents types cellulaires sur une même surface ou encore d'utiliser différents composés (protéines, SAM) toujours sur la même surface, ce que ne permet le $\mu \mathrm{CP}$ (Chiu et al., 2000; Anderson et al., 2000 ; Park et Schuler, 2003). Par contre, les cellules ne restent dans le motif que tant que le tampon reste en place (Chiu et al., 2000).

Ces deux méthodes présentent donc chacune leurs avantages. Cuvelier et al. (2003) ont réussi à combiner les avantages de ces deux méthodes pour l'étude de l'adhésion des globules rouges sur certains types de surface. Toutefois, les types cellulaires utilisés lors des expériences de $\mu \mathrm{CP}$ sont en général des cellules sensibles au phénomène d'inhibition de contact (arrêt de la croissance de la population lorsque les cellules remplissent leur zone d'adhérence), comme des cellules endothéliales bovines (Mrksich et al., 1997) ou encore des cellules d'hippocampe d'embryon (Chang et al., 2003). Or les cellules SHEP ne sont pas sensibles à l'inhibition de contact ${ }^{3}$. D'un autre coté, il est évident que la méthode de $\mu \mathrm{FS}$ est difficilement adaptable à notre montage (voir chapitre 3). Nous avons évité l'utilisation de la photolitographie, méthode que nous considérions comme lourde à mettre en place. Nous avons donc tenté, dans un premier temps de créer des patrons grâce à des scies circulaires de très faible épaisseur, mais la résolution maximale que nous pouvions atteindre était de l'ordre de la centaine de micromètres, ce qui n'est pas adapté aux expériences que nous voulons mener (écart trop grand entre les cellules des différents motifs pour que les résultats sur le mode de transmission puissent être significatifs). Nous avons donc cherché à établir des motifs par un autre moyen.

\section{2-2) Méthode de motifs cellulaires pour les SHEP-Neuroblastomes}

Nous devons établir une méthode de motifs cellulaires qui tient compte de trois contraintes expérimentales. Tout d'abord cette méthode doit s'adapter à notre montage et comme nous voulons pouvoir éventuellement utiliser cette méthode lors d'expérience de diffusion de la lumière, les cellules ne doivent adhérer que sur du verre (pour éviter une diffusion de la lumière parasite). Ensuite, nous cherchons à créer les motifs sans faire appel à la photolithographie, tout en nous assurant que nous pouvons obtenir une résolution de l'ordre de la dizaine de micromètres. Enfin, les motifs créés doivent être suffisamment robustes pour contenir les cellules en développement pendant plusieurs heures, voire plusieurs jours.

\footnotetext{
${ }^{3}$ Nous avons même pu noter que tant que le milieu de culture le permet, les cellules peuvent commencer à se développer les unes sur les autres et former des foci.
} 


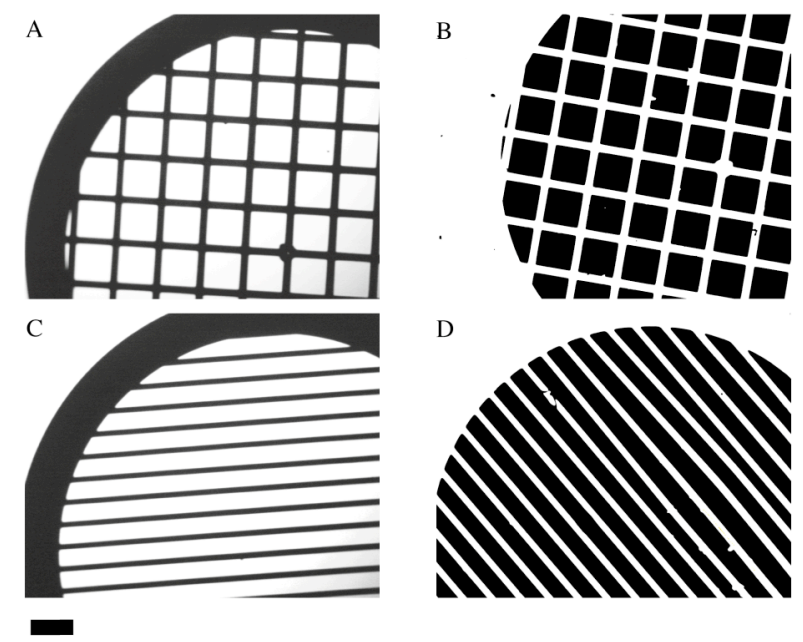

Figure 5-5: Grilles de microscope électronique utilisées comme masque pour l'évaporation d'or sur la lame de verre et motifs obtenus sur la lame de verre suite à l'évaporation (la barre représente $250 \mu \mathrm{m})$. A. Grille avec motifs carrés. Les carrés font $200 \mu \mathrm{m}$ de coté et les séparation $50 \mu \mathrm{m}$ de large. B. Motifs obtenus sur la lame de verre suite à l'évaporation d'or avec la grille montrée en A pour masque. $\boldsymbol{C}$. Grille avec motifs en ligne. Les lignes font 100 $\mu \mathrm{m}$ de large et les séparations $25 \mu \mathrm{m}$. D. Motifs obtenus sur la lame de verre suite à l'évaporation d'or avec la grille montrée en $C$ pour masque.

Dans un premier temps, nous avons besoin de masque contenant des motifs qui nous permettraient de séparer les cellules de seulement quelques dizaines de micromètre. Puis pouvoir faire adhérer les cellules dans ces motifs, il faut trouver un moyen de les imprimer sur une lame de verre. Ensuite, nous devons enduire la lame avec un composé sur lequel les cellules ne peuvent pas adhérer. Il suffira alors de retirer les motifs de la lame de verre de sorte que le composé anti-adhérence soit retiré aux emplacements exacts où se trouvaient les motifs. Les cellules adhèreront alors sur la lame de verre. Un masque simple et commercial nous a permis de créer des motifs suffisamment précis: des grilles de microscope électronique (SPI Supplies). Nous avons choisi d'utiliser deux types de grilles : la première se compose de motifs carrés de $200 \mu \mathrm{m}$ de coté séparés par des lignes de $50 \mu \mathrm{m}$ de large (Figure 5-5 A) et la deuxième se compose de lignes de $100 \mu \mathrm{m}$ de large séparées par des lignes de 25 $\mu \mathrm{m}$ de large (Figure 5-5 C). Pour imprimer ces motifs sur une lame de verre, nous avons utilisé un évaporateur d'or (ME 300 ; Plassys). L'intérêt de cette méthode est que l'or peut ensuite aisément s'ôter de la lame de verre en trempant cette dernière dans du gold etcher (solution d'iodure de potassium et d'iode moléculaire). Ensuite, nous avons cherché un composé capable de s'adsorber sur une lame de verre et sur lequel les cellules ne peuvent pas adhérer. Rohr et al. (2003) ont mis au point une méthode de patterning cellulaire sur des lames de verre dans laquelle ils utilisent de l'agar-agar (extrait d'algue principalement utilisé en bactériologie et dans l'industrie alimentaire) comme composé anti-adhérence pour les cellules. Leurs expériences montrent que ce procédé est très efficace sur des cellules HeLa, dont le comportement, en terme de prolifération, est assez proche des SHEP. Nous avons donc choisi d'utiliser l'agar-agar pour nos expériences.

\footnotetext{
${ }^{4}$ Ce type de matériel est aisément accessible pour de nombreux laboratoires de biologie.
} 

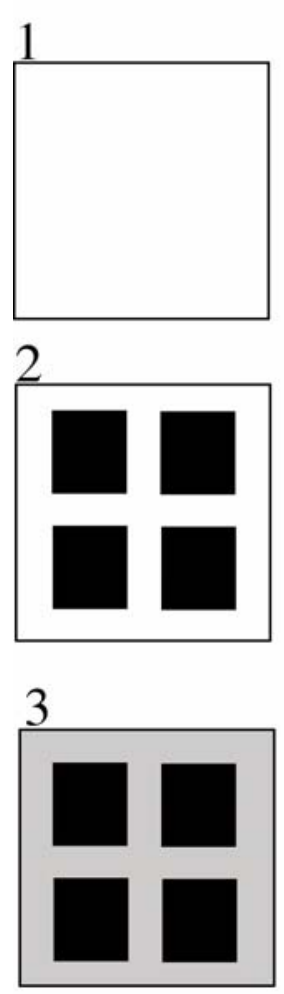

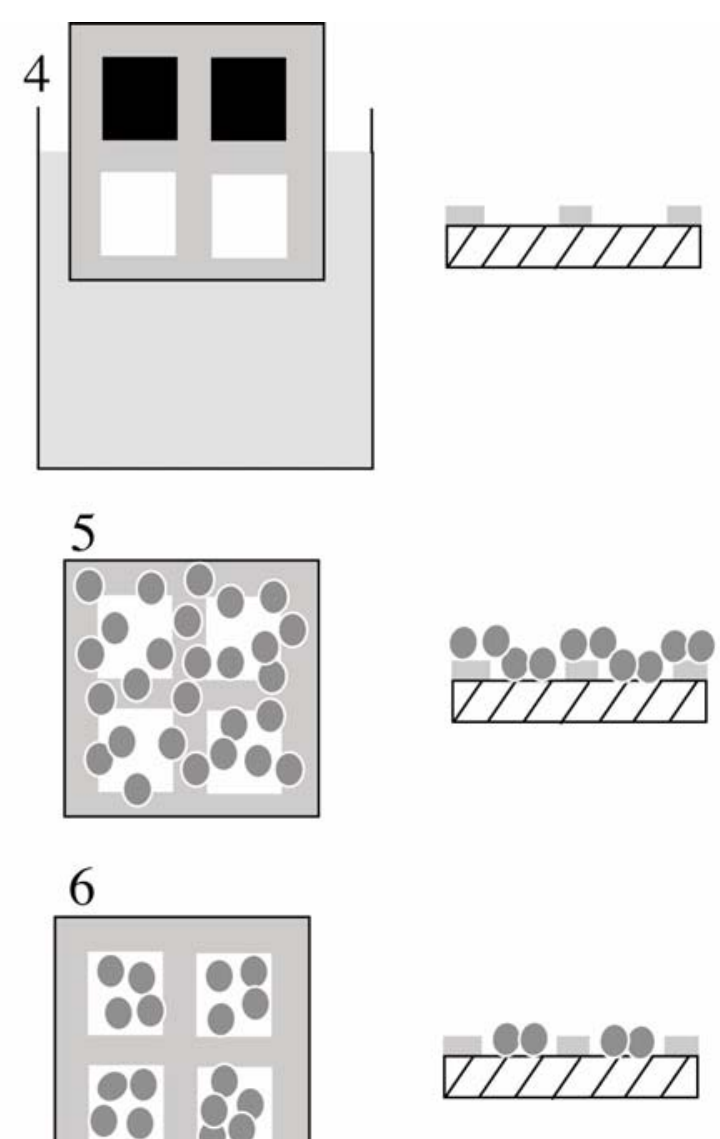

Figure 5-6 : Schéma du protocole pour la réalisation des motifs cellulaires (représentation de dessus et de profil de la lame de verre). 1. La lame de verre est nettoyée. 2. Le motif est imprimé par évaporation d'or en se servant d'une grille de microscope électronique comme masque. 3. Une solution d'agar-agar est déposée par tournette sur la lame de verre. 4. L'or est enlevé en trempant la lame de verre dans du gold etcher. 5. Les cellules sont déposées sur la lame de verre. 6. 15 heures après le dépôt des cellules, la lame est rincée deux fois avec du milieu neuf. Les cellules restantes après le rinçage sont dans les motifs.

Le protocole de l'expérience est présenté en Figure 5-6. Brièvement, nous imprimons les motifs sur la lame de verre (nettoyée selon le protocole présenté en annexe) avec une épaisseur de $100 \mathrm{~nm}$ d'or. La solution d'agar-agar est composée de 0,2\% d'agar-agar (Sigma) et d'eau distillée. Nous déposons grâce à une tournette (7000 tours/min) cette solution sur la lame de verre où les motifs sont imprimés, afin que la couche de solution soit fine et complètement uniforme. Ensuite l'or est enlevé grâce au gold etcher. Pour vérifier que l'agaragar s'ôte bien avec l'or, nous avons préalablement ajouté, à la solution d'agar-agar 0,2\%, de la fluorescéine (un indicateur coloré phtalique utilisé dans le cadre du diagnostic des plaies de cornée). Une fois l'or ôté, l'observation de la lame de verre au microscope à fluorescence (Figure 5-7) montre que la fluorescence a disparu aux endroits où se trouvaient les motifs, confirmant que l'agar-agar a bien été ôtée. Il reste donc, sur la lame de verre, de l'agar-agar aux endroits où il n'y avait pas de motifs. On dispose ensuite la lame de verre dans une boîte de Pétri et on place dessus des cellules dans du milieu de culture (composition du milieu au chapitre 3). Au bout de 15 heures (temps donné par Rohr et al. (2003)), la lame de verre est rincée deux fois avec du milieu propre, puis la boîte de Pétri est remplie de milieu neuf. 

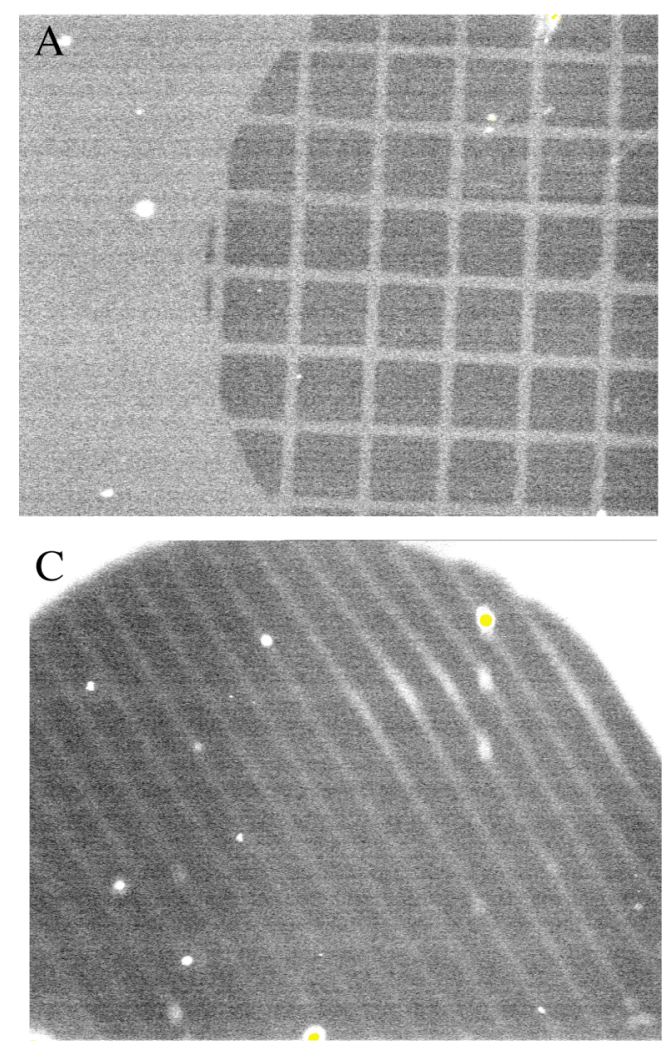

B

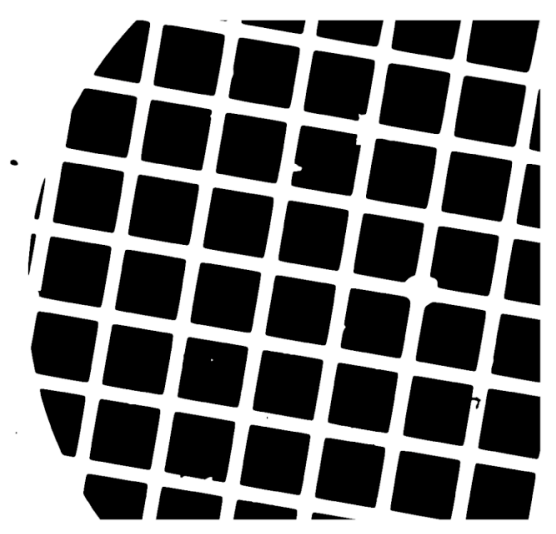

$\mathrm{D}$

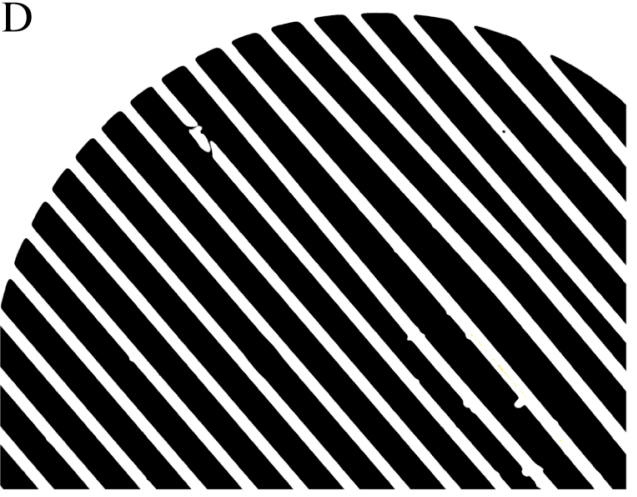

Figure 5-7: Observation par microscopie de fluorescence de la répartition sur la lame de verre de la solution d'agar-agar 0,2\% et de fluorescéine une fois les motifs d'or ôtés (voir Figure 5-6). A. Motif initiaux carrés (B). Absence d'agar-agar sur les zones sombres. $\boldsymbol{C}$. Motifs initiaux en ligne $(\boldsymbol{D})$. Absence d'agar-agar sur les zones sombres.

Les résultats obtenus sont présentés en Figure 5-8 pour les motifs carrés et en Figure 5-9 pour les motifs en ligne. On remarque que, après le rinçage, les cellules qui restent sur la lame de verre se situent toutes dans les motifs. On peut donc en conclure que l'agar-agar a efficacement empêché l'adhérence des cellules. Bien que les cellules ont visiblement proliféré, elles sont encore toutes incluses dans les motifs au bout de 48 heures. Après 96 heures, les cellules se sont divisées de nombreuses fois (environ 4 à 5 fois), et l'on peut remarquer qu'elles se sont empilées dans certains motifs et que seulement quelques espaces entre les motifs commencent à être envahis (non montré). On peut en déduire que les cellules adhèrent plus facilement les unes sur les autres que sur l'agar-agar. Enfin, plus d'une semaine après le dépôt des cellules, les motifs peuvent toujours être distingués bien que les cellules ont énormément proliféré. On remarque un nombre important de cellules empilées dans les motifs ce qui confirme la grande efficacité de notre méthode. Cette technique permet, donc, une remarquable conservation des motifs cellulaires, pour des cellules en phase proliférative. 
A1
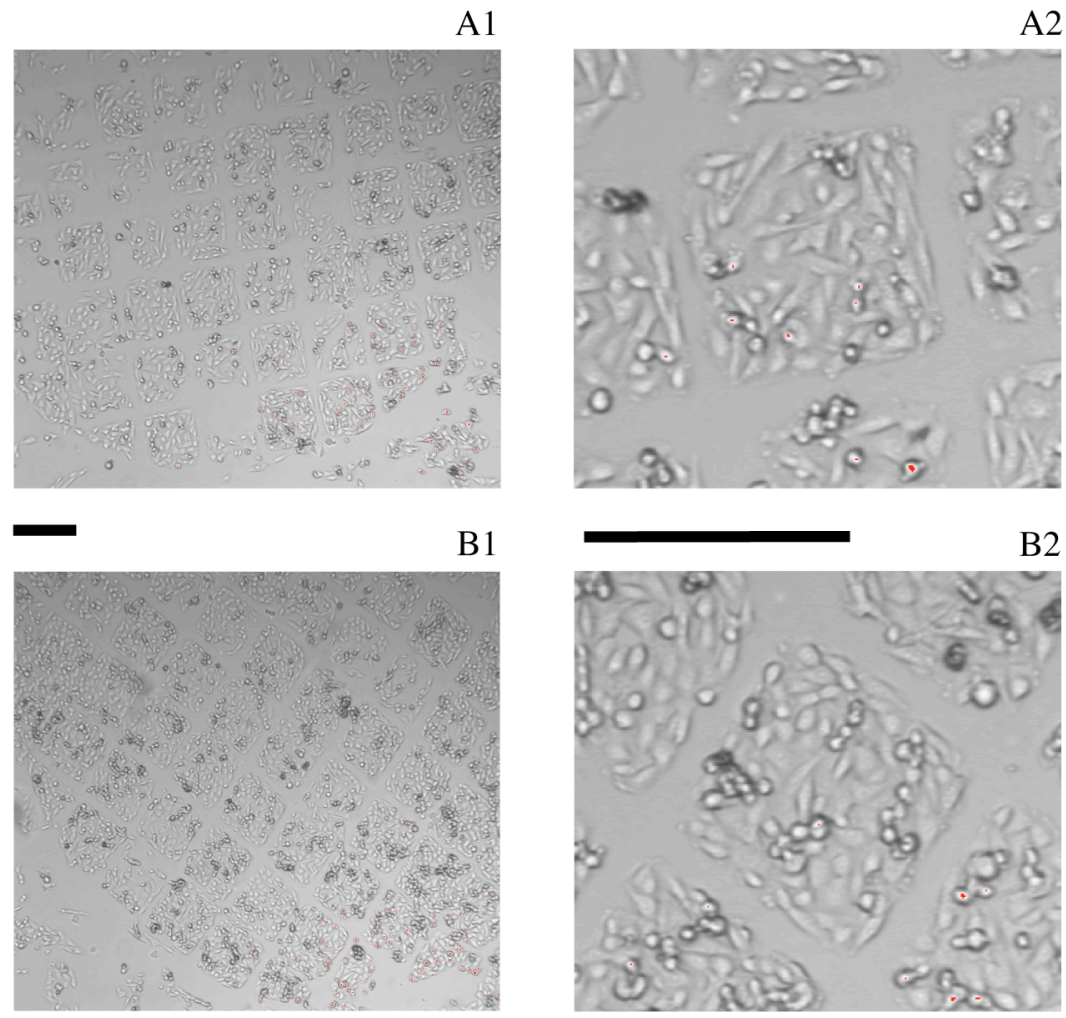

$\mathrm{C} 1$

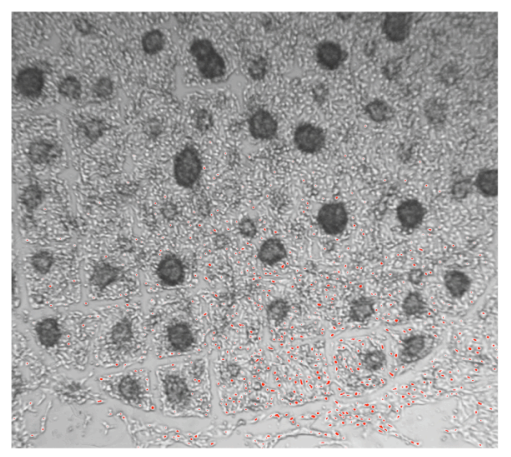

$\mathrm{C} 2$

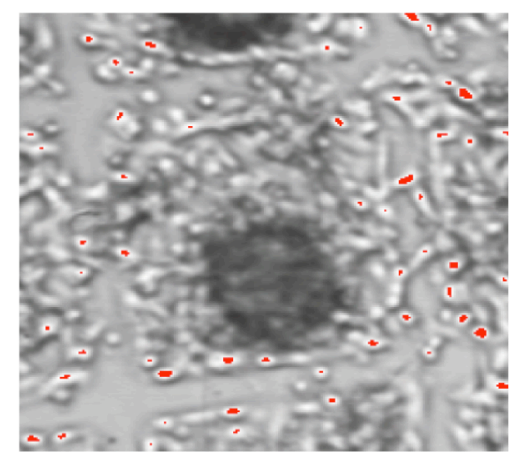

Figure 5-8: Résultats obtenus par la méthode de motifs cellulaires présentée pour les motifs carrés A1. Etat du motif quelques heures après le rinçage. Grossissement x10 (la barre représente $250 \mu \mathrm{m}$ ). A2. Même état que A1, grossissement $\mathrm{x} 40$ (la barre représente $250 \mu \mathrm{m}$ ) B1. Etat du motif 48 heures après le dépôt des cellules. Grossissement x10. B2. Même état que B1, grossissement $\mathrm{x} 40$. C1. Etat du motif 1 semaine après le dépôt des cellules. Grossissement x10. C2. Même état que C1, grossissement x40.

En conclusion, nous avons établi une méthode de motifs cellulaires simple et efficace qui permet de conserver les cellules dans les motifs pendant plusieurs journées. Cette méthode peut aisément s'adapter sur le montage présenté au chapitre 3. En effet, il suffit de préparer une lame de verre selon les étapes 1 à 4 de la Figure 5-6. Cette lame est ensuite scellée sur l'un des cotés de la chambre de culture (chapitre 3). Les cellules sont introduites dans la chambre de culture, puis le milieu est changé trois fois de suite (ce qui équivaut à deux rinçages) 15 heures après l'introduction des cellules. Les cellules restantes après les changements de milieu se situent dans les motifs. 
A1
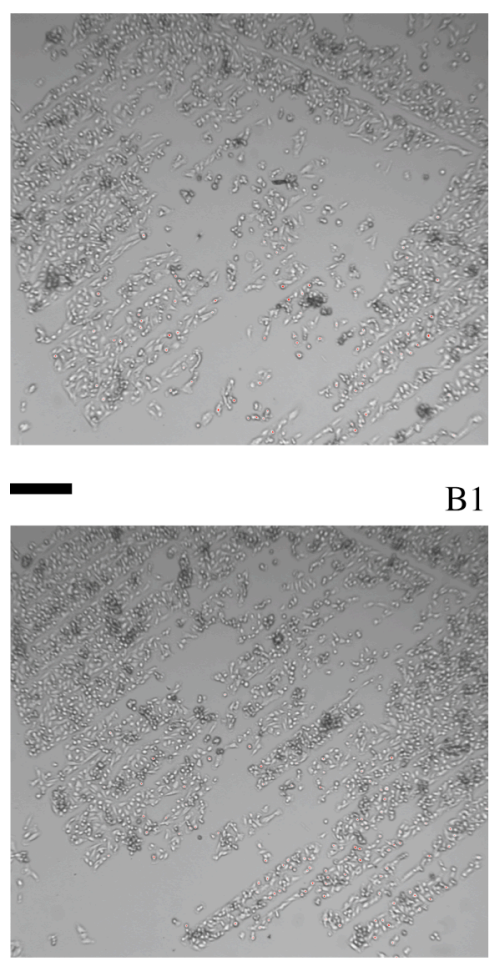

$\mathrm{C} 1$

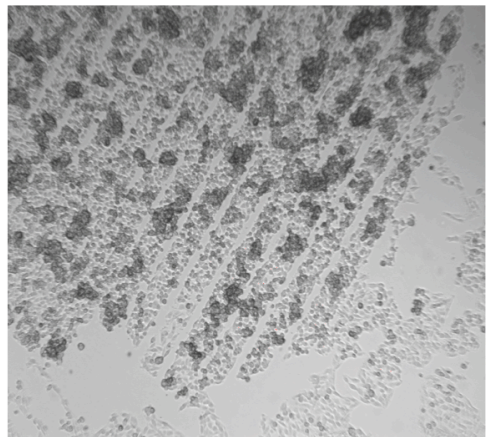

A2

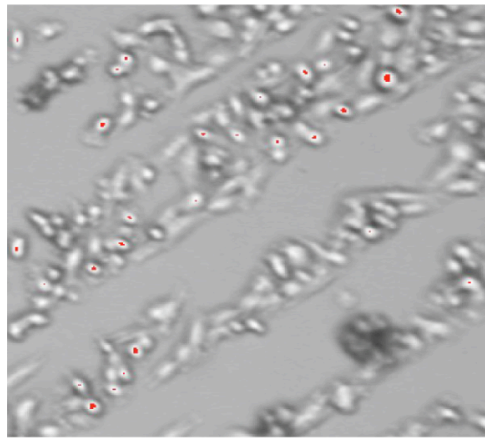

B2

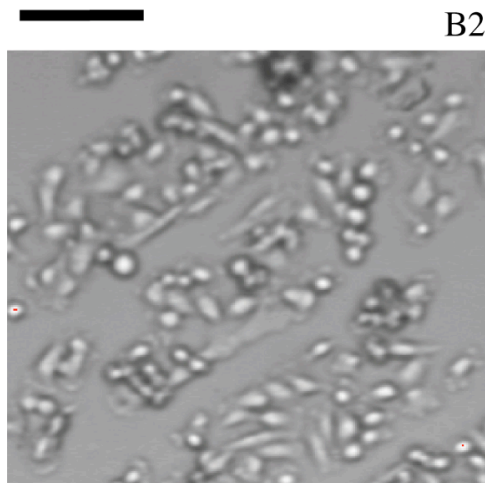

$\mathrm{C} 2$

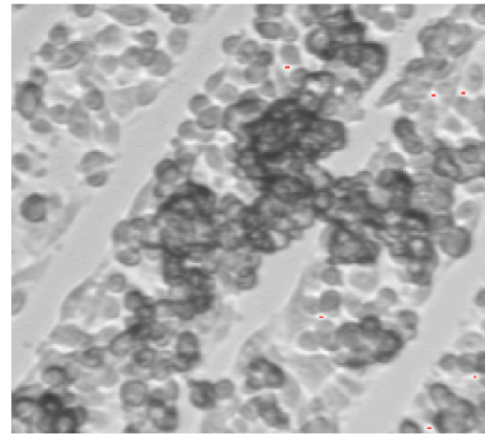

Figure 5-9 : Résultats obtenus par la méthode de motifs cellulaires présentée pour les motifs carrés A1. Etat du motif quelques heures après le rinçage. Grossissement x10 (la barre

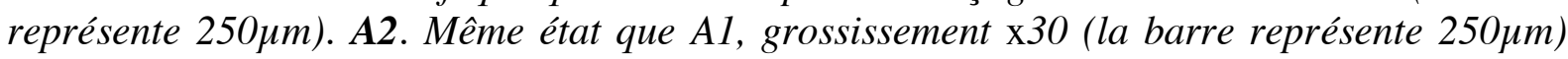
B1. Etat du motif 48 heures après le dépôt des cellules. Grossissement x10. B2. Même état que B1, grossissement x30. C1. Etat du motif 1 semaine après le dépôt des cellules. Grossissement x10. C2. Même état que C1, grossissement x30.

Après cela, nous avons réalisé de nouvelles expériences d'irradiation d'une seule cellule, dans une population de cellules, avec le montage présenté au chapitre 3. La lame de verre de la chambre de culture sur laquelle les cellules adhèrent, a été préparée avec le protocole de motifs cellulaires présenté en Figure 5-6. La concentration de départ de cellules introduites dans la chambre de culture est de $2 / 5$. Nous avons, alors, irradié une cellule dans l'un des motifs puis nous avons observé la propagation de l'apoptose. A chaque fois, la propagation se déroule de la même façon que pour l'expérience présentée en Figure 5-4. Aucune apoptose n'est observée dans les motifs voisins (résultats non montrés). Ces résultats confirment les conclusions que nous avons faites après les expériences d'irradiation sans motifs cellulaires. 
Toutefois, ils seraient intéressant de faire de nouvelles expériences d'irradiation avec des motifs encore moins espacé que ceux présentés dans ce chapitre (néanmoins, la méthode présentée dans ce paragraphe n'a pas donné de résultats satisfaisants pour des motifs séparé d'une distance inférieure à $25 \mu \mathrm{m}$ ).

\section{$\underline{\text { IV > Etude de l'arrêt de la transmission de l'apoptose }}$}

\section{1) Hypothèse}

L'hypothèse que nous avons émise concernant l'arrêt de la transmission du facteur apoptotique est liée au cycle cellulaire. En effet, plusieurs auteurs ont remarqué que plusieurs types cellulaires étaient plus sensibles à l'apoptose activée par FAS-R lors de la phase G1, que lors des autres phases du cycle cellulaire (Beletskaya et al., 1997 ; Alcegiras et al., 1999 ; Jedema et al., 2003). Si cette transmission se fait par contact, il est possible que ces récepteurs membranaires soient impliqués. On peut considérer que des cellules appartenant à un voisinage restreint sont dans la même phase du cycle cellulaire. En effet, elles proviennent probablement après plusieurs mitoses de la même cellule et de ce fait elles sont sans doute encore synchronisées dans le cycle. On peut donc supposer que les cellules voisines de la cellule irradiée entrent en apoptose du fait qu'elles sont toutes en G1. Puis, plus on s'éloigne de la cellule irradiée, moins les cellules sont synchronisées avec leur voisine. Les cellules n'étant plus dans la même phase, la transmission du signal ne peut se faire correctement. Pour tester cette hypothèse, nous avons tout d'abord regardé si les cellules SHEP étaient plus sensibles à l'apoptose activée par le récepteur FAS en phase G1 que dans les autres phases du cycle. Puis, nous avons irradié le noyau d'une cellule dans une population de cellules à majorité en phase G1.

\section{2) Sensibilité des cellules SHEP à l'apoptose en fonction du cycle cellulaire}

A

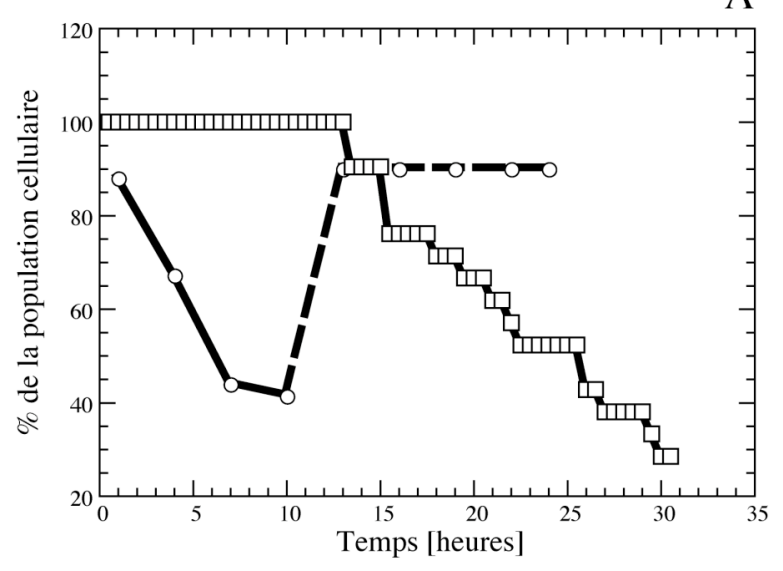

B

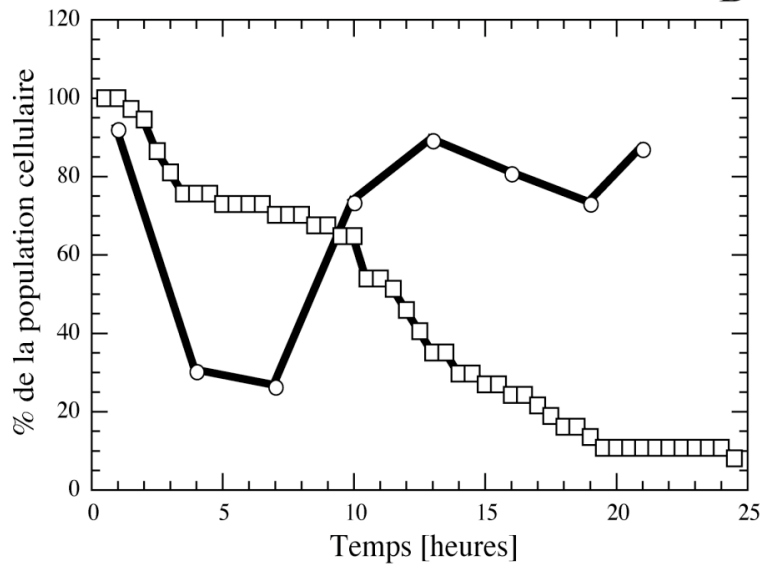

Figure 5-10 : Evolutions comparées de l'apoptose d'une population de cellules (motifs carrés) et du taux de cellules en G1 (motifs ronds). A. Evolutions des cellules après 10 heures sous HU. Les données que nous avons ne vont pas plus loin que 10 heures pour l'évolution de la phase G1. Toutefois, nous avons fait remarquer au chapitre 3, qu'un nombre important de mitoses était observé environ 10 heures après l'ajout de HU. Le taux de cellules en phase G1 peut donc être estimé comme étant proche de $90 \%$ (partie de la courbe en pointillé). B. Evolutions des cellules après 15 heures sous HU. On note un nombre important de mitoses environ 10 heures après le retrait de $H U$. 
Les expériences menées pour vérifier une sensibilité accrue des cellules SHEP en phase G1, nous avons, tout d'abord, synchronisé les cellules en G1 grâce à HU en suivant le protocole présenté au chapitre 3. Ainsi, après être resté soit 10 heures, soit 15 heures sous HU, dans le porte-échantillon, le milieu de culture est retiré puis remplacé par du milieu avec une concentration de $100 \mathrm{ng} / \mathrm{mL}$ en anticorps anti-FAS (Upstate). Nous avons ensuite observé, par vidéomicroscopie time-lapse dans notre montage (1 image toutes les 30 secondes), l'évolution de la population de cellules sur 24 heures en relevant le nombre de cellules apoptotiques en fonction du temps (Figure 5-10). La courbe obtenue a ensuite été comparée à celle de l'évolution des cellules dans le cycle suite au retrait de HU du milieu. La Figure 5-10 A montre les résultats obtenus après avoir laissé les cellules pendant 10 heures sous HU. Au départ, le taux de cellules en G1 est très important (plus de 90\%) et l'on note une forte décroissance de la population de cellules. Ensuite, le taux de cellules en G1 diminue à peu près en même temps que le taux de décroissance de la population et on observe alors un plateau.. Lorsque, 10 heures après le retrait de HU et l'ajout des anti-FAS, un grand nombre de cellules sont à nouveau en G1 (elles ont effectué un cycle complet), on note à nouveau un fort taux de décroissance de la population de cellules. Les mêmes observations peuvent être menées lorsque les cellules restent 15 heures sous HU (Figure 5-10 B). Les cellules SHEP semblent donc bien plus sensibles à l'apoptose dans la phase G1 .

Il faut donc à présent regarder si l'arrêt de la transmission du facteur apoptotique se produit de façon différente lorsqu'une majorité des cellules est en phase G1.

\section{3) Transmission du facteur apoptotique dans une population de cellules à majorité en $\underline{\text { G1 }}$}

Pour mener ces expériences, les cellules sont préparées de la même manière que pour les expériences de diffusion de la lumière présentée au chapitre 4, de façon à avoir plus de $90 \%$ de cellules en phase G1 pendant plusieurs heures (nous n'avons pas utilisé de motifs cellulaires). Ainsi, les cellules sont introduites dans la chambre de culture avec une densité de 2/5 (voir annexe). La chambre de culture est laissée trois heures dans incubateur à $\mathrm{CO}_{2}$ pour permettre aux cellules d'adhérer. Ensuite le milieu de culture est retiré, puis remplacé par du milieu contenant 0,5 mM de HU. 10 heures plus tard le milieu avec HU est retiré puis remplacé par du milieu neuf. La chambre de culture est alors placée dans le montage de diffusion de la lumière. Une cellule est irradiée avec le faisceau laser pendant environ 3 heures et une fois qu'elle est entrée en apoptose nous observons le comportement des cellules voisines par vidéomicroscopie time-lapse pendant 24 heures (1 image/ 30 secondes). Nous avons mené 4 expériences suivant ce protocole. Sur aucune de ces expériences nous n'avons observé de transmission de l'apoptose, y compris aux premières voisines. Ces observations ne confirment pas les premières observations que nous avons précédemment présentées dans ce chapitre. Cela pourrait s'expliquer par le peu d'expériences que nous avons menées jusqu'à maintenant (4 contre 20 pour les expériences sur des cellules non synchronisées en phase G1). D'un autre coté, l'hypothèse selon laquelle le facteur de transmission du signal apoptotique active l'apoptose de la même manière que la fixation d'un ligand sur le récepteur FAS de la cellule est très forte. En effet, les cellules SHEP ont plusieurs récepteurs membranaires de mort, comme les récepteurs DR4 et DR5 (Death Receptor 4 et 5 ; Johnsen et al., 2004), qui n'agissent pas de la même manière que le FAS-R. Il est donc possible que la transmission de l'apoptose ne se fasse pas mieux en phase G1. Mais, les limites imposées par notre matériel (pas de possibilité de faire de la vérification au niveau de la biochimie, montage expérimental imposé,...) ne nous permettent pas de tester d'autres types d'hypothèses. 


\section{4) Conclusion}

En ajoutant des anti-corps anti-FAS-R dans le milieu de culture de cellules synchronisées en phase G1, nous avons observé que les cellules étaient plus sensibles à l'apoptose dans cette phase. Malgré cela, nous n'avons observé aucune transmission de l'apoptose lors des expériences d'irradiation menées sur des cellules synchronisées en phase G1. Néanmoins, le peu d'expériences de ce type que nous avons réalisées ne permet de conclure.

\section{BIBLIOGRAPHIE :}

- Algeciras-Schimnich A, Griffith TS, Lynch DH et Paya CV. (1999) Cell cycle-dependent regulation of FLIP levels and susceptibility to Fas-mediated apoptosis. Journal of Immunology. 162 : 5205-5211.

- Anderson JR, Chiu DT, Jackman RJ, Cherniavskaya O, McDonald JC, Wu H, Whitesides SH et Whitesides GM. (2000) Fabrication of topologically complex three-dimensional microfluidic systems in PDMS by rapid prototyping. Analytical Chemistry. 72 : 31583164.

- Beletskaya IV, Nikonova LV et Beletsky IP. (1997) Cell cycle specificity of Fas-mediated apoptosis in WIL-2 cells. FEBS letters. 412 : 91-93.

- Bergeron L et Yuan J. (1998) Sealing one's fate: control of cell death in neurons. Current Opinion in Neurobiology. 8 : 55-63.

- Chang JC, Brewer GJ et Wheeler BC. (2003) A modified microstamping technique enhances polylysine transfer and neuronal cell patterning. Biomaterials. 24 : 2863-2870.

- Chinnaiyan AM, O'Rourke K, Tewari M et Dixit VM. (1995) FADD, a novel death domain-containing protein, interacts with the death domain of Fas and initiates apoptosis. Cell. 81 : 505-512.

- Chiu DT, Jeon NL, Huang S, Kane RS, Wargo CJ, Choi IS, Ingber DE et Whitesides GM. (2000) Patterned deposition of cells and proteins onto surfaces by using three-dimensional microfluidic systems. PNAS. 97 : 2408-2413.

- Cuvelier D, Rossier O, Bassereau P et Nassoy P. (2003) Micropatterned "adherent/repellent" glass surfaces for studying the spreading kinetics of individual red blood cells onto protein-decorated substrates. European Biophysics Journal. 32 : 342-354.

- Earnshaw WC. (1995) Nuclear changes in apoptosis. Current Opinion in Cell Biology. 7 : 337-343.

- Fadeel B et Orrenius S. (2005) Apoptosis: a basic biological phenomenon with wideranging implications in human disease. Journal of Internal Medicine. 258 : 479-517.

- Goillot E, Raingeaud J, Ranger A, Tepper RI, Davis RJ, Harlow E et Sanchez I. (1997) Mitogen-activated protein kinase-mediated Fas apoptotic signaling pathway. PNAS. 94 : 3302-3307.

- Hays R, Wickline L et Cagan R. (2002) Morgue mediates apoptosis in the Drosophila melanogaster retina by promoting degradation of DIAP1. Nature Cell Biology. $4: 425-431$.

- Holley CL, Olson MR, Colon-Ramos DA et Kornbluth S. (2002) Reaper eliminates IAP proteins through stimulated IAP degradation and generalized translational inhibition. Nature Cell Biology. 4 : 439-444.

- Jedema I, Barge RM, Willemze R et Falkenburg JH. (2003) High susceptibility of human leukemic cells to Fas-induced apoptosis is restricted to G1 phase of the cell cycle and can be increased by interferon treatment. Leukemia. 17 : 576-584.

- Johnsen JI, Pettersen I, Ponthan F, Sveinbjornsson B, Flaegstad T et Kogner P. (2004) Synergistic induction of apoptosis in neuroblastoma cells using a combination of cytostatic 
drugs with interferon-gamma and TRAIL. International Journal of Oncology. 25: 18491857.

- Kane RS, Takayama S, Ostuni E, Ingber DE et Whitesides GM. (1999) Patterning proteins and cells using soft lithography. Biomaterials. $20: 2363-2376$.

- Kerr JF. (2002) History of the events leading to the formulation of the apoptosis concept. Toxicology. 181-182 : 471-474.

- Kerr JF, Wyllie AH et Currie AR. (1972) Apoptosis: a basic biological phenomenon with wide-ranging implications in tissue kinetics. British Journal of Cancer. 26 : 239-257.

- Kiechle FL et Zhang X. (2002) Apoptosis: biochemical aspects and clinical implications. Clinica Chimica Acta. 326 : 27-45.

- Kothakota S, Azuma T, Reinhard C, Klippel A, Tang J, Chu K, McGarry TJ, Kirschner MW, Koths K, Kwiatkowski DJ et Williams LT. (1997) Caspase-3-generated fragment of gelsolin: effector of morphological change in apoptosis. Science. 278 : 294-298.

- Kulms D, Zeise E, Poppelmann B et Schwarz T. (2002) DNA damage, death receptor activation and reactive oxygen species contribute to ultraviolet radiation-induced apoptosis in an essential and independent way. Oncogene. 21 : 5844-5851.

- Levine AJ. (1997) p53, the cellular gatekeeper for growth and division. Cell. 88 : 323-331.

- Li H, Zhu H, Xu CJ et Yuan J. (1998) Cleavage of BID by caspase 8 mediates the mitochondrial damage in the Fas pathway of apoptosis. Cell. 94 : 491-501.

- Lüschen S, Ussat S, Scherer G, Kabelitz D et Adam-Klages S. (2000) Journal of Biological Chemistry. 275 : 24670-24678.

- Mrksich M, Dike LE, Tien J, Ingber DE et Whitesides GM. (1997) Using microcontact printing to pattern the attachment of mammalian cells to self-assembled monolayers of alkanethiolates on transparent films of gold and silver. Experimental Cell Research. 235 : 305-313.

- Park TH et Shuler ML. (2003) Integration of cell culture and microfabrication technology. Biotechnology Progress. 19 : 243-253.

- Peter ME, Heufelder AE et Hengartner MO. (1997) Advances in apoptosis research. PNAS. 94 : 12736-12737.

- Rohr S, Fluckiger-Labrada R et Kucera JP. (2003) Photolithographically defined deposition of attachment factors as a versatile method for patterning the growth of different cell types in culture. Pflügers Archiv : European journal of physiology. 446 : 125-132.

- Ryan KM, Phillips AC et Vousden KH. (2001) Regulation and function of the p53 tumor suppressor protein. Current Opinion in Cell Biology. 13 : 332-337.

- Sartorius U, Schmitz I et Krammer PH. (2001) Molecular mechanisms of death-receptormediated apoptosis. Chembiochem. 2 : 20-29.

- Shiozaki EN et Shi Y. (2004) Caspases, IAPs and Smac/DIABLO: mechanisms from structural biology. Trends in Biochemical Sciences. 29 : 486-494.

- Tanaka H, Arakawa H, Yamaguchi T, Shiraishi K, Fukuda S, Matsui K, Takei Y et Nakamura Y. (2000) A ribonucleotide reductase gene involved in a p53-dependent cellcycle checkpoint for DNA damage. Nature. $404: 42-49$.

- van Loo G, Saelens X, van Gurp M, MacFarlane M, Martin SJ, Vandenabeele P. (2002) The role of mitochondrial factors in apoptosis: a Russian roulette with more than one bullet. Cell death and differentiation. 9 : 1031-1042.

- Ye H, Cande C, Stephanou NC, Jiang S, Gurbuxani S, Larochette N, Daugas E, Garrido C, Kroemer $\mathrm{G}$ et $\mathrm{Wu} \mathrm{H}$. (2002) DNA binding is required for the apoptogenic action of apoptosis inducing factor. Nature Structural Biology. 9 : 680-684.

- Yoo SJ, Huh JR, Muro I, Yu H, Wang L, Wang SL, Feldman RM, Clem RJ, Muller HA, Hay BA. (2002) Hid, Rpr and Grim negatively regulate DIAP1 levels through distinct mechanisms. Nature Cell Biology. 4 : 416-424. 
- Zhang S, Yan L, Altman M, Lassle M, Nugent H, Frankel F, Lauffenburger DA, Whitesides GM et Rich A. (1999) Biological surface engineering: a simple system for cell pattern formation. Biomaterials. 20 : 1213-1220. 


\section{Chapitre 6 : CONCLUSIONS ET PERSPECTIVES}

\section{$\underline{\text { I }>\text { Conclusions }}$}

\section{1) Diffusion dynamique de la lumière}

Dans un premier temps, nous avons construit un montage expérimental de diffusion dynamique de la lumière original et nous avons mis au point des protocoles de manipulation des cellules, pour permettre l'étude de la dynamique interne du noyau d'une cellule vivante.

En pratique, ce dispositif permet de focaliser un faisceau laser sur une surface de quelques $\mu \mathrm{m}^{2}$ à l'intérieur du noyau d'une cellule vivante. Un système de visualisation nous permet de positionner les cellules là où le faisceau laser est focalisé. Les cellules adhèrent sur une lame de verre et, de ce fait, leurs déplacements sont suffisamment faibles pour que les mesures puissent durer quelques minutes. Un système de détection nous permet de recueillir l'intensité de la lumière diffusée par le noyau. Il est relié à deux dispositifs qui transforme cette intensité en un signal que l'on peut analyser : une carte corrélateur grâce à laquelle nous mesurons l'autocorrélation de l'intensité de la lumière diffusée $(\langle\boldsymbol{I}(\boldsymbol{0}) \boldsymbol{I}(\boldsymbol{t})\rangle)$ et une carte d'acquisition qui nous donne le « signal brut », c'est-à-dire $I(t)$. Enfin, les protocoles que nous avons mis au point nous permettent de maintenir les cellules dans un bon état physiologique. Ceci, en particulier, grâce à la chambre de culture que nous avons construite. Nous sommes également capables de contrôler le cycle des cellules SHEP, ce qui nous permet de réaliser nos mesures sur des cellules dans une phase donnée du cycle cellulaire.

Grâce à ce montage expérimental, nous avons étudié la dynamique interne du noyau de cellules SHEP, dans les différentes phases du cycle cellulaire. Les expériences que nous avons menées nous donnent de nombreux résultats sur la dynamique interne du noyau. Comme attendu, cette dynamique est très riche et très complexe, avec un très grand nombre de temps caractéristiques s'étalant de quelques millisecondes à quelques dizaines de secondes. Nos résultats sont donnés par l'analyse des mesures des fonctions d'autocorrélation de l'intensité diffusée $(\langle\boldsymbol{I}(\mathbf{0}) \boldsymbol{I}(\boldsymbol{t})\rangle)$ qui nous ont permis de sonder, plus particulièrement, la dynamique du noyau entre la milliseconde et la seconde. Ces résultats montrent que la dynamique du noyau présente toujours deux distributions indépendantes de temps caractéristiques. La première de ces distributions est une distribution de temps caractéristiques courts, de quelques dizaines de millisecondes, qui est différente pour chaque phase du cycle cellulaire. Nous ne sommes pas encore capables de relier ces temps caractéristiques à un processus particulier. Néanmoins, comme la décroissance rapide de la fonction d'autocorrélation est une exponentielle étirée, on suppose que ces temps sont la signature de relaxations s'effectuant par un ensemble de processus hiérarchisés. La deuxième de ces distributions est une distribution de temps caractéristiques plus lents, de l'ordre de la seconde, soit 100 fois moins rapides que les temps courts. Elle semble moins dépendante du cycle cellulaire que la distribution des temps courts. Là encore, nous ne sommes pas en mesure de relier de façon certaine ces temps caractéristiques à des processus biologiques. Toutefois, on peut remarquer que la gamme dans laquelle se situe ces temps longs est compatible avec les résultats de Shav Tal et al. (1994) sur la dynamique des complexes mRNP dans le noyau.

Nous avons aussi pu observer que la présence d'une drogue cytobloquante (HU) modifiait la dynamique interne du noyau. La présence de cette drogue semble accélérer la dynamique rapide et ralentir la dynamique lente. 


\section{2) Transmission de l'apoptose}

Grâce à notre montage expérimental, nous avons également mis en évidence un phénomène de transmission de l'apoptose d'une cellule vers ses voisines. Nous avons établi que cette transmission se faisait par contact cellule/cellule. Néanmoins, cette transmission ne se fait que dans le voisinage restreint de la première cellule à entrer en apoptose. Nous n'avons pas encore pu identifier le mécanisme de cette transmission.

\section{II> Perspectives}

Les résultats que nous avons obtenus ouvrent la voie à de nombreuses perspectives.

\section{1) Processus biologiques}

La première de ces perspectives est de relier les temps caractéristiques que nous avons obtenus à des phénomènes biologiques particuliers. Dans cette optique, il faudrait coupler, sur le dispositif expérimental existant, les mesures de diffusion dynamique de la lumière à des observations de microscopie de fluorescence afin d'établir un lien entre le signal de diffusion de la lumière et l'activité biochimique du noyau.

Il serait aussi intéressant d'utiliser des drogues pour bloquer (ou favoriser) des activités biologiques bien particulières et analyser, ensuite, la nouvelle dynamique du noyau.

Ensuite, toutes nos expériences ont été réalisées sur des neuroblastomes de la lignée SHEP. Notre montage expérimental pourrait être utilisé pour étudier la dynamique interne du noyau d'autres lignées cellulaires lors du cycle cellulaire.

Jusqu'ici, nous n'avons étudié que la dynamique du noyau en fonction du cycle cellulaire. On pourrait, aussi, étudier la dynamique du noyau lors d'autres processus biologiques fondamentaux comme l'apoptose. Ainsi, on pourrait réaliser des expériences sur des cellules «pré-apoptotiques »; c'est-à-dire étudier la dynamique interne du noyau entre le moment où la cellule entre en contact avec un «agent » provoquant l'apoptose et le moment où l'on observe la cellule en train de « mourir ».

Pour finir, il est nécessaire de mesurer la dynamique du noyau en fonction de l'échelle spatiale sondée, c'est-à-dire du vecteur d'onde de diffusion $\boldsymbol{q}$, pour avoir une relation entre les temps caractéristiques mesurés et l'échelle sondée. Ceci nous permettra de savoir si les processus observés sont diffusifs, ou non (ce qui est une information certainement très importante pour les physiciens théoriciens s'intéressant à la physique de la cellule).

\section{2) Traitement du signal}

Pour le moment, nous mesurons la fonction d'autocorrélation de l'intensité lumineuse diffusée car c'est une technique très simple. Cependant, nous savons que cette analyse nous fait perdre de l'information et ne nous permet pas d'obtenir toute la dynamique du noyau que nous pourrions extraire des signaux mesurés. De ce fait, afin de sortir plus d'information de nos observations, il faut travailler directement avec le signal brut détecté. Notre montage nous permet déjà de recueillir ce signal. Il faudrait maintenant lui appliquer des méthodes de traitement du signal (comme la transformée en ondelettes) pour en extraire l'information dynamique.

\section{3) Transmission de l'apoptose}

Le mode de transmission ayant été identifié, il reste maintenant à comprendre pourquoi cette transmission s'arrête. Nous avons commencé à regarder si le cycle cellulaire jouait un rôle dans cet arrêt. Nos expériences n'ont pas encore abouti et il faudrait finir de vérifier cette hypothèse. 
Ensuite, une fois les raisons de l'arrêt de la transmission établies, il serait intéressant de pouvoir identifier le facteur de transmission ainsi que les éventuels récepteurs membranaires de la cellule impliqués.

Enfin, il faudrait réaliser des expériences sur d'autres types cellulaires afin de regarder si ce phénomène de transmission de la mort par apoptose est limité ou non aux cellules SHEP. 
ANNEXES 



\section{ANNEXE A : Diffusion dynamique de la lumière}

\section{A.I > Diffusion de la lumière}

La diffusion de la lumière est une technique classique qui consiste à envoyer un faisceau lumineux à travers un échantillon, et à étudier l'intensité $i$ de la lumière diffusée (Bern et Pecora ; 1976). Cette diffusion provient des propriétés optiques de l'échantillon, elles-mêmes liées à la structure et à la dynamique interne de l'échantillon.

Les propriétés optiques d'ensemble d'un milieu sont données par son indice de réfraction. L'indice de réfraction est une valeur moyenne, notée $\langle n\rangle$, qui dépend principalement de la composition moléculaire du milieu et de sa concentration moyenne. Localement, ces deux paramètres peuvent subir des modifications d'ordre spatial (inhomogénéités structurelles,...) et/ou temporel (mouvement de particules,...) entraînant des variations locales de l'indice de réfraction. L'indice de réfraction en un point $\mathbf{r}$ du milieu, au temps $t$ s'écrit donc :

$$
n(\mathbf{r}, t)=\langle n\rangle+\delta n(\mathbf{r}, t)(A-1)
$$

où $\delta n$ représente les variations locales de l'indice de réfraction autour de $\langle n\rangle$. Si l'on envoie un faisceau lumineux à travers ce milieu, les variations $\delta n$ vont entraîner la diffusion de la lumière du faisceau dans tout l'espace.

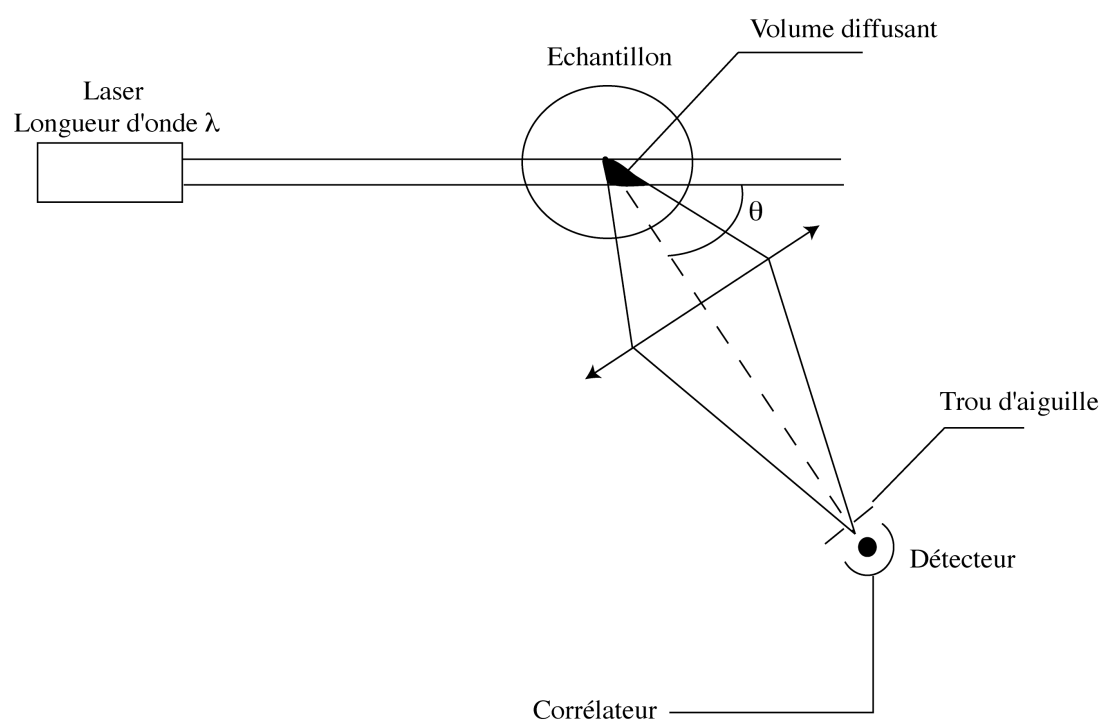

Figure A-1 : Schéma d'une expérience de diffusion de la lumière. Un faisceau laser de longueur d'onde $\lambda$ est envoyé sur un échantillon. Les fluctuations de l'indice de réfraction à l'intérieur de l'échantillon entraînent la diffusion de la lumière dans tout l'espace. La lumière diffusée est recueillie en plaçant un détecteur à un angle $\theta$ du faisceau incident. La taille du volume diffusant est définie par la taille du trou d'aiguille placé devant le détecteur.

L'intensité $i$ de la lumière diffusée par un échantillon peut être recueillie grâce à un détecteur (photomultiplicateur,...). Cette intensité dépend directement des variations $\delta n$ de l'indice de réfraction. L'analyse de cette intensité permet donc de remonter aux origines de $\delta n$ et donc à la dynamique de l'échantillon : si le faisceau lumineux utilisé est monochromatique et cohérent (faisceau laser) on peut à l'aide d'un corrélateur, bâtir la fonction d'autocorrélation de l'intensité de la lumière diffusée pour des temps allant de la microseconde à la dizaine de secondes et remonter ainsi aux temps caractéristiques des fluctuations dans l'échantillon. En pratique, on ne récupère pas toute l'intensité $i$, mais seulement l'intensité diffusée à un angle 
$\theta$ donné du faisceau incident qui correspond à la position du détecteur. De plus, la lumière recueillie ne provient pas de tout le volume à l'intersection entre le faisceau incident et l'échantillon, mais d'un volume plus petit dont la taille dépend du système optique qui permettra de faire son image sur la surface photosensible du détecteur (Figure A-1). Ce volume est appelé volume diffusant. Il est ensuite possible de sonder différentes échelles de longueur dans le volume diffusant. En effet, l'échelle de longueur, $L$, sur laquelle on sonde le volume diffusant dépend de l'angle $\theta$ par la relation :

$$
L=\frac{2 \pi}{q}(A-2)
$$

avec :

$$
q=\frac{4 \pi\langle n\rangle}{\lambda} \sin \left(\frac{\theta}{2}\right)(A-3)
$$

où $\lambda$ est la longueur d'onde du faisceau incident. Ainsi, en faisant varier $\theta$, on peut mesurer, dans le volume diffusant, les temps caractéristiques des fluctuations d'indice sur des échelles spatiales allant de la centaine de nanomètres $\left(L=\lambda /(2\langle n\rangle)\right.$ pour $\left.\theta=180^{\circ}\right)$ au micromètre (environ $3 \mu \mathrm{m}$ pour $\theta=10^{\circ}$ et $\lambda=632,8 \mathrm{~nm}$ ).

\section{A.II> Autocorrélation}

La fonction d'autocorrélation de l'intensité de la lumière diffusée $i(t)$ s'écrit :

$$
C(\tau)=\langle i(0) i(\tau)\rangle=\lim _{T \rightarrow \infty} \frac{1}{T} \int_{0}^{T} i(t) i(t+\tau) d t(A-4)
$$

Chacun des points de la fonction $C$ correspond à la similitude entre la fonction $i$ et une version décalée d'elle-même d'un temps $\tau$. Les décroissances de cette fonction donnent accès aux temps caractéristiques de $i$. La gamme de temps $\tau$ doit donc être suffisamment grande pour contenir toute l'information recherchée. Concernant la variable $T$, elle représente la durée pendant laquelle l'autocorrélation du signal sera effectuée. Plus $T$ est grand, plus l'autocorrélation sera satisfaisante.

\section{BIBLIOGRAPHIE :}

- Bern BJ et Pecora R. Dynamic Light Scattering. Wiley \& Sons, New York. 1976. 


\section{ANNEXE B : Protocoles expérimentaux}

\section{$\underline{B}$.I> Protocole de remise en culture des cellules}

Le maintien des cellules dans un bon état physiologique dépend de la façon dont les cellules sont cultivées. De manière générale, elles sont réparties dans une boîte de Petri de $10 \mathrm{~cm}$ de diamètre. Elles adhèrent sur le fond de la boîte et sont recouvertes de $10 \mathrm{~mL}$ de milieu de culture. Les éléments nutritifs présents dans ce milieu sont consommés par les cellules et se dégradent d'autant plus que la densité de cellules dans la boîte est importante. Lorsque le milieu est trop dégradé, les cellules passent en phase G0 et finissent par entrer en apoptose. Les cellules SHEP se divisant rapidement elles atteignent cet état en seulement quelques jours. Si l'on veut les préserver correctement pour nos expériences, lorsque les cellules occupent environ $80 \%^{1}$ du fond de la boîte de Petri, il est nécessaire de répartir les cellules dans une nouvelle boîte, à une densité moins importante et avec du milieu neuf. C'est ce que nous appellons « la remise en culture des cellules ».

Nous pouvons décider de remettre les cellules en culture à différentes concentrations en fonction des expériences que nous voulons mener. Nous présenterons ici le protocole pour remettre les cellules en culture à une concentration de $x / 10$. Ce protocole est réalisé sous hotte à flux laminaire vertical afin de préserver la stérilité de nos cultures. Ainsi, une fois la densité de $80 \%$ atteinte dans une boîte, le milieu de culture est retiré. Les cellules sont rincées avec environ 5mL d'une solution neutre, le PBS (Phosphate Buffered Saline; Gibco), afin de s'assurer qu'il ne reste plus de trace de sérum. En effet, celui-ci inhibe l'enzyme qui va nous servir à détacher les cellules de leur support : la trypsine. Il s'agit à la base d'une enzyme du suc pancréatique qui hydrolyse les liaisons entre la cellule et le substrat. Environ $0,5 \mathrm{~mL}$ de trypsine non diluée (Gibco) réparti sur les cellules, puis immédiatement enlevé, suffit pour détacher toutes les cellules de la boîte. Une fois les cellules détachées, elles sont abondamment rincées avec $10 \mathrm{~mL}$ de milieu neuf. Nous obtenons alors une solution composée de milieu et de cellules en suspension. On prélève $x \mathrm{~mL}$ de cette solution que l'on réparti dans une nouvelle boîte de Petri préalablement remplie de $10-x \mathrm{~mL}$ de milieu. La nouvelle boîte de Petri est immédiatement placée dans un incubateur à $\mathrm{CO}_{2}$. Toutes les cellules auront adhéré au fond de la boîte en environ 3 heures. Elles recommenceront alors leur cycle.

Notons, toutefois, que les cellules ne sont en mesure de subir qu'un nombre limité de remise en culture. De façon à toujours avoir des cellules dans le meilleur état possible, nous avons décidé de ne jamais faire plus d'une douzaine de remise en culture avec le même lot de cellules de départ. Un nouveau lot est décongelé chaque fois que cette limite est atteinte.

\section{B.II> Stérilisation de la chambre de culture}

La survie des cellules dans le montage de diffusion de la lumière dépend avant tout de la stérilité de la chambre de culture. Cette stérilité est assurée par le nettoyage méticuleux de la pièce métallique et des lames de verre qui compose la chambre de culture. Ainsi :

- concernant la pièce métallique, une attention particulière est donnée aux canaux par lesquelles les cellules sont introduites (voir chapitre 3). En effet, leur petite taille les rend difficilement accessibles et des impuretés peuvent s'y loger. C'est pourquoi nous les nettoyons avec une aiguille de seringue stérile. Ils sont ensuite abondamment rincés à l'eau ultra-pure et à l'éthanol absolu. Toute la pièce est ensuite rincée à l'éthanol absolu, puis séchée à l'azote sec. Elle est autoclavée et stockée sous une hotte à flux laminaire stérile jusqu'à utilisation.

\footnotetext{
${ }^{1}$ Cette densité se juge approximativement en visualisant la boîte de Petri sous un microscope.
} 
- concernant les lames de verres, elles doivent non seulement être stérilisées mais en plus être parfaitement propre. En effet, la moindre poussière créerait une inhomogénéité spatiale sur la lame qui pourrait être à l'origine d'une diffusion de la lumière parasite (voir chapitre 3). Afin d'éviter cela, les lames sont plongées pendant 48 heures dans une solution composée d'un puissant détergent, le Décon, dilué à hauteur de 4\% dans de l'eau distillée. Puis, afin d'enlever le Décon, les lames sont plongées deux fois une heure dans de l'eau distillée. Elles sont ensuite rincées à l'eau ultra-pure et à l'éthanol absolu avant d'être séchées à l'azote sec. Elles sont immédiatement autoclavées puis stockées sous une hotte à flux laminaire stérile jusqu'à utilisation.

\section{B.III> Introduction des cellules dans la chambre de culture}

Une fois la chambre de culture scellée par les lames de verres, les cellules peuvent y être introduites, sous hotte à flux laminaire. Pour cela, nous commençons par suivre le protocole de remise en culture. Une fois les cellules détachées de leur support, elles sont mises à la concentration souhaitée dans une éprouvette en plastique munie d'un bouchon (Falcon). On en prélève, ensuite, $400 \mu \mathrm{L}$ avec une seringue qui sont introduits dans la chambre de culture par les canaux se trouvant sur le coté de la pièce. On s'assure qu'il ne reste aucune bulle d'air dans la chambre de culture à la fin de l'introduction ${ }^{2}$. Les canaux sont ensuite bouchés par un capillaire de $1 \mathrm{~mm}$ de diamètre, préalablement stérilisé et rempli de milieu, qui les relient l'un à l'autre (cela nous permet d'assurer la stérilité de l'ensemble et d'éviter que des bulles d'air ne se forment dans la chambre de culture par la suite). En mettant la pièce à plat dans incubateur à $37^{\circ} \mathrm{C}$, les cellules sédimentent sur la lame de verre inférieure et y adhérent en s'étalant (le processus prend environ 3 heures). Une fois les cellules adhérées la pièce est placée sur le montage de diffusion de la lumière.

\footnotetext{
${ }^{2}$ La présence de bulles d'air est, toutefois, difficilement évitable.
} 


\section{ANNEXE C : Techniques diverses}

\section{C.I>Cytométrie en flux : CMF}

A
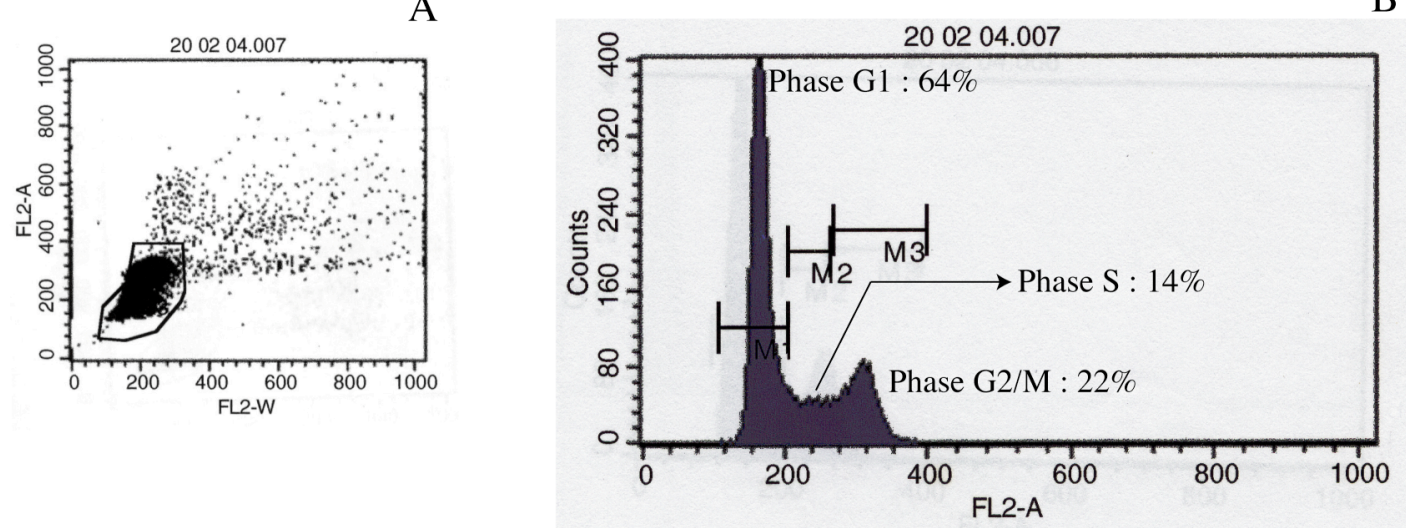

Figure C-1: Analyse par cytométrie en flux de la répartition d'une population de Neuroblastomes de la lignée SHEP dans les différentes phases du cycle cellulaire. Le cytomètre analyse 20000 cellules pour établir la statistique de répartition dans le cycle cellulaire. A. Diagramme taillelfluorescence (unités arbitraires). La fluorescence de chaque cellule est représentée en fonction de sa taille. Seules les cellules contenues dans la zone encadrée seront finalement considérées pour la statistique de répartition (ici, environ 16 500). B. Histogramme représentant le nombre de cellules en fonction de la fluorescence émise par leur noyau (unité arbitraire). Les statistiques sont établies en fonction des cellules sélectionnées sur le diagramme A. La fraction de cellules dans chaque phase du cycle est déterminée par la mise en place de zones d'intérêt sur l'histogramme.

La cytométrie en flux $(\mathrm{CMF})$ est une technique qui consiste à faire défiler, une par une et à grande vitesse, devant un faisceau laser, des cellules dont l'ADN a été préalablement marqué par un intercalant fluorescent. La fluorescence émise par chaque cellule est recueillie par un détecteur puis numérisée et stockée sur ordinateur. Le cytomètre que nous utilisons est un FACScan (Fluorescent Activated Cell Sorter; BDBiosciences) et les données sont traitées grâce au logiciel CellQuest (BDBiosciences). Nous avons utilisé deux traitements possibles des données (Figure C-1) :

- diagramme pic du signal de fluorescence/surface du signal de fluorescence (Figure C-1 A) : ce diagramme permet d'éliminer les doublets, triplets ou agrégats de cellules. A l'aide d'un région, il est possible de sélectionner à partir de ce diagramme les éléments qui serviront à l'étude statistique des données.

- histogramme fluorescence (Figure C-1 B) : cet histogramme représente le nombre de cellule en fonction de l'intensité de la fluorescence émise par le noyau. Il est établi en fonction des cellules sélectionnées sur le diagramme précédent. On notera qu'une cellule en phase G2+M contient deux fois plus d'ADN qu'une cellule en G0/1. De fait, la fluorescence émise par une cellule en $\mathrm{G} 2+\mathrm{M}$ sera deux fois plus importante. Nous pouvons également distinguer la phase $\mathrm{S}$ (entre le pic G0/1 et le pic G2+M). Le pourcentage de cellules dans chaque phase du cycle est déterminé par la mise en place de zones d'intérêt. 


\section{C.II> Méthodes de redistribution de fluorescence après photoblanchiment (FRAP)}

La technique de redistribution de fluorescence après photoblanchiment, ou FRAP (Fluorescence Recovery After Photobleaching) est principalement utilisé pour étudier la diffusion de molécules dans un échantillon donné. Les molécules étudiées doivent être préalablement marquées par un fluorochrome (comme la Green Fluorescent Protein). Ensuite, une portion limitée de l'échantillon est temporairement illuminée, en général par un faisceau laser, avec une forte intensité afin de procéder à une extinction localisée, ou photoblanchiment (photobleaching), de la fluorescence. Si les molécules se déplacent dans l'échantillon, il y aura une redistribution des molécules fluorescentes et non fluorescentes entre la zone photoblanchie et le reste de l'échantillon. L'analyse de la cinétique de récupération de la fluorescence par la zone photoblanchie permet d'obtenir le coefficient de diffusion des molécules à l'intérieur du milieu. Cette technique est particulièrement bien adaptée à l'étude du trafic et des mouvements dans et entre différents compartiments cellulaires.

La technique de FLIP (Fluorescence Loss In Photobleaching) est un dérivé de la technique de FRAP. Elle consiste à illuminer en permanence une portion de l'échantillon jusqu'à ce que la fluorescence ait disparu ou ne varie plus dans tout l'échantillon. Cette technique renseigne sur la perméabilité entre différents compartiments, ainsi que sur les relations entre différents compartiments.

\section{C.III> Immuno-précipitation de la chromatine (ChIP)}

L'immuno-précipitation de la chromatine est une technique qui permet l'étude in vivo des protéines interagissant avec l'ADN. Elle permet, notamment, d'étudier les sites de fixations de facteurs de transcription sur l'ADN. Pour cela, les protéines sont fixées à l'ADN in vivo par un traitement au formaldéhyde (qui provoquera des pontages covalents entre les protéines et l'ADN). Puis l'ADN est extrait de la cellule, mis en solution et coupé en petites portions (entre 500 et $1000 \mathrm{pb}$ ). Ensuite, la protéine étudiée est ciblée par des anticorps. Les anticorps sont eux-mêmes liés à des billes magnétiques. Les billes magnétiques permettent de retenir les portions d'ADN pendant que le reste de la solution est retiré. A la fin, il ne reste plus que les portions d'ADN auxquelles sont fixées les protéines. Les liaisons entre les protéines et l'ADN sont ensuite cassées. Les brins d'ADN sont ensuite répliqués un grand nombre de fois in vitro (méthode PCR (Polymerase Chain Reaction)) pour permettre une identification plus aisée de la séquence de nucléotides. 

Résumé : De récents progrès en biologie cellulaire ont montré que le noyau d'une cellule vivante est un ensemble bien organisé de différents domaines ayant chacun une fonction propre. Cette organisation est hautement dynamique. En effet, elle est la clé de l'adaptation de la cellule à son environnement. La dynamique du noyau est ainsi le reflet de l'état de la cellule.

Bien que l'étude de cette dynamique soit devenue l'un des enjeux majeurs de la recherche en biologie cellulaire, la dynamique globale du noyau est encore peu comprise. Pour étudier cette dynamique nous avons mis au point un montage expérimental original de diffusion dynamique de la lumière. Il est à noter que si la diffusion dynamique de la lumière est une technique «classique » pour l'étude des propriétés dynamiques des systèmes moléculaires organisés (i.e. systèmes colloïdaux, surfactants, polymères en solution, gels, cristaux liquides), elle n'avait, encore, jamais été utilisée pour étudier les propriétés dynamiques du noyau d'une cellule vivante. Grâce à ce montage, nous avons étudié la dynamique globale du noyau de cellules neuroblastomes de la lignée SHEP, au cours du cycle cellulaire. Nous avons ainsi pu observer que la dynamique interne du noyau est très riche et très complexe, avec un très grand nombre de temps caractéristiques s'étalant de quelques millisecondes à quelques dizaines de secondes. Par l'analyse des fonctions d'autocorrélation de l'intensité diffusée $\langle I(0) I(t)\rangle$, nous avons, plus particulièrement, sondé la dynamique interne du noyau entre la milliseconde et la seconde. Nous avons mis en évidence deux distributions indépendantes de temps caractéristiques. La première est une distribution de temps rapides compris entre 5 et $70 \mathrm{~ms}$. La deuxième est une distribution de temps plus lent compris entre 0,5 et $2 \mathrm{~s}$. Nous avons montré que ces distributions étaient dépendantes de la phase du cycle dans laquelle se trouvaient les cellules.

Le montage expérimental que nous avons construit nous a également permis de mettre en évidence et d'étudier un processus de transmission de la mort par apoptose d'une cellule vers ses plus proches voisines.

Mots-clés : dynamique interne du noyau d'une cellule, diffusion de la lumière, cycle cellulaire, apoptose, motifs cellulaires.

Abstract: Recent breakthroughs in cell biology have shown that living cell nucleus is an organized set of distinct domains, each of them having its own role. This organization is highly dynamic. That is, indeed, the key of the cell adaptation to its environment. Therefore, nucleus dynamics reflects the cell state.

Although the study of this dynamics has become one of the main stakes of research in cell biology, global dynamics of the nucleus is still badly understood. To investigate this dynamics, we elaborated an original setup to carry out dynamic light scattering experiments. It should be noticed that, if dynamic light scattering is a «classical » technique used to study dynamical properties of organized molecular systems (e.g. colloidal systems, surfactants, polymers in solution, gels, liquid crystals), so far it has never been used to study the dynamical properties of living cell nuclei. By means of this setup, we investigated global dynamics of the nucleus of neuroblastoma cells (SHEP line) during the cell cycle. We observed that the internal dynamics of the nucleus is very rich and complex, with a large range of characteristic times ranging from some milliseconds to decades of seconds. By analyzing the autocorrelation function of the scattered intensity, $\langle I(0) I(t)\rangle$, we probed the internal nucleus dynamics accurately from millisecond to second. We point out two independent distributions of characteristic times. The first one is a distribution of fast times ranging from 5 to $70 \mathrm{~ms}$. The second one is a distribution of slow times ranging from 0.5 to $2 \mathrm{~s}$. We shown that these distributions depend on the stage of the cycle in which the cells are.

Using this experimental setup, we were also able to point out and investigate a transmission process of apoptotic death from a cell toward its neighbors.

Keywords: internal dynamics of cell nucleus, light scattering, cell cycle, apoptosis, cell patterning. 